Universidade de SÃo PaUlo - USP

INSTITUTO DE QUÍMICA DE SÃo CARLOS - IQSC

\title{
SÍNTESE E CARACTERIZAÇÃO DE NANOMATERIAIS SUPERPARAMAGNÉTICOS DO TIPO CORE-SHELL PARA APLICAÇÃO EM CATÁLISE E BIOMEDICINA
}

WATSON BECK JUNIOR

SÃO CARLOS

-2016- 
WATSON BECK JUNIOR

\title{
SÍNTESE E CARACTERIZAÇÃO DE NANOMATERIAIS SUPERPARAMAGNÉTICOS DO TIPO CORE-SHELL PARA APLICAÇÃO EM CATÁLISE E BIOMEDICINA
}

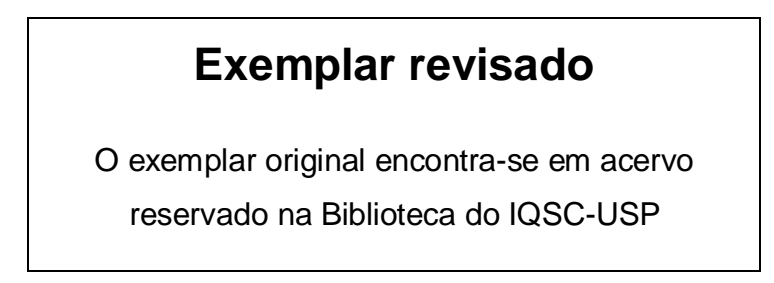

\begin{abstract}
Tese apresentada ao Instituto de Química de São Carlos da Universidade de São Paulo, como parte dos requisitos necessários para obtenção do título de Doutor em Química, no Programa de Pós-graduação em Química, Área de concentração: Físico-Química.
\end{abstract}

Orientador: Prof. Dr. Laudemir Carlos Varanda 
Autorizo a reprodução e divulgação total ou parcial deste trabalho, por qualquer meio convencional ou eletrônico para fins de estudo e pesquisa, desde que citada a fonte.

\section{Assinatura:}

Data:

\section{Beck Junior, Watson}

Síntese e caracterização de nanomateriais superparamagnéticos do tipo core-shell para aplicação em catálise e biomedicina. / Watson Beck Junior. São Carlos, 2016.

$147 \mathrm{f}$.

Tese (Doutorado em Físico-Química) - Instituto de Química de São Carlos / Universidade de São Paulo, 2016.

Edição revisada

Orientador: Prof. Dr. Laudemir Carlos Varanda

1. Nanociência. 2. Nanopartículas. 3. Magnetismo. I. Título.

$$
\begin{aligned}
& \text { Referencias Biblográficas } \\
& \text { conferibas pelo SBRliosC }
\end{aligned}
$$


Às três mulheres de minha vida:

minha esposa Nathalia, minha mãe Vanda e minha avó Idaty. 


\section{AGRADECIMENTOS}

Agradeço...

... inicialmente a Deus pela dádiva da vida;

... ao Prof. Laudemir, meu "pai científico", com quem venho aprendendo deste 2004, quando tive meu primeiro contato com a pesquisa científica. Desde então são 12 anos de uma grande amizade, o que sem dúvida foi um fator determinante para meu desenvolvimento como pessoa, cientista e professor;

... ao Prof. Miguel Jafelicci Jr., meu "avô científico", com quem, juntamente com o Prof. Laudemir, iniciei minhas pesquisas na Iniciação Científica em 2004 e tive meu primeiro contado com a físico-química na disciplina de Físico-Química 1. Alguns dos estudos aqui apresentados foram iniciados sob sua orientação;

... à pessoa com quem divido minhas alegrias e tristezas, conquistas e frustrações, planos e imprevistos... enfim com quem divido minha vida... à minha companheira, amiga, namorada e esposa Nathalia;

...aos meus amados pais Watson e Vanda, que não somente me trouxeram à vida, mas também me amaram e me deram um lar abençoado no qual sempre fui criado com carinho, respeito, bom exemplos e muito amor;

... à minha avó Idaty, meu exemplo de pessoa. Ela e minha mãe foram, sem dúvida, as pessoas que mais me apoiaram nas decisões que culminaram no desenvolvimento desta obra, decisões estas iniciadas em 2003 com a escolha da carreira de químico;

... aos meus avós Joel e Zezé (que na verdade são tios com amor de avós), os quais sempre me apoiaram nos caminhos por mim percorridos;

... à minha irmã Viviane e cunhado Bolinha pelo amor e companheirismo de sempre;

... aos membros de minha família, tios e tias, primos e primas, que cada um a seu modo, me auxiliaram a traçar o caminho da vida;

... a meu sogro, sogra, cunhados, cunhadas e sobrinhos (incluindo os que estão por vir), os quais são minha segunda família;

... aos companheiros de laboratório Caio (Maradona), Tiago (Jeca), Daniel (Stalone Bandeiras), Herbert (Perereca, João (irmão gêmeo), Rafael (Piá), Gustavo, Rebecca, Mônica, Daniely, Nayane, Mariana, Simone. Em especial ao Maradona e ao Jeca, que iniciaram seus caminhos na pós-graduação juntamente comigo e compartilharam comigo suas formações;

... aos professores e amigos Carlos Serna e Puerto os quais tive o prazer de conhecer durante o estágio na Espanha e que orientaram parte do trabalho aqui apresentado. Incluo aqui meus agradecimentos aos amigos do ICMM Marzia e Marco, Sabino, Terezita, Yurena, MariCarmen, Pedro (FTIR), Vero, Lucía, Gorka, Isabel, Virgínia, Sandra, Julian, Perce, Daniel, Amália, Rocío e Wilmer;

... ao Instituto de Química de Araraquara (IQ-UNESP) pela excelente graduação que tive o prazer de cursar e conhecimentos adquiridos durante a mesma; 
... ao Instituto de Química de São Carlos (IQSC-USP) por toda a infra-estrutura disponibilizada para os estudos aqui apresentados;

... ao Instituto de Ciencia de Materiales de Madrid (ICMM-CSIC) pela infra-estrutura disponibilizada para realização do estágio de doutorado-sanduíche;

... ao Instituto Federal de Santa Catarina por disponibilizar a mim afastamento parcial para finalização do projeto de doutorado;

... ao Prof. Daniel Reinaldo Cornejo (IF-USP) por disponibilizar os equipamentos necessários para caracterização magnética dos materiais;

... ao Prof. Ubirajara P. Rodrigues Filho e ao doutorando Elias Paiva Neto (IQSC-USP) por todo o auxílio e disponibilidade quanto aos ensaios de fotocatálise;

... ao Prof. Edenir Rodrigues Pereira-Filho (DQ-UFSCar) e Dr. Francisco Wendel Batista de Aquino pelas análises de ICP das amostras submetidas a ensaios de estabilidade química;

... aos servidores do IQSC-USP por fazerem deste instituto um centro de excelência em ensino e pesquisa. Em especial, agradeço aos servidores técnicos Carlos Bento, Márcio de Paula e Luiz A. Ramos pelas análises realizadas as quais "recheiam" este trabalho;

... a todos aqueles que, direta ou indiretamente, contribuíram para o desenvolvimento deste trabalho, àqueles que influenciaram de maneira positiva em minha formação no âmbito pessoal e profissional;

... à FAPESP, pelo apoio financeiro aos projetos de nosso grupo de pesquisa e pelas bolsas de doutorado regular e BEPE a mim concedidas;

... aos professores Celso Valentim Santilli, Daniel Reinaldo Cornejo, Joelma Perez e Watson Loh, por se prontificarem a compor a banca examinadora, contribuindo assim para a melhoria desta obra. 
There's plenty of room at the bottom.

Richard P. Feynman 


\section{RESUMO}

As diversas aplicações tecnológicas de nanopartículas magnéticas (NPM) vêm intensificando o interesse por materiais com propriedades magnéticas diferenciadas, como magnetização de saturação $\left(M_{S}\right)$ intensificada e comportamento superparamagnético. Embora MNP metálicas de $\mathrm{Fe}$, Co e bimetálicas de FeCo e FePt possuam altos valores de $\mathrm{M}_{\mathrm{s}}$, sua baixa estabilidade química dificulta aplicações em escala nanométrica. Neste trabalho foram sintetizadas NPM de $\mathrm{Fe}, \mathrm{Co}, \mathrm{FeCo}$ e FePt com estabilidade química e rigoroso controle morfológico. NPM de óxido metálicos (Fe e Co) também foram obtidas. Dois métodos de síntese foram empregados. Usando método baseado em sistemas nanoeterogêneos (sistemas micelares ou de microemulsão inversa), foram sintetizadas NPM de $\mathrm{Fe}_{3} \mathrm{O}_{4}$ e Co metálico. Foram empregados surfactantes cátion-substituídos: dodecil sulfato de ferro(III) (FeDS) e dodecil sulfato de cobalto(II) (CoDS). Para a síntese das NPM, foram estudados e determinados a concentração micelar crítica do FeDS em 1-octanol $\left(\mathrm{cmc}=0,90 \mathrm{mmol} \mathrm{L}^{-1}\right)$ e o diagrama de fases pseudoternário para o sistema $n$-heptano/CoDS $/ n$-butanol/ $\mathrm{H}_{2} \mathrm{O}$. NPM esferoidais de magnetita com 3,4 nm de diâmetro e comportamento quase-paramagnético foram obtidas usando sistemas micelares de FeDS em 1-octanol. Já as NPM de Co obtidas via microemulsão inversa, apesar da larga distribuição de tamanho e baixa $M_{S}$, são quimicamente estáveis e superparamagnéticas. O segundo método é baseado na decomposição térmica de complexos metálicos, pelo qual foram preparadas NPM esféricas de FePt e de óxidos metálicos $\left(\mathrm{Fe}_{3} \mathrm{O}_{4}, \mathrm{Fe}_{\mathrm{x}} \mathrm{O}_{1-\mathrm{x}},(\mathrm{Co}, \mathrm{Fe})_{\mathrm{x}} \mathrm{O}_{1-\mathrm{x}} \mathrm{e}\right.$ $\mathrm{CoFe}_{2} \mathrm{O}_{4}$ ) com morfologia controlada e estabilidade química. O método não mostrou a mesma efetividade na síntese de NPM de FeAg e FeCo: a liga FeAg não foi obtida enquanto que NPM de FeCo com estabilidade química foram obtidas sem controle morfológico. NPM de Fe e FeCo foram preparadas a partir da redução térmica de NPM de $\mathrm{Fe}_{3} \mathrm{O}_{4}$ e $\mathrm{CoFe}_{2} \mathrm{O}_{4}$, as quais foram previamente recobertas com sílica. A sílica previne a sinterização inter-partículas, além de proporcionar caráter hidrofílico e biocompatibilidade ao material. As amostras reduzidas apresentaram aumento dos valores de $M_{s}$ (entre 21,3 e 163,9\%), o qual é diretamente proporcional às dimensões das NPM. O recobrimento com sílica foi realizado via hidrólise de tetraetilortosilicato (TEOS) em sistema de microemulsão inversa. A espessura da camada de sílica foi controlada variando-se o tempo de reação e as concentrações de TEOS e de NPM, sendo então proposto um mecanismo do processo de recobrimento. Algumas amostras receberam um recobrimento adicional de $\mathrm{TiO}_{2}$ na fase anatase, para o qual foi empregado etilenoglicol como solvente e ligante para formação de glicolato de Ti como precursor. A espessura da camada de $\mathrm{TiO}_{2}(2-12 \mathrm{~nm})$ é controlada variando as quantidades relativas entre NPM e o precursor de Ti. Ensaios de hipertermia magnética foram realizados para as amostras recobertas com sílica. Ensaios de hipertermia magnéticas mostram grande aumento da taxa de aquecimento das amostras após a redução térmica, mesmo para dispersões diluídas de NPM $\left(0,6\right.$ a $\left.4,5 \mathrm{mg} \mathrm{mL}^{-1}\right)$. Taxas de aquecimento entre 0,3 e 3,0 ${ }^{\circ} \mathrm{C} \mathrm{min}^{-1}$ e SAR entre 37,2 e $96,3 \mathrm{~W} \mathrm{~g}^{-1}$ foram obtidos. A atividade fotocatalítica das amostras recobertas foram próximas à da fase anatase pura, com a vantagem de possuir um núcleo magnético que permite a recuperação do catalisador pela simples aplicação de campos magnéticos externos. Os resultados preliminares dos ensaios de hipertermia magnética e fotocatálise indicam um forte potencial dos materiais aqui relatados para aplicações em biomedicina e em fotocatálise.

Palavras-chave: nanopartículas magnéticas, magnetização de saturação intensificada, aplicações biomédicas, catalisadores magnéticos. 


\begin{abstract}
The most diverse technological applications of magnetic nanoparticles (MNP) have intensified the interest for materials with different magnetic properties such as enhanced saturation magnetization $\left(M_{S}\right)$ and superparamagnetic behavior. Despite the high $M_{s}$ values of metal particles of $\mathrm{Fe}, \mathrm{Co}, \mathrm{FeCo}$ and FePt, their low chemical stability hinders most applications at the nanoscale. This thesis reports the synthesis of metallic Fe and Co and bimetallic FeCo and FePt MNP with high chemical stability and strict morphology control. MNP of iron oxide and mixed iron-cobalt oxide were also synthesized. Two methods were employed. The first method, based on nanoheterogeneous systems (micellar or reverse microemulsion systems), was used to prepare magnetite and metallic Co NPM. The method applies cation-substituted surfactants: iron(III) dodecyl sulfate iron (FeDS) and cobalt(II) dodecyl sulfate (CoDS). Before the MNP syntheses, it were studied e determined the critical micelle concentration of FeDS in 1-octanol $\left(\mathrm{cmc}=0.90 \mathrm{mmol} \mathrm{L^{-1 }}\right)$ and the pseudo-ternary phase diagram of $n$-heptane/CoDS $/ n$ butanol/ $\mathrm{H}_{2} \mathrm{O}$. Spheroidal MNP of magnetite with $3.4 \mathrm{~nm}$ in diameter and quasi-paramagnetic behavior were prepared in octanolic FeDS micellar systems. Despite their broad size distribution and low $\mathrm{M}_{\mathrm{s}}$, metallic Co MNP were produced in reverse microemulsions with chemical stability and superparamagnetic behavior. The second synthesis method, based on thermal decomposition of metal complexes, was employed to prepare spherical FePt and metal

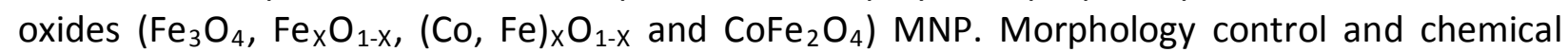
stability were reached. Such method does not show the same effectiveness to synthesize FeAg and FeCo MNP: the FeAg bimetallic alloy was not obtained while FeCo MNP with chemical stability and compositional control were prepared with no morphological control. Fe and FeCo MNP were produced by thermal reduction of silica-coated $\mathrm{Fe}_{3} \mathrm{O}_{4}$ and $\mathrm{CoFe}_{2} \mathrm{O}_{4}$ MPN. The coating, beyond to prevent inter-particle sintering, provides biocompatibility and hydrophilic character. The reduced samples showed a significant increase in $M_{S}$ values (between 21.3 and $163.9 \%)$, which is directly proportional to MNP size. The silica coating was accomplished by tetraethylorthosilicate (TEOS) hydrolysis in reverse microemulsions. The thickness of the silica layer is controlled by varying the reaction time and concentration of TEOS and NPM. The observations during coating process allowed to propose its probable mechanism. An additional coating of $\mathrm{TiO}_{2}$ (anatase phase) was performed onto silica layer for some samples. Anatase coating was achieved by using ethylene glycol as both solvent and ligand to produce an intermediate complex Ti precursor. The variation of the relative amounts of NPM and the Ti precursor allows to control the thickness of the anatase layer between 2 and $12 \mathrm{~nm}$. Assays of magnetic hyperthermia were performed for silica-coated samples. The heating rate of the reduced samples increases after thermal reduction, even for dilute MNP dispersions ( 0.6 to 4.5 $\mathrm{mg} \mathrm{mL}^{-1}$ ). Heating rates between 0.3 and $3.0^{\circ} \mathrm{C} \mathrm{min}^{-1}$ and SAR in the range of $37.2-96.3 \mathrm{~W} \mathrm{~g}^{-1}$ were obtained. The photocatalytic activities of pure anatase particles and $\mathrm{TiO}_{2}$-coated $\mathrm{MNP}$ were close, but the magnetic samples has the advantage of being recovered from reaction media by applying the external magnetic fields. The preliminary results of magnetic hyperthermia and photocatalysis assays indicate such materials have strong potential for applications in biomedicine and photocatalysis.
\end{abstract}

Keywords: magnetic nanoparticles, enhanced saturation magnetization, biomedical applications, magnetic catalysts. 


\section{LISTA DE FIGURAS}

Figura 1 - Ilustração da aplicabilidade de sistemas de NPM na área de biomedicina (esquerda) e em processos de catálise heterogênea (direita).

Figura 2 - Representação do momento magnético associado aos movimentos eletrônicos (a) orbital e (b) de spin.

Figura 3 - Representação do comportamento magnético para um material: (a) diamagnético e (b) paramagnético. ${ }^{(13) \text { (modificado) }}$

Figura 4 - Ilustração da estrutura dos domínios magnéticos dispostos aleatoriamente em um material policristalino e constituído por multidomínios magnéticos. ${ }^{(14)}$

Figura 5 - Comparação entre o efeito do tamanho e temperatura da partícula sobre o comportamento superparamagnético da mesma. ${ }^{(16)(\text { Modificado) }}$

Figura 6 - Exemplos ilustrativos de curvas de magnetização em função do campo magnético aplicado para materiais (a) ferromagnéticos e (b) superparamagnéticos. (17)

Figura 7 - Tipos de microemulsão: (a) direta, (b) inversa e (c) bicontínua. (37)

Figura 8 - Comportamento dos monômeros de surfactantes em solução cujo solvente possui caráter apolar. (38) ${ }^{\text {(Modificado) }}$

Figura 9 - Ilustração da síntese de nanopartículas de FePt via método poliol, onde $\mathrm{Fe}(\mathrm{CO})_{5}$ e Pt(acac) ${ }_{2}$ são os precursores metálicos, 1,2-hexadecanodiol é o diol redutor, ácido oléico e oleilamina são os estabilizadores e dioctiléter é o solvente. (17) (modificado) $^{\text {..... }}$

Figura 10 - Esquema da ligação de moléculas de um alquilcarboxilato e de uma alquilamina sobre a superfície de uma nanopartícula de FePt. (17).

Figura 11 - Fluxograma do procedimento de síntese de NPM de Co através do método de microemulsão inversa.

Figura 12 - Fluxograma geral do método utilizado nas sínteses via decomposição térmica.

Figura 13 - Rampas de aquecimento usadas na síntese de NPM via decomposição térmica. A relação entre a as amostras e suas respectivas rampas é dada na Tabela 5.

Figura 14 - Fluxograma do procedimento experimental usado na síntese dos precursores oleato. ........42

Figura 15 - Fluxograma do procedimento de recobrimento das NP com sílica. ...................................44

Figura 16 - Ilustração do aparato experimental utilizado na redução e passivação das amostras. ...........46

Figura 17 - Equipamento magneTherm ${ }^{T M}$ Nanotherics, sensor de fibra óptica OpSens e câmera infravermelho OpTris utilizados para realização das medidas de hipertermia magnética.

Figura 18 - Aparato experimental utilizado nos ensaios de atividade catalítica....................................48

Figura 19 - Curvas TGA/DTG obtidas para o FeDS sob atmosfera de ar sintético. ....................................52

Figura 20 - Espectro FTIR obtido para os surfactante FeDS. Para efeito de comparação, o espectro do surfactante NaDS usado na síntese do FeDS também é mostrado.

Figura 21 - Medidas de condutividade elétrica (ponto cheio) e diâmetro hidrodinâmico (ponto aberto) em função da concentração do surfactante FeDS em soluções octanólicas.

Figura 22 - Difratograma e imagens de MET da amostra FeOx-01 com o histograma de contagem de tamanho de partículas.

Figura 23 - À esquerda, curva de magnetização da amostra FeOx-01 obtida a $5 \mathrm{~K}$ após tratamento térmico $\left(400^{\circ} \mathrm{C}\right.$ por $1 \mathrm{~h}$ em $\left.\mathrm{N}_{2}\right)$, destacando uma ampliação do centro da curva. À direita, curvas ZFC/FC indicando a temperatura de bloqueio magnético.

Figura 24 - Curvas de condutividade em função da composição em água do sistema n-heptano/nbutanol/CoDS/água, para diferentes valores de $\mathrm{R}$. 
Figura 25 - Diagrama de fases pseudo-ternário obtido para o sistema $n$-heptano/n-butanol/CoDS/água, destacando as regiões de microemulsão direta (I), inversa (III) e sistema bicontínuo (II). As estrelas indicam as composições utilizadas na síntese das NP.

Figura 26 - DRX das amostras de NPM de Co metálico e os respectivos padrões JCPDS do fcc-Co, $h c p$-Co, $\mathrm{CoO}, \mathrm{CO}_{3} \mathrm{O}_{4}, \mathrm{CoB}$, borax e tincalconita.

Figura 27 - Imagem de MET obtida para as amostras Co-01 e Co-05.

Figura 28 - Curvas de magnetização medidas à temperatura ambiente para as amostras Co-03, Co-04 e Co-05.

Figura 29 - Difratogramas obtidos para as amostras de nanopartículas de FePt comparados aos padrões

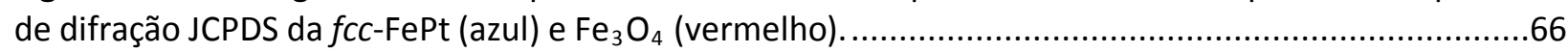

Figura 30 - Imagens obtidas por MET para as amostras de NPM de FePt. ...........................................67

Figura 31 - Ajustes do tipo LogNormal aplicados aos histogramas de contagem de NPM de FePt. .........68

Figura 32 - Espectros de EDX das amostras de NPM de FePt...........................................................69

Figura 33 - Espectros EDX obtidos para as amostras FeAg-01, FeAg-02, FeAg-03 e FeAg-04 indicando as respectivas composições relativas entre $\mathrm{Fe}$ e $\mathrm{Ag}$ presentes nas amostras.

Figura 34 - DRX das amostras de FeAg-01 a FeAg-04 comparadas aos padrões JCPDS ds fases fcc-Ag, $\mathrm{Fe}_{3} \mathrm{O}_{4}, \mathrm{Ag}_{2} \mathrm{O}$ e $\mathrm{Ag}_{3} \mathrm{Fe}_{2}$.

Figura 35 - Imagens de MET das amostras FeAg-01 a FeAg-04 juntamente com seus respectivos histogramas de contagem de partículas.

Figura 36 - Curvas de histerese magnética obtidas à temperatura ambiente para as amostras FeAg-01 e FeAg-02. Em destaque, uma ampliação da região central das curvas.

Figura 37 - Difratogramas obtidos para as amostras FeCo-01, FeCo-02, FeCo-03 e FeCo-04. Na parte inferior do gráfico são apresentados os padrões de difração JCPDS das fases cristalográficas $\alpha$-Fe (vermelho), $\mathrm{FeCo}$ (azul) e $\mathrm{CoFe}_{2} \mathrm{O}_{4}$ (verde).

Figura 38 - Imagens obtidas por MET para as amostras FeCo-03 e FeCo-04 juntamente com seus respectivos histogramas de contagem de NP.

Figura 39 - Espectros de EDX obtido para as amostras de NP de FeCo.

Figura 40 - Curvas de histerese magnética obtidas à temperatura ambiente para as amostras de NP de FeCo. As curvas referem-se às amostras como sintetizadas, sem normalização por sua massa magnética. Em destaque, uma ampliação da região central das curvas.

Figura 41 - DRX da amostra FeC-01 ecomparada aos padrões JCPDS das fases $\mathrm{Fe}_{3} \mathrm{C}, \alpha$-Fe, $\delta$-Fe, $\varepsilon$ - $\mathrm{Fe}$ e $\gamma$ Fe.

Figura 42 - Imagens de MET da amostra FeC-01.

Figura 43 - Diagrama de equilíbrio de fases ferro-carbeto de ferro destacando a composição atômica de $25 \%$ em carbono correspondente à fase cementita $\left(\mathrm{Fe}_{3} \mathrm{C}\right) .(115)$.

Figura 44 - DRX das amostras $\mathrm{CoC}-01$ e CoC-02 comparadas aos padrões JCPDS das fases $\mathrm{Co}_{2} \mathrm{C}, \mathrm{Co}_{3} \mathrm{C}$, fcc-Co e $h c p$-Co. Em destaque, imagens de MET da amostra CoC-02.

Figura 45 - Imagens de MET das amostras de NPM de óxido de ferro obtidas pelo método de Salas. ....87

Figura 46 - Histogramas de contagem de partículas das amostras de NPM de óxido de ferro mostrando os valores de tamanho médio $\left(d_{m}\right)$ e de grau de polidispersividade obtidos a partir de ajustes do tipo LogNormal.

Figura 47 - Imagens de TEM das NPM de óxido misto de ferro e cobalto obtidas pelo método de Salas e

o histograma de contagem de partículas referente a amostra.. .90

Figura 48 - DRX das amostras de óxido de ferro e ferrita de cobalto comparados aos padrões JCPDS das fases $\mathrm{Fe}_{3} \mathrm{O}_{4}, \mathrm{FeO}, \alpha-\mathrm{Fe}, \mathrm{CoFe}_{2} \mathrm{O}_{4}, \mathrm{CoO}$ e fcc-Co. 
Figura 49 - DRX das amostras de óxido de ferro comparadas aos padrões JCPDS das fases wustita (vermelho), magnetita (azul) e $\alpha$-ferro (verde). Os losangos coloridos destacam os picos de difração relativos a cada fase cristalina presente na constituição das amostras.

Figura 50 - Imagens de TEM das amostras de óxido de ferro (FeOx-08 a FeOx-12) e de óxido misto de ferro e cobalto (CoFeOx-02 e CoFeOx-03). Em destaque, tabela apresentando as dimensões médias e grau de polidispersividade relativos a cada amostra.

Figura 51 - Ajustes do tipo LogNormal aplicados aos histogramas de contagem de NPM. Para facilitar a visualização, os ajustes são apresentados em escala linear (à esquerda) e escala logarítmica (à direita). As cores de cada curva fazem referência às cores usadas nas legendas de cada imagem de TEM da Figura 51.

Figura 52 - Estrutura sal-gema da wustita seguida de ilustração do processo de formação de vacâncias de ferro na estrutura cristalina da wustita.

Figura 53 - Curvas de histerese magnética obtidas a $298 \mathrm{~K}$. Em destaque, ampliação da região central das curvas e respectivos valores de $\mathrm{M}_{\mathrm{S}}$ e $\mathrm{H}_{\mathrm{c}}$. Os valores não estão normalizados pela massa magnética das amostras.

Figura 54 - Fragmento da estrutura molecular da carboximetil-dextrana.

Figura 55 - Espectros FTIR obtidos para CM-Dex pura (verde) e para as amostras de NPM de magnetita antes (FeOx-01, em vermelho) e após o recobrimento com CM-Dex (FeOx@CM-Dex, em azul)..............98

Figura 56 - Esquema ilustrativo da adsorção da CM-Dex sobre a superfície das NPM de magnetita.......99

Figura 57 - Imagens de MET das amostras de NPM após serem submetidas ao procedimento de recobrimento com sílica.....

Figura 58 - Sistemas bifásicos contendo as amostras FeOx@S2, FeOx@S4 e FeOx@S4 dispersas entre as fases água e hexano.

Figura 59 - Espetros FTIR obtidos para as amostras de NPM antes e após recobrimento com sílica. Em verde, espectro de uma amostra de NP coletadas imediatamente antes da adição de TEOS.

Figura 60 - Ilustração esquemática do mecanismo proposto para o processo de recobrimento de NP com sílica via hidrólise básica de TEOS em sistema de microemulsão inversa.

Figura 61 - Imagens de MET das amostras obtidas nas tentativas de recobrimento com anatase através do método de microemulsão.

Figura 62 - Difratograma das amostras obtidas antes e após recobrimento com $\mathrm{TiO}_{2} \ldots \ldots \ldots \ldots \ldots \ldots \ldots . . . . . . . .106$

Figura 63 - Imagens de MET da amostra de partículas de TiO2.

Figura 64 - Difratogramas das amostras de partículas de $\mathrm{TiO}_{2}$ e de NPM após recobrimento com $\mathrm{TiO}_{2}$ comparadas aos padrões JCPDS das fases anatase, bruquita, rutilo, magnetita, cohenita, wustita e $\alpha$ ferro.

Figura 65 - Imagens de MET das amostras de NPM após recobrimento com $\mathrm{TiO}_{2}$. Nas imagens, é possível distinguir o núcleo magnético e as duas camadas de recobrimento $\left(\mathrm{SiO}_{2}\right.$ e $\left.\mathrm{TiO}_{2}\right)$ pela diferença de contraste.

Figura 66 - Difratogramas das amostras reduzidas comparados ao da amostra não-reduzida e aos padrões JCPDS das fases $\mathrm{Fe}_{3} \mathrm{O}_{4}$, $\mathrm{FeO}$ e $\alpha$-Fe.

Figura 67 - DRX das amostras de óxido de ferro e ferrita de cobalto após redução comparados às amostras não-reduzidas. Em cores, os padrões JCPDS das fases $\mathrm{Fe}_{3} \mathrm{O}_{4}, \mathrm{FeO}, \alpha-\mathrm{Fe}, \mathrm{CoFe}_{2} \mathrm{O}_{4}$ e bcc-FeCo.

Figura 68 - Imagens de MET das amostras reduzidas a $600{ }^{\circ} \mathrm{C}$ sob fluxo de $\mathrm{H}_{2}$ de $90 \mathrm{~L} \mathrm{~h}^{-1}$.

Figura 69 - Ampliações das imagens de MET da amostra com caroço magnético de 15,2 nm (FeOx@S4R6) destacando os espaço existentes entre a fase magnética e a camada de sílica. 
Figura 70 - Curvas de magnetização a $290 \mathrm{~K}$ para as amostras de NP de óxido de ferro antes e após redução térmica destacando os respectivos valores de $\mathrm{M}_{\mathrm{s}}$ e $\mathrm{H}_{\mathrm{c}}$. A região central das curvas é ampliada como destaque no canto inferior direito do gráfico.

Figura 71 - Curvas de magnetização ZFC e FC obtidas para a amostra Feox@S4R6. A região central das curvas é ampliada como destaque no canto inferior direito do gráfico.

Figura 72 - Medidas de potencial zeta em função do pH para as amostras FeOx-01 e FeOx@CM-Dex.120

Figura 73 - Medidas de potencial zeta em função do pH para as amostras FeOx@S3 e FeOx@S4R6....122

Figura 74 - Imagens de MET das amostras mantidas por 144 horas em meios de tampão acetato e fosfato.

Figura 75 - DRX das amostras mantidas por 144 horas tampões acetato e fosfato comparados ao da amostra FeOx@S3-R6 original. Em cores, os padrões JCPDS das fases $\mathrm{Fe}_{3} \mathrm{O}_{4}$ e $\mathrm{FeO}$

Figura 76 - Variação das concentrações de ferro (০) and silício ( $\square$ ) em função do tempo de contato entre as NPM da amostra FeOx@S4R6 com soluções tampão fosfato (curvas em vermelho) e acetato (curvas em azul). As concentrações foram medidas por ICP.

Figura 77 - Curvas de aquecimento das amostras de NPM de $\mathrm{Fe}_{3} \mathrm{O}_{4}$ e $\alpha$-Fe recobertas com sílica.......126

Figura 78 - Imagens obtidas com a câmera infravermelho OpTris durante ensaio com dispersão da FeOx@S11R1 (concentração de 4,5 mg (Fe) $\mathrm{mL}^{-1}$ ). A amostra se encontra no ponto central das imagens.

Figura 79 - À esquerda, ajuste da equação de BoxLucas1 à curva de aquecimento da amostra FeOx@S11R1, destacando a curva correspondente ao produto dos parâmetros a e b. 0 gráfico à direita relaciona valores de SAR (curva em azul) e taxas de aquecimento máximas (curva em vermelho) às concentrações normalizadas da amostra.

Figura 80 - Espectros UV-Vis coletados com diferentes tempos de irradiação com luz UV para as amostras $\mathrm{TiO}_{2}$ e FeOx@S4@T2 antes e após os tratamentos térmicos em $\mathrm{N}_{2}$ (FeOx@S4@T2-N) e $\mathrm{H}_{2}$ (FeOx@S4@T2-H).

Figura 81 - (a) Área correspondente às bandas de absorção do cristal violeta (CV) em função do tempo de exposição à radiação UV. Os valores de área foram obtidos a partir da integração dos espectros da Figura 80 no intervalo $430 \mathrm{~nm}<\lambda<700 \mathrm{~nm}$. (b) Valores normalizados pela massa de $\mathrm{TiO}_{2}$ presente nas amostras contendo núcleos magnéticos. 


\section{LISTA DE TABELAS}

Tabela 1 - Resumo comparativo de quatro diferentes métodos de síntese de nanopartículas.(31) ........23

Tabela 2 - Valores de entalpia e entropia de superfície das fases anatase e rutilo.(75) .........................32

Tabela 3 - Lista de reagentes utilizados e respectivas purezas.

Tabela 4 - Identificação das amostras obtidas via microemulsão inversa. As composições mássicas entre os componentes da microemulsão usada nas sínteses e a razão mássica entre o redutor $\mathrm{NaBH}_{4}$ e o surfactante CoDS são apresentadas.

Tabela 5 - Parâmetros experimentais utilizados nas sínteses via decomposição térmica. As principais diferenças entre cada síntese são destacadas em negrito.

Tabela 6 - Parâmetros experimentais variados nos recobrimentos com sílica. As principais diferenças entre cada síntese são destacadas em negrito.

Tabela 7 - Parâmetros usados no preparo das amostras de NPM recobertas com $\mathrm{TiO}_{2}$.

Tabela 8 - Parâmetros experimentais usados na redução térmica das NPM de óxido de ferro

Tabela 9 - Composições percentuais correspondentes aos pontos de transição para o sistema $n$ heptano/n-butanol/CoDS/água.

Tabela 10 - Análise de EDX mostrando a composição relativa entre os elementos ferro e platina presentes nas amostras de NPM de FePt.

Tabela 11 - Parâmetros experimentais empregados em cada síntese e resultados obtidos.

Tabela 12 - Parâmetros respectivos a cada síntese de NPM e resultados da análise de DRX

Tabela 13 - Condições experimentais usados nos recobrimentos com sílica e resultados obtidos

Tabela 14 - Atribuições dos picos observados no difratograma da amostra de partículas de $\mathrm{TiO}_{2}$. 109

Tabela 15 - Condições experimentais utilizadas para cada amostra durante a etapa de redução térmica e seus respectivos resultados obtidos por DRX.

Tabela 16 - Composições mássicas relativas entre as fases cristalinas presentes em cada amostra (calculada por EDX) e concentrações das suspensões de NP (normalizadas pela massa de material magnético). 


\section{PRINCIPAIS ABREVIATURAS}

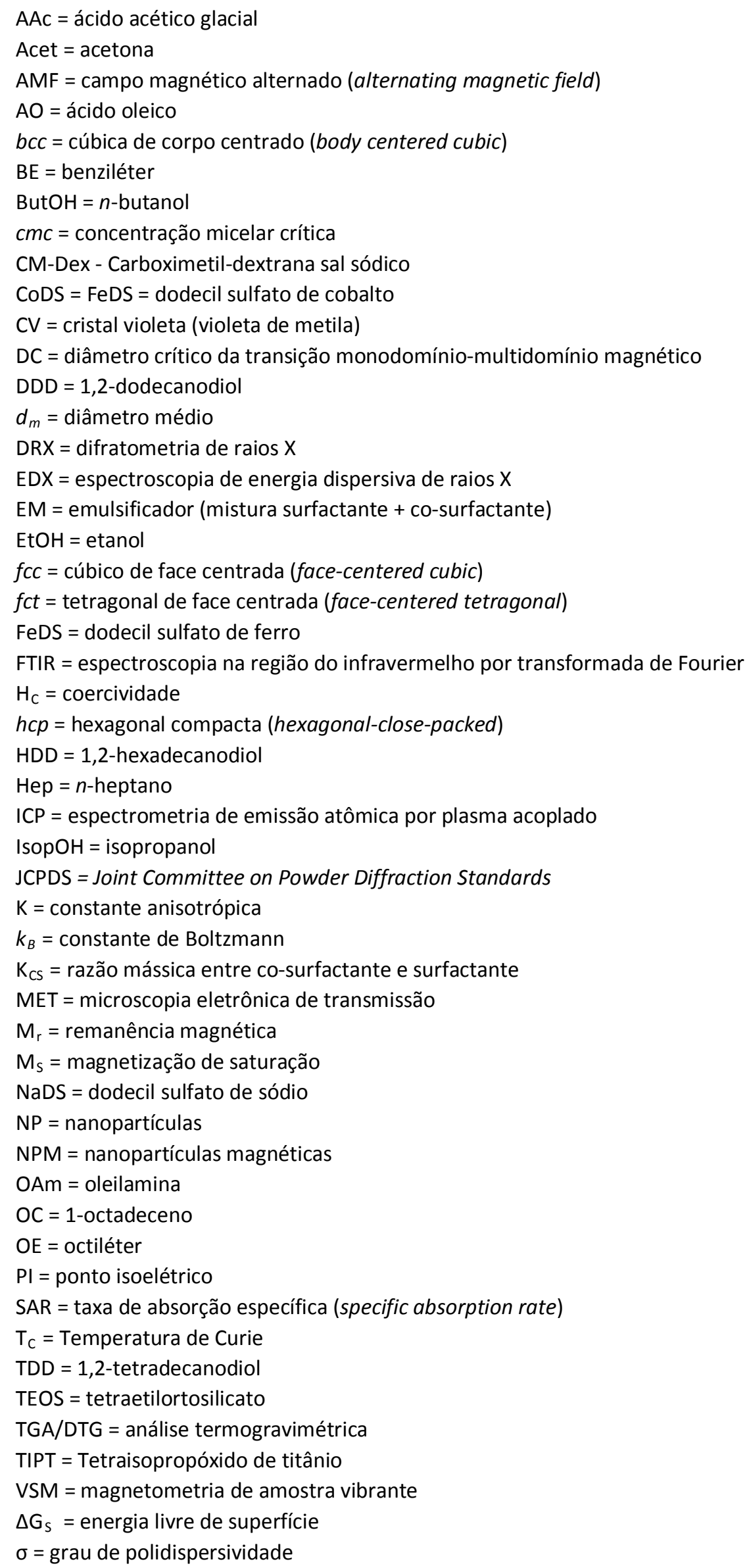




\section{SUMÁRIO}

1 INTRODUÇÃO .17

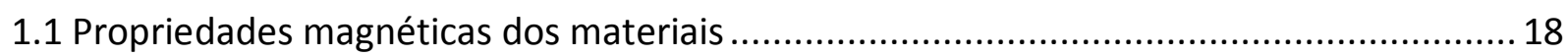

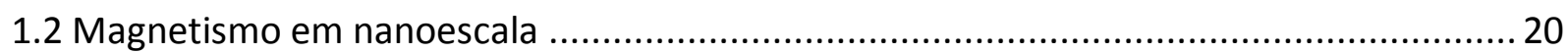

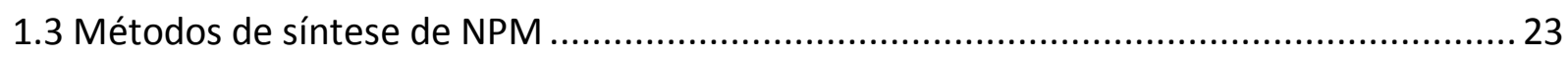

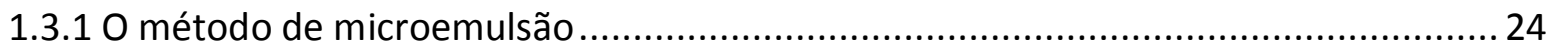

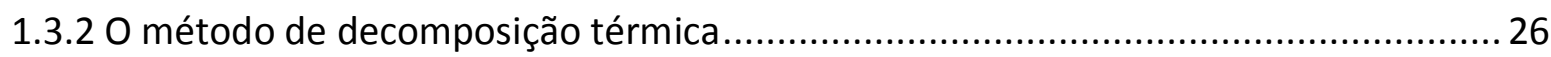

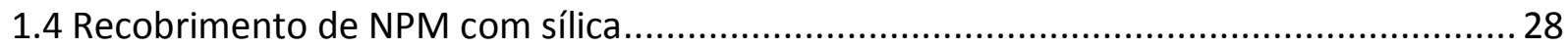

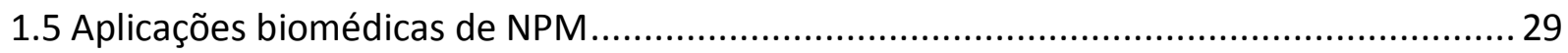

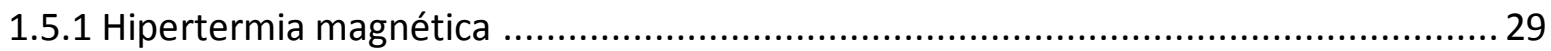

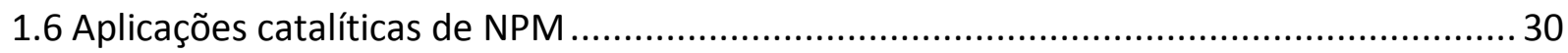

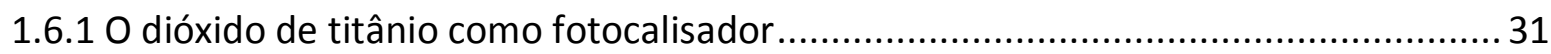

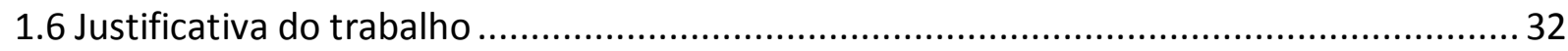

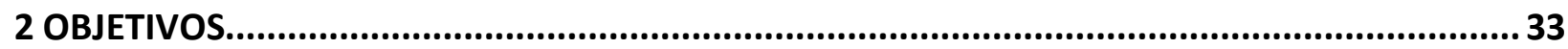

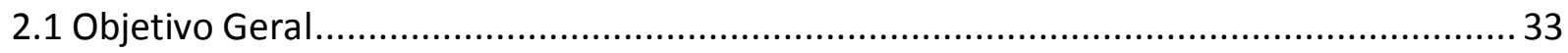

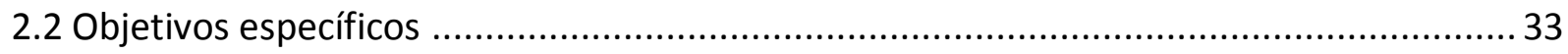

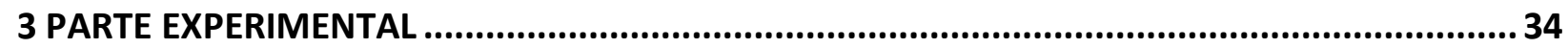

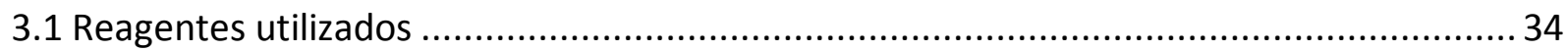

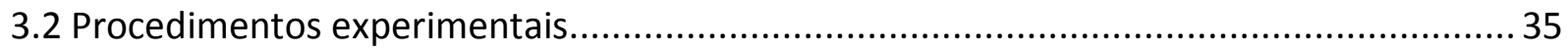

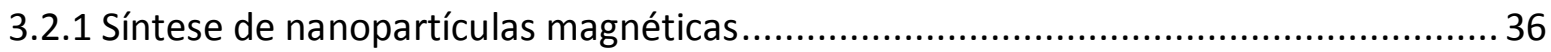

3.2.1.1 Síntese de NPM via sistemas de microemulsão inversa ................................. 36

3.2.1.1.1 Síntese dos surfactantes cátion-substituídos ........................................................36

3.2.1.1.2 Obtenção dos diagramas de fase pseudo-ternários ................................................36

3.2.1.1.3 Determinação da concentração micelar crítica do FeDS em 1-octanol ......................37

3.2.1.1.4 Síntese de NPM de Co metálico via microemulsão......................................................37

3.2.1.1.5. Síntese das NPM de magnetita via sistema micelar ...............................................38

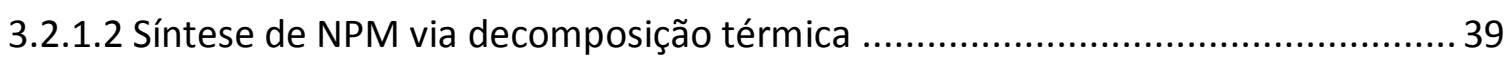

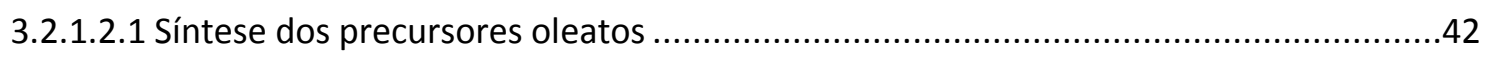

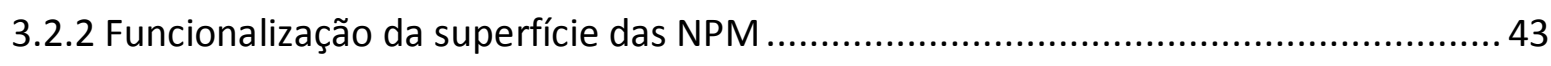

3.2.2.1 Recobrimento das NP de óxido de ferro com CM-Dex ................................... 43

3.2.2.2 Recobrimento das NP de óxido de ferro com sílica ........................................ 43

3.2.2.3 Recobrimento das NPM de óxidos metálicos com anatase ............................... 45

3.2.3 Redução térmica das NPM de óxidos metálicos.................................................. 45

3.2.4 Ensaios da aplicabilidade das NPM em biomedicina e catálise ............................... 46

3.2.4.1 Ensaios de estabilidade coloidal em meio líquido ........................................ 46 
3.2.4.2 Ensaios de estabilidade química em diferentes meios tamponados..... 47

3.2.4.3 Ensaios de hipertermia magnética............................................................ 47

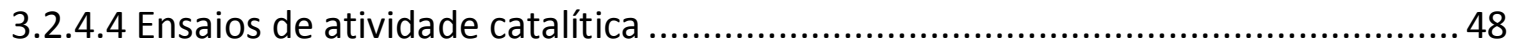

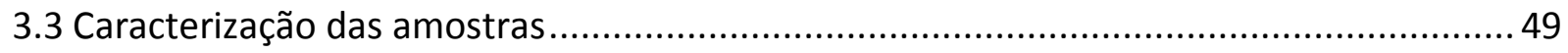

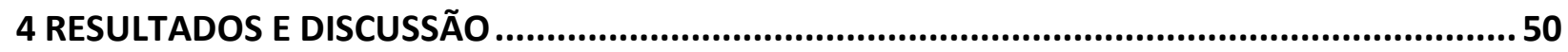

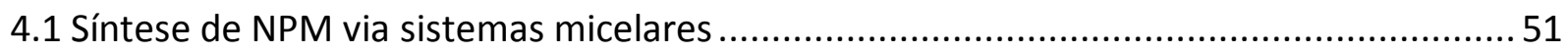

4.1.1 Caracterização do surfactante FeDS e síntese de NPM .......................................52

4.1.2 Caracterização do surfactante CoDS e síntese de NPM .........................................57

4.2 Síntese de NPM via decomposição térmica ................................................................. 64

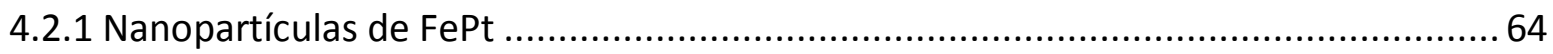

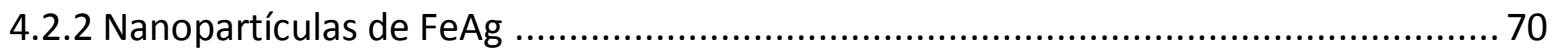

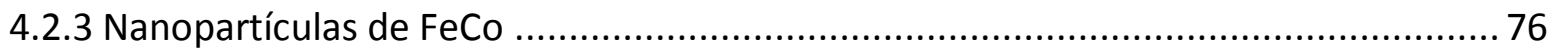

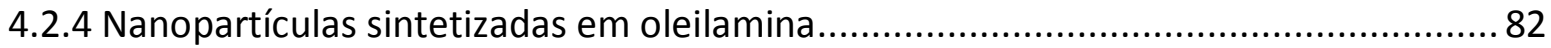

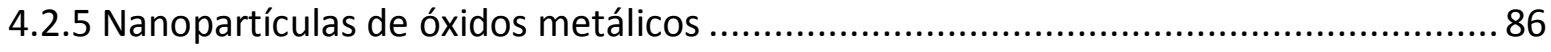

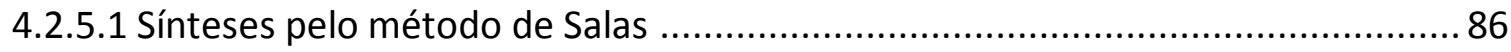

4.2.5.2 Sínteses pelo método de Moraes .................................................................... 91

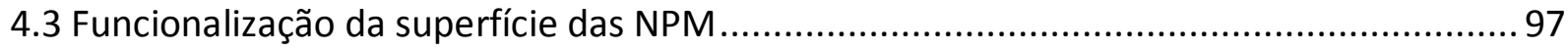

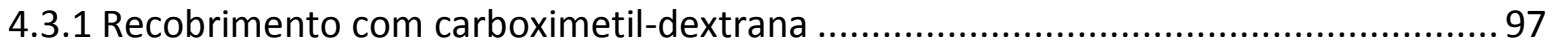

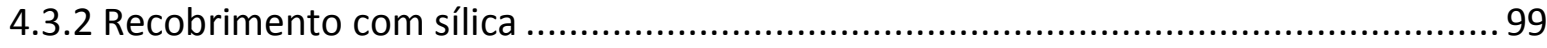

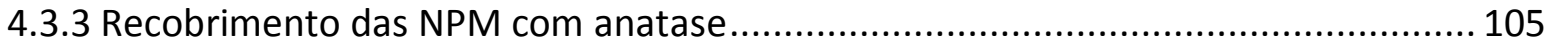

4.4 Redução térmica de NPM de óxidos metálicos.......................................................... 111

4.5 Ensaios da aplicabilidade das NPM em biomedicina e catálise .................................. 119

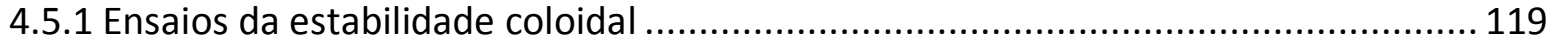

4.5.2 Ensaios da estabilidade química em diferentes meios tamponados...................... 122

4.5.3 Ensaios de hipertermia magnética .............................................................. 125

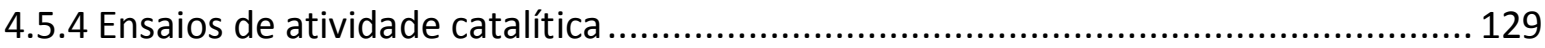

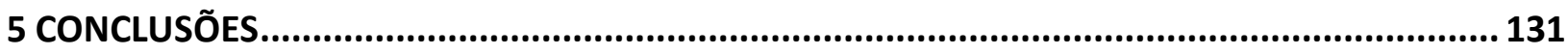

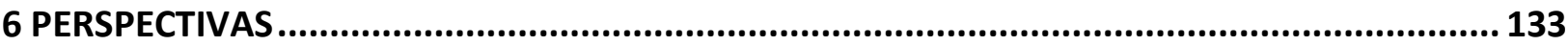

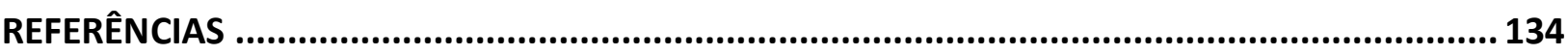




\section{INTRODUÇÃo}

A forte dependência observada entre as propriedades apresentadas por um material e as dimensões das partículas que o compõem faz hoje da nanociência um campo em grande ascensão. Neste contexto, nanopartículas magnéticas (NPM) vêm sendo alvo de crescente interesse dentro da comunidade científica, uma vez que efeitos quânticos de tamanho, elevada razão área de superfície/volume e a criação de monodomínios magnéticos resultam em propriedades magnéticas diferenciadas.(1) Tais propriedades, juntamente com as propriedades mesoscópicas mecânicas e térmicas apresentadas pelas NPM, fazem com que estas ofereçam um alto potencial para diversas aplicações, tais como refrigeração magnética,(2,3) descontaminação ambiental,(4) gravação magnética de ultra-alta densidade,(5) impressão magnética,(6) armazenamento de energia,(7) entre outras. Ainda, duas outras áreas de aplicação de NPM têm atraído grande interesse da comunidade científica: catálise $(8,9)$ e biomedicina (Figura 1).(10,11) Para ambas as aplicações, há preferência por nanopartículas (NP) que apresentem (i) alta emanação magnética, uma vez que o recobrimento da superfície desses materiais com catalisadores e compostos biocompatíveis tende a reduzir drasticamente sua resposta magnética, e (ii) comportamento superparamagnético, para evitar a ocorrência de agregação entre as partículas quando na ausência de campos magnéticos externos, bem como obter uma resposta mais rápida ao campo aplicado.

Figura 1 - llustração da aplicabilidade de sistemas de NPM na área de biomedicina (esquerda) e em processos de catálise heterogênea (direita).
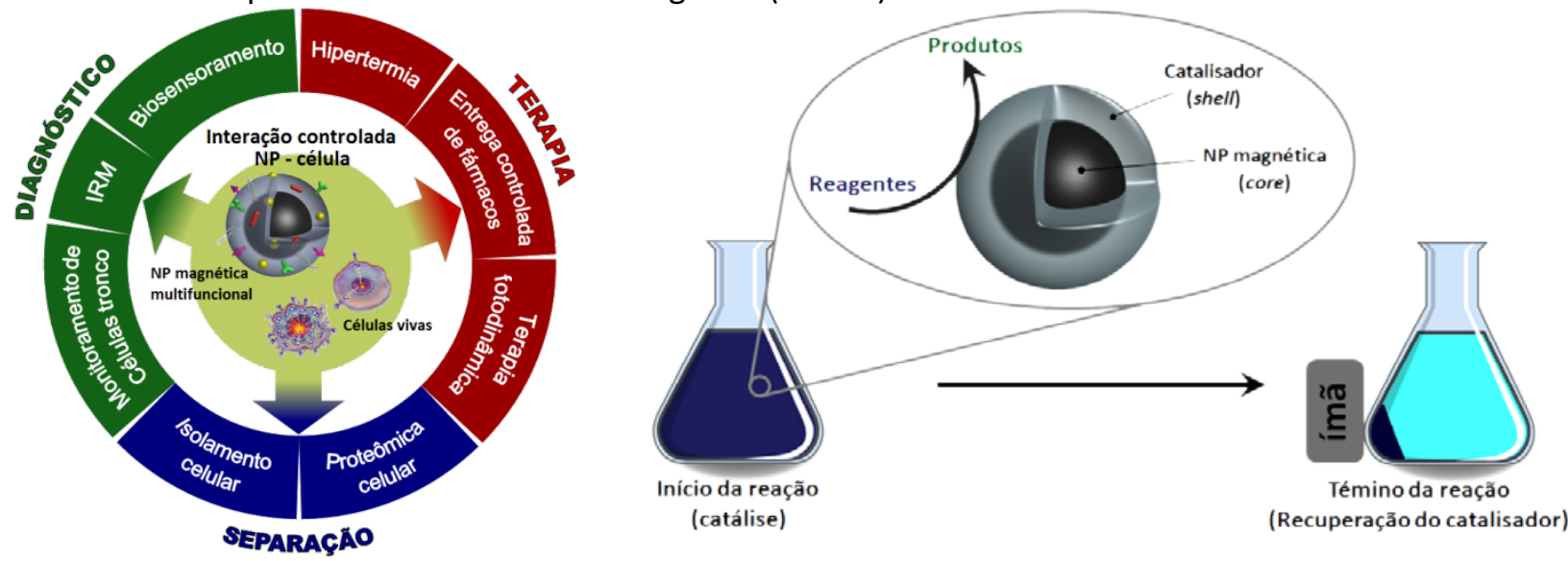

Fonte: Figura à esquerda: PARTON,E. et al., 2007(12) $)^{\text {(Modificado) }}$; Figura à direita: Autoria própria. 


\subsection{Propriedades magnéticas dos materiais}

O magnetismo é um fenômeno físico que, na visão clássica, é resultado do movimento dos elétrons nos átomos, uma vez que cargas em movimento geram campo magnético. A quantidade de elétrons presentes em um átomo e a maneira como os mesmos encontram-se organizados caracterizam o tipo de magnetismo apresentado por este átomo. Cabe ressaltar que o movimento de núcleos atômicos também contribui para as propriedades magnéticas dos materiais, mas esta contribuição é geralmente desprezível se comparada à contribuição eletrônica. Cada um dos elétrons que constituem um átomo possui dois tipos de movimento possíveis: movimento orbital ao redor do núcleo e movimento de rotação ao redor de seu próprio eixo (spin). Tais movimentos dão origem a momentos magnéticos (Figura 2), cuja existência é a fonte do comportamento magnético dos materiais.

Figura 2 - Representação do momento magnético associado aos movimentos eletrônicos (a) orbital e (b) de spin.

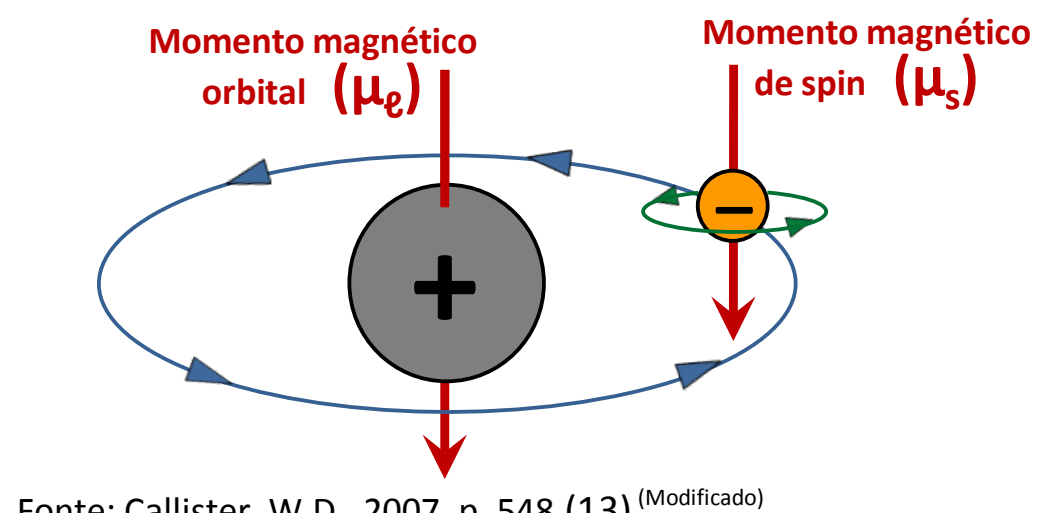

Fonte: Callister, W.D., 2007, p. 548.(13) ${ }^{\text {(Modificado) }}$

Os átomos possuem em sua estrutura muitos elétrons em movimento orbital e de spin. Sendo o momento magnético associado a cada tipo de movimento uma grandeza vetorial, o momento magnético total do átomo nada mais é do que a soma vetorial de todos os momentos eletrônicos, considerando as duas diferentes contribuições. Em um átomo é possível que os momentos magnéticos de todos os elétrons encontram-se orientados de tal forma que se cancelem mutuamente, e o átomo não apresenta nenhum momento magnético resultante. Este comportamento é característico de materiais diamagnéticos, os quais, mesmo não apresentando momento magnético permanente, quando submetidos a um campo externo $(H)$, respondem a este de forma a se afastarem da região em que este campo é mais forte, apresentando momentos magnéticos induzidos (com baixa magnitude) e em sentido contrário ao sentido do campo aplicado, conforme mostrado na Figura 3(a). 
Outra possibilidade seria a ocorrência do cancelamento parcial entre os momentos magnéticos dos elétrons, ficando o átomo com um momento magnético resultante. Esse é o caso dos materiais paramagnéticos, ferromagnéticos, antiferromagnéticos e ferrimagnéticos.(14)

Em materiais paramagnéticos, cada átomo possui um momento magnético permanente devido ao incompleto cancelamento dos momentos magnéticos de seus elétrons constituintes. Os momentos magnéticos desses átomos encontram-se, na ausência de um campo externo, orientados de maneira aleatória de forma que o material como um todo não apresenta nenhuma magnetização líquida. Quando um campo magnético externo é aplicado, os momentos magnéticos atômicos se alinham no mesmo sentido do campo aplicado, conforme mostrado na Figura 3(b).

Figura 3 - Representação do comportamento magnético para um material: (a) diamagnético e (b) paramagnético. (13) ${ }^{\text {(Modificado) }}$

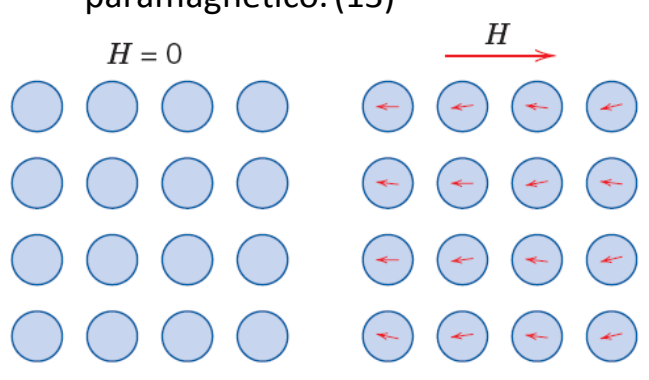

(a)

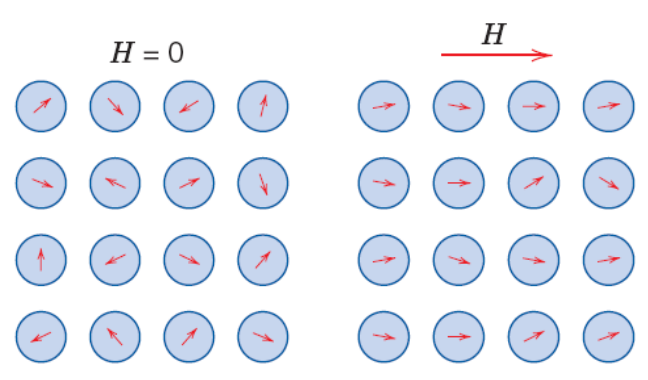

(b)

Fonte: Callister, W.D., 2007, p. 547.

Materiais com comportamento ferromagnético apresentam magnetização espontânea, isto é, os momentos magnéticos permanentes dos átomos encontram-se alinhados mesmo na ausência de um campo externo. Tal alinhamento deve-se à existência de um campo magnético interno chamado campo molecular, o qual envolve uma interação eletrônica entre dois átomos vizinhos, denominado acoplamento de troca. Este acoplamento é contraposto pela energia térmica, a qual age no sentido de aumento de entropia do sistema, isto é, em sentido contrário ao alinhamento dos momentos magnéticos. Conforme a temperatura de um material ferromagnético aumenta, a energia térmica vai aumentando no sentido de desalinhar os momentos magnéticos atômicos, diminuindo a magnetização do material. Atingida uma dada temperatura, conhecida como temperatura de Curie $\left(T_{C}\right)$, os momentos magnéticos encontramse totalmente desalinhados e o material passa a exibir comportamento paramagnético. Em temperaturas abaixo de $T_{C}$, cada átomo constituinte de um material ferromagnético se comporta como um minúsculo ímã permanente e, espontaneamente, se alinha paralelamente aos seus vizinhos em regiões delimitadas dentro do material. Tais regiões, nas quais predomina somente 
um alinhamento magnético, são conhecidas como domínios magnéticos, os quais são ilustrados na Figura 4.

Figura 4 - Ilustração da estrutura dos domínios magnéticos dispostos aleatoriamente em um material policristalino e constituído por multidomínios magnéticos. (14)

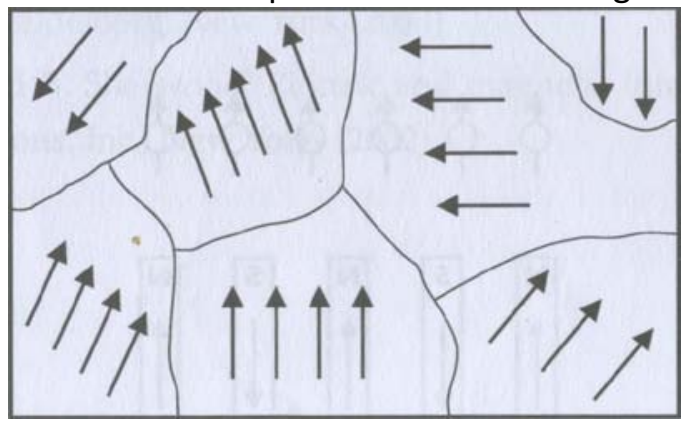

Fonte: Faria, R. N. et al., 2005, p. 30.

Materiais ferri e antiferromagnéticos também possuem acoplamento de troca e, conseqüentemente, seus momentos magnéticos atômicos alinhados espontaneamente. Porém, diferentemente dos ferromagnéticos, o alinhamento ocorre antiparalelamente. Nos materiais ferrimagnéticos, os diferentes momentos magnéticos de dois ou mais íons cancelam-se parcialmente, e o material apresenta magnetização resultante menor que a de materiais ferromagnéticos, mas diferente de zero. Já nos antiferromagnéticos, o alinhamento antiparalelo faz com que os momentos magnéticos atômicos sejam quase que totalmente cancelados, fazendo com que materiais antiferromagnéticos apresentem magnetização resultante praticamente nula.(14)

\subsection{Magnetismo em nanoescala}

O magnetismo de amostras com dimensões nanométricas apresenta importantes diferençcas comparativamente ao magnetismo de amostras macroscópicas. De modo simplificado, algumas das explicações para tais diferenças são: (i) quebra de simetria de translação, (ii) presença de sítios com número de coordenação reduzido, (iii) maior proporção de átomos superficiais, (iv) dimensões comparáveis entre o tamanho das NPM e o tamanho limite de monodomínios magnéticos.(15)

Com o intuito de diminuir sua energia magnetostática, materiais ferromagnéticos macroscópicos possuem múltiplos domínios magnéticos, os quais são separados por paredes de domínios móveis. Com a diminuição das dimensões do material até um valor limite, denominado diâmetro crítico da partícula $\left(D_{C}\right)$, o aumento na energia devido à formação das paredes de 
domínio passa a ser mais pronunciada que o decréscimo na energia magnetostática devido à formação de múltiplos domínios, tornando-se um processo não vantajoso do ponto de vista energético. Abaixo de $D_{C}$, os monodomínios constituem a configuração mais favorável para as partículas.(16) $O$ valor de $D_{c}$ é característico de cada tipo de material, encontrando-se, na grande maioria das vezes, na escala de nanômetros.

Partículas pequenas o suficiente para serem constituídas por um único domínio magnético podem apresentar um comportamento magnético especial e característico conhecido como superparamagnetismo. Este termo é usado para se fazer uma analogia entre o comportamento do pequeno momento magnético de um único átomo paramagnético e o de um momento magnético resultante de uma partícula nanométrica que surge do acoplamento ferromagnético de muitos spins atômicos dentro de um monodomínio.

De forma geral, o superparamagnetismo é explicado com base na equação de relaxação magnética (Equação de Néel-Arrhenius, Equação (I)):

$$
\tau=\tau_{0} e^{K V / k_{B} T} \quad \text { Equação (I) }
$$

De acordo com esta equação, cada partícula possui um tempo de relaxação (tempo característico), que é essencialmente o tempo médio para reverter o momento magnético de um estado de equilíbrio até outro. O tempo de relaxação $\tau_{0}$ é determinado por uma freqüência de tentativa de saltos (da ordem de $10^{9}-10^{10} \mathrm{~Hz}$ ), e por um fator de Bolztmann, $e^{[-K V / k B T]}$, onde $k_{B}$ é a constante de Bolztmann, $T$ a temperatura, $V$ o volume da partícula e $K$ é a constante de anisotropia. Pequenas partículas magnéticas possuem dois mínimos de energia anisotrópica, ambos alinhados ao eixo de anisotropia $\left(\theta=0^{\circ}\right.$ e $\left.\theta=180^{\circ}\right)$. Esses mínimos energéticos são separados por uma barreira de energia anisotrópica correspondente ao produto $K V$, conforme mostrado na Figura 5. Esta barreira energética atua no sentido de estabilizar o acoplamento entre os momentos magnéticos presentes na partícula, impedindo que o momento magnético total da partícula tenha liberdade de orientação no espaço. Contrária a essa barreira de energia anisotrópica, a energia térmica correspondente ao produto $k_{B} T$, atua no sentido de desestabilizar tal acoplamento. A diminuição do tamanho da partícula faz com que $K V$ atinja dimensões comparáveis à energia térmica $k_{B} T$ e a magnetização da partícula passa a apresentar energia suficiente para oscilar livremente de uma direção a outra, o que caracteriza o comportamento superparamagnético.(15) 
Figura 5 - Comparação entre o efeito do tamanho e temperatura da partícula sobre o comportamento superparamagnético da mesma. (16) ${ }^{\text {(Modificado) }}$

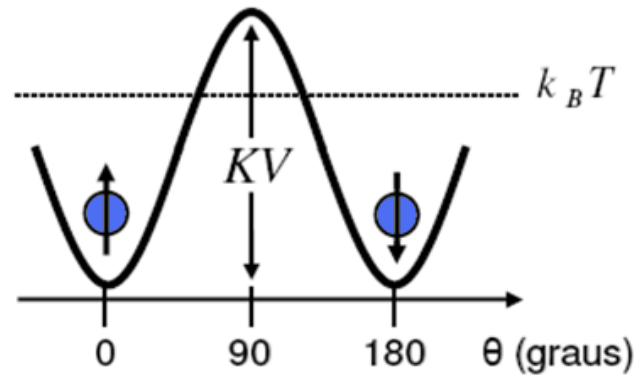

Fonte: Alves, T.M.M.T., 2007, p. 4.

É importante salientar que o superparamagnetismo depende da escala de tempo da medida. Para técnicas espectroscópicas o tempo de medida é tomado como $t_{m}=100 \mathrm{~s}$. Se o tempo de relaxação $\tau$ for mais curto do que $t_{m}$, a magnetização medida é zero, e diz-se que a partícula está no regime superparamagnético. Se o oposto acontece (isto é, $\tau>t_{m}$ ) a partícula está num regime bloqueado, e uma magnetizaãoo não-nula é observada.(15)

O comportamento magnético de uma amostra de NP pode ser analisado através de uma curva de histerese, a qual mede a variação da magnetização da amostra (M) com a variação do campo magnético externamente aplicado. Como mostrado na Figura 6, na ausência do campo (ponto “O"), os múltiplos domínios magnéticos apresentam alinhamentos aleatórios e a magnetização total da amostra é zero. Quando o campo magnético externo $(\vec{H})$ é aplicado, os domínios com alinhamento preferencial a $\vec{H}$ crescem em detrimento da diminuição dos domínios com alinhamento não preferencial, o que ocorre divido ao movimento das paredes de domínios. Isso ocorre até que $\vec{H}$ seja suficientemente forte para que todos os momentos magnéticos das partículas estejam alinhados ao campo. Nete ponto diz-se que a magnetização da amostra está saturada, sendo o seu valor denominado magnetização de saturação $\left(\mathrm{M}_{\mathrm{S}}\right)$. Com a redução do campo aplicado, os momentos magnéticos das partículas vão se desalinhando, e a magnetização da amostra vai diminuindo. Quando o campo atinge o valor de zero, partículas ferromagnéticas (Figura 6a) ainda possuem uma magnetização residual devido à existência de acoplamentos magnéticos resultantes, cujo valor é chamado de remanência $\left(M_{r}\right)$. Para que tais partículas sejam completamente desmagnetizadas, o campo aplicado deve ser invertido e seu módulo variar até o valor em que a magnetização da amostra atinja o valor zero. $O$ valor de campo magnético necessário para levar a magnetização a zero é conhecido como coercividade $\left(H_{C}\right)$. Se as partículas são superparamagnéticas (Figura 6b), seus momentos magnéticos estão sujeito a flutuações térmicas e, com a remoção do campo, desalinham-se novamente, resultando em valores de $\mathrm{M}_{\mathrm{r}} \mathrm{e}$ 
$\mathrm{H}_{\mathrm{C}}$ nulos. Este segundo tipo de comportamento magnético de partículas é bastante interessante para aplicações biomédicas e catalíticas, pois, como as partículas não estão sujeitas a interações magnéticas fortes em uma dispersão, estas tendem a apresentar considerável estabilidade em condições fisiológicas e em meios reacionais catalíticos.

Figura 6 - Exemplos ilustrativos de curvas de magnetização em função do campo magnético aplicado para materiais (a) ferromagnéticos e (b) superparamagnéticos. (17)
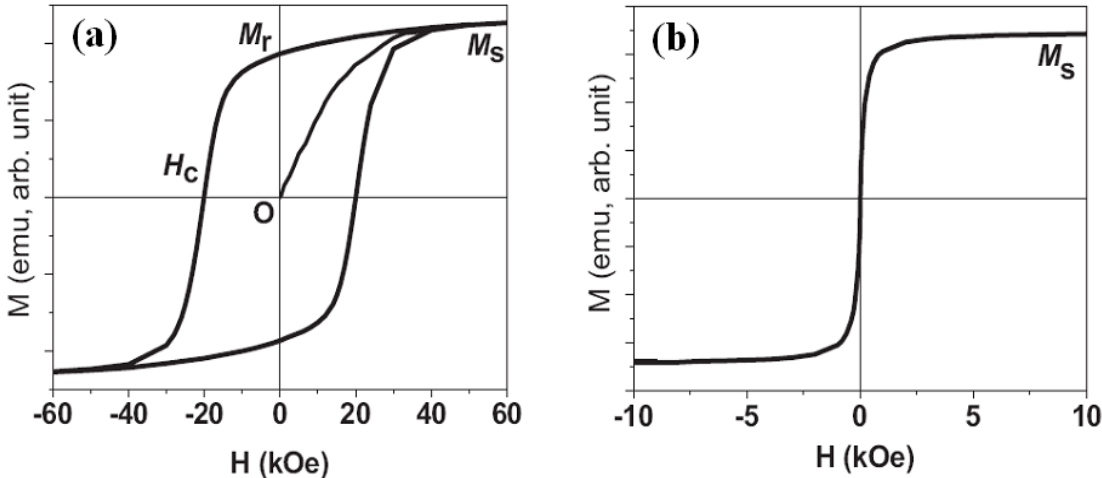

Fonte: SUN, S. et al., 2006, p 393.

\subsection{Métodos de síntese de NPM}

Muitos trabalhos da literatura relatam a busca por diferentes métodos de síntese de NPM que permitam o maior controle possível sobre as propriedades do produto final. Dentre os mais variados métodos de síntese de NPM destacam-se os métodos de co-precipitação,(18,19) sistemas micelares ou microemulsões, $(20,21)$ síntese hidrotérmica, $(22,23)$ pirólise a laser $(24,25)$ e decomposição/redução térmica,(26-30) cada qual com suas respectivas particularidades, vantagens e desvantagens, as quais podem ser resumidas como mostrado na Tabela 1.

Tabela 1 - Resumo comparativo de quatro diferentes métodos de síntese de nanopartículas.(31)

\begin{tabular}{c|c|c|c|c|c|c|c}
\hline Método & Síntese & $\begin{array}{c}\text { Temperatura } \\
\text { Reação (-C) }\end{array}$ & $\begin{array}{c}\text { Tempo de } \\
\text { reação }\end{array}$ & Solvente & $\begin{array}{c}\text { Agentes de } \\
\text { superfície }\end{array}$ & $\begin{array}{c}\text { Distribuição de } \\
\text { tamanho }\end{array}$ & $\begin{array}{c}\text { Controle de } \\
\text { forma }\end{array}$ \\
\hline Co-precipitação & $\begin{array}{c}\text { Muito simples, } \\
\text { condição ambiente }\end{array}$ & $20-90$ & Minutos & $\begin{array}{c}\text { Necessário durante } \\
\text { ou após reação }\end{array}$ & $\begin{array}{c}\text { Relativamente } \\
\text { estreita }\end{array}$ & Ruim \\
\hline $\begin{array}{c}\text { Decomposição } \\
\text { térmica }\end{array}$ & $\begin{array}{c}\text { Complicado, } \\
\text { atmosfera inerte }\end{array}$ & $100-320$ & Horas/dias & Orgânico & $\begin{array}{c}\text { Necessário durante } \\
\text { a reação }\end{array}$ & Muito estreita \\
\hline $\begin{array}{c}\text { Microemulsão } \\
\text { Complicado, } \\
\text { condições } \\
\text { ambiente }\end{array}$ & $20-50$ & Horas & Orgânico/água & $\begin{array}{c}\text { Necessário durante } \\
\text { a reação }\end{array}$ & $\begin{array}{c}\text { Relativamente } \\
\text { estreita }\end{array}$ \\
\hline $\begin{array}{c}\text { Síntese } \\
\text { hidrotérmica }\end{array}$ & $\begin{array}{c}\text { Simples, altas } \\
\text { pressões }\end{array}$ & 220 & Horas/dias & Água-etanol & $\begin{array}{c}\text { Necessário durante } \\
\text { a reação }\end{array}$ & Muito estreita \\
\hline
\end{tabular}

Fonte: LU, A.H. et al., 2007. 
Dentre os métodos de síntese acima mostrados, dois deles têm se destacado: microemulsão e decomposição térmica. Os mesmos são melhor descritos como segue.

\subsubsection{0 método de microemulsão}

Dentre os mais promissores métodos de síntese de nanomateriais com alto controle de forma e tamanho estão os métodos envolvendo sistemas nanoheterogêneos tais como microemulsões e soluções de substâncias tensoativas.

Microemulsões são nanodispersões coloidais formadas por dois líquidos imiscíveis estabilizadas pela ação de um filme surfactante que diminui a tensão interfacial do sistema.(32) Ainda, é possível a utilização de um co-surfactante, normalmente um álcool de cadeia pequena, que atua juntamente com o surfactante promovendo uma maior estabilidade do sistema. Dependendo da razão entre água, óleo e surfactante, ocorre a solubilização de uma fase (fase dissolvida) sobre a outra (meio de dissolução), na qual a fase dissolvida fica recoberta pelo filme surfactante. As microemulsões são termodinamicamente estáveis e, macroscopicamente, podem apresentar-se como um meio líquido isotrópico.(33,34) De acordo com o tipo da fase dissolvida e do meio de dissolução, as microemulsões podem ser classificadas como direta (óleo em água), formada por uma fase apolar dissolvida em um meio de dissolução polar (Figura 7a); inversa (água em óleo), onde a fase dissolvida é polar e o meio de dissolução é apolar (Figura 7b); e bicontínua, onde água e óleo encontram-se organizadas na forma de canais separados por um filme surfactante (Figura 7c). (35)

As soluções de substâncias tensoativas possuem algumas propriedades características: quando em pequenas concentrações, funcionam como simples eletrólitos, mas quando em um faixa específica de concentração, sofrem consideráveis variações em suas propriedades físicoquímicas, tais como: pressão osmótica, condutância, turbidez, tensão superficial ou medidas de espalhamento. Tais alterações podem ser explicadas em termos da formação de agregados organizados, conhecidos como micelas, as quais surgem acima de uma determinada concentração, chamada concentração micelar crítica $(\mathrm{cmc})$.(36) Quando em pequenas concentrações, as moléculas do surfactante se encontram aleatoriamente dissolvidas por todo o sistema na forma de monômeros. Quando a $\mathrm{cmc}$ é atingida, esses monômeros passam a se organizar de modo a buscar um estado de menor energia, formando assim as micelas. Concentrações muito superiores à $\mathrm{cmc}$ resultam na perda da organização e as micelas são quebradas (Figura 8). 
Figura 7 - Tipos de microemulsão: (a) direta, (b) inversa e (c) bicontínua. (37)

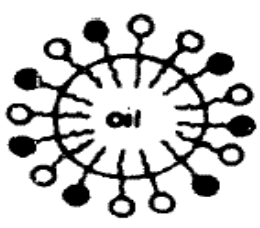

(a)

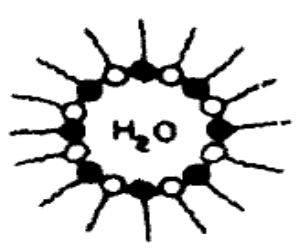

(b)

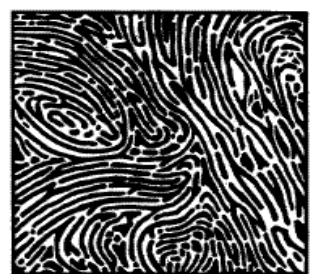

(c)

Fonte: Shinoda, K. et al., 1987.

Figura 8 - Comportamento dos monômeros de surfactantes em solução cujo solvente possui caráter apolar. (38) $)^{\text {(Modificado) }}$

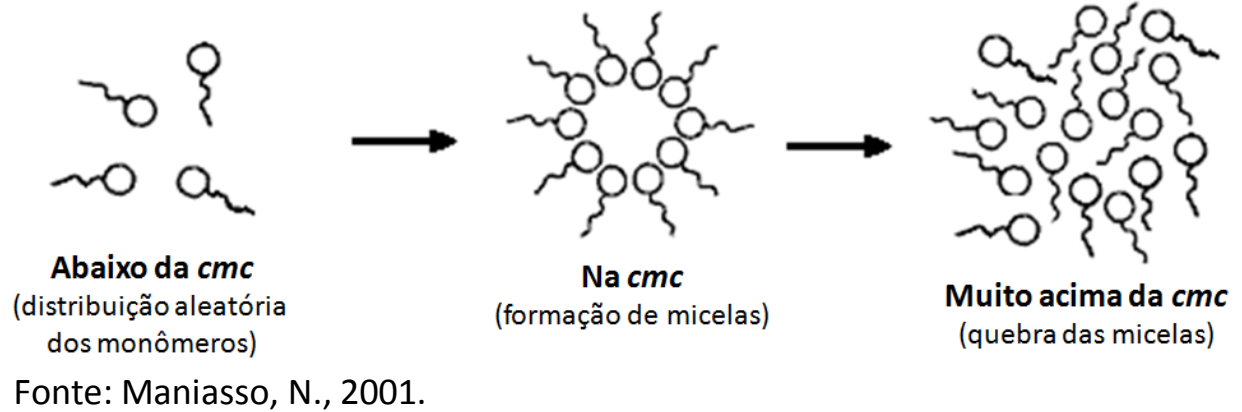

Tanto as microemulsões quanto as soluções de substâncias tensoativas são exemplos de sistemas nanoheterogêneos por possuirem pequenos domínios separados em determinadas composições. Em sínteses de NP, tais domínios podem atuar como nanoreatores, aprisionando as espécies precursoras das NP e disponibilizando um ambiente único para sua nucleação e crescimento. O acúmulo dessas espécies precursoras e o conseqüente crescimento das nanopartículas no interior dos nanoreatores são limitados pelo espaço disponível, promovendo satisfatório controle sobre tamanho e forma dessas nanopartículas.(21)

O encapsulamento de nanopartículas dentro de nanoheterogeneidades permite a investigação de um grande número de fenômenos bastante intrigantes e ainda inexplorados, tais como reação e cristalização em sistema confinado, a adsorção preferencial de moléculas de surfactante em determinadas faces cristalográficas das nanopartículas, a inibição do crescimento e a organização estrutural dentro de estruturas auto-organizadas.(21)

A grande maioria dos trabalhos de síntese de NP via sistemas nanoheterogêneos consiste da mistura de duas microemulsões, cada qual carregando um reagente apropriado (sais e agentes redutores, por exemplo).(39) A reação ocorre através da troca de reagentes durante o processo dinâmico de formação/explosão das micelas dentro das quais os reagentes se encontram. Entretanto, a presença de contra-íons pode modificar propriedades físico-química das micelas, afetando o equilíbrio entre as diferentes fases do sistema e, consequentemente, as 
características do produto.(40) Recentemente, alguns artigos têm empregado surfactantes que já possuem o cátion de interesse em sua estrutura.(41) O uso desses surfactantes cátionsubstituídos possibilita o uso de apenas um sistema microemulsionado, ao qual o reagente promotor da reação de formação da NP é adicionado diretamente ao meio. Permite ainda que os efeitos relacionados à presença dos contra-íons dos surfactantes convencionais sejam minimizados. Um inconveniente dos surfactantes cátion-substituídos é que os mesmos são normalmente sintetizados utilizando-se resinas de troca iônica específicas, o que eleva o custo do processo.

\subsubsection{0 método de decomposição térmica}

Recentemente, métodos químicos envolvendo decomposição térmica de precursores organometálicos têm demonstrado grande eficiência quanto ao controle de tamanho, morfologia, arranjos bi e tridimensionais, composição, entre outras propriedades das nanopartículas obtidas. Em sua grande maioria, tais métodos consistem na utilização direta ou com pequenas modificações do método poliol. O método poliol foi pioneiramente relatado por Fiévet e colaboradores na síntese de micropartículas através da utilização de etilenoglicol na redução de íons metálicos em altas temperaturas.(42) Entretanto, ficou amplamente conhecido após trabalhos realizados por S. Sun e colaboradores nos quais o etilenoglicol foi substituído por um alcanodiol de cadeia longa (1,2-hexadecanodiol), sendo assim obtidas nanopartículas monodispersas. $(17,27)$ A Figura 9 ilustra o método poliol sendo empregado na síntese de nanopartículas bimetálicas de FePt.

Figura 9 - Ilustração da síntese de nanopartículas de FePt via método poliol, onde $\mathrm{Fe}(\mathrm{CO})_{5}$ e $\mathrm{Pt}(\mathrm{acac})_{2}$ são os precursores metálicos, 1,2-hexadecanodiol é o diol redutor, ácido oléico e oleilamina são os estabilizadores e dioctiléter é o solvente. (17) ${ }^{\text {(modificado) }}$

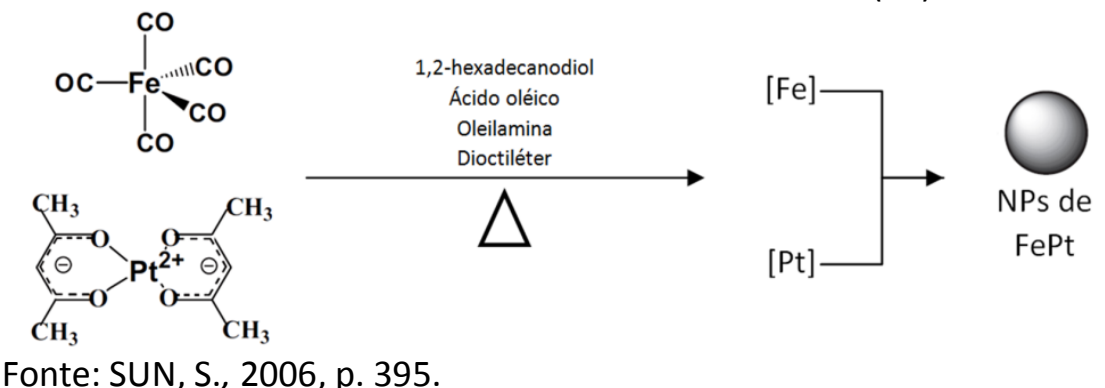

O método poliol utilizado por $S$. Sun e colaboradores para síntese de nanopartículas de FePt baseia-se na decomposição térmica do ferro pentacarbonil $\left(\mathrm{Fe}(\mathrm{CO})_{5}\right)$ e redução do 
acetilacetonato de platina(II) $\left(\mathrm{Pt}(\mathrm{acac})_{2}\right)$ na presença de um 1,2-alcanodiol. Segundo os autores, a utilização de um 1,2-alcanodiol com cadeia longa facilita a redução da Pt(acac) 2 para Pt metálica, levando a um aumento a taxa de nucleação e consumo dos precursores metálicos, resultando em partículas menores.(17) Ainda, o tamanho das partículas pode ser controlado pelo ajuste da razão molar entre os estabilizadores e o precursor de platina e também pelo controle da taxa de aquecimento e temperatura de refluxo. A utilização de dois diferentes estabilizadores ao invés de apenas um deve-se à maior afinidade do ácido oléico pelo ferro e da oleilamina pela platina. $\mathrm{O}$ grupamento amina $\left(-\mathrm{NH}_{2}\right)$ da oleilamina, por ser um doador de densidade eletrônica, liga-se via ligação coordenada à platina. Já o grupamento carboxilato (-COO$)$ pode tanto ligar-se covalentemente ao ferro quanto atuar como um ligante monodentado (ligando-se ao ferro através de um único átomo de oxigênio) ou bidentado (ligando-se ao ferro através de dois átomos de oxigênio). A Figura 10 ilustra a atuação dos estabilizadores sobre a superfície das nanopartículas de FePt.

Figura 10 - Esquema da ligação de moléculas de um alquilcarboxilato e de uma alquilamina sobre a superfície de uma nanopartícula de FePt. (17)

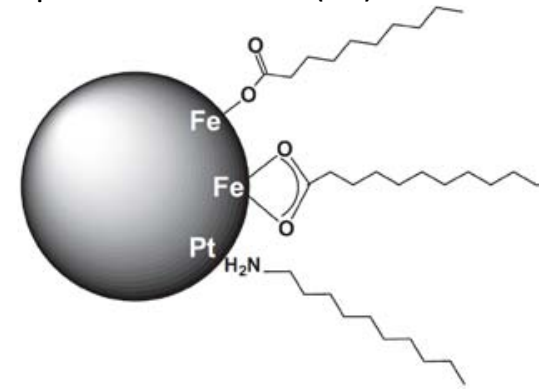

Fonte: SUN, S., 2006, p. 397.

Atualmente diversas variantes do método poliol vêm sendo empregadas na literatura, nas quais a principal modificação é a substituição dos precursores metálicos carbonílicos, por precursores de menor toxicidade, tais como acetatos e acetilacetonatos. $(26,28,43)$ Além da toxicidade, outro problema associado à utilização de compostos carbonílicos em sínteses de decomposição térmica é a alta volatilidade destes compostos, o que faz com que parte do reagente adicionado à síntese acaba por não participar da reação, dificultando assim o controle sobre a composição das partículas. Neste ponto reside a maior vantagem da utilização de sais acetatos e acetilacetonatos como precursores metálicos, uma vez que por apresentarem volatilidade desprezível, o controle sobre a composição do produto final é amplamente facilitado. 


\subsection{Recobrimento de NPM com sílica}

O recobrimento com sílica é um artifício bastante usado na biocompatibilização de NPM. Dentre as vantagens da sílica, estão: biocompatibilidade com muitos sistemas biológicos, versatilidade de funcionalização de sua superfície com biocompostos, estrutura porosa que aumenta sua área de superfície, estabilidade coloidal em pH fisiológico por repulsão eletrostática devido à carga negativa de sua superfície, entre outras. $(31,44,45)$

Os métodos de Stöber e sol-gel estão entre os mais usados para a síntese de partículas de sílica.(46-48) Basicamente, tais métodos realizam a hidrólise de precursores alcoxisilados como o tetraetilortosilicato. Alguns trabalhos tem realizado esta reação de hidrólise em sistemas de microemelsão inversa (água em óleo), o que possibilita a síntese de nanopartículas de sílica com grande versatilidade no controle de suas dimensões. $(49,50)$ Resultados bastante interessantes vêm sendo obtidos a partir do uso de sistemas de microemulsão para o recobrimento de NPM hidrofóbicas com sílica.(51-54) Em tais sistemas, a hidrólise do alcoxisilano ocorre no interoir das micelas contendo NPM em seu interior, promovendo a formação da sílica sobre a superfície das NPM. No entanto, é interessante e talvez inesperado que partículas hidrofóbicas possam ser recobertas no interior de micelas inversas devido à sua maior afinidade pela fase apolar. Com base neste comportamento controverso, um grande número de autores têm proposto diferentes mecanismos para a formação da casca de sílica. Zhang et al.(52) propõe que, após a adição das NPM, moléculas de surfactante interagem com o ácido oleico ligados à superfície da NPM e, depois da adição de $\mathrm{NH}_{4} \mathrm{OH}$ aquoso, as nanopartículas são transferidas para o interior das micelas. $\mathrm{O}$ alcoxisilano é então hidrolisado no interior das micelas e os produtos à base de silício condensam formando um escudo de sílica sobre as moléculas orgânicas na superfície da NPM. Apesar dos bons resultados, este trabalho não apresenta evidências físicas que comprovem este mecanismo. Um mecanismo em três etapas é proposto por Vogt et al.(53) Os autores utilizam espectroscopia infravermelho (FTIR) para mostrar que as moléculas de ácido oleico presentes na superfície de nanopartículas são substituídos por espécies hidrolisadas de TEOS. É proposto que, depois desta substituição, as NPM são internalizadas pelas micelas. Então, a associação entre moléculas de TEOS hidrolisado com as micelas produz a condensação e o crescimento de casca de sílica. Recentemente, Ding et al.(51) propuseram um mecanismo para o qual afirmam a ocorrência de um processo de troca de ligantes, em que o ácido oleico é substituído por moléculas do surfactante, o que permitiria a internalização das NPM. Após a hidrólise de TEOS, 
ocorre uma segunda troca de ligantes na qual os surfactantes ligados à superfície das NPM são substituídos por espécies hidrolizadas de TEOS que se condensam para formar a casca de sílica.

Recobrimentos com sílica também são usados para evitar processos de sinterização entre partículas durante tratamentos térmicos, o que deve-se à estabilidade térmica desse material. Assim, esta estabilidade térmica da sílica somada à sua biocompatibilidade, versatilidade de funcionalização, porosidade e carga superficial negativa a tornam um material promissor para o recobrimento de NPM metálicas para aplicações em biomedicina.

\subsection{Aplicações biomédicas de NPM}

A possibilidade de aplicação de nanomateriais magnéticos em biomedicina (55-58) decorre primeiramente das dimensões apresentadas por tais materiais, uma vez que estes podem possuir tamanhos controláveis da ordem de poucos nanômetros, o que os coloca em dimensões menores ou comparáveis às de células (10-100 $\mu \mathrm{m})$, vírus (20-450 nm), proteínas (5$50 \mathrm{~nm}$ ) ou genes ( $2 \mathrm{~nm}$ de largura e 10-100 nm de comprimento). Além disso, a grande área de superfície relativa das NP pode ser apropriadamente modificada para receber agentes biológicos, o que possibilita processos de transporte e imobilização no interior do corpo humano de modo não invasivo, pela simples aplicação de campos magnéticos externos.(59) Dentre as mais variadas aplicações biomédicas de nanomateriais magnéticos é possível citar: tratamentos anti-câncer por hipertermia magnética,(60-63) realce de contrastes em imagens por ressonância magnética,(60,64) marcação e separação magnética de células e proteínas,(65) entrega controlada de fármacos (Drug Delivery),(66,67) entre outras. Para todas essas aplicações, o recobrimento da superfície desses nanomateriais merece especial atenção, pois além de evitar a formação de aglomerados, ele é responsável por tornar as partículas dispersáveis em condições fisiológicas, não-tóxicas, biocompatíveis, além de possibilitar a funcionalização da superfície com agentes biologicamente ativos. Esses agentes podem ser anticorpos, nucleotídeos, peptídeos, vitaminas, hormônios, antibióticos e outras moléculas que guiem as NP a um alvo específico (um tipo de célula ou um órgão) durante sua distribuição no corpo humano.

\subsubsection{Hipertermia magnética}

Dentre as mais diversas aplicações biomédicas de NPM, a técnica de hipertermia magnética têm se mostrado como uma alternativa promissora em tratamento de câncer, atuando como uma terapia complementar à quimioteratia e/ou radioterapia. A hipertermia 
magnética pode ser vista como um protocolo clínico baseado na aplicação de campos magnéticos alternados (AMF) que visa o aumento de temperatura em meio intracelular, partindo de níveis fisiológicos $\left(T=37^{\circ} \mathrm{C}\right)$ até temperaturas ao redor de $45^{\circ} \mathrm{C}$, o suficiente para causar a lise e morte de células cancerosas.(62) O tratamento baseia-se no uso de NPM que possuam em sua superfície substâncias que lhe conferem seletividade pela células cancerosas e facilidade de internalização por esta célula. Com a aplicação de AMF com alta freqüência (na escala de $\mathrm{MHz}$ ), a energia do AMF é transferida para as NPM devido ao acoplamento da componente magnética da radiação eletromagnética e o momento magnético de cada partícula. Esta energia é então transformada em calor através de flutuações mecânicas (relaxação Browniana) e/ou magnéticas (relaxação de Néel).(68) A capacidade do material em gerar calor é medido pela taxa de absorção específica (SAR, do inglês specific absorption rate), também conhecida como specific power absorption ou specific power losses. De modo simplificado, SAR mede a energia absorvida pelas NPM por unidade de massa. É importante salientar que o potencial de aquecimento é fortemente dependente do tamanho e forma da partícula, e assim rotas sintéticas bem definidas capazes de produzir partículas com morfologia controlada são essenciais para um rigoroso controle de temperatura.

\subsection{Aplicações catalíticas de NPM}

Com relação às aplicações de NPM em catálise, a grande preocupação ambiental observada nos dias de hoje exige que os processos industriais de produção apresentem os menores danos possíveis ao meio ambiente. Isso resultou no reconhecimento da necessidade do desenvolvimento de novos catalisadores para uma tecnologia limpa, que permita a manufatura de produtos de maneira eficiente, com alto rendimento, sem causar grandes prejuízos ambientais.(9) A utilização de processos homogêneos de catálise, apesar de conferir grande especificidade e altos rendimentos às reações, apresenta a desvantagem de necessitar de etapas posteriores de separação e regeneração do catalisador, resultando em um grande aumento da energia gasta durante todo o processo de produção. Já a catálise heterogênea apresenta uma maior facilidade de recuperação do catalisador, a qual pode ser realizada por processos simples como filtração ou centrifugação. Entretanto, este tipo de catálise normalmente apresenta falta de seletividade e difícil compreensão do mecanismo catalítico, $(69,70)$ além de um menor rendimento decorrente da própria distribuição heterogênea do catalisador pelo meio de reação. Nesse contexto, a utilização de NPM em catálise mostra-se uma área de pesquisa bastante 
promissora, uma vez que as dimensões reduzidas desse tipo de material somadas às propriedades magnéticas apresentadas pelo mesmo possibilitam a realização de um processo catalítico semi-homogêneo que combina vantagens como alta dispersibilidade no meio reacional, alta reatividade que resulta em melhores rendimentos e fácil separação do meio reacional após a realização da reação, o que é possível pela simples aplicação de campos magnéticos externos. A separação magnética do catalisador elimina a necessidade do uso de agentes floculantes ao meio, o que normalmente resultava em uma perda parcial da atividade catalítica do material, permitindo que este seja reutilizado posteriormente por muitos ciclos catalíticos.(31,71-74)

\subsubsection{0 dióxido de titânio como fotocalisador}

Dentre os materiais normalmente aplicados em catálise, o dióxido de titânio $\left(\mathrm{TiO}_{2}\right)$ está entre os mais estudados. Trata-se de um semicondutor muito empregado como fotocatalisador na degradação de poluentes ambientais. O sucesso de tais aplicações depende principalmente das propriedades físicas do material, tais como fase cristalina, cristalinidade da fase, área de superfície, forma e tamanho das partículas, dimensões de poro e rugosidade de superfície.

As três principais fases cristalinas do $\mathrm{TiO}_{2}$ são anatase, rutilo e brookita, das quais as duas primeiras são as mais estudadas. Dentre elas, a anatase é conhecida por apresentar a melhor atividade fotocatalítica. Ambas as fases anatase e rutilo apresentam estrutura cristalina formada por octaedros ligeiramente distorcidos de $\mathrm{TiO}_{6}$. A diferença estrutural entre as fases está na conexão entre esses octaedros: na anatase os octaedros compartilham faces enquanto que no rutilo compartilham vértices. Outras duas diferenças existentes entre anatase e rutilo são a densidade $\left(3,894 \mathrm{~g} \mathrm{~cm}^{-3}\right.$ para anatase e $4,52 \mathrm{~g} \mathrm{~cm}^{-3}$ para o rutilo) e de estrutura eletrônica (energia de band-gap de 3,2 eV e 3,0 eV respectivamente para anatase e rutilo), as quais têm grande influência sobre as propriedades físicas e químicas desses materiais.

Embora o rutilo apresente a maior estabilidade termodinâmica entre as três fases de $\mathrm{TiO}_{2}$, esta estabilidade depende do tamanho de partícula. Partículas menores apresentam maior razão área de superfície / volume e, consequentemente, maior energia de superfície, que passa a contribuir significativamente para a energia total do sistema. Isso significa que, para partículas muito pequenas, a fase com menor energia de superfície tende a apresentar a maior estabilidade termodinâmica. Dessa forma, a anatase passa a ser mais estável que o rutilo em sistemas de nanopartículas menores que $14 \mathrm{~nm}$ por possuir a menor energia de superfície. Os valores de entalpia e entropia de superfície das fases anatase e rutilo são mostrados na Tabela 2. 
Tabela 2 - Valores de entalpia e entropia de superfície das fases anatase e rutilo.(75)

\begin{tabular}{c|c|c}
\hline Fase & $\begin{array}{c}\text { Entalpia de superfície } \\
\left(\mathrm{J} \mathrm{m}^{-2}\right)\end{array}$ & $\begin{array}{c}\text { Entropia de superfície } \\
\left(\mathrm{J} \mathrm{K}^{-1} \mathrm{~mol}^{-1}\right)\end{array}$ \\
\hline Anatase & $0,4 \pm 0,1$ & $49,9 \pm 0,3$ \\
\hline Rutilo & $2,2 \pm 0,2$ & $50,6 \pm 0,6$ \\
\hline
\end{tabular}

Fonte: ZHANG, H., et al., 1998;(76) RANADE, M. R., et al., 2002.

A atividade fotocatalítica do $\mathrm{TiO}_{2}$ deve-se à excitação de um elétron entre as bandas de valência e de condução, o que ocorre após irradiação com luz UV de energia igual ou superior à sua energia de band-gap. Os pares elétron-buraco formados desencadeiam uma série de reações que podem levar à formação de radicais $\mathrm{HO}^{\bullet}$, sendo estes os responsáveis primários pela degradação fotocatalítica de poluentes e microorganismos. O elétron da banda de condução pode migrar para a superfície do material e reduzir moléculas adsorvidas de $\mathrm{O}_{2} \mathrm{a} \mathrm{O}_{2}{ }^{-}$, o qual pode ser novamente reduzido a $\mathrm{H}_{2} \mathrm{O}_{2}$. Ambas as espécies reduzidas podem gerar $\mathrm{HO}^{\circ}$, que é considerado o principal responsável pela atividade fotocatalítica do $\mathrm{TiO}_{2}$. Assim, a anatase apresenta-se com um melhor fotocatalisador que o rutilo porque possui: (i) um band-gap indireto que diminui a taxa de recombinação elétron-buraca, (ii) maior energia de band-gap, (iii) maior mobilidade dos elétrons pelo cristal e (iv) maior habilidade de formar espécies peróxidos em sua superfície.(77)

\subsection{Justificativa do trabalho}

Atualmente a maioria das pesquisas envolvendo a aplicação de NPM em catálise e biomedicina utiliza NP de óxido de ferro, as quais apresentam valores de magnetização de saturação abaixo de 80 emu $\mathrm{g}^{-1}$. Entretanto, a funcionalização dessas NP com compostos catalisadores, biocompatíveis e/ou biosseletivos, normalmente diamagnéticos, tende a reduzir a já baixa emanação magnética. Uma opção seria o uso de NP metálicas, que apresentam $M_{S}$ superior a $150 \mathrm{emu} \mathrm{g}^{-1}$. Entretanto, tais partículas apresentam duas grandes desvantagens frente aos óxidos: (i) baixa estabilidade frente à oxidação e (ii) maior limitação quanto à funcionalização de sua superfície devido à baixa afinidade pela grande maioria dos grupos funcionais orgânicos. ${ }^{22}$ Diante do exposto, este trabalho descreve métodos em desenvolvimento para a síntese de NP metálicas de Fe e Co e bimetálicas de FeCo e FePt recobertas com óxidos em uma estrutura caroço-casca. Estas estruturas visam combinar em um único tipo de material a alta emanação magnética do núcleo metálico à já conhecida estabilidade química e versatilidade de 
funcionalização dos óxidos. Adicionalmente, tais materiais foram funcionalizados com materiais biocompatíveis (visando aplicações biomédicas) e catalisadores (para aplicações catalíticas). Ao final do trabalho, alguns testes de estabilidade coloidal e química, hipertermia magnética e atividade fotocatalítica foram feitos para analisar a aplicabilidade dos materiais obtidos.

\section{OBJETIVOS}

\subsection{Objetivo Geral}

Desenvolver e adequar procedimentos experimentais baseados em métodos de decomposição térmica de complexos metálicos e microemulsão por micela inversa para obtenção de sistemas nanoparticulados do tipo caroço-casca com alta magnetização de saturação e caráter superparamagnético para aplicação em catálise e biomedicina.

\subsection{Objetivos específicos}

Desenvolver e/ou adequar de rotas sintéticas baseadas em métodos de decomposição térmica e de sistemas de microemulsão inversa para obtenção de NP metálicas de Fe e Co, bimetálicas de FeCo, FePt e FeAg e de óxidos de ferro e de ferro-cobalto com tamanho, morfologia e composição rigorosamente controlados e alta magnetização de saturação;

$\checkmark$ Sintetizar surfactantes cátion-substituídos dodecil sulfato de ferro(III) (FeDS) e dodecil sulfato de cobalto(II) (CoDS) e determinar suas respectivas estruturas moleculares;

$\checkmark$ Estudar as propriedades magnéticas, químicas e físico-químicas dos diferentes produtos obtidos ao final de cada síntese;

Realizar o recobrimento da superfície das NPM com óxidos buscando a obtenção de nanomateriais com estabilidade química contra oxidação;

$\checkmark$ Para as NPM com as propriedades magnéticas mais adequadas, desenvolver processos de recobrimento com carboximetil-dextrana e com sílica buscando as melhores condições de biocompatibilidade, biosseletividade e estabilidade coloidal em sistemas biológicos;

$\checkmark$ Para as NPM com as propriedades magnéticas mais adequadas, realizar o recobrimento de sua superfície com dióxido de titânio na fase anatase para obtenção de nanomateriais aplicáveis em fotocatálise heterogênea;

$\checkmark$ Realizar testes in vitro para estudo da aplicabilidade das NPM em hipertermia magnética;

Realizar testes da atividade catalítica das NPM recobertas com dióxido de titânio. 


\section{PARTE EXPERIMENTAL}

\subsection{Reagentes utilizados}

Os reagentes utilizados neste trabalho encontram-se descritos na Tabela 3.

Tabela 3 - Lista de reagentes utilizados e respectivas purezas.

\begin{tabular}{|c|c|c|}
\hline Reagente - (abreviatura) & Fabricante & Pureza \\
\hline 1,2-dodecanodiol - (DDD) & Sigma-Aldrich & $90 \%$ \\
\hline 1,2-hexadecanodiol - (HDD) & Sigma-Aldrich & $90 \%$ \\
\hline 1,2-tetradecanodiol - (TDD) & Sigma-Aldrich & $90 \%$ \\
\hline 1-octadeceno - (OD) & Sigma-Aldrich & $90 \%$ \\
\hline 1-octanol & JT Baker & $99 \%$ \\
\hline Acetato de prata - $(\mathrm{Ag}(\mathrm{ac}))$ & Sigma-Aldrich & $99 \%$ \\
\hline Acetilacetonato de cobalto - $\left(\mathrm{Co}(\mathrm{acac})_{2}\right)$ & Sigma-Aldrich & $97 \%$ \\
\hline Acetilacetonato de ferro(III) - $\left(\mathrm{Fe}(\mathrm{acac})_{3}\right)$ & Sigma-Aldrich & $99 \%$ \\
\hline Acetilacetonato de platina - $\left(\mathrm{Pt}(\mathrm{acac})_{2}\right)$ & Sigma-Aldrich & $97 \%$ \\
\hline Acetona (Acet) & JT Baker & $99,6 \%$ \\
\hline Ácido oleico (AO) & Sigma-Aldrich & $90 \%$ \\
\hline Ácido acético glacial - (AAc) & JT Baker & $100 \%$ \\
\hline Borohidreto de sódio $\left(\mathrm{NaBH}_{4}\right)$ & Fluka & $>96 \%$ \\
\hline Carboximetil-dextrana sal sódico 10-20 kDa - (CM-Dex) & Sigma-Aldrich & n.i.* \\
\hline Ciclohexano & Mallinckrodt & $99,0 \%$ \\
\hline Cloreto de cobalto(II) hexahidratado $-\left(\mathrm{CoCl}_{2} \cdot 6 \mathrm{H}_{2} \mathrm{O}\right)$ & Sigma-Aldrich & $98 \%$ \\
\hline Cloreto de ferro(III) hexahidratado- $\left(\mathrm{FeCl}_{3} .6 \mathrm{H}_{2} \mathrm{O}\right)$ & Sigma-Aldrich & $99,10 \%$ \\
\hline Benziléter - (BE) & Sigma-Aldrich & $99 \%$ \\
\hline Octiléter - (OE) & Fluka & $>97 \%$ \\
\hline Dodecil sulfato de sódio - (NaDS) & JT Baker & $95 \%$ \\
\hline Etanol (EtOH) & Synth & $99,50 \%$ \\
\hline Hexano & Quemis & $98,50 \%$ \\
\hline Hidrogênio gás $\left(\mathrm{H}_{2}\right)$ & White Martins & $99,995 \%$ \\
\hline Hidróxido de amônio - $\left(\mathrm{NH}_{4} \mathrm{OH}\right)$ & JT Baker & $28-30 \%$ \\
\hline Igepal CO-520 & Sigma-Aldrich & n.i.* \\
\hline Isopropanol (IsopOH) & Synth & $99,50 \%$ \\
\hline$n$-butanol - (ButOH) & JT Baker & $99,9 \%$ \\
\hline$n$-heptano - (Hep) & JT Baker & $99,2 \%$ \\
\hline Nitrato de cobalto(II) hexahidratado $\left(\mathrm{Co}\left(\mathrm{NO}_{3}\right)_{3} .6 \mathrm{H}_{2} \mathrm{O}\right)$ & Sigma-Aldrich & $98 \%$ \\
\hline Nitrato de ferro(III) nonahidratado $\left(\mathrm{Fe}\left(\mathrm{NO}_{3}\right)_{3} .9 \mathrm{H}_{2} \mathrm{O}\right)$ & Sigma-Aldrich & $98 \%$ \\
\hline Nitrato de prata - $\left(\mathrm{AgNO}_{3}\right)$ & Sigma-Aldrich & $99 \%$ \\
\hline Nitrogênio gás $\left(\mathrm{N}_{2}\right)$ & White Martins & $99,996 \%$ \\
\hline Oleilamina - (OAm) & Sigma-Aldrich & $70 \%$ \\
\hline Tetraetilortosilicato (TEOS) & Sigma-Aldrich & $98 \%$ \\
\hline Tetraisopropóxido de titânio (TIPT) & Sigma-Aldrich & $97 \%$ \\
\hline
\end{tabular}

* n.i. = não informado pelo fabricante. Fonte: Autoria própria. 


\subsection{Procedimentos experimentais}

Os procedimentos experimentais realizados neste trabalho são divididos em 4 partes, sendo elas: síntese de NPM, modificação da superfície das NPM, redução térmica de NPM e ensaios da aplicabilidade dos sistemas de NPM.

No item 3.2.1, são descritas rotas de síntese de NPM, as quais se subdividem em sínteses via sistemas de microemulsão inversa e sínteses via decomposição térmica. Nas sínteses via sistemas de microemulsão inversa, foram aplicados surfactantes cátion-substituídos, os quais atuam simultaneamente como tensoativo e fonte do metal de interesse para a formação das NPM. Tais surfactantes foram previamente sintetizados e caracterizados para determinar sua estrutura molecular e algumas de suas propriedades, bem como para obter diagramas de fases pseudo-ternários de sistemas compostos por $n$-heptano, $n$-butanol, água e o respectivo surfactante. Tais diagramas estabelecem as composições entre os componentes do sistema que resultam em microemulsão direta, inversa e bicontínua ou em emulsão. A partir das rotas baseadas em sistemas de microemulsão foram sintetizadas NPM de óxido de ferro e de cobalto metálico. Já as sínteses via decomposição térmica de complexos metálicos foram empregadas no preparo de NPM metálicas de Fe e Co, bimetálicas de FePt, FeCo e FeAg e de óxidos metálicos nas fases ferrita e wustita. Em cada caso foram variados alguns parâmetros experimentais, como solvente, precursor metálico, agente redutor, tensoativo e rampas de aquecimento, os quais foram escolhidos de acordo com as características e propriedades almejadas para cada produto.

O item 3.2.2 descreve métodos de funcionalização da superfície das NPM. Visando aplicações biomédicas, NPM foram separadamente recobertas com carboximetil-dextrana e com sílica enquanto que o recobrimento com dióxido de titânio visa à aplicação das NPM em catálise heterogênea. NPM de óxidos metálicos foram reduzidas ao estado metálico através de tratamento térmico em atmosfera redutora seguido de passivação da superfície. O procedimento empregado nas reduções é descritos no item 3.2.3. Ensaios de hipertermia magnética e fotocatálise heterogênea foram realizados para avaliar a aplicabilidade das NPM respectivamente em biomedicina e catálise. O item 3.2.4 descreve os procedimentos empregados. Os equipamentos e técnicas usados para caracterização dos produtos obtidos em cada etapa do trabalho são apresentados e brevemente descritos no item 3.3. 


\subsubsection{Síntese de nanopartículas magnéticas}

\subsubsection{Síntese de NPM via sistemas de microemulsão inversa}

\subsection{Síntese dos surfactantes cátion-substituídos}

Os surfactantes cátion-substituídos dodecil sulfato de ferro(III) e dodecil sulfato de cobalto(II) foram obtidos diretamente em meio aquoso a partir do precursor dodecil sulfato de sódio. Para a preparação do surfactante férrico foram misturadas soluções aquosas $0,1 \mathrm{~mol} \mathrm{~L}^{-1} \mathrm{de}$ $\mathrm{NaDS}$ e $\mathrm{Fe}\left(\mathrm{NO}_{3}\right)_{3} \cdot 9 \mathrm{H}_{2} \mathrm{O}$. Imediatamente após a mistura, pôde-se notar a formação de um precipitado amarelo claro de aparência pastosa, o qual foi envelhecido em banho de água a $4^{\circ} \mathrm{C}$ por 6 horas. $O$ produto foi então filtrado em funil de Büchner usando papel de filtro comum e purificado com sucessivas lavagens com água resfriada $\left(4^{\circ} \mathrm{C}\right)$. O produto final foi seco em dessecador sob vácuo durante 72 horas. Para o preparo do surfactante de cobalto, procedimento semelhante foi realizado substituindo-se respectivamente o precursor de ferro pelo precursor $\mathrm{Co}\left(\mathrm{NO}_{3}\right)_{2} \cdot 6 \mathrm{H}_{2} \mathrm{O}$. Cabe ressaltar que os precipitados somente são formados durante o envelhecimento em baixa temperatura. Depois de sintetizados, os surfactantes foram submetidos a análises de espectroscopia de absorção no infravermelho, termogravimetria, absorção atômica e análise elementar CHNS para determinação de suas respectivas estruturas moleculares.

\subsection{Obtenção dos diagramas de fase pseudo-ternários}

Os diagramas foram obtidos usando método baseado em trabalhos de Mo et al.(35) e Malheiro et al.(78): 2,025 g do surfactante cátion-substituído (CoDS) e $5 \mathrm{~mL}$ de $n$-butanol foram misturados sob agitação magnética, resultando em uma mistura denominada emulsificador (EM). Após a completa solubilização do surfactante, um volume de $2,250 \mathrm{~mL}$ de $n$-heptano foi adicionado, sendo o sistema mantido fechado e sob agitação para homogeneização da mistura. Iniciou-se então a adição de pequenos volumes de água $(0,2 \mathrm{~mL})$, sendo, entre cada adição, analisada a turbidez/transparência do sistema e medida a sua condutividade elétrica. A análise da turbidez/transparência teve o objetivo determinar a transição entre regiões de emulsão e microemulsão, enquanto que as medidas de condutividade elétrica visaram determinar transições entre os três diferentes tipos de microemulsão (direta, indireta e sistema bicontínuo). Este mesmo procedimento foi repetido com diferentes volumes de $n$-heptano $(5 \mathrm{~mL}, 9 \mathrm{~mL}, 13,5$ 
$\mathrm{mL}, 21 \mathrm{~mL}$ e $35 \mathrm{~mL}$ ) para varrer toda a região interna do diagrama. Vale ressaltar que o diagrama foi levantado somente para uma razão $\left(K_{C S}\right)$ fixa entre co-surfactante e surfactante $K_{C S}=2$. 0 diagrama respectivo ao composto FeDS não foi obtido devido à baixa solubilidade apresentada pelo mesmo tanto em água quanto em $n$-heptano.

\subsection{Determinação da concentração micelar crítica do FeDS em 1-octanol}

A concentração micelar crítica $(\mathrm{cmc})$ do FeDS em 1-octanol foi determinada por medidas de condutividade elétrica e de espalhamento de luz dinâmico. Nove solução com diferentes concentrações de FeDS foram preparadas no intervalo de concentração $0,18-7,6 \mathrm{mmol}^{-1}$. Para cada solução, medidas de espalhamento de luz e de condutividade elétrica foram realizadas em triplicata. Ao comportamento da curva de condutividade versus concentração foram feitos ajustes lineares e a $\mathrm{cmc}$ obtida a partir do ponto de intersecção entre as duas retas. Esses dados foram comparados às medidas de espalhamento de luz dinâmico, as quais mostraram valores do diâmetro hidrodinâmico dos agregados micelares presentes em cada solução.

\subsection{Síntese de NPM de Co metálico via microemulsão}

A partir do diagrama de fases obtido para o surfactante CoDS foram escolhidos dois pontos cujas composições encontram-se dentro da região de microemulsão inversa, determinando assim as quantidades respectivas a cada reagente para as sínteses. Para cada síntese foram adicionadas quantidades adequadas de CoDS, água e $n$-butanol, seguida de agitação até solubilização do surfactante. Após a adição do $n$-heptano, o sistema foi mantido sob agitação magnética por 30 minutos antes da adição do redutor $\mathrm{NaBH}_{4}$. A agitação magnética foi mantida até cessar a liberação de gás. Ao final da reação, o precipitado de coloração preta foi lavado com acetona e separado magneticamente com o auxílio de um ímã, sendo esse processo de lavagem repetido outras duas vezes. O precipitado foi então disperso em acetona e armazenado para posterior caracterização. As composições mássicas entre os componentes $n$ heptano, EM e água utilizadas na síntese das amostras bem como a quantidade de redutor empregada são apresentados na Tabela 4, enquanto que o procedimento experimental acima descrito é representado no fluxograma da Figura 11. 
Tabela 4 - Identificação das amostras obtidas via microemulsão inversa. As composições mássicas entre os componentes da microemulsão usada nas sínteses e a razão mássica entre o redutor $\mathrm{NaBH}_{4}$ e o surfactante CoDS são apresentadas.

\begin{tabular}{|c|c|c|c|c|c|c|c|c|}
\hline \multirow[t]{2}{*}{ Amostra } & \multicolumn{2}{|c|}{ n-heptano } & \multicolumn{2}{|c|}{ Água* } & \multicolumn{2}{|c|}{$\begin{array}{c}\text { EM } \\
\text { (CoDS, n-butanol) }\end{array}$} & \multirow{2}{*}{$\begin{array}{c}\mathrm{NaBH}_{4} \\
\mathrm{~m} \text { (g) }\end{array}$} & \multirow[t]{2}{*}{$m_{\mathrm{NaBH} 4} / m_{\mathrm{CODS}}$} \\
\hline & $\%$ & $\mathrm{~m}(\mathrm{~g})$ & $\%$ & $\mathrm{~m}(\mathrm{~g})$ & $\%$ & $\mathrm{~m}(\mathrm{~g})$ & & \\
\hline Co-01 & 19,8 & 2,44 & 7,3 & 0,9 & 72,9 & 3,0 e 6,0 & 0,48 & 0,16 \\
\hline Co-02 & 80 & 16,1 & 5 & 1 & 15 & 1,0 e 2,02 & 0,16 & 0,16 \\
\hline Co-03 & 80 & 16,1 & 5 & 1 & 15 & 1,0 e 2,03 & 0,16 & 0,16 \\
\hline Co-04 & 80 & 16,1 & 5 & 1 & 15 & 1,0 e 2,04 & 0,16 & 0,16 \\
\hline Co-05 & 80 & 16,1 & 5 & 1 & 15 & 1,0 e 2,05 & 0,09 & 0,09 \\
\hline
\end{tabular}

*Observação: entre as amostras Co-02, Co-03 e Co-04 foi variado o pH da água utilizada, sendo respectivamente $\mathrm{pH}=7,0, \mathrm{pH}=1,0$ e $\mathrm{pH}=3,0$. Fonte: Autoria própria.

Figura 11 - Fluxograma do procedimento de síntese de NPM de Co através do método de microemulsão inversa.

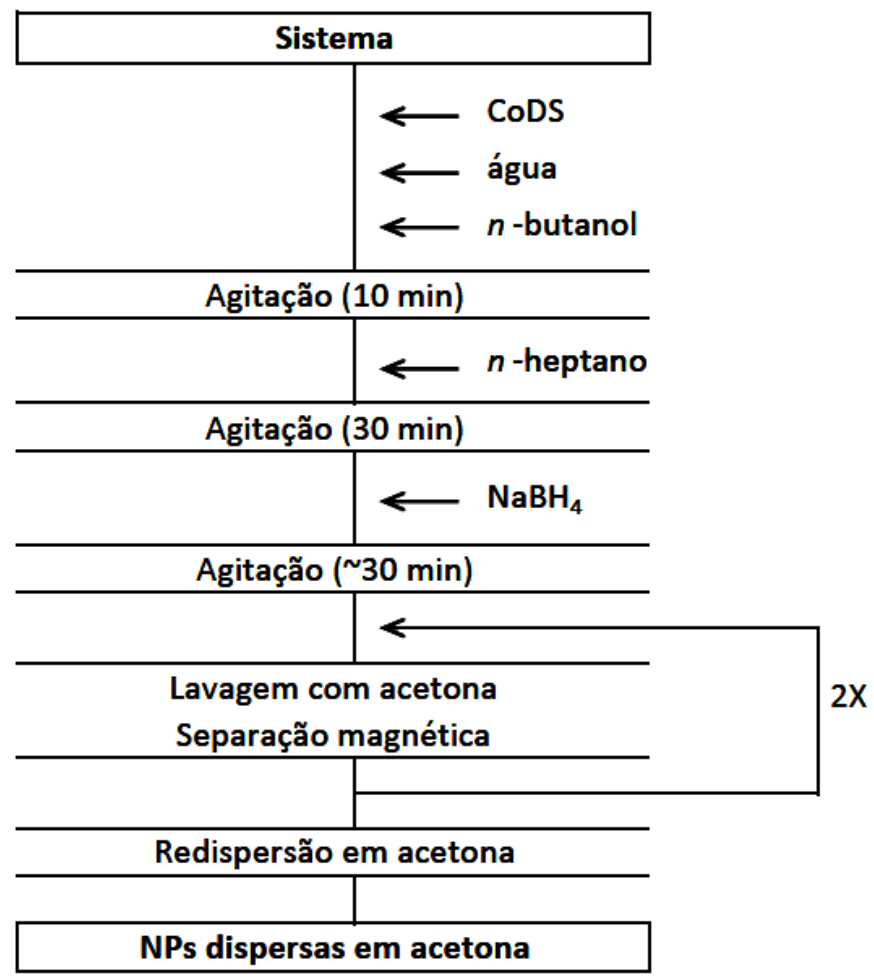

Fonte: Autoria própria.

\subsection{Síntese das NPM de magnetita via sistema micelar}

Em um erlenmeyer de $500 \mathrm{~mL}, 100 \mathrm{~mL}$ de água destilada e previamente deaerada foi adicionado a $250 \mathrm{~mL}$ de uma solução $1,04 \mathrm{mmol} \mathrm{L}^{-1}$ de FeDS em 1-octanol. Após 5 minutos sob leve agitação magnética, 5,0 g de $\mathrm{NaBH}_{4}$ foi adicionado ainda sob agitação e atmosfera inerte de $\mathrm{N}_{2}$. O sistema foi parcialmente vedado com parafilme e mantido sob agitação até que a reação de redução dos íons $\mathrm{Fe}^{3+}$ se completasse, o que era indicada pelo término da efervescência da 
solução. As NP foram separadas por atração magnética com auxílio de um ímã, lavadas com água deaerada e isopropanol, e secas sob vácuo.

\subsubsection{Síntese de NPM via decomposição térmica}

Procedimentos baseados na decomposição térmica de complexos metálicos foram utilizados no preparo de NP metálicas ( $\mathrm{Fe}, \mathrm{FePt}, \mathrm{FeAg}$, $\mathrm{FeCo}$ ), óxidos de ferro $\left(\mathrm{Fe}_{3} \mathrm{O}_{4}\right.$ e $\mathrm{FeO}$ ) e de ferro-cobalto ( $\mathrm{CoFe}_{2} \mathrm{O}_{4}$ e $\left.\mathrm{Fe}_{\mathrm{x}} \mathrm{Co}_{1-\mathrm{x}} \mathrm{O}\right)$. Os solventes utilizados foram benziléter ( $\left.\mathrm{BE}\right)$, octiléter (OE), oleilamina (OAm) e 1-octadeceno (OD). 1,2-hexadecanodiol (HDD), 1,2-tetradecanodiol (TDD) e 1,2-dodecanodiol (DDD) foram utilizados como redutor diol. Os precursores metálicos foram acetilacetonato e oleato de ferro(III) $\left(\mathrm{Fe}(\mathrm{acac})_{3}\right.$ e $\left.\mathrm{Fe}(\mathrm{ol})_{3}\right)$, acetilacetonato e oleato de cobalto(II) $\left(\mathrm{Co}(\mathrm{acac})_{2}\right.$ e $\left.\mathrm{Co}(\mathrm{ol})_{2}\right)$, acetilacetonato de platina(II) $\left(\mathrm{Pt}(\mathrm{acac})_{2}\right)$, acetato e nitrato de prata $(\mathrm{Ag}(\mathrm{ac})$ e $\mathrm{AgNO}_{3}$ ). Ácido oleico ( $\mathrm{AO}$ ) e oleilamina foram utilizados como surfactantes. Cabe ressaltar que os precursores $\mathrm{Fe}(\mathrm{ol})_{3}$ e $\mathrm{Co}(\mathrm{ol})_{2}$ foram sintetizados conforme procedimento descrito no item 3.2.1.2.1. A Tabela 5 e Figura 13 apresentam respectivamente as quantidades empregadas de cada reagente e as rampas de aquecimento usadas em cada síntese. O método de decomposição térmica empregado é representado de forma geral no fluxograma da Figura 12.

O seguinte procedimento descreve o método geral utilizado nas sínteses via decomposição térmica: em um balão de 3 bocas são adicionadas quantidades adequadas dos precursores metálicos, do solvente, do redutor diol e dos surfactantes (ver Tabela 5). O balão é acoplado a um sistema de refluxo e, sob agitação magnética e atmosfera controlada, os reagentes são aquecidos usando a rampa de aquecimento adequada a cada material (ver Figura 13). Após resfriamento, as NP são lavadas com mistura etanol/hexano e separadas por centrifugação, sendo esse processo de lavagem repetido 4 vezes. Após a lavagem, o precipitado é redisperso em hexano e a dispersão armazenada em refrigerador a $2^{\circ} \mathrm{C}$. O recobrimento das NP de FePt com óxido de ferro foi feito seguindo o mesmo procedimento na presença de NP de FePt previamente preparadas. 
Tabela 5 - Parâmetros experimentais utilizados nas sínteses via decomposição térmica. As principais diferenças entre cada síntese são destacadas em negrito.

\begin{tabular}{|c|c|c|c|c|c|c|c|c|c|c|c|c|c|c|}
\hline \multirow[b]{2}{*}{ Amostra } & \multicolumn{2}{|c|}{ Precursor metal 1} & \multicolumn{2}{|c|}{ Precursor metal 2} & \multicolumn{2}{|c|}{ Solvente } & \multicolumn{2}{|c|}{ Redutor diol } & \multicolumn{2}{|c|}{ Surfactantes } & \multirow[b]{2}{*}{ Rampa } & \multirow[b]{2}{*}{ Lavagem } & \multirow[b]{2}{*}{ *Obs. } & \multirow[b]{2}{*}{ Gás } \\
\hline & Tipo & $\begin{array}{c}\text { Qtde } \\
(\mathrm{mmol})\end{array}$ & Tipo & $\begin{array}{l}\text { Qtde } \\
(\mathrm{mmol})\end{array}$ & Tipo & $\begin{array}{l}\text { Qtde } \\
(\mathrm{mL})\end{array}$ & Tipo & $\begin{array}{c}\text { Qtde } \\
\text { (mmol) }\end{array}$ & Tipo & $\begin{array}{c}\text { Qtde } \\
(\mathrm{mmol})\end{array}$ & & & & \\
\hline FePt-01 & $\mathrm{Fe}(\mathrm{acac})_{3}$ & 0,37 & $\mathrm{Pt}(\mathrm{acac})_{2}$ & 0,3 & $\mathrm{BE}$ & 20 & HDD & 0,9 & $\begin{array}{c}\mathrm{AO} \\
\mathrm{OAm}\end{array}$ & $\begin{array}{l}0,4 \\
0,4 \\
\end{array}$ & R1 & EtOH & - & $\mathrm{N}_{2}$ \\
\hline FePt-02 & $\mathrm{Fe}(\mathrm{acac})_{3}$ & 0,37 & $\mathrm{Pt}(\mathrm{acac})_{2}$ & 0,3 & $\mathrm{BE}$ & 20 & TDD & 0,9 & $\begin{array}{c}A O \\
\text { OAm }\end{array}$ & $\begin{array}{l}0,4 \\
0,4 \\
\end{array}$ & R1 & $\mathrm{EtOH}$ & - & $\mathrm{N}_{2}$ \\
\hline FePt-03 & $\mathrm{Fe}(\mathrm{acac})_{3}$ & 0,37 & $\mathrm{Pt}(\mathrm{acac})_{2}$ & 0,3 & $\mathrm{BE}$ & 20 & DDD & 0,9 & $\begin{array}{c}\mathrm{AO} \\
\mathrm{OAm}\end{array}$ & $\begin{array}{l}0,4 \\
0,4\end{array}$ & R1 & EtOH & - & $\mathrm{N}_{2}$ \\
\hline FePt-04 & $\mathrm{Fe}(\mathrm{acac})_{3}$ & 0,37 & $\mathrm{Pt}(\mathrm{acac})_{2}$ & 0,3 & $\mathrm{OE}$ & 20 & $\mathrm{HDD}$ & 0,9 & $\begin{array}{c}\text { AO } \\
\text { OAm }\end{array}$ & $\begin{array}{l}0,4 \\
0,4\end{array}$ & R1 & $\mathrm{EtOH}$ & - & $\mathrm{N}_{2}$ \\
\hline FeCo-01 & $\mathrm{Fe}(\mathrm{acac})_{3}$ & 0,45 & $\mathrm{Co}(\mathrm{acac})_{2}$ & 0,3 & BE & 10 & $\mathrm{HDD}$ & 0,9 & $\begin{array}{c}\mathrm{AO} \\
\mathrm{OAm}\end{array}$ & $\begin{array}{l}3 \\
3 \\
\end{array}$ & R2 & Acet & - & $\mathrm{H}_{2}$ \\
\hline FeCo-02 & $\mathrm{Fe}(\mathrm{acac})_{3}$ & 0,45 & $\mathrm{Co}(\mathrm{acac})_{2}$ & 0,3 & $\begin{array}{c}\text { BE } \\
\text { purif. }\end{array}$ & 10 & $\mathrm{HDD}$ & 0,9 & $\begin{array}{c}\mathrm{AO} \\
\mathrm{OAm}\end{array}$ & $\begin{array}{l}3 \\
3 \\
\end{array}$ & R2 & Acet & - & $\mathrm{H}_{2}$ \\
\hline $\mathrm{FeCo}-03$ & $\mathrm{Fe}(\mathrm{acac})_{3}$ & 0,45 & $\mathrm{Co}(\mathrm{acac})_{2}$ & 0,3 & $\mathrm{OE}$ & 10 & $\mathrm{HDD}$ & 0,9 & $\begin{array}{c}\mathrm{AO} \\
\mathrm{OAm}\end{array}$ & $\begin{array}{l}3 \\
3 \\
\end{array}$ & R2 & Acet & - & $\mathrm{H}_{2}$ \\
\hline FeCo-04 & $\mathrm{Fe}(\mathrm{acac})_{3}$ & 0,45 & $\mathrm{Co}(\mathrm{acac})_{2}$ & 0,3 & $\mathrm{OE}$ & 10 & HDD & - & $\begin{array}{c}\mathrm{AO} \\
\mathrm{OAm}\end{array}$ & \begin{tabular}{|l}
3 \\
3 \\
\end{tabular} & R2 & Acet & - & $\mathrm{H}_{2}$ \\
\hline FeAg-01 & $\mathrm{Fe}(\mathrm{acac})_{3}$ & 1 & $\mathrm{AgAc}$ & 0,25 & $\mathrm{BE}$ & 20 & $\mathrm{HDD}$ & 1,7 & $\begin{array}{c}\mathrm{AO} \\
\mathrm{OAm} \\
\end{array}$ & $\begin{array}{l}0,75 \\
0,75 \\
\end{array}$ & R1 & $\mathrm{EtOH}$ & - & $\mathrm{N}_{2}$ \\
\hline FeAg-02 & $\mathrm{Fe}(\mathrm{acac})_{3}$ & 1 & $\mathrm{AgNO}_{3}$ & 0,25 & $\mathrm{BE}$ & 20 & $\mathrm{HDD}$ & 1,7 & $\begin{array}{c}\mathrm{AO} \\
\mathrm{OAm}\end{array}$ & $\begin{array}{l}0,75 \\
0,75 \\
\end{array}$ & R1 & $\mathrm{EtOH}$ & - & $\mathrm{N}_{2}$ \\
\hline $\mathrm{FeAg}-03$ & $\mathrm{Fe}(\mathrm{acac})_{3}$ & 1 & $\mathrm{AgAc}$ & 0,25 & $\begin{array}{c}\text { OD } \\
\text { OAm }\end{array}$ & $\begin{array}{l}8 \\
2 \\
\end{array}$ & - & - & AO & 1 & R3 & $\mathrm{EtOH}$ & - & $\mathrm{N}_{2}$ \\
\hline $\mathrm{FeAg}-04$ & $\mathrm{Fe}(\mathrm{acac})_{3}$ & 1 & $\mathrm{AgAc}$ & 0,25 & $\begin{array}{c}\text { OD } \\
\text { OAm }\end{array}$ & $\begin{array}{c}8+10 \\
2 \\
\end{array}$ & - & - & AO & 1 & R3 & EtOH & [1] & $\mathrm{N}_{2}$ \\
\hline $\mathrm{FeC}-01$ & $\mathrm{Fe}(\mathrm{acac})_{3}$ & 1,5 & - & - & OAm & 15 & - & - & - & - & R4 & IsopOH & - & $\mathrm{N}_{2}$ \\
\hline CoC-01 & Co(acac) ${ }_{2}$ & 1,5 & - & - & OAm & 15 & - & - & - & - & R4 & IsopOH & - & $\mathrm{N}_{2}$ \\
\hline CoC-02 & $\mathrm{Co}(\mathrm{acac})_{2}$ & 1,5 & - & - & OAm & 15 & - & - & - & - & R4 & IsopOH & - & $\mathrm{H}_{2}$ \\
\hline $\mathrm{FeO} x-02$ & $\mathrm{Fe}(\mathrm{ol})_{3}$ & 2,5 & - & - & OD & 25 & - & - & $\mathrm{AO}$ & 1,1 & R5 & EtOH & [2] & $\mathrm{N}_{2}$ \\
\hline FeOx-03 & $\mathrm{Fe}(\mathrm{ol})_{3}$ & 2,5 & - & - & $O D$ & 25 & - & - & $\mathrm{AO}$ & 1,1 & R6 & $\mathrm{EtOH}$ & [2] & $\mathrm{N}_{2}$ \\
\hline $\mathrm{FeO} x-04$ & $\mathrm{Fe}(\mathrm{ol})_{3}$ & 2,5 & - & - & OD & 25 & - & - & $\mathrm{AO}$ & 1,1 & R5 & $\mathrm{EtOH}$ & [2] & $\mathrm{N}_{2}$ \\
\hline FeOx-05 & $\mathrm{Fe}(\mathrm{ol})_{3}$ & 2,5 & - & - & OD & 25 & - & - & $\mathrm{AO}$ & 1,1 & R5 & $\mathrm{EtOH}$ & [2] & $\mathrm{N}_{2}$ \\
\hline FeOx-06 & $\mathrm{Fe}(\mathrm{ol})_{3}$ & 2,5 & - & - & OD & 25 & - & - & $\mathrm{AO}$ & 1,1 & R5 & $\mathrm{EtOH}$ & [2] & $\mathrm{N}_{2}$ \\
\hline $\mathrm{FeOx}-07$ & $\mathrm{Fe}(\mathrm{ol})_{3}$ & 2,5 & - & - & OD & 25 & - & - & $\mathrm{AO}$ & 1,1 & R6 & EtOH & [2] & $\mathrm{N}_{2}$ \\
\hline FeOx-08 & $\mathrm{Fe}(\mathrm{acac})_{3}$ & 2 & - & - & $O D$ & 8,8 & - & - & $\mathrm{AO}$ & 5 & R7 & IsopOH & [3] & $\mathrm{N}_{2}$ \\
\hline FeOx-09 & $\mathrm{Fe}(\mathrm{acac})_{3}$ & 2 & - & - & OD & 8,8 & - & - & $\mathrm{AO}$ & 5 & R8 & IsopOH & [3] & $\mathrm{N}_{2}$ \\
\hline FeOx-10 & $\mathrm{Fe}(\mathrm{acac})_{3}$ & 2 & - & - & OD & 8,8 & - & - & $\mathrm{AO}$ & 5 & R9 & IsopOH & [3] & $\mathrm{N}_{2}$ \\
\hline $\mathrm{FeOx}-11$ & $\mathrm{Fe}(\mathrm{acac})_{3}$ & 2 & - & - & OD & 9,7 & - & - & AO & 2,5 & R8 & IsopOH & [3] & $\mathrm{N}_{2}$ \\
\hline FeOx-12 & $\mathrm{Fe}(\mathrm{acac})_{3}$ & 2 & - & - & OD & 7,9 & - & - & AO & 7,5 & R8 & IsopOH & [3] & $\mathrm{N}_{2}$ \\
\hline CoFeOx-01 & $\mathrm{Fe}(\mathrm{ol})_{3}$ & 1,7 & $\mathrm{Co}(\mathrm{ol})_{2}$ & 0,8 & OD & 25 & - & - & $\mathrm{AO}$ & 1,1 & R6 & $\mathrm{EtOH}$ & [3] & $\mathrm{N}_{2}$ \\
\hline CoFeOx-02 & $\mathrm{Fe}(\mathrm{acac})_{3}$ & 1,3 & $\mathrm{Co}(\text { acac })_{2}$ & 0,7 & OD & 8,8 & - & - & $\mathrm{AO}$ & 5 & R7 & IsopOH & [3] & $\mathrm{N}_{2}$ \\
\hline $\mathrm{CoFeOx}-03$ & $\mathrm{Fe}(\mathrm{acac})_{3}$ & 1,3 & $\mathrm{Co}(\mathrm{acac})_{2}$ & 0,7 & $O D$ & 8,8 & - & - & $\mathrm{AO}$ & 5 & R8 & IsopOH & [3] & $\mathrm{N}_{2}$ \\
\hline
\end{tabular}

*OBS: [1] $\mathrm{Fe}(\mathrm{acac})_{3}, \mathrm{AO}$ e $\mathrm{OD}(10 \mathrm{~mL})$ foram adicionados após patamar em $150^{\circ} \mathrm{C}$; [2] Taxas de aquecimento de 0,5, 0,5, 1, 4, 5 e $10^{\circ} \mathrm{C} \mathrm{min}^{-1}$ respectivamente para as amostras de FeOx-02 a FeOx-07; [3] A quantidade de OD foi ajustada para manter constante a concentração dos íons metálicos $\left(\left[\mathrm{Fe}^{3+}\right]+\left[\mathrm{Co}^{2+}\right]=1,9 \mathrm{~mol} \mathrm{~L}^{-1}\right)$. Fonte: Autoria própria. 
Figura 12 - Fluxograma geral do método utilizado nas sínteses via decomposição térmica.

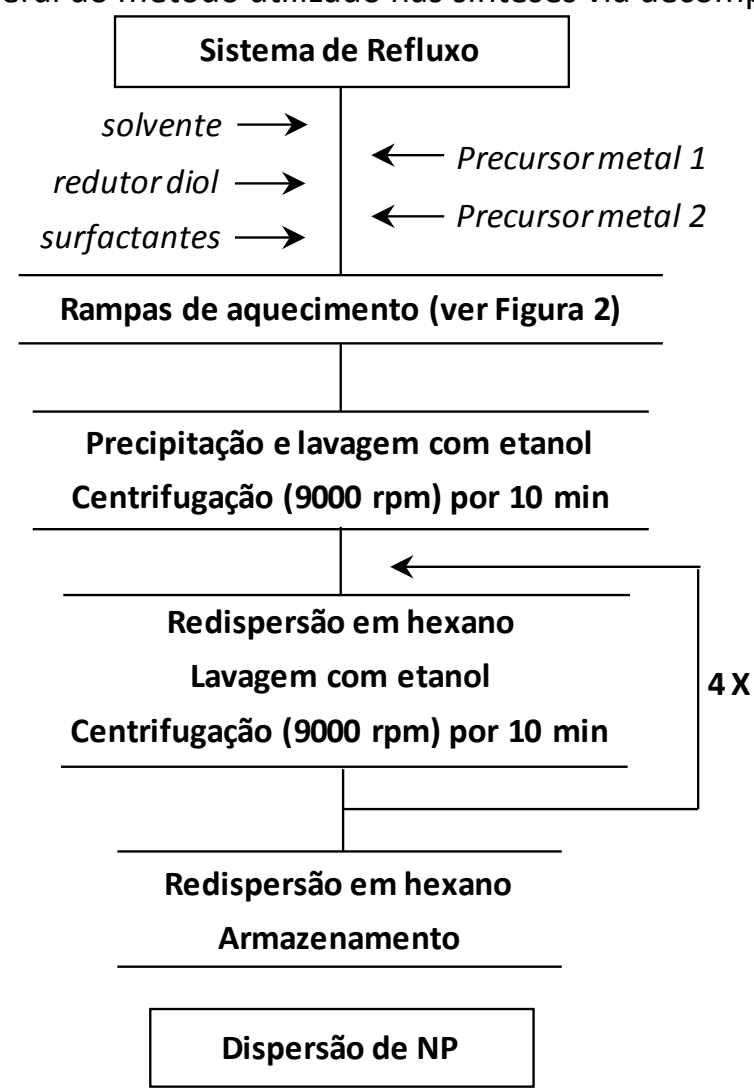

Figura 13 - Rampas de aquecimento usadas na síntese de NPM via decomposição térmica. A relação entre a as amostras e suas respectivas rampas é dada na Tabela 5.

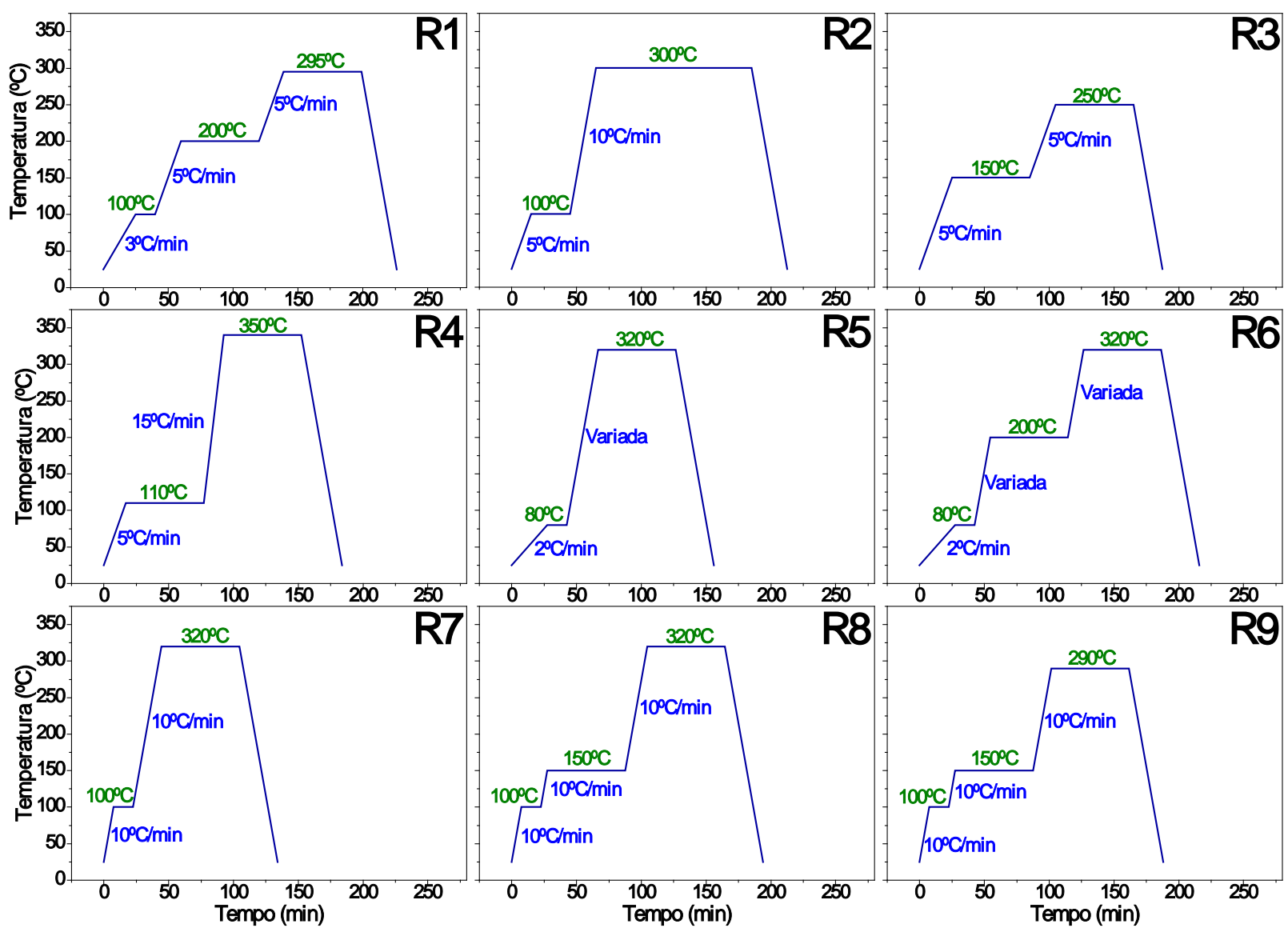

Fonte: Autoria própria. 


\subsection{Síntese dos precursores oleatos}

Os precursores oleato de ferro(III) e oleato de cobalto(II) foram sintetizados usando modificações do método de Li et al.(79) Para a síntese do $\mathrm{Fe}(\mathrm{ol})_{3}, 20 \mathrm{mmol}$ de $\mathrm{FeCl}_{3} .6 \mathrm{H}_{2} \mathrm{O}$ foi solubilizado em $100 \mathrm{~mL}$ de etanol anidro, sendo então adicionado $60 \mathrm{mmol}$ de ácido oleico. Após 10 minutos de agitação, a mistura foi titulada com uma solução etanólica de $\mathrm{NaOH} 1 \mathrm{~mol} \mathrm{~L}^{-1}$ até a formação do oleato como uma fase inferior viscosa. Na titulação foram gastos $68 \mathrm{~mL}$ da solução de $\mathrm{NaOH}$. A fase aquosa foi descartada, sendo adicionados $120 \mathrm{~mL}$ de hexano para solubilização do oleato. A mistura foi transferida para um funil de separação e lavada 5 vezes com água deionizada. Após a última lavagem, o produto foi transferido para um béquer e seco em estufa à vácuo na temperatura de $50^{\circ} \mathrm{C}$. Para a síntese do $\mathrm{Co}(\mathrm{ol})_{2}$ foi usado $\mathrm{CoCl}_{2} \cdot 6 \mathrm{H}_{2} \mathrm{O}(20 \mathrm{mmol}$ ) e ácido oleico ( $40 \mathrm{mmol}$ ), sendo gasto $46 \mathrm{~mL}$ da solução de $\mathrm{NaOH}$ na titulação. Este procedimento é representado no fluxograma da Figura 14.

Figura 14 - Fluxograma do procedimento experimental usado na síntese dos precursores oleato.

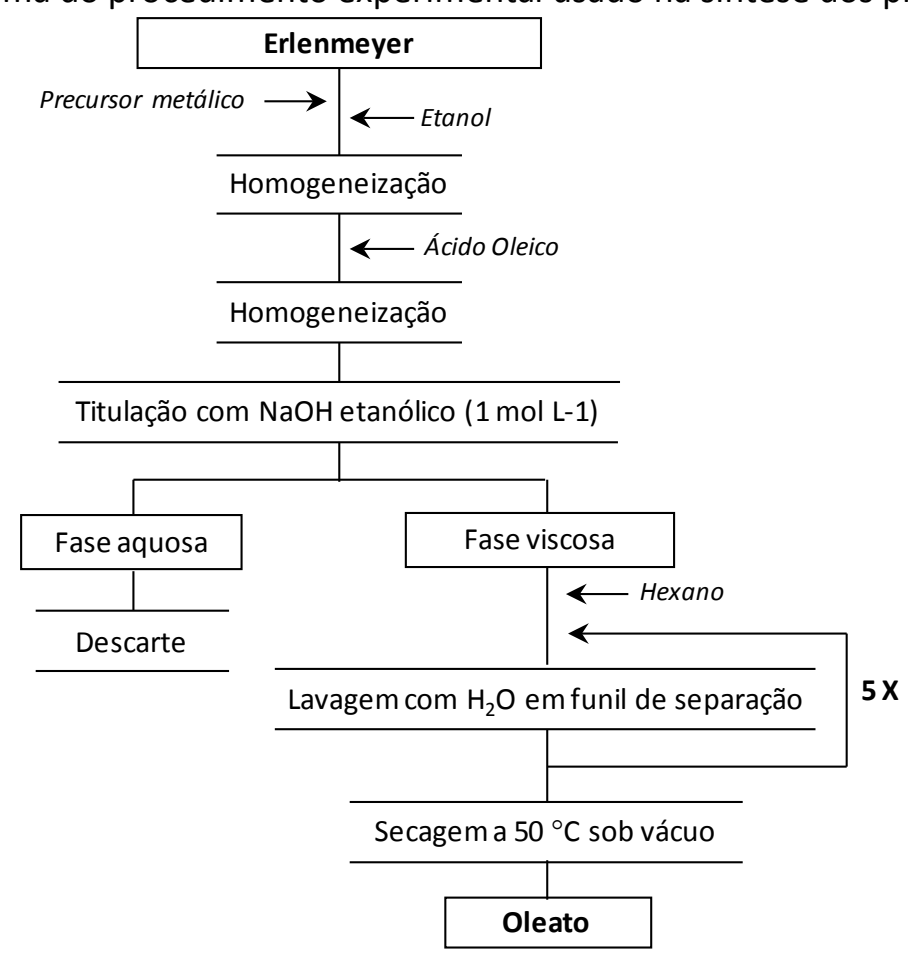

Fonte: Autoria própria. 


\subsubsection{Funcionalização da superfície das NPM}

\subsubsection{Recobrimento das NP de óxido de ferro com CM-Dex}

O seguinte procedimento tem como base trabalhos de Dutz et al.(80) e Bautista et al.(81): 50,0 mg de NP de $\mathrm{Fe}_{3} \mathrm{O}_{4}$ obtidas via sistema micelar foram dispersos em $10 \mathrm{~mL}$ de água deionizada, sendo o $\mathrm{pH}$ ajustado para $\mathrm{pH}=11 \mathrm{com}$ solução $0,1 \mathrm{~mol} \mathrm{~L}^{-1}$ de $\mathrm{NaOH}$. A dispersão foi mantida a $45^{\circ} \mathrm{C}$, sendo então adicionado $10,0 \mathrm{~mL}$ de uma solução $5 \mathrm{~g} \mathrm{~L}^{-1}$ de sal sódico de carboximetil-dextrana, sendo o sistema mantido nesta temperatura sob ultrassom por 60 minutos. A dispersão foi dialisada por 6 horas em $1 \mathrm{~L}$ de água deionizada utilizando uma membrana de acetato de celulose. A água de diálise foi trocada em intervalos de 2 horas. As NPM foram lavadas com água deionizada, separadas via centrifugação e secas sob vácuo. A amostra obtida foi nomeada comoFeOx@CM-Dex.

\subsubsection{Recobrimento das NP de óxido de ferro com sílica}

NP de óxido de ferro tiveram sua superfície recoberta com sílica através da hidrólise básica de tetraetilortosilicato (TEOS) em meio de microemulsão inversa. $(44,45)$ Em um tubo de ensaio foram misturados $16,5 \mathrm{~mL}$ de ciclohexano e 0,8 $\mathrm{mL}$ de Igepal CO-520. Após homogeneização da mistura, diferentes massas de NPM $(2,5-30 \mathrm{mg})$ foram adicionadas, sendo o sistema mantido sob agitação por 15 min antes da adição de 0,13 mL de $\mathrm{NH}_{4} \mathrm{OH} 30 \%$. Após agitação adicional por $20 \mathrm{~min}$, foi adicionado TEOS $(0,10-0,15 \mathrm{~mL})$ ao sistema, sendo o mesmo fechado e mantido sob agitação durante diferentes tempos de reação (8 - 72 horas). A microemulsão foi então desestabilizada pela adição de $10 \mathrm{~mL}$ de metanol e as NP separadas com a ajuda de um ímã. O sobrenadante foi descartado e as NP lavadas três vezes com metanol e outras três vezes com etanol. A cada lavagem o sistema foi mantido sob ultrassom por 3 min e as NP separadas sob centrifugação. Ao final do processo de lavagem, as NP foram secas sob fluxo de ar e armazenadas na forma de pó para futuras análises. Este procedimento encontra-se esquematizado no fluxograma da Figura 15. A Tabela 6 resume os parâmetros experimentais variados em cada síntese com o intuito de obter a mais fina e homogênea camada de recobrimento de sílica. 
Figura 15 - Fluxograma do procedimento de recobrimento das NP com sílica.

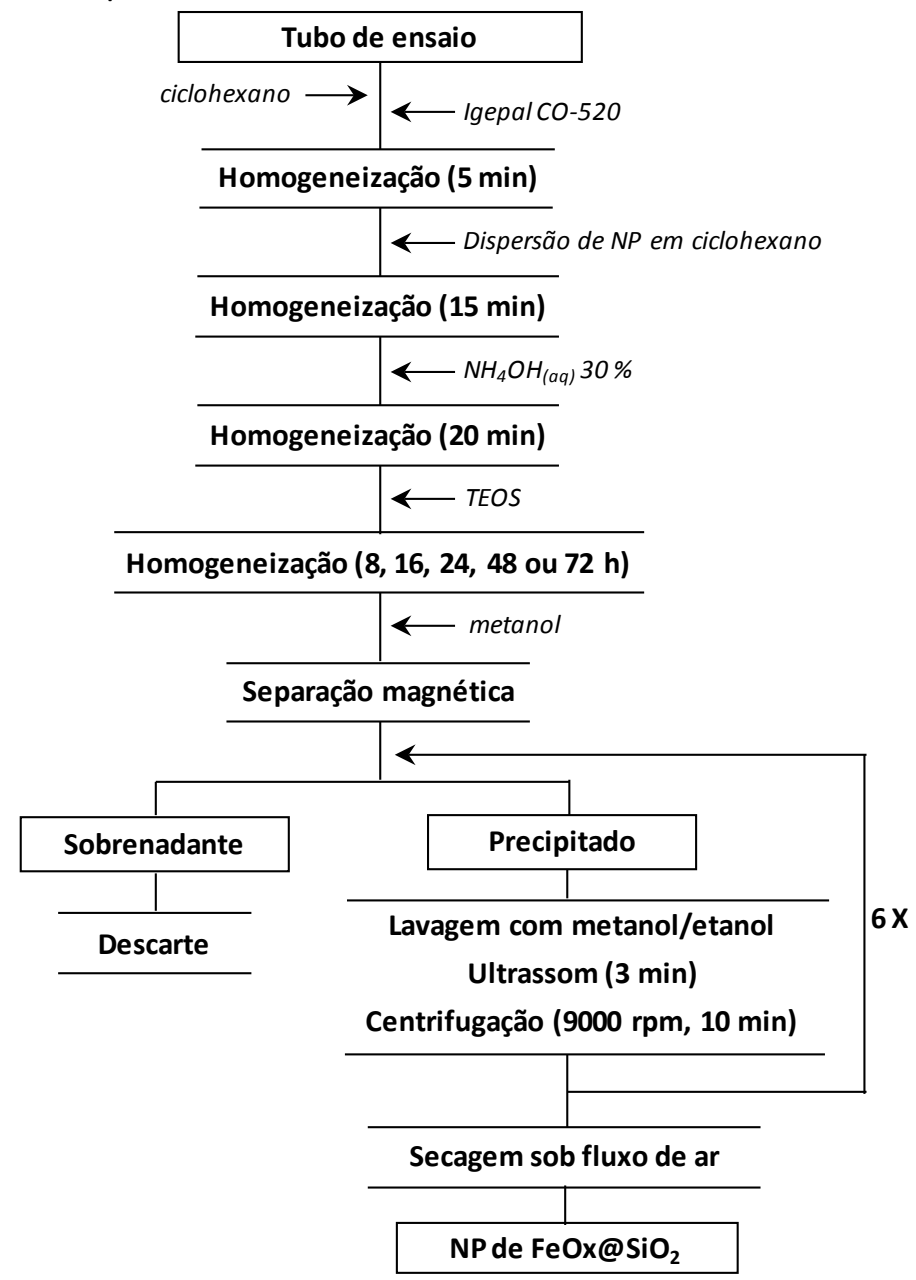

Fonte: Autoria própria.

Tabela 6 - Parâmetros experimentais variados nos recobrimentos com sílica. As principais diferenças entre cada síntese são destacadas em negrito.

\begin{tabular}{|c|c|c|c|c|c|}
\hline \multirow[b]{2}{*}{ Amostra } & \multicolumn{2}{|c|}{ Núcleo magnético } & \multirow{2}{*}{$\begin{array}{l}\text { TEOS } \\
(\mathrm{mL})\end{array}$} & \multirow[b]{2}{*}{ Agitação } & \multirow{2}{*}{$\begin{array}{l}\text { Tempo de } \\
\text { reação (h) }\end{array}$} \\
\hline & $\begin{array}{c}\text { Diâmetro } \\
\text { (nm) }\end{array}$ & $\begin{array}{c}\text { Massa } \\
\text { (mg) }\end{array}$ & & & \\
\hline FeOx@S1 & 15,2 & 5 & 0,15 & magnética & 72 \\
\hline FeOx@S2 & 15,2 & 5 & 0,15 & mecânica & 16 \\
\hline FeOx@S3 & 15,2 & 5 & 0,10 & mecânica & 24 \\
\hline FeOx@S4 & 15,2 & 5 & 0,15 & mecânica & 24 \\
\hline FeOx@S5 & 15,2 & 5 & 0,15 & mecânica & 48 \\
\hline FeOx@S6 & 15,2 & 5 & 0,15 & mecânica & 72 \\
\hline FeOx@S7 & 15,2 & 5 & 0,10 & mecânica & 72 \\
\hline FeOx@S8 & 15,2 & 20 & 0,15 & mecânica & 24 \\
\hline FeOx@S9 & 15,2 & 30 & 0,15 & mecânica & 24 \\
\hline FeOx@S10 & 23,7 & 5 & 0,15 & mecânica & 24 \\
\hline FeOx@S11 & 23,7 & 20 & 0,15 & mecânica & 24 \\
\hline CoFeOx@S1 & 10,9 & 2,5 & 0,15 & mecânica & 24 \\
\hline
\end{tabular}

Fonte: Autoria própria. 


\subsubsection{Recobrimento das NPM de óxidos metálicos com anatase}

O recobrimento com $\mathrm{TiO}_{2}$ na fase anatase foi baseado em trabalhos de Damato et al.(82) e Cheng et al.(83) Em um tubo de ensaio de $70 \mathrm{~mL}$ foram adicionados etilenoglicol (EG) e NPM recobertas com sílica. Após $10 \mathrm{~min}$ de ultrassom, adicionou-se tetraisopropóxido de titânio (TIPT), sendo o sistema fechado e mantido sob agitação mecânica por 8 horas. A dispersão foi então adicionada a uma mistura de água, ácido acético glacial (AAc) e acetona, sendo o sistema novamente agitado mecanicamente por 3 horas. Após centrifugação, o precipitado de glicolato de titânio foi lavado com etanol e armazenado na forma de dispersão. A dispersão foi exposta a um ímã para descartar partículas sem núcleo magnético. O material atraído pelo imã foi redisperso em $10 \mathrm{~mL}$ de água e mantido a $70^{\circ} \mathrm{C}$ por 1 hora sob agitação mecânica para promover a hidrólise do glicolato para formação da fase $\mathrm{TiO}_{2}$. As quantidades empregadas de cada reagente são listadas na Tabela 7.

Tabela 7 - Parâmetros usados no preparo das amostras de NPM recobertas com $\mathrm{TiO}_{2}$.

\begin{tabular}{c|c|c|c|c|c|c|c}
\hline Amostra & $\begin{array}{c}\text { EG } \\
(\mathbf{m m o l})\end{array}$ & $\begin{array}{c}\mathbf{N P M} \\
(\mathbf{m g})\end{array}$ & $\begin{array}{c}\text { TIPT } \\
(\mathbf{m g})\end{array}$ & $\begin{array}{c}\mathbf{R} \\
\left(\mathbf{m}_{\text {TIPT }} / \mathbf{m}_{\text {NPM }}\right)\end{array}$ & $\begin{array}{c}\text { Acetona } \\
(\mathbf{m L})\end{array}$ & $\begin{array}{c}\mathbf{H}_{\mathbf{2}} \mathbf{O} \\
(\mathbf{m L})\end{array}$ & $\begin{array}{c}\text { AAc } \\
(\mathbf{m L})\end{array}$ \\
\hline $\mathrm{TiO}_{2}$ & 160 & - & 330 & - & 40 & 0,5 & 0,2 \\
\hline FeOx@S4@T1 & 160 & 3,0 & 330 & 110 & 40 & 0,5 & 0,2 \\
\hline FeOx@S4@T2 & 160 & 6,0 & 66,0 & 11 & 40 & 0,2 & 0,08 \\
\hline FeOx@S4@T3 & 160 & 6,0 & 36,0 & 6 & 40 & 0,1 & 0,04 \\
\hline
\end{tabular}

* a massa de NPM refere-se à massa relativa somente ao núcleo magnético, desprezando a sílica.

Fonte: Autoria própria.

\subsubsection{Redução térmica das NPM de óxidos metálicos}

A redução térmica das NP de óxido de ferro recobertas com sílica foi realizada usando o aparato experimental ilustrado na Figura 16. O mesmo é composto por um pequeno forno (1) no qual uma célula de quartzo (2) contendo a amostra (3) é introduzida. O aquecimento $\left(10^{\circ} \mathrm{C} \mathrm{min}^{-1}\right)$ foi controlado através de um controlador de temperatura Eurotherm 2132 (4) ao qual o forno é conectado. A medida de temperatura é realizada por meio de um termopar tipo K (5). O fluxo de gás no interior da célula de quartzo é controlado por um sistema de mangueiras que conecta a célula a um fluxômetro de gás (6). Um frasco de vidro (7) com etanol anidro (8) foi adaptado ao sistema de mangueiras para passivação da amostra. Um conjunto de três presilhas (9) foi colocado em posições adequadas do sistema de mangueiras para direcionar o fluxo de gás. Para buscar as condições menos drásticas capazes de promover a completa redução do óxido de ferro à ferro metálico, foram variados parâmetros experimentais como temperatura de redução (400 - 
$600^{\circ} \mathrm{C}$ ), tempo de redução (4 - 15 horas) e fluxo de gás $\mathrm{H}_{2}\left(30-90 \mathrm{~L} \mathrm{~h}^{-1}\right.$ ) foram testados (Tabela 8). A passivação das amostras foi realizado após o resfriamento do sistema através do borbulhamento por 1 hora de gás $\mathrm{N}_{2}$ em etanol anidro utilizando fluxo de gás de $2 \mathrm{~L} \mathrm{~h}^{-1}$.

Figura 16 - Ilustração do aparato experimental utilizado na redução e passivação das amostras.

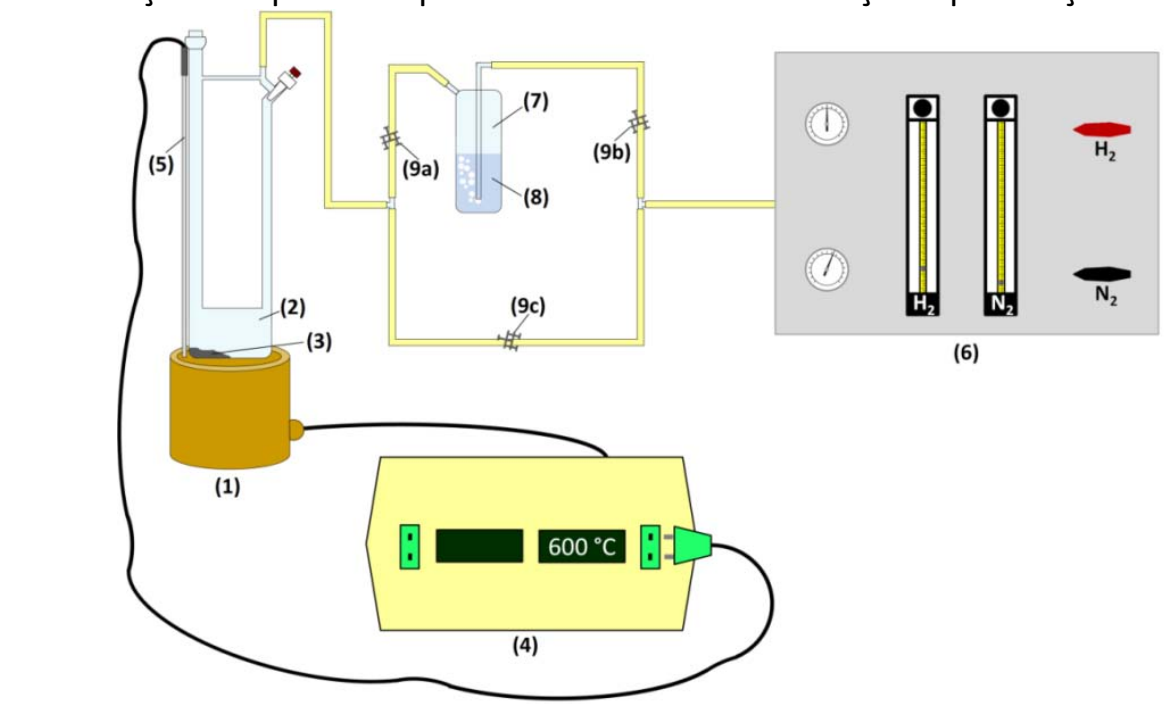

Fonte: Autoria própria.

Tabela 8 - Parâmetros experimentais usados na redução térmica das NPM de óxido de ferro.

\begin{tabular}{c|c|c|c}
\hline Amostra & $\begin{array}{c}\text { Temperatura } \\
\text { de redução }\left({ }^{\circ} \mathbf{C}\right)\end{array}$ & $\begin{array}{c}\text { Tempo de } \\
\text { redução }(\mathbf{h})\end{array}$ & $\begin{array}{c}\text { Fluxo de } \mathbf{H}_{\mathbf{2}} \\
\left(\mathbf{L ~} \mathbf{~}^{-1} \mathbf{)}\right.\end{array}$ \\
\hline FeOx@S4R1 & $400^{\circ} \mathrm{C}$ & 4 & 60 \\
\hline FeOx@S4R2 & $500^{\circ} \mathrm{C}$ & 4 & 30 \\
\hline FeOx@S4R3 & $600^{\circ} \mathrm{C}$ & 4 & 30 \\
\hline FeOx@S4R4 & $500^{\circ} \mathrm{C}$ & 15 & 30 \\
\hline FeOx@S4R5 & $500^{\circ} \mathrm{C}$ & 4 & 90 \\
\hline FeOx@S4R6 & $600^{\circ} \mathrm{C}$ & 4 & 90 \\
\hline FeOx@S11R1 & $600^{\circ} \mathrm{C}$ & 4 & 90 \\
\hline CoFeOx@S1R1 & $600^{\circ} \mathrm{C}$ & 4 & 90 \\
\hline
\end{tabular}

Fonte: Autoria própria

\subsubsection{Ensaios da aplicabilidade das NPM em biomedicina e catálise}

\subsubsection{Ensaios de estabilidade coloidal em meio líquido}

Os ensaio de estabilidade coloidal foram realizas através de medidas de potencial zeta em função do $\mathrm{pH}$. As medidas foram realizadas em um equipamento Zetasizer Nano ZS da Malvern Instruments. A força iônica do meio foi controlada pelo uso de uma solução aquosa $10^{-3} \mathrm{~mol} \mathrm{~L}^{-1}$ 
de $\mathrm{KNO}_{3}$ como meio de dispersão. As medidas foram realizadas variando-se o pH da solução entre valores adequados de $\mathrm{pH}$ com soluções de $\mathrm{KNO}_{3}$ e $\mathrm{KOH}$ com diferentes concentrações. $\mathrm{O}$ ajuste da força iônica se faz necessário para garantir que a mobilidade das partículas se desse por migração e o transporte de carga na solução ficasse a cargo do eletrólito de suporte.

\subsubsection{Ensaios de estabilidade química em diferentes meios tamponados}

A estabilidade química da amostra de NPM recobertas com sílica submetida à redução térmica (FeOx@S4R6) foi analisada em meio de tampão acetato $(\mathrm{pH}=4,5)$ e fosfato $(\mathrm{pH}=7,4)$. Para isso, $10 \mathrm{mg}$ de partículas foram dispersas separadamente em $10 \mathrm{~mL}$ de cada tampão, sendo cada dispersão dialisada por 144 horas em $500 \mathrm{~mL}$ do mesmo tampão. Alíquotas de $10 \mathrm{~mL}$ foram coletadas do meio de diálise em diferentes tempos de reação. Tais alíquotas foram analisadas por ICP para determinação das concentrações de ferro e silício.

\subsubsection{Ensaios de hipertermia magnética}

Os ensaios de hipertermia magnética foram realizados com o auxílio de um sistema magneTherm $^{T M}$ da Nanotherics utilizando um campo de $25 \mathrm{mT}$ e freqüência nominal de $109 \mathrm{MHz}$. O sistema é composto por um osciloscópio, um gerador de função, uma fonte de alimentação DC, um gabinete no qual encontra-se o conjunto bobina e capacitor que regula a freqüência e a intensidade do campo magnético alternado e um banho termostatizado para refrigeração da bobina. Todas as análises foram realizadas com volumes de 1,0 $\mathrm{mL}$ de dispersões aquosas de NPM recobertas com sílica. Cada amostra foi analisada com diferentes concentrações de NPM. Para as análises, cada amostra foi colocada em um frasco de 2,0 mL com um pequeno orifício na tampa pelo qual o sensor de temperatura foi inserido. A amostra foi então envolta por uma cobertura de isopor e posicionado no centro da bobina localizada no gabinete do equipamento. A temperatura foi medida através de uma sonda de fibra óptica GaAs acoplada a um transdutor de sinal, ambos da OpSens Inc. A extremidade da sonda foi colocada no interior de um capilar de 2 $\mathrm{mm}$ de diâmetro e este sistema posicionado no centro da dispersão de NPM. Adicionalmente, a amostra com melhor resposta ao campo aplicado teve seu teste acompanhado através de uma câmera de infravermelho da OpTris. Os resultados foram coletados através de softwares específicos da OpSens e OpTris. A montagem do equipamento magneTherm ${ }^{T M}$ bem como os dois sistemas de medida de temperatura são apresentados na imagem da Figura 17. 
Figura 17 - Equipamento magneTherm ${ }^{T M}$ Nanotherics, sensor de fibra óptica OpSens e câmera infravermelho OpTris utilizados para realização das medidas de hipertermia magnética.

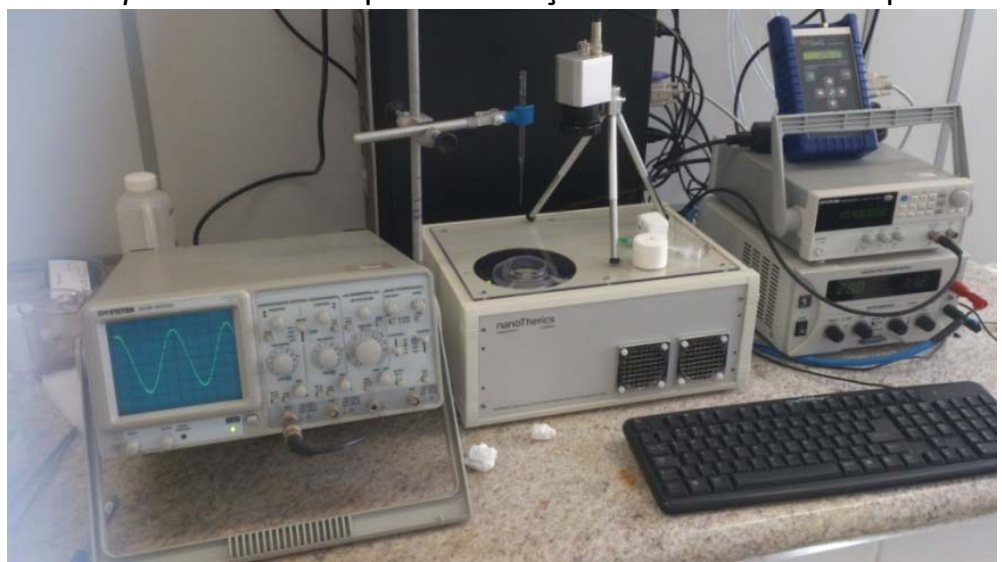

Fonte: Autoria própria.

\subsubsection{Ensaios de atividade catalítica}

Os ensaios de atividade catalítica foram realizados em cooperação com o Grupo de Química de Materiais Híbridos e Inorgânicos (IQSC-USP) utilizando os aparatos experimentais mostrados na Figura 18.

Figura 18 - Aparato experimental utilizado nos ensaios de atividade catalítica.

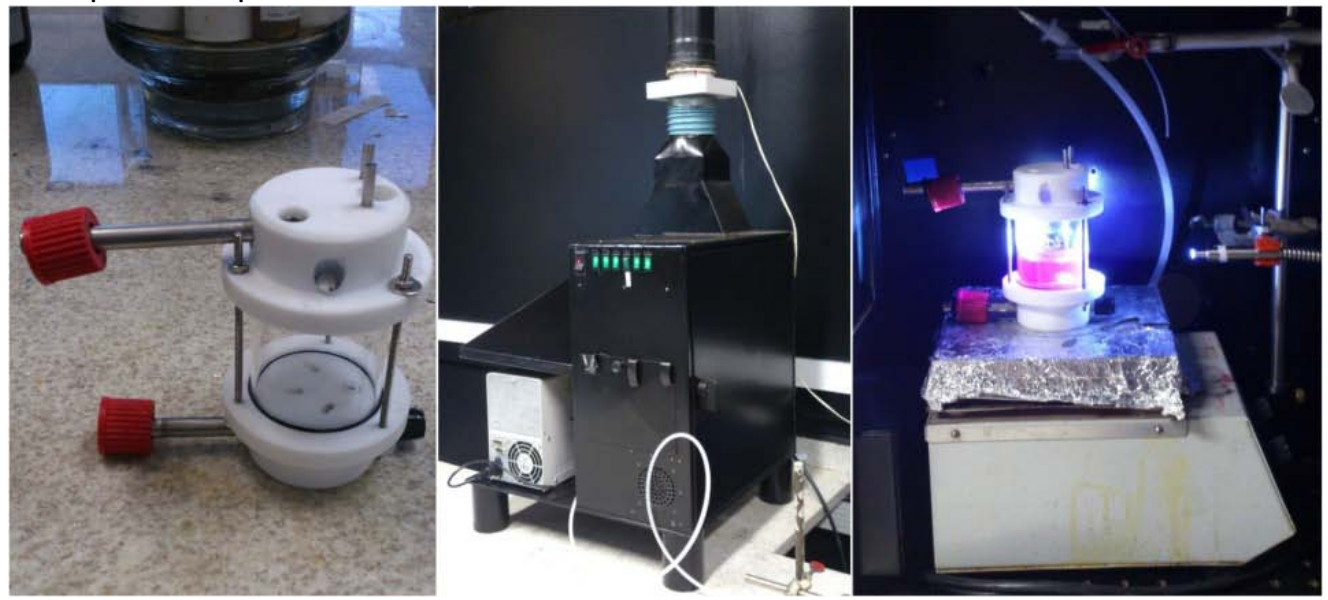

Fonte: Autoria própria.

Em cada análise, $15 \mathrm{mg}$ de catalisador foi disperso em $35 \mathrm{~mL}$ de água deionizada em banho de ultrassom por $30 \mathrm{~min}$. A dispersão foi adicionada a um reator cilíndrico de borosilicato (diâmetro interno de 4,5 cm) contendo $35 \mathrm{~mL}$ de solução $20 \mathrm{ppm}$ de cristal violeta (CV). O sistema foi colocado no interior de uma câmara escura e mantido sob agitação na ausência de luz por 30 minutos para promover a adsorção do cristal violeta sobre as partículas, sendo então irradiado com $28,8 \mathrm{~J} \mathrm{~cm}^{-2}$ radiação UVA por minuto (lâmpada de arco de Xe Lightningcure LC8, Hamamamatsu, Japão). A fonte de radiação foi colocada a uma distância de $7 \mathrm{~cm}$ da amostra. As 
radiações UVB e UVC foram filtradas pelas paredes de borosilicato do reator. Durante cada ensaio foram recolhidas alíquotas de $1,5 \mathrm{~mL}$, as quais foram centrifugadas e o sobrenadante analisado por espectroscopia UV-Vis no intervalo de 430-700 nm. Para estimar a fotólise direta, um ensaio controle foi realizado na ausência do catalisador.

\subsection{Caracterização das amostras}

A análise do tamanho, distribuição de tamanho, morfologia e homogeneidade das NP sintetizadas foi realizada por microscopia eletrônica de transmissão (MET) utilizando três diferentes microscópios eletrônicos: Philips CM120, JEOL-JEM1010 e JEOL JEM 2100. As amostras para análise foram preparadas em uma grade de cobre previamente recoberta por um filme fino do polímero Formvar $^{\oplus}$ e carbono depositado por sputtering, onde uma gota de uma dispersão diluída de NP em hexano foi depositada e o solvente evaporado. O diâmetro médio $\left(d_{m}\right)$ e grau de polidispersividade $(\sigma)$ das NP foram determinados estatisticamente pela contagem de aproximadamente 200 partículas. Os dados de cada contagem foram organizados na forma de um histograma de frequência ao qual ajustou-se uma distribuição do tipo LogNormal para o cálculo de $d_{m}$ e $\sigma$.

A análise por difratometria de raios $X(D R X)$ foi realizada com as amostras em pó utilizando dois difratômetros: AXS-Analytical X-Ray Systems Siemens D-5005 e Bruker D8 Advance, ambos operando com radiação $\mathrm{K}_{\alpha}$ do cobre $(\lambda=1,5406 \AA ̊)$ e v elocidade de varredura de $0,032^{\circ} \mathrm{s}^{-1}$ em $2 \theta$. Os difratogramas foram obtidos em intervalos de $2 \theta$ adequados para cada tipo de amostra analisada.

A composição química das amostras foi determinada semi-quantitativamente por espectroscopia de energia dispersiva de raios $X(E D X)$ realizada em um equipamento EDX LINK ANALYTICAL, (Isis System Series 200), com detector de SiLi Pentafet, janela ultrafina ATW II (Atmosphere Thin Window), acoplado a um microscópio eletrônico de varredura Zeiss-Leica/440.

O comportamento magnético das amostras foi analisado por magnetometria de amostra vibrante (VSM, do inglês vibrating sample magnetometry) usando um magnetômetro MLVSM9 MagLab $9 \mathrm{~T}$, Oxford Instruments. Valores de $\mathrm{H}_{\mathrm{C}}, \mathrm{M}_{\mathrm{r}}$ e $\mathrm{M}_{\mathrm{s}}$ foram obtidos a partir de curvas de magnetização medidas a 5 e $250 \mathrm{~K}$ com aplicação de campos magnéticos entre 50 e -50 kOe. Para as NP de óxido de ferro e ferro metálico, as curvas foram normalizadas pela massa em ferro. As curvas de magnetização field-cooled (FC) e zero field-cooled (ZFC) foram medidas sob 
resfriamento da amostra na presença de um campo magnético de 100 Oe (curva FC) ou sob campo magnético nulo (curva ZFC), sendo as medidas realizadas a $5 \mathrm{~K}$.

A composição em ferro das amostras de NP de óxido de ferro e de ferro metálico foi determinada por espectrometria de emissão atômica por plasma acoplado (ICP) utilizando um espectrômetro Perkin Elmer OPTIMA 2100 DV. As amostras foram digeridas em água régia, sendo necessário um prévio tratamento com ácido fluorídrico para as amostras recobertas com sílica.

A presença de compostos orgânicos sobre a superfície de NP de óxido de ferro foi analisada antes e após o recobrimento com sílica por espectroscopia infravermelho por transformada de Fourier (FTIR) usando um espectrômetro Nicolet 20SXC FTIR. As amostras foram pulverizadas em $\mathrm{KBr}$ (proporção mássica de $2 \%$ ) e analisadas na forma de pastilha no intervalo entre 400 e $4000 \mathrm{~cm}^{-1}$.

A determinação da $\mathrm{cmc}$ do FeDS em 1-octanol e o estudo da estabilidade coloidal das NPM recobertas com sílica foram realizados em um equipamento Malvern Zetasizer Nano ZS. No primeiro caso, 9 amostras com diferentes concentrações de FeDS foram preparadas e o diâmetro hidrodinâmico foi medido em triplicata para cada amostra. No segundo caso, as amostras foram preparadas pela dispersão de uma pequena massa de NPM recobertas com sílica em $10 \mathrm{~mL}$ de uma solução aquosa de $\mathrm{KNO}_{3} 10^{-2} \mathrm{~mol} \mathrm{~L}$.- O potencial zeta de cada amostra foi medido à $25^{\circ} \mathrm{C}$ em diferentes valores de $\mathrm{pH}$, o qual foi ajustado pela adição de soluções diluídos de $\mathrm{HNO}_{3}$ e $\mathrm{KOH}$.

A estrutura molecular dos surfactantes cátion-substituídos foi analisada por análise elementar CHNS, análise termogravimétrica (TGA/DTG) e espectroscopia na região do infravermelho por transformada de Fourier (FTIR). A análise elementar CHNS foi realizada utilizando um analisador Perkin Elmer CHN 2400, sendo a análise de cada surfactante feita em duplicata. Os espectros FTIR foram coletados no intervalo entre 400 e $4000 \mathrm{~cm}^{-1}$ (resolução de 2 $\mathrm{cm}^{-1}$ ) com as amostras na forma de pastilha de brometo de potássio (proporção mássica 1:100) em um espectrofotômetro Shimadzu modelo IR-PRESTIGE 21. A análise termogravimétrica dos surfactantes foi realizada em fluxo de ar sintético com taxa de aquecimento de $5^{\circ} \mathrm{C} \min ^{-1}$ utilizando um analisador térmico Shimadzu TA-50WSI equipado com um módulo TGA-50.

\section{RESULTADOS E DISCUSSÃO}

Para facilitar a apresentação e discussão dos dados obtidos para os diferentes sistemas de NPM, os resultados encontram-se divididos em 4 partes, as quais incluem separadamente a síntese de NPM, modificação da superfície das NPM, redução térmica de NPM e ensaios da 
aplicabilidade dos sistemas de NPM. As NPM foram sintetizadas usando duas rotas sintéticas distintas, sendo a primeira baseada em sistemas micelares e a segunda, em métodos de decomposição térmica de complexos metálicos. A funcionalização da superfície das NPM foi realizada com carboximetil-dextrana, sílica e anatase, das quais as duas primeiras visam aplicações biomédicas e a última, aplicações catalíticas. Alguns dos sistemas de NPM foram submetidos a tratamento térmico em atmosfera redutora para obtenção de nanopartículas metálicas a partir de óxidos metálicos. Tais partículas foram previamente recobertas com sílica para evitar processos de coalescência durante o aquecimento. A aplicabilidade dos sistemas de NPM foi analisada através de ensaios de estabilidade química e coloidal, de hipertermia magnética e de fotocatálise de degradação de corantes, no caso de avaliar aplicações catalíticas.

\subsection{Síntese de NPM via sistemas micelares}

Com base no método descrito no item 3.2.1.1.1 da parte experimental, os surfactantes cátion-substituídos CoDS e FeDS foram sintetizados. A estrutura molecular do surfactante férrico foi determinada por análise elementar de CHNS, TGA/DTG, ICP e FTIR. Algumas dificuldades encontradas durante a análise do surfactante de cobalto impediram a completa caracterização de sua estrutura molecular, a qual ainda encontra-se em estudo. Ambos os surfactantes foram utilizados na síntese de NPM. O surfactante CoDS foi empregado na síntese de NPM de cobalto metálico. Para isso foram utilizados sistemas de microemulsão inversa compostos por $n$ heptano/n-butanol/CoDS/água, para os quais foi construído um diagrama de fases pseudoternário. Este diagrama tem o intuito de determinar composições relativas entre os componentes que resultem em regiões de domínio de microemulsões diretas, inversas e sistemas bicontínuos ou em emulsões. Com base neste diagrama, algumas composições dentro da região de microemulsão inversa foram utilizadas para a síntese de NPM de cobalto metálico. Já o surfactante de FeDS apresentou baixa solubilidade em água e em $n$-heptano, o que impossibilitou o estudo de seu respectivo diagrama de fases pseudo-ternário. Entretanto, por apresentar alta solubilidade em alcoóis, o surfactante foi empregado em um sistema micelar contendo 1-octanol como solvente para a síntese de NPM de óxido de ferro. Anteriormente à síntese da NPM, a concentração micelar crítica do FeDS em 1-octanol foi determinada. Cabe ressaltar que não há relatos na literatura da síntese do surfactante dodecil sulfato de ferro trivalente, tampouco de seu uso na síntese de NPM. A caracterização dos surfactantes e a síntese de NPM são discutidas separadamente para cada surfactante. É importante salientar que o mesmo método de síntese 
dos surfactantes FeDS e CoDS foi aplicado com sucesso na síntese de surfactantes dodecil sulfato de níquel(II) e dodecil sulfato de crômio(III). A caracterização desses surfactantes está em andamento, com perspectiva de utilização em trabalhos futuros do nosso grupo de pesquisa.

\subsubsection{Caracterização do surfactante FeDS e síntese de NPM}

Após análises de TGA/DTG, ICP e análise elementar CHNS, a estrutura molecular [Fe(DS) $\left.{ }_{2}\left(\mathrm{H}_{2} \mathrm{O}\right)_{4} \mathrm{NO}_{3}\right]$ (DS = ânion dodecil sulfato) é proposta para o surfactante FeDS. Quatro perdas de massa podem ser observadas nas curvas TGA/DTG da Figura 19. A primeira ocorre entre 25 e $105^{\circ} \mathrm{C}$ e refere-se à desidratação de 4 moléculas de $\mathrm{H}_{2} \mathrm{O}$ (Calculado $=10,0 \%$, TG $=$ $10,2 \%)$. A segunda perda ocorre em duas etapas entre 105 e $215^{\circ} \mathrm{C}$ e corresponde à queima da cadeia orgânica do ligante DS. A terceira perda ocorre até $405^{\circ} \mathrm{C}$ devido à perda de nitrato na forma de radical (Calculado $=8,6 \%, \mathrm{TG}=8,7 \%$ ), resultando em $\mathrm{Fe}_{2}\left(\mathrm{SO}_{4}\right)_{3}$ como intermediário. Entre 510 e $670^{\circ} \mathrm{C}, 15,6 \%$ de massa é perdida na forma dos grupos sulfato, restando um resíduo de hematita $\left(\alpha-\mathrm{Fe}_{2} \mathrm{O}_{3}\right)$ com $11,2 \%$ da massa inicial. Para uma hematita estequiométrica, a quantidade de ferro calculada a partir da curva TG corresponde a 7,7\% da massa inicial de FeDS, muito próximo aos valores de 7,9\% (calculado para a estrutura $\left[\mathrm{Fe}(\mathrm{DS})_{2}\left(\mathrm{H}_{2} \mathrm{O}\right)_{4} \mathrm{NO}_{3}\right]$ ) e $8,2 \%$ (obtido por ICP). Esta estrutura molecular é também corroborada pela análise elementar CHNS, que mostra uma composição elementar de carbono (41,9\%), hidrogênio $(8,2 \%)$, nitrogênio $(2,6 \%)$ e enxofre $(8,0 \%)$ muito próxima à calculada teoricamente para a estrutura molecular aqui proposta $(40,0 \%, 8,1 \%, 2,0 \%$ e $8,9 \%$, respectivamente).

Figura 19 - Curvas TGA/DTG obtidas para o FeDS sob atmosfera de ar sintético.

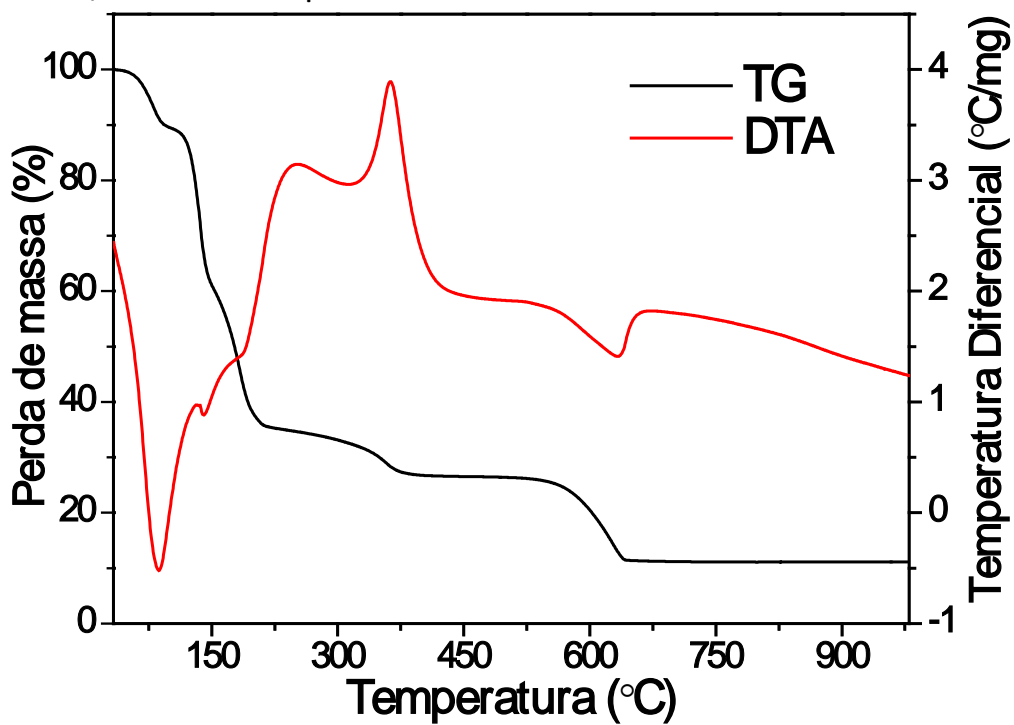

Fonte: Autoria própria. 
A análise de FTIR (Figura 20) confirma a estrutura proposta para o FeDS. Embora os espectros obtidos para o NaDS e o FeDS apresentem certa similaridade, algumas diferenças são observadas. As bandas de absorção nas regiões de 3400 e $1650 \mathrm{~cm}^{-1}$ aparecem mais intensas e alargadas no espectro do surfactante de ferro, sendo elas atribuídas às 4 moléculas de água presentes na estrutura do composto. O grupo sulfato do ligante DS pode estar presente na estrutura do FeDS como um contra-íon livre ou estar coordenado ao cátion ferro(III) de maneira monodentada, bidentada ou bidentada em ponte.(84) Cada tipo de coordenação apresenta diferentes absorções no infravermelho e as principais diferenças são esperadas no intervalo 1350 - $750 \mathrm{~cm}^{-1}$ nos espectros.(85) O espectro do NaDS apresenta bandas de absorção características de modos de estiramento assimétrico e simétrico do grupo sulfato em uma simetria $\mathrm{C} 3_{\mathrm{V}}: 1251$ and $1220 \mathrm{~cm}^{-1}\left(\mathrm{~V}_{\mathrm{as}}\left(\mathrm{O}-\mathrm{SO}_{3}^{-}\right)\right)$and $1083 \mathrm{~cm}^{-1}\left(\mathrm{~V}_{\mathrm{s}}\left(\mathrm{O}-\mathrm{SO}_{3}^{-}\right)\right)$. Embora essas três bandas sejam também observadas para o FeDS, as duas últimas aparecem deslocadas para menor número de onda (1209 and $1068 \mathrm{~cm}^{-1}$, respectivamente). Este deslocamento está associado aos fortes efeitos eletrostáticos envolvidos na coordenação do grupo sulfato com o cátion ferro(III). Observações similares foram relatadas para complexos de praseodímio trivalente com ligantes dodecil sulfato.(86) As duas bandas com atribuição $v_{\text {as }}\left(\mathrm{O}-\mathrm{SO}_{3}{ }^{-}\right)$apresentam alargamento na direção de menor número de onda. Como algumas bandas de absorção entre 1150 e $1190 \mathrm{~cm}^{-1}$ são atribuídas a interações do tipo ligação de hidrogênio entre moléculas de água coordenadas e o grupo sulfato do ligante DS coordenado,(85) o alargamento das bandas evidencia que as 4 moléculas de água completam a primeira esfera de coordenação do ferro(III).

Figura 20 - Espectro FTIR obtido para os surfactante FeDS. Para efeito de comparação, o espectro do surfactante NaDS usado na síntese do FeDS também é mostrado.

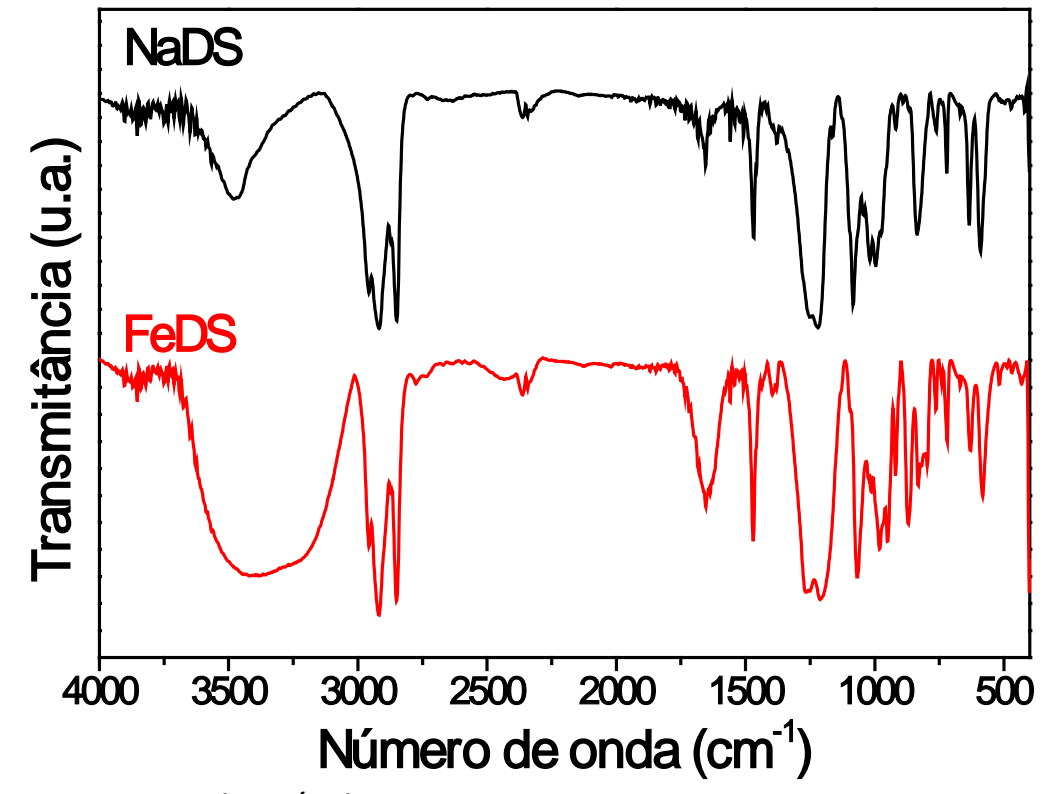

Fonte: Autoria própria. 
A $\mathrm{cmc}$ do FeDS em 1-octanol foi determinada através de medidas de condutividade elétrica e de espalhamento de luz, sendo obtido o valor $c m c=0,90 \mathrm{mmol} \mathrm{L}^{-1}$. A utilização de tais medidas para determinação da $c m c$ é possível devido ao processo de micelização atuar sobre algumas propriedades de soluções de surfactantes, como pressão osmótica, turbidez, condutividade elétrica e espalhamento de luz. Os pontos cheios da Figura 21 mostram um aumento linear da condutividade elétrica com a concentração de FeDS. Uma abrupta descontinuidade ocorre em concentrações ao redor de $1 \mathrm{mmol} \mathrm{L}^{-1}$ com alteração da inclinação da reta, o que é explicado pela formação de agregados micelares devido à agregação de monômeros de DS. As duas retas ajustadas aos comportamentos lineares se interceptam em 0,90 $\mathrm{mmol} \mathrm{L}^{-1}$, que corresponde ao valor da $c m c$. Esses dados são corroborados por medidas de espalhamento de luz (Figura 21, pontos abertos), que indicam a presença de aglomerados micelares com diâmetro hidrodinâmico entre 3 e 4 nm para soluções com concentrações de FeDS acima de 0,90 $\mathrm{mmol} \mathrm{L}^{-1}$. Para soluções com concentração inferior a essa, tais agregados não foram detectados.

Figura 21 - Medidas de condutividade elétrica (ponto cheio) e diâmetro hidrodinâmico (ponto aberto) em função da concentração do surfactante FeDS em soluções octanólicas.

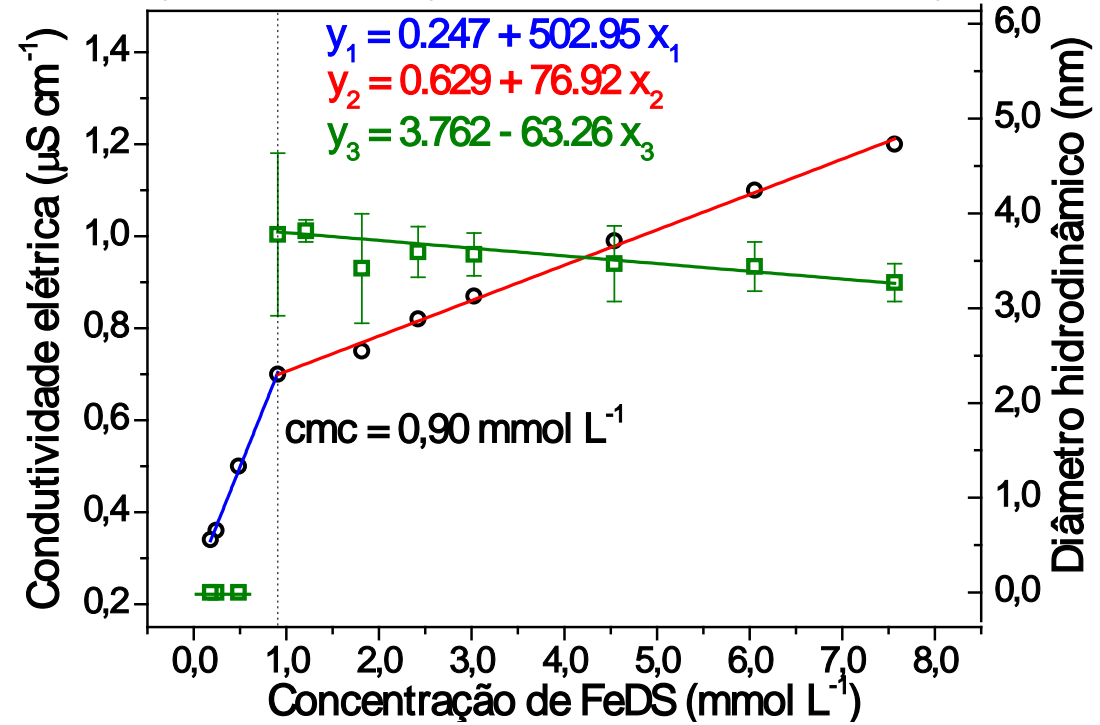

Fonte: Autoria própria.

NPM foram obtidas em um sistema bifásico composto por água e uma solução 1,04 mmol $\mathrm{L}^{-1}$ de FeDS em 1-octanol ao qual foi adicionado o redutor $\mathrm{NaBH}_{4}$ (amostra FeOx-01). Esta concentração foi escolhida por estar um pouco acima da $c m c$ do FeDS em 1-octanol. Logo após a solubilização do redutor na fase água, observa-se efervescência na interface água/octanol, o que indica o início da reação de redução dos íons $\mathrm{Fe}^{3+}$ próximos a essa interface. Imediatamente forma-se um precipitado alaranjado, o qual adquire coloração preta após alguns minutos. Assim que formado, o precipitado preto passa à fase água devido à superfície hidrofílica das NPM e é 
atraído pela superfície da barra magnética de agitação. De acordo com análises de DRX e MET (Figura 22), NPM monodispersas na fase magnetita foram obtidas com diâmetro médio de 3,4 \pm 0,3 $\mathrm{nm}$ e grau de polidispersividade de 9,7\%. Deve-se destacar a proximidade entre o diâmetro médio das NP e os valores de diâmetro hidrodinâmico dos agregados micelares medidos por espalhamento de luz. Assim, o controle de forma e tamanho obtido é explicado pela formação de agregados micelares altamente organizados, os quais evitam o crescimento descontrolado das NP fazendo uso de impedimento estérico.

Figura 22 - Difratograma e imagens de MET da amostra FeOx-01 com o histograma de contagem de tamanho de partículas.
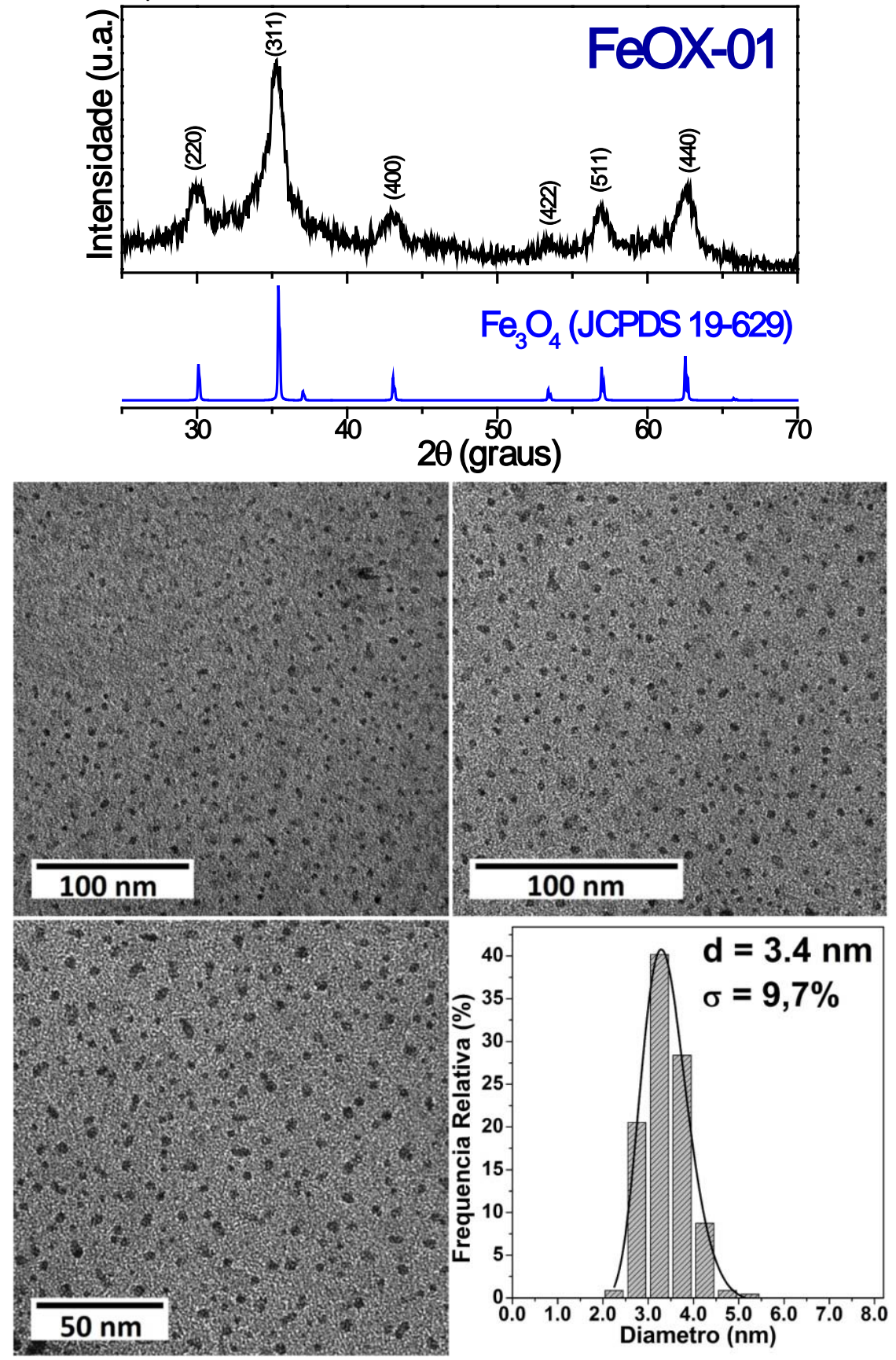

Fonte: Autoria própria. 
A curva de magnetização da amostra FeOx-01 (Figura 23) mostrou baixos valores de coercividade $(0,3 \mathrm{kOe})$ e remanência $\left(0,6 \mathrm{emu} \mathrm{g}^{-1}\right)$ mesmo à temperatura de $5 \mathrm{~K}$. O pico observado em $35 \mathrm{~K}$ na curva ZFC corresponde à temperatura de bloqueio magnético da amostra $\left(T_{B}\right)$, o qual é menor que os valores 107 e $45 \mathrm{~K}$ reportados respectivamente para NP de magnetita com 11,5 e $4 \mathrm{~nm}$.(87) Isso indica que o baixo valor de $T_{B}$ observado deve-se às dimensões reduzidas da NPM. É importante notar que, com exceção do intervalo entre -10 e 10 kOe, a curva apresenta linearidade sem saturação, o que indica um efeito quase-paramagnético para a amostra. De fato, esse comportamento tem sido relatado na literatura para NPM com dimensões abaixo de $5 \mathrm{~nm}$, sendo estas classificadas como "ultrasmall nanoparticles". Segundo alguns autores, NPM de magnetita com dimensões tão reduzidas são promissoras como agentes de contraste $T_{1}$, uma vez que aumenta-se o efeito $T_{1}$ devido à alta área de superfície com 5 elétrons desemparelhados simultaneamente à supressão do efeito $T_{2}$ resultante dos baixos valores de momento magnético apresentado pela amostra. $(88,89)$ Agentes de contraste $T_{2}$ apresentam contraste escuro, o qual muitas vezes pode ser confundido com sangramento e calcificação. Já os agentes de contraste $T_{1}$ atuam sobre o tempo de relaxação longitudinal de átomos de hidrogênio da água, apresentando contraste brilhante. Entretanto, os agentes de contraste $T_{1}$ atualmente utilizados são baseados em complexos de $\mathrm{Gd}^{3+}$ e $\mathrm{Mn}^{2+}$ que apresentam elevada toxicidade.(90) Neste ponto reside a importância das NP aqui obtidas, uma vez que o ferro está presente em muitos dos processos biológicos no corpo humano, apresentando toxicidade muito inferior a grande maioria dos compostos usados como agentes de contraste.

Figura 23 - À esquerda, curva de magnetização da amostra FeOx-01 obtida a $5 \mathrm{~K}$ após tratamento térmico $\left(400^{\circ} \mathrm{C}\right.$ por $\left.1 \mathrm{~h} \mathrm{em} \mathrm{N}_{2}\right)$, destacando uma ampliação do centro da curva. À direita, curvas ZFC/FC indicando a temperatura de bloqueio magnético.
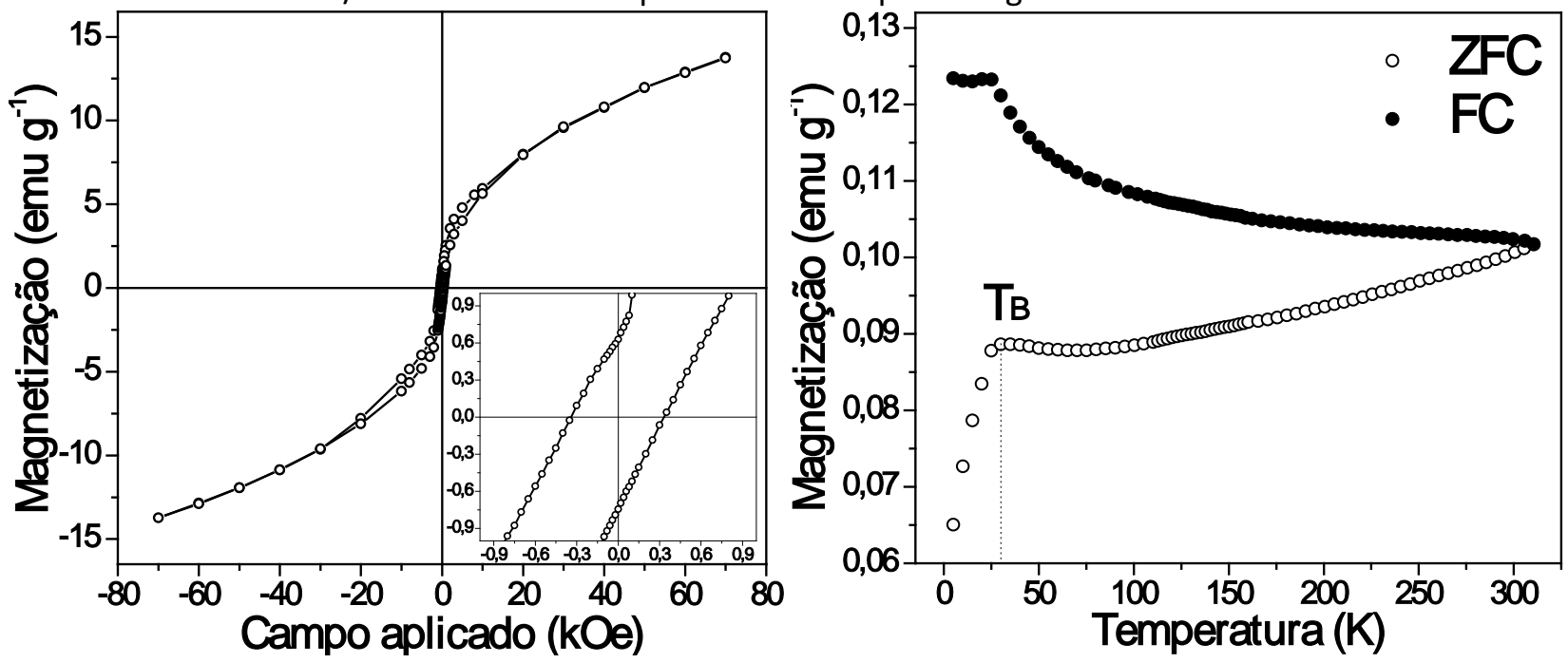

Fonte: Autoria própria. 


\subsubsection{Caracterização do surfactante CoDS e síntese de NPM}

As mesmas técnicas de análise usadas para o FeDS foram também empregadas no estudo da estrutura molecular do CoDS. Entretanto, divergências entre alguns dos dados experimentais vem dificultando uma conclusão a respeito da estrutura molecular deste composto, a qual encontra-se sob investigação. Embora a estrutura do CoDS ainda seja desconhecida, a determinação do diagrama de fases pseudo-ternário deste composto não foi comprometida pois o mesmo relaciona quantidades em massa entre os componentes do sistema de microemulsão.

O diagrama de fases pseudo-ternário do sistema $n$-heptano/n-butanol/CoDS/água foi levantado usando procedimento similar ao adotado em trabalhos de Mo(35) e Malheiro.(78) Tal procedimento tem como base observações de transições turbidez-transparência e medidas de condutividade elétrica para identificar, respectivamente, as regiões de emulsão e microemulsão e as diferentes estruturas do sistema microemulsionado. Nestes sistemas, o $n$-heptano (Hep) atua como fase óleo, o $n$-butanol (ButOH) como co-surfactante e CoDS como surfactante. Para possibilitar a representação deste sistema em um diagrama ternário, surfactante e co-surfactante foram misturados em uma razão mássica fixa ButOH/CoDS $=2$, sendo esta mistura denominada emulsificador (EM). Este emulsificador foi então tratado como um único componente do sistema.

É sabido que a condutividade elétrica de sistemas microemulsionados é sensível a mudanças na forma de organização dos monômeros de surfactantes em solução. Assim, optou-se pela análise desta propriedade para determinar composições que resultem nas três diferentes estruturas que as microemulsões podem adquirir, haja vista que mudanças na composição do sistema resultam em mudanças na forma de organização das moléculas dos surfactantes.

A partir da observação de transições transparência-turbidez foram determinados limites de transição microemulsão-emulsão. Tais composições são apresentadas na Tabela 9.

Tabela 9 - Composições percentuais correspondentes aos pontos de transição para o sistema $n$-heptano/n-butanol/CoDS/água.

\begin{tabular}{c|c|c|c}
\hline Ponto & $\begin{array}{c}\mathbf{R} \\
(\text { Hep/(EM+Hep)) }\end{array}$ & $\begin{array}{c}\text { Transparência } \\
\text { (EM:Hep:H } \mathbf{O})\end{array}$ & $\begin{array}{c}\text { Turbidez } \\
\text { (EM:Hep:H } \mathbf{~ O ) ~}\end{array}$ \\
\hline 1 & 0,08 & $79: 7: 14$ & $32: 3: 65$ \\
\hline 2 & 0,2 & $74: 19: 7$ & $46: 11: 46$ \\
\hline 3 & 0,36 & $59: 33: 8$ & $40: 23: 37$ \\
\hline 4 & 0,5 & $45: 46: 9$ & $26: 27: 47$ \\
\hline 5 & 0,6 & $36: 55: 9$ & $24: 37: 39$ \\
\hline 6 & 0,7 & $19: 74: 7$ & $18: 70: 12$ \\
\hline 7 & 0,8 & $10: 88: 2$ & $9: 83: 8$ \\
\hline
\end{tabular}

Fonte: Autoria própria. 
Para se determinar as composições dos diferentes domínios microemulsionados, foram construídas curvas de condutividade versus volume de água adicionado. Os comportamentos observados são apresentados nos gráficos da Figura 24.

Figura 24 - Curvas de condutividade em função da composição em água do sistema n-heptano/nbutanol/CoDS/água, para diferentes valores de $\mathrm{R}$.
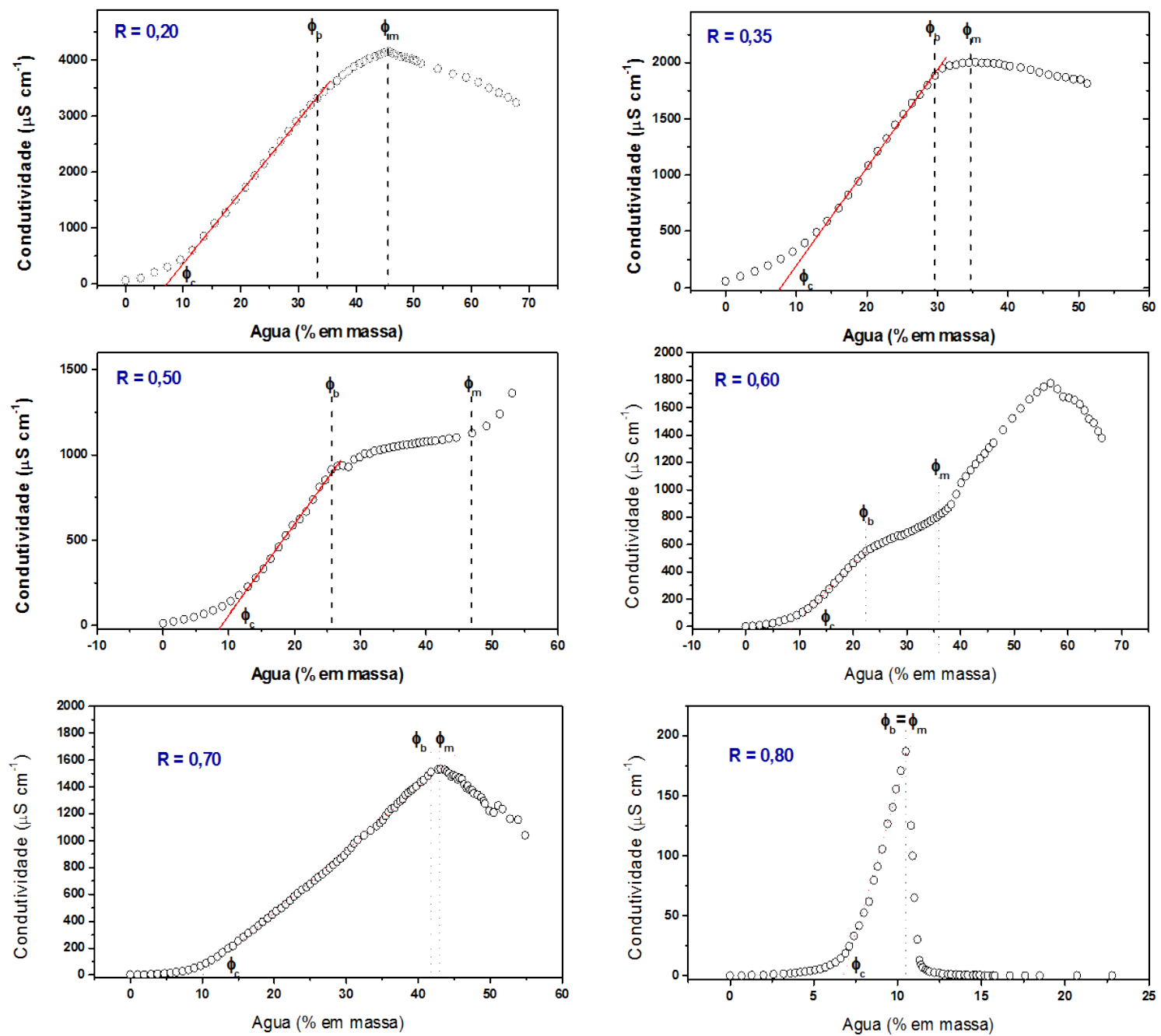

Fonte: Autoria própria.

As curvas que representam os sistemas com $R=0,2$ e $R=0,35$ são semelhantes e se diferem apenas nos valores de condutividade e volume de água nos quais ocorrem mudança de comportamento do sistema. Cabe ressaltar que o comportamento observado para esses dois sistemas encontra-se em acordo com o comportamento explicado pelo modelo de condução percolativa.(35) As curvas apresentam aumento linear à medida que se adiciona água, caracterizando o sistema de microemulsão inversa. Em $\phi_{b}$, o sistema passa de micelas inversas para o sistema bicontínuo. Este ocorre até $\phi_{m}$, onde há o ponto máximo de condutividade da curva. A partir deste ponto tem-se a microemulsão direta, que ocorre até a turvação do sistema. 
Para $\mathrm{R}=0,50$ tem-se um intervalo maior onde há sistema bicontínuo e o comportamento da curva após $\phi_{\mathrm{m}}$ difere um pouco do comportamento observado nas outras curvas. No entanto, acredita-se que em $\phi_{\mathrm{m}}$ seja onde há a mudança desse sistema para o de micelas diretas porque há uma mudança no comportamento observado até então.

A curva que representa $R=0,60$ é semelhante ao gráfico anterior, diferindo apenas em seu final, que apresenta decaimento em composições superiores a $55 \%$ em água. No entanto, a região deste decaimento não corresponde a microemulsão e sim de emulsão, uma vez que foi observada uma considerável turvação do sistema em composições acima de 39\% em água.

Apesar do comportamento da curva $\mathrm{R}=0,70$ ser semelhante ao apresentado pelas curvas $R=0,20$ e $R=0,35$, observa-se o turvamento do sistema em composições em água acima de $34 \%$. Esta composição encontra-se dentro da faixa do comportamento linear da curva, indicando a ocorrência de transição direta de microemulsão inversa para emulsão.

Analisando a curva para $R=0,80$, conclui-se que, para pequenos volumes de água, a condutividade é aproximadamente zero, com um aumento linear a partir de $\phi_{c}$. Este caracteriza o sistema de micelas inversas, o qual ocorre até $\phi_{b}=\phi_{m}$. Neste estudo, não se observou formação de sistema bicontínuo e microemulsão direta, pois logo após o ponto de máximo de condutividade, em 11,55\% em massa de água, o sistema ficou turvo, caracterizando a emulsão. Cabe ressaltar que na análise realizada para $R=0,90$ o sistema se mostrou turvo para todas as compostições.

A partir das análises de transparência/turbidez e das medidas de condutividade elétrica foi possível construir o diagrama de fases pseudo-ternário apresentado na Figura 25. As regiões de microemulsão direta, sistema bicontínuo e microemulsão inversa são respetivamente destacados nas regiões I, II e III. As regiões em branco do diagrama não foram mapeadas. É importante ressaltar a extensa região de microemulsão inversa (região III), o que é positivo para a síntese de nanopartículas por possibilitar que partículas de diferentes dimensões sejam obtidas, haja vista que o tamanho interno das micelas depende da razão molar água/surfactante.(78) Para a síntese de NPM foram escolhidos duas composições pertencentes à região de microemulsão inversa no diagrama de fases do sistema $n$-heptano/n-butanol/CoDS/água. As duas composições são destacadas no diagrama na forma de estrelas de cor laranja e roxa. A obtenção de microemulsão inversa faz-se necessária a fim de garantir que os íons $\mathrm{Co}^{2+}$ estejam inseridos no interior das micelas, haja vista sua maior afinidade pela fase aquosa. Tais composições encontram-se na Tabela 4 da Parte Experimental (item 3.2.1.1.4). 
Figura 25 - Diagrama de fases pseudo-ternário obtido para o sistema $n$-heptano $/ n$ butanol/CoDS/água, destacando as regiões de microemulsão direta (I), inversa (III) e sistema bicontínuo (II). As estrelas indicam as composições utilizadas na síntese das NP.

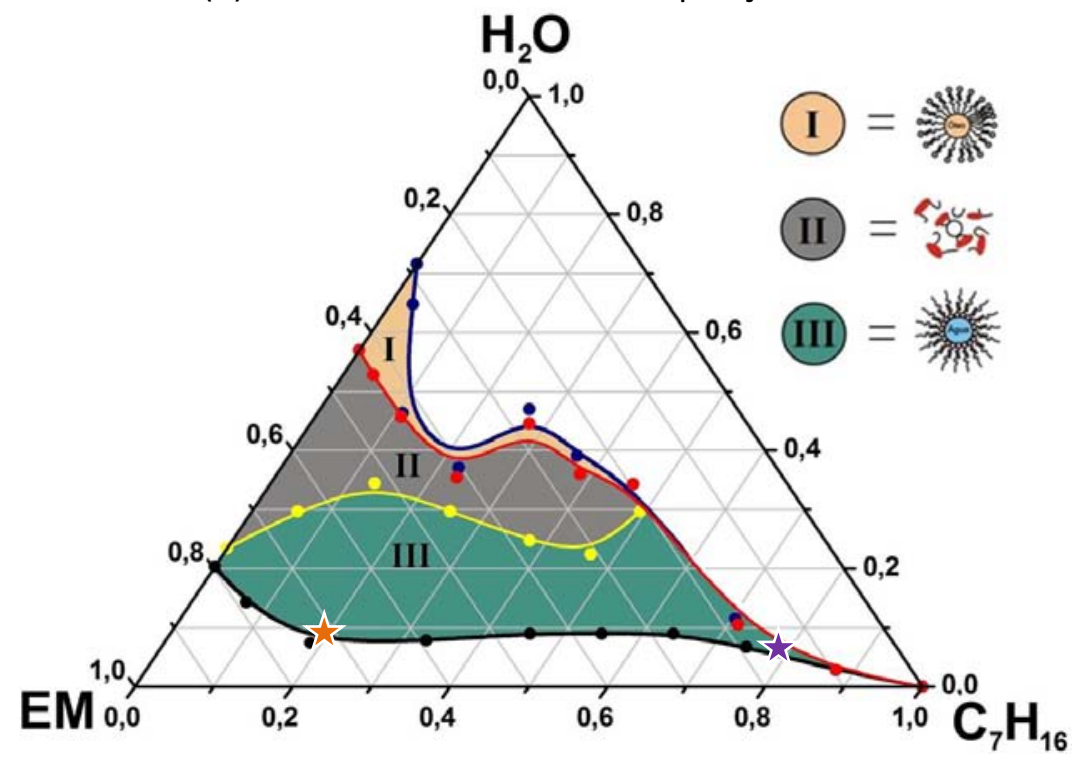

Fonte: Autoria própria.

$\mathrm{O}$ agente redutor $\mathrm{NaBH}_{4}$ foi usado em excesso em relação à quantidade molar de íons $\mathrm{Co}^{2+}$ presentes no sistema a fim de proporcionar um meio bastante redutor para a obtenção de NPM de Co metálico. Cabe aqui ressaltar que os óxidos de cobalto não apresentam emanação magnética considerável, o que explica a necessidade de obtenção da fase metálica do cobalto. Assim que adicionado ao sistema, o redutor percola para o interior das micelas e lá se dissocia, promovendo uma reação de óxido-redução na qual os íons $\mathrm{Co}^{2+}$ são reduzidos. Dessa forma, iniciam-se as fases de nucleação e posterior crescimento das partículas que, por se formarem no interior das micelas, tendem a adquirir as dimensões e a forma das mesmas.

Durante a primeira síntese (Co-01, estrela laranja no diagrama da Figura 25), observou-se uma forte efervescência e a formação de um precipitado preto quase que instantaneamente após a adição de $\mathrm{NaBH}_{4}$, indicando a rápida percolação de íons $\mathrm{BH}_{4}{ }^{-}$para o interior da micela e redução dos cátions $\mathrm{Co}^{2+}$ lá presentes. Para as sínteses posteriores, optou-se por uma composição (estrela roxa no diagrama) cuja composição em água fosse um pouco menor, de forma a diminuir a taxa de percolação de íons $\mathrm{BH}_{4}{ }^{-}$para a fase aquosa presente no interior das micelas e, conseqüentemente, possibilitar o crescimento das partículas de forma mais lenta e cristalina. Nessa síntese, a formação do precipitado preto foi observada rapidamente, porém a reação ocorreu em intervalo de tempo um pouco maior. Cabe aqui ressaltar que os precipitados formados para ambas as composições, eram rapidamente atraídos para a superfície da barra magnética de agitação assim que formados, o que mostra o caráter magnético dos produtos. 
Após a síntese das NPM, iniciou-se a caracterização do produto obtido. A fase formada foi então analisada por DRX (Figura 26), enquanto que o tamanho e a morfologia das NP foram analisados através de imagens obtidas por MET (Figura 27).

Figura 26 - DRX das amostras de NPM de Co metálico e os respectivos padrões JCPDS do fcc-Co, hcp-Co, $\mathrm{CoO}, \mathrm{Co}_{3} \mathrm{O}_{4}, \mathrm{CoB}$, borax e tincalconita.

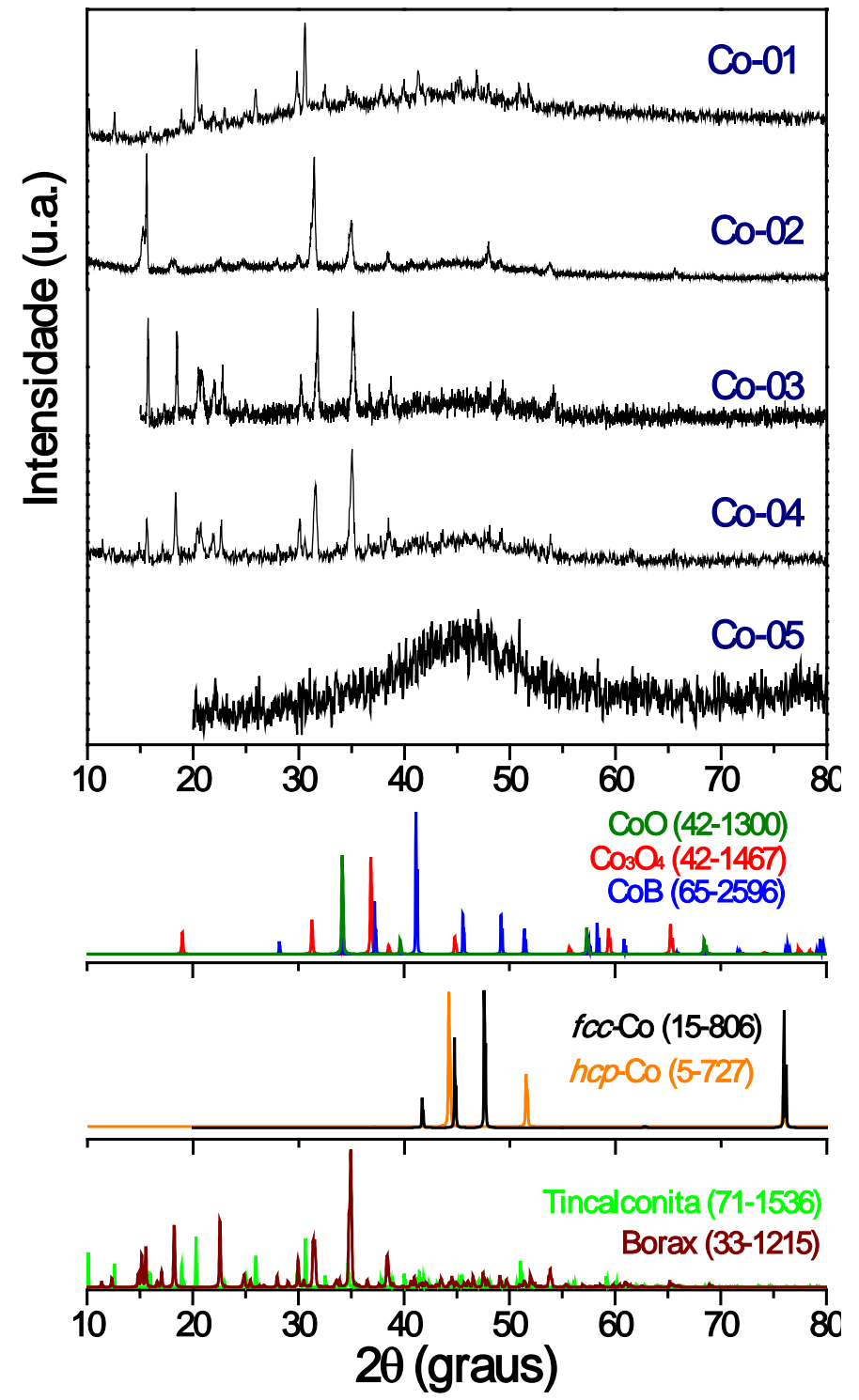

Fonte: Autoria própria.

O difratograma obtido para a amostra Co-01 indica a formação de uma fase de hidroxiborato de sódio hidratado, mais precisamente a tincalconita com fórmula $\mathrm{Na}_{2} \mathrm{~B}_{4} \mathrm{O}_{7}\left(\mathrm{H}_{2} \mathrm{O}\right)_{5}$. Embora picos característicos de cobalto metálico ou óxido de cobalto não são observados no difratograma, um halo bastante alargado aparece na região entre $40^{\circ}$ e $55^{\circ}$ em $2 \theta$, região esta na qual as fases $f c c$-Co e $h c p$-Co apresentam seus picos principais. A presença desse halo ao invés de picos pode ser explicada pelas pequenas dimensões das partículas de cobalto, bem como pela 
baixa cristalinidade das mesmas. Outro indício da presença de cobalto metálico na amostra Co-01 reside no fato de que a mesma apresentou forte resposta a campos magnéticos externos, sendo a tincalconita diamagnética. Assim, pode-se inferir que a amostra é composta por uma mistura entre a fase tincalconita e uma ou mais fases de cobalto metálico amorfo (fcc-Co e/ou hcp-Co). Essa afirmação foi confirmada através da análise por MET apresentada na Figura 27.

Figura 27 - Imagem de MET obtida para as amostras Co-01 e Co-05.

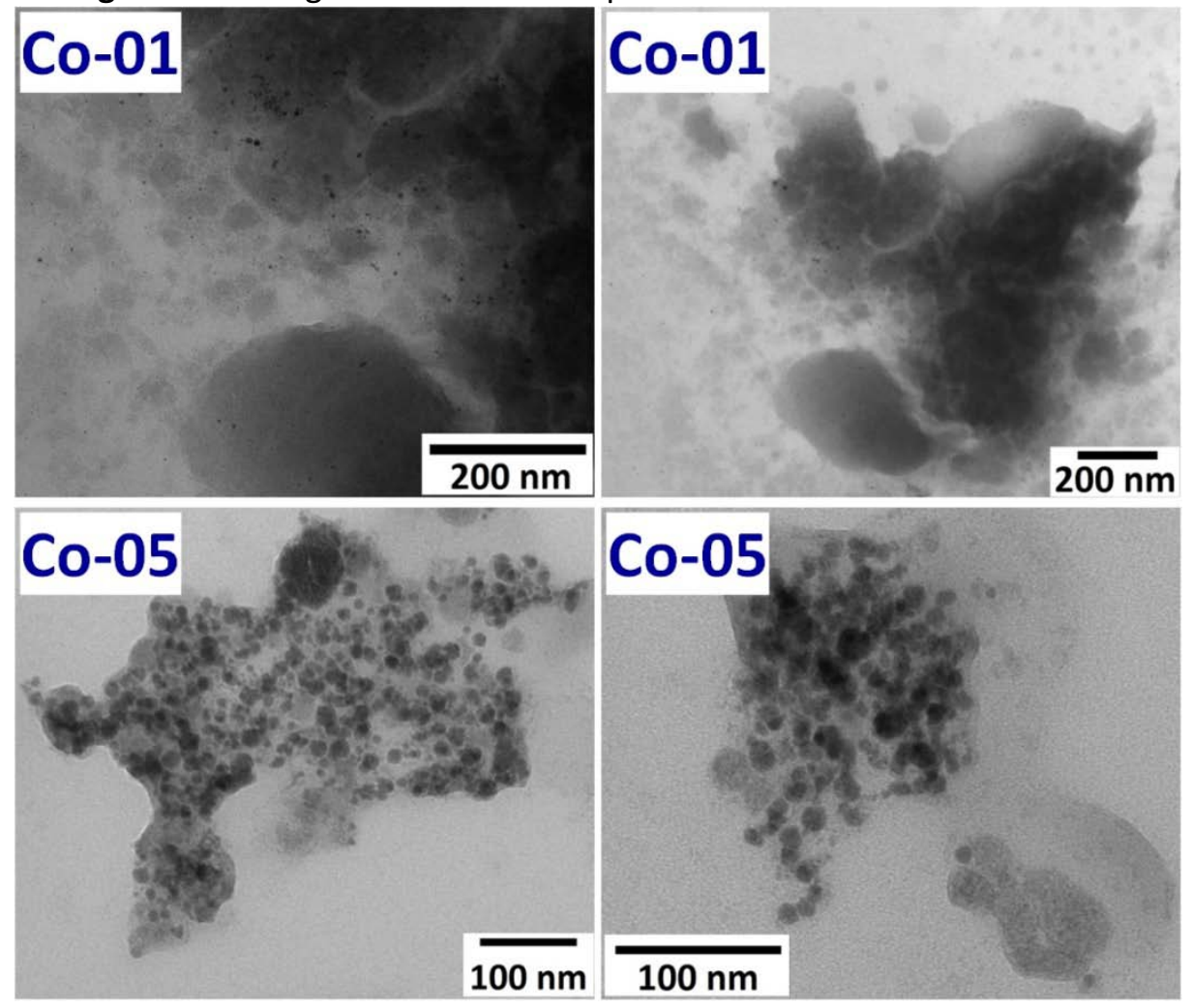

Fonte: Autoria própria.

Assim como para a amostra Co-01, a análise por DRX da amostra Co-02 indicou a formação de uma fase de hidroxiborato de sódio hidratado, neste caso, o bórax $\left(\mathrm{Na}_{2} \mathrm{~B}_{4} \mathrm{O}_{5}(\mathrm{OH})_{4}\left(\mathrm{H}_{2} \mathrm{O}\right)_{8}\right.$. Ainda, também é possível visualizar um halo próximo à região correspondente aos picos de Co, que pelo fato da amostra ser magnética, acredita-se que seja o próprio cobalto metálico.

Os difratogramas da Figura 26 não apresentam picos característicos de fases cristalinas de boreto de cobalto ou outros compostos magnéticos contendo cobalto em sua estrutura. Assim, dada o forte caráter magnético apresentado pelas amostras Co-01 e Co-02, pode-se inferir que o composto magnético encontrado nas amostras é mesmo cobalto metálico, o material de interesse do estudo. Neste contexto, fez-se necessário alguns ajustes no método de síntese de modo a evitar a formação de fases de hidroxiborato de sódio. Trabalhos da literatura apontam 
que a cinética de reação do redutor borohidreto tende a diminuir com a diminuição do $\mathrm{pH}$, o que poderia evitar a formação de fases secundárias indesejadas. Para isso, duas sínteses foram realizadas utilizando água acidificada com pH = 1,0 e 3,0 (amostras Co-03 e Co-04, respectivamente). Entretanto, a análise por DRX mostrou que fases secundárias de hidroxiborato de sódio ainda estão presentes.

Reduzindo a quantidade do redutor em $45 \%$ é possível evitar a formação das fases bórax e tincalconita. O difratograma da amostra Co-05 indica ausência de fases hidroxiborato de sódio e apresenta apenas um halo na região entre 45 e $50^{\circ}$. É nesta região que se encontra os principais picos das fases $f c c$-Co e $h c p$-Co, o que mostra a presença de ao menos uma das fases de cobalto metálico. Entretanto, o difratograma não apresenta picos bem resolvidos devido à baixa cristalinidade das NPM e seu tamanho diminuto.

As imagens apresentadas na Figura 27 mostram que a amostra Co-01 é composta por pequenas partículas esferoidais com dimensões próximas a $6 \mathrm{~nm}$, envoltas por uma matriz com menor contraste na imagem MET. O maior contraste apresentado pelas pequena partículas indicam que as mesmas são compostas por cobalto enquanto que a matriz de menor contraste possui provavelmente a estrutura da tincalconita. A imagem MET da amostra Co-05 revela nanopartículas com diâmetro ao redor de $10 \mathrm{~nm}$, porém com grande polidispersividade $(\sigma=$ $32 \%)$, o que não é desejável na maioria das aplicações de NPM.

Figura 28 - Curvas de magnetização medidas à temperatura ambiente para as amostras Co-03, Co-04 e Co-05.

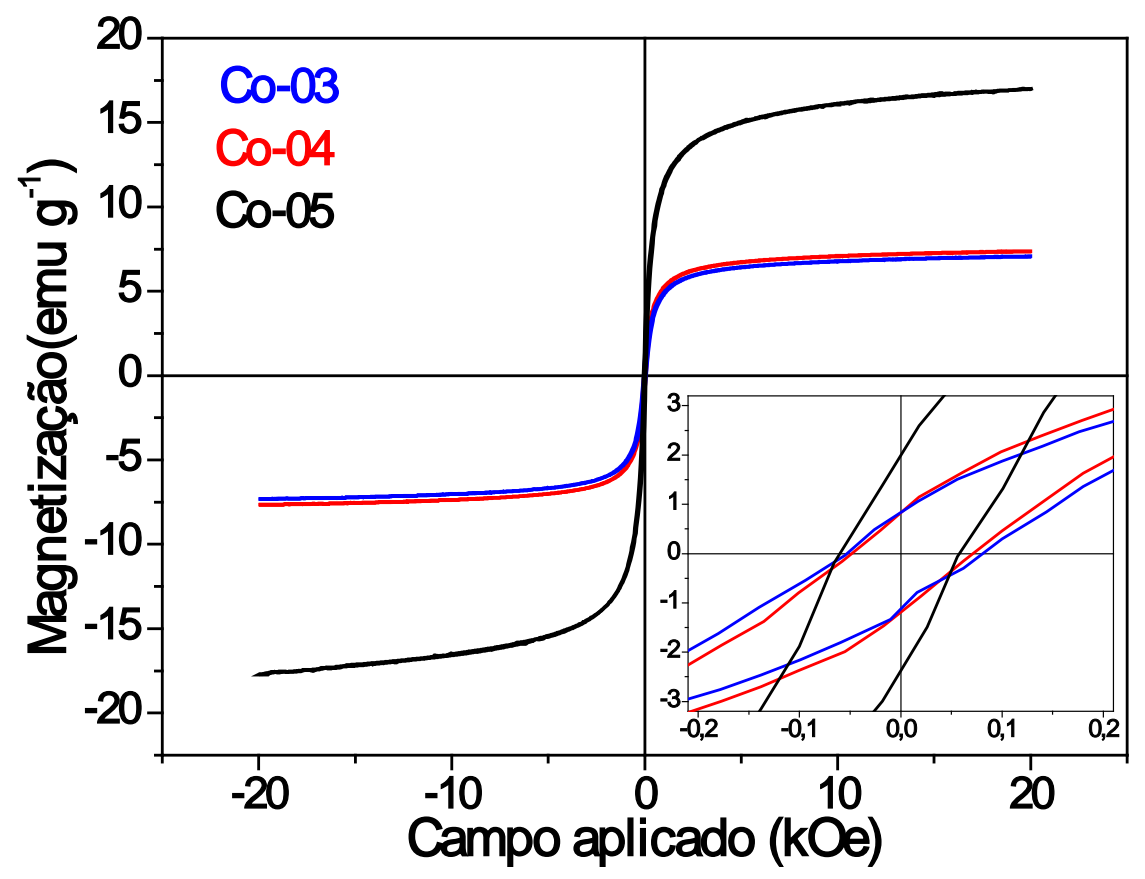

Fonte: Autoria própria. 
As curvas de magnetização obtidas por VSM para as amostras Co-03 e Co-04 (Figura 28) mostram valores de magnetização de saturação bastante próximos para ambas as amostras (7,0 e 7,4 emu $\mathrm{g}^{-1}$, respectivamente). Entretanto, tais valores de $M_{s}$ estão muito abaixo dos valores esperado para nanopartículas de cobalto metálico,(91) e podem ser explicados pela presença da fase de hidroxiborato de sódio hidratado, a qual é diamagnética e contribui somente para a massa do material, mas não para sua magnetização. A ausência da fase hidroxiborato de sódio na amostra Co-05 resultou em um aumento em seu valor de $M_{\mathrm{S}}\left(17,2 \mathrm{emu} \mathrm{g}^{-1}\right)$, o qual ainda está bem abaixo do valor esperado. Entretanto, apesar dos baixos valores de $M_{S}$, é importante observar que ambas as amostras apresentaram comportamento superparamagnético (ausência de remanência e coercividade desprezível) à temperatura ambiente, o que é uma característica imprescindível para a aplicação de NPM em biomedicina. Outra característica interessante apresentada pelas nanopartículas é que as mesmas alcançaram a magnetização de saturação com baixos valores de campo magnético aplicado. Tal característica torna-se interessante principalmente em aplicações de hipertermia magnética, que requerem partículas com rápida resposta magnética sob campos magnéticos externos de baixa intensidade.

\subsection{Síntese de NPM via decomposição térmica}

\subsubsection{Nanopartículas de FePt}

A síntese de NP de FePt foi realizada usando procedimento experimental baseado no processo poliol modificado, $(26,28,45)$ no qual os cátions $\mathrm{Fe}^{3+}$ e $\mathrm{Pt}^{2+}$ provindos de sais acetilacetonatos são reduzidos em uma reação de oxi-redução envolvendo 1,2-hexadecanodiol. As quantidades de cada precursor metálico foram calculadas para obter um produto final com composição molar de 55\% em ferro e 45\% em platina (Fe:Pt $=55: 45)$. A escolha desta composição deve-se ao fato da mesma ser relatada na literatura como aquela com maior emanação magnética.(17)

Para analisar o efeito do tamanho da cadeia carbônica do redutor alcanodiol sobre as características finais das NPM de FePt, bem como diminuir o custo de cada síntese, três redutores foram testados: 1,2-hexadecanodiol, 1,2-tetradecanodiol e 1,2-dodecanodiol. Ainda, dois solventes foram testados (benziléter e octiléter) para avaliar seu efeito sobre a morfologia e a composição das NPM. 
Em todas as sínteses, durante o aumento de temperatura até o primeiro patamar $\left(90^{\circ} \mathrm{C}\right)$ pode-se notar que a coloração da solução foi passando de incolor para amarelada até atingir uma coloração avermelhada, indicando a gradativa solubilização dos precursores metálicos. Cabe ressaltar que todos os redutores encontravam-se totalmente solubilizados antes de atingida a temperatura de $90^{\circ} \mathrm{C}$. Ao término do primeiro patamar, foram adicionados os surfactantes ácido oleico e oleilamina, sendo o sistema novamente aquecido até $200^{\circ} \mathrm{C}$ por 60 minutos. Durante esta rampa de aquecimento, atingida a temperatura de aproximadamente $185^{\circ} \mathrm{C}$, a solução rapidamente adquiriu uma aparência turva e coloração preta, evidenciando uma formação rápida e homogênea de partículas no meio. Tais resultados concordam com trabalhos recentes de nosso grupo de pesquisa para sínteses de NP de FePt utilizando 1,2-hexadecanodiol e dioctiléter como redutor e solvente, respectivamente. $(26,28)$ Em um estudo do mecanismo de formação de NP de FePt pelo método poliol modificado, ${ }^{55}$ foi proposto que o redutor diol promove primeiramente a redução dos cátions $\mathrm{Pt}^{2+}$ em temperaturas entre 160 e $170^{\circ} \mathrm{C}$, levando à formação de pequenos núcleos metálicos de Pt. Em temperaturas ao redor de $190^{\circ} \mathrm{C}$, a decomposição térmica do $\mathrm{Fe}(\mathrm{acac})_{3}$ leva à formação de pequenos aglomerados (clusters) de espécies oxidadas de ferro, os quais ficam heterocoagulados sobre a superfície dos núcleos de Pt recém-formados. Nesta etapa da síntese é proposto a redução das espécies de ferro por um processo de spillover de CO (CO é formado durante a decomposição dos ânions acetilacetonatos) catalisado pelos núcleos de $\mathrm{Pt}$ (catálise heterogênea). Formadas as partículas, o sistema foi aquecido até refluxo $\left(295^{\circ} \mathrm{C}\right)$, sendo mantido nesta condição por 30 minutos para promover difusão dos átomos de ferro pela estrutura cristalina da platina, buscando assim maior homogeneidade composicional do produto final. Após o resfriamento do sistema, as NP são lavadas com mistura hexano/etanol para eliminar produtos secundários indesejados que podem ter sido formados durante a síntese. Após a lavagem, as NP foram facilmente dispersas em hexano, apresentando esta dispersão estabilidade coloidal por vários dias.

A análise da estrutura cristalina das NP de FePt foi realizada por DRX (Figura 29). Os quatro difratogramas indicam a obtenção da fase cúbica de face centrada ( $f c c$, do inglês facecentered cubic) da liga FePt, a qual é bastante semelhante à estrutura $f c c$ da platina metálica, mas com os picos levemente deslocados para maiores valores de $2 \theta$. Tal deslocamento explica-se com base na Lei de Bragg (Equação II):(92) o menor raio atômico do ferro $\left(R_{\text {calculado }}=1,56 \AA\right.$ ) com relação ao da platina $\left(R_{\text {calculado }}=1,77 \AA\right)(93)$ leva a uma diminuição das distâncias interplanares (d), sendo necessário um aumento do termo $\operatorname{sen} \theta$ para que o produto $n \lambda(n=$ número inteiro e $\lambda$ = comprimento de onda da radiação $X$ incidente) permaneça constante. 


$$
n \lambda=2 d \operatorname{sen} \theta
$$

Equação II

Ressalta-se que, como na ausência do precursor de platina o procedimento experimental aqui empregado resulta em NP de magnetita,(94) a platina não somente deve facilitar a redução dos íons $\mathrm{Fe}^{3+}$ a $\mathrm{Fe}^{0}$, mas também estabilizar este elemento em sua forma metálica.

Figura 29 - Difratogramas obtidos para as amostras de nanopartículas de FePt comparados aos padrões de difração JCPDS da fcc-FePt (azul) e $\mathrm{Fe}_{3} \mathrm{O}_{4}$ (vermelho).

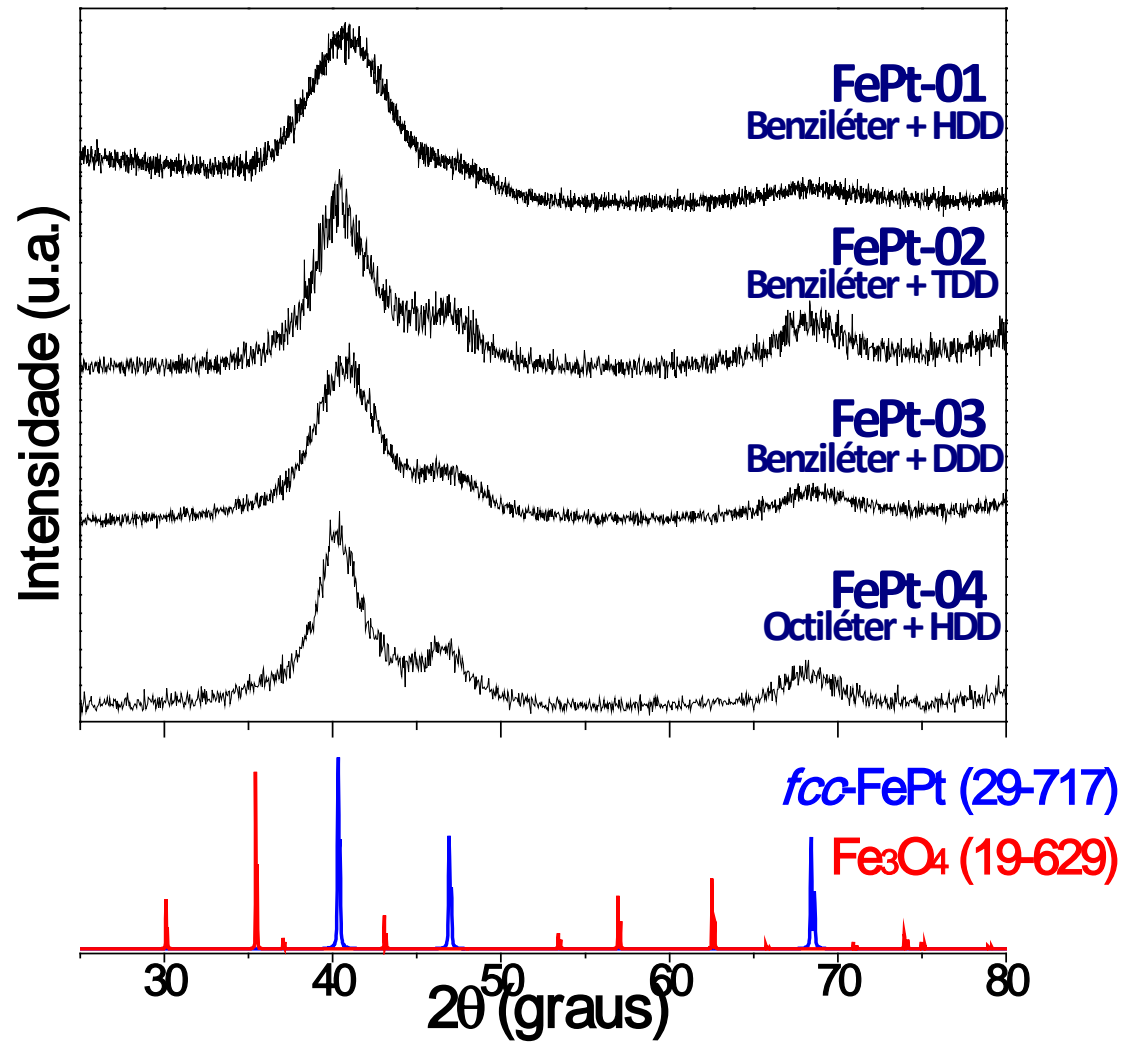

Fonte: Autoria própria.

Os difratogramas apresentam picos bastante alargados, o qual é explicado pelo tamanho nanométrico das partículas. Tais observações sugerem o sucesso da metodologia de síntese aplicada para obtenção de NP de FePt e corrobora a hipótese de que, durante a síntese primeiramente são formados os núcleos de platina metálica na fase cúbica e, depois de reduzidos, os átomos de ferro difunde-se pela rede cristalina dos núcleos formados, passando a substituir átomos de platina em algumas posições da estrutura cúbica da platina. É importante observar que os difratogramas não apresentam reflexões características das fases de ferro metálico ou de óxido de ferro (magnetita ou maghemita), o que indica que o procedimento de síntese utilizado não promove segregação de fases nem formação de fases secundárias, estando o ferro substituído na estrutura cristalina da platina na forma de liga. Ainda, a ausência de um pico centrado em $33^{\circ}$ em $2 \theta$ indica a ausência da fase tetragonal de face centrada $(f c t$, do inglês 
face-centered tetragonal) na estrutura cristalina das NP sintetizadas. A análise por DRX contribuiu para análise do efeito da substituição do redutor da síntese, uma vez que tal análise não indicou grandes modificações estruturais, sendo um indicativo da vantagem dessa substituição pelo menor custo dos reagentes 1,2-tetradecanodiol e 1,2-dodecanodiol comparado ao 1,2hexadecanodiol. A substituição do solvente benziléter por octiléter também não levou a modificações quanto à fase cristalográfica presente nas amostras.

Figura 30 - Imagens obtidas por MET para as amostras de NPM de FePt.

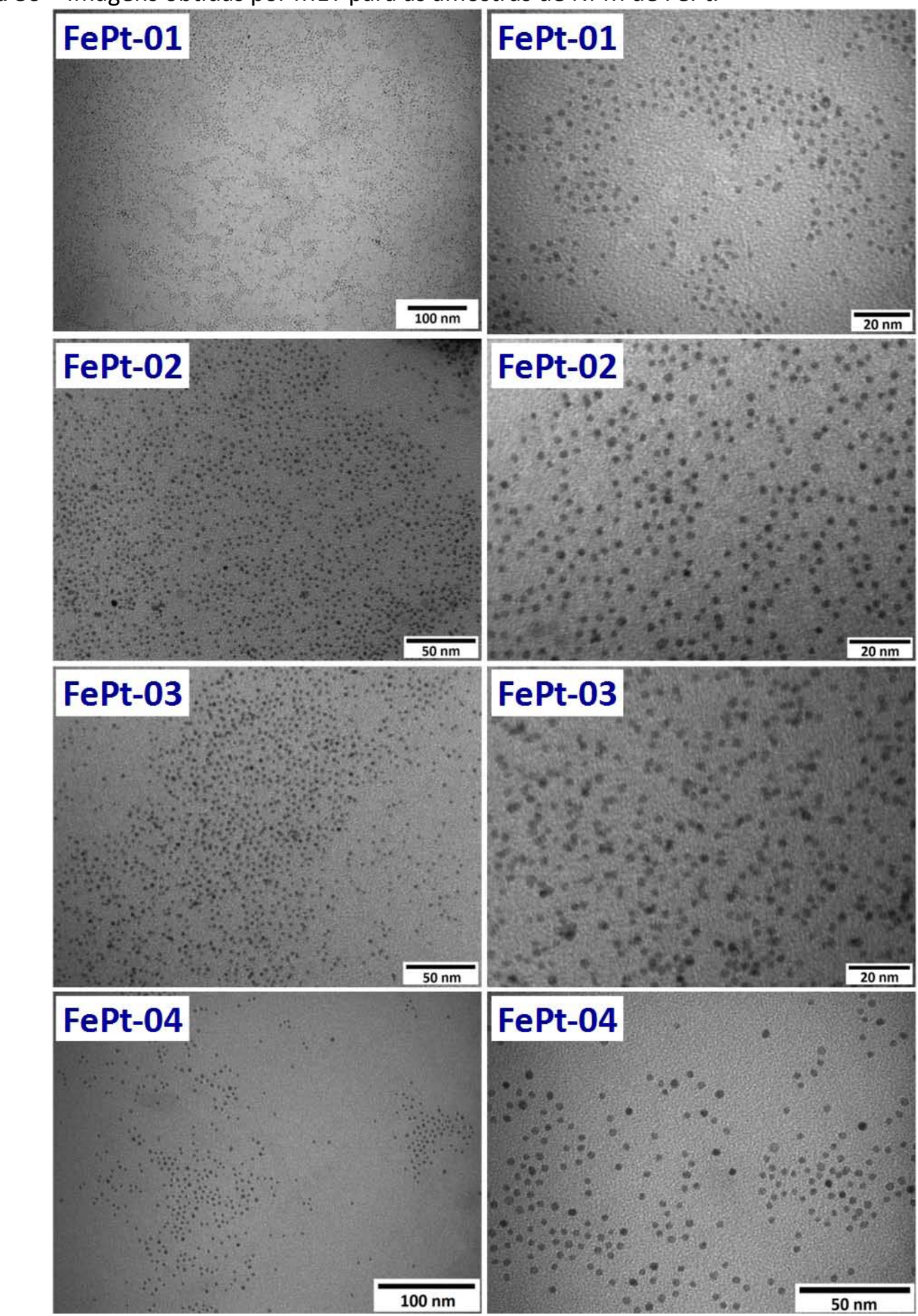

Fonte: Autoria própria. 
Tamanho e forma das partículas foram analisados por MET (Figura 30). Observa-se que a metodologia empregada, independente do redutor utilizado, possibilitou a obtenção de NPM esféricas com rigoroso controle de tamanho. As NPM apresentaram-se bem dispersas, não sendo observado a formação de agregados, o que deve-se ao impedimento estérico que resulta da presença dos surfactantes ácido oleico e oleilamina sobre sua superfície. Os diâmetros médios medidos para as amostras FePt-01, FePt-02, FePt-03 e FePt-04 foram, respectivamente, 2,4 nm, 2,7 nm, 3,0 nm e 3,6 nm. A partir do diâmetro médio e do desvio padrão é possível calcular o grau de polidispersividade do sistema, para o qual existe um limite superior de $10 \%$ abaixo do qual os sistemas podem ser classificados como monodispersos.(34) Os respectivos valores de $\sigma$ calculados para as amostras FePt-01, FePt-02, FePt-03 e FePt-04 foram 9,3\%, 5,9\%, 6,2\% e 9,3\%, o que indica monodispersividade para as quatro amostras. Diâmetro médio e grau de polidispersividade foram obtidos a partir de ajustes do tipo Lognormal aos histogramas de contagem de partículas (Figura 31).

Figura 31 - Ajustes do tipo LogNormal aplicados aos histogramas de contagem de NPM de FePt.

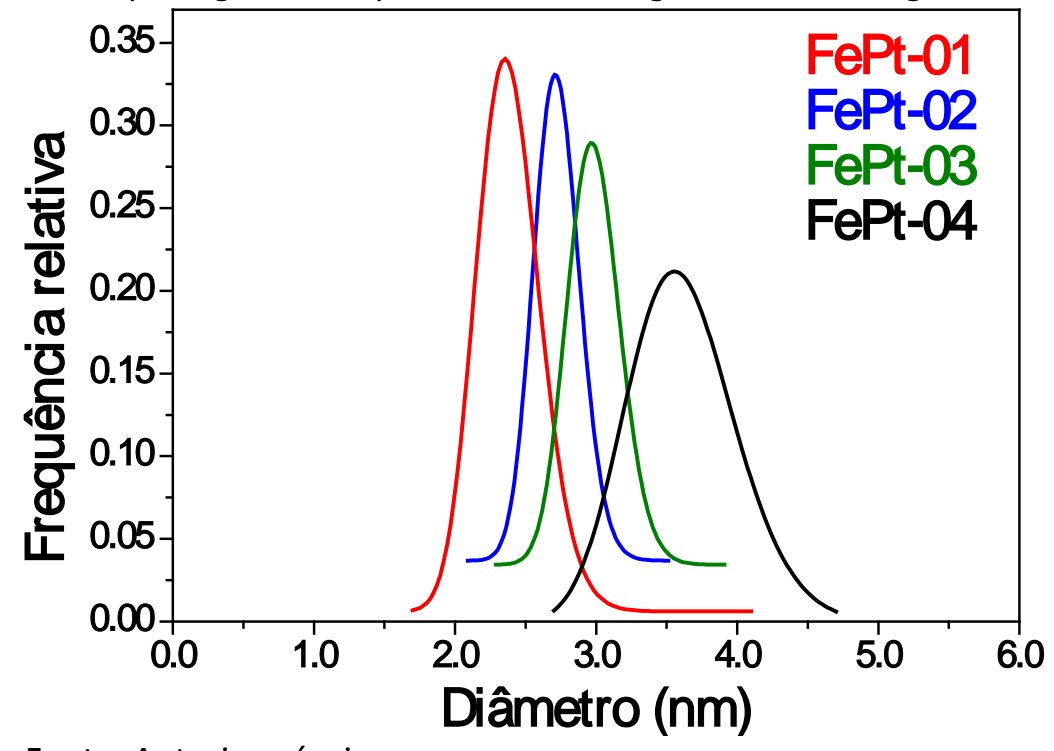

Fonte: Autoria própria.

A análise semi-quantitativa da proporção composicional das amostras de FePt foi realizada por EDX, sendo os espectros obtidos apresentados na Figura 32. Para cada amostra foram realizadas análises em 3 regiões distintas das amostras, sendo a composição determinada pela média aritmética entre as 3 análises. As composições calculadas a partir dos espectros são mostradas na Tabela 10. Cabe ressaltar que o software de aquisição dos espectros faz uma normalização pela massa molar dos elementos, resultando em espectros com intensidades de banda proporcional à composição em massa de cada elemento. Assim, dada a maior composição 
das amostras em platina aliada à maior massa molar deste elemento $\left(195,8 \mathrm{~g} \mathrm{~mol}^{-1}\right)$ comparado ao ferro $\left(55,85 \mathrm{~g} \mathrm{~mol}^{-1}\right)$, as bandas referentes à platina apresentam intensidades muito superiores à intensidade da banda referente ao ferro. A mesma normalização é feita para todos os outros espectros de EDX apresentados neste trabalho.

Figura 32 - Espectros de EDX das amostras de NPM de FePt.

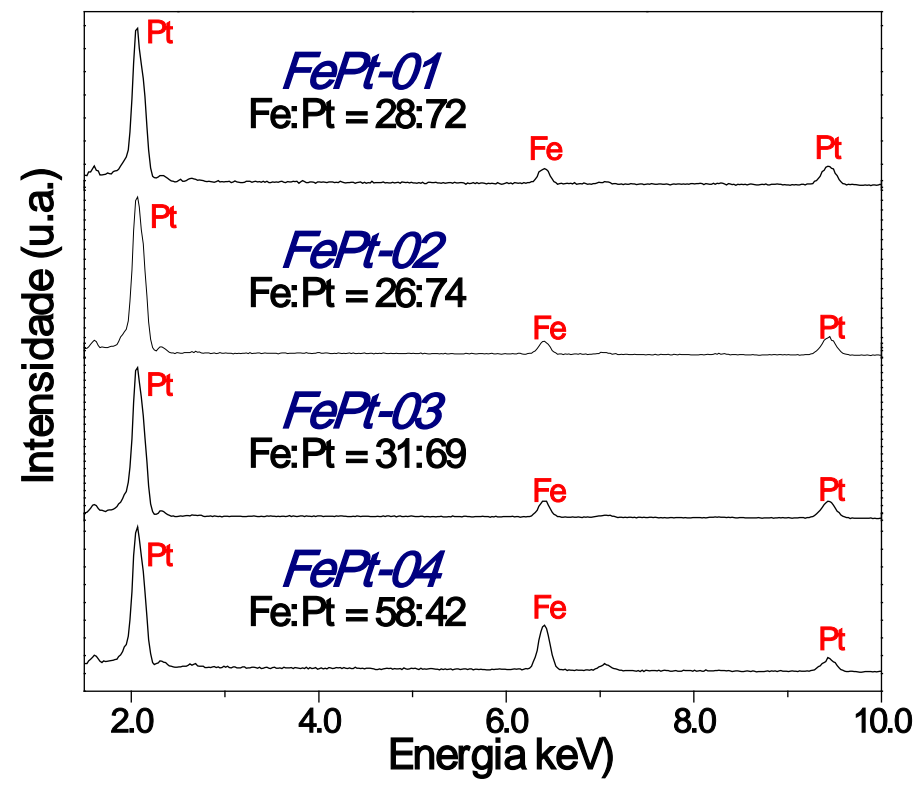

Fonte: Autoria própria.

Tabela 10 - Análise de EDX mostrando a composição relativa entre os elementos ferro e platina presentes nas amostras de NPM de FePt.

\begin{tabular}{c|c|c|c|c|c|c|c|c}
\hline \multirow{2}{*}{ Amostra } & \multirow{2}{*}{ Elemento } & \multicolumn{2}{|c|}{ Porcentagem em massa (\%) } & \multicolumn{4}{|c}{ Porcentagem molar (\%) } \\
\cline { 3 - 8 } & & Área 1 & Área 2 & Área 3 & Área 1 & Área 2 & Área 3 & Média \\
\hline \multirow{2}{*}{ FePt-01 } & Fe & 9,10 & 8,92 & 11,70 & 25,92 & 25,50 & 31,63 & $\mathbf{2 7 , 6 8}$ \\
& $\mathrm{Pt}$ & 90,90 & 91,08 & 88,30 & 74,08 & 74,50 & 68,37 & $\mathbf{7 2 , 3 2}$ \\
\hline \multirow{2}{*}{ FePt-02 } & $\mathrm{Fe}$ & 9,04 & 9,49 & 9,10 & 25,77 & 26,81 & 25,90 & $\mathbf{2 6 , 1 6}$ \\
& $\mathrm{Pt}$ & 90,96 & 90,51 & 90,90 & 74,23 & 73,19 & 74,10 & $\mathbf{7 3 , 8 4}$ \\
\hline \multirow{2}{*}{ FePt-03 } & $\mathrm{Fe}$ & 12,28 & 10,95 & 11,62 & 32,85 & 30,05 & 31,47 & $\mathbf{3 1 , 4 6}$ \\
& $\mathrm{Pt}$ & 87,72 & 89,05 & 88,38 & 67,15 & 69,95 & 68,53 & $\mathbf{6 8 , 5 4}$ \\
\hline \multirow{2}{*}{ FePt-04 } & $\mathrm{Fe}$ & 27,89 & 28,05 & 27,91 & 57,46 & 57,66 & 57,48 & $\mathbf{5 7 , 5 3}$ \\
& $\mathrm{Pt}$ & $\mathbf{7 2 , 1 1}$ & $\mathbf{7 1 , 9 5}$ & 72,09 & 42,54 & 42,34 & 42,52 & $\mathbf{4 2 , 4 7}$ \\
\hline
\end{tabular}

Fonte: Autoria própria.

Como é possível observar em todos os espectros da Figura 32, as bandas observadas em 2,0 keV e 9,4 keV são atribuídas respectivamente às linhas $M \alpha$, L $\alpha$ da platina, enquanto que a linha $\mathrm{K} \alpha$ do ferro aparece em 6,4 keV. A análise semi-quantitativa da composição química da 
amostra é possível pela comparação relativa entre as áreas totais abaixo das bandas referentes ao ferro e à platina, a qual é proporcional à quantidade presente de cada um desses metais na amostra. As composições Fe:Pt observadas para as amostras FePt-01, FePt-02 e FePt-03 foram, respectivamente $28: 72$, 26:74 e 31:69. Em vários trabalhos encontrados na literatura(95-97) é reportada a obtenção de NP com composição ao redor de Fe:Pt $=30: 70$, sendo nos mesmos reportada a grande estabilidade da liga FePt com esta composição. Diante disso é possível inferir que o simples ajuste das quantidades relativas entre os dois precursores metálicos pode não ser o único parâmetro da síntese a ser analisado na tentativa de ajuste composicional das amostras. Outros parâmetros, tais como temperatura de adição dos reagentes, patamares e taxas de aquecimento, poderiam também ter influência sobre a composição do material obtido ao final da síntese. A substituição do solvente benziléter $\left(T_{e b}=298^{\circ} \mathrm{C}\right)$ por octiléter $\left(T_{e b}=287^{\circ} \mathrm{C}\right)$ resultou em uma composição muito próxima da desejada (Fe:Pt $=58: 42$, amostra FePt-04). Isso indica que a falta de controle composicional das sínteses deve estar relacionado à natureza do solvente e não à temperatura de reação. Conforme será tratado mais adiante, o octiléter mostrou-se também mais eficiente que o benziléter no preparo de NPM de FeCo, sendo tal observação creditada à presença de impurezas de menor temperatura de ebulição no solvente benzílico. Assim, tais impurezas podem estar reagindo com parte dos íons $\mathrm{Fe}^{3+}$ presentes no meio, formando intermediários indesejados e impedindo a total incorporação do ferro às amostras.

\subsubsection{Nanopartículas de FeAg}

Trabalhos da literatura mostram que, na ausência do precursor de platina, a síntese via decompostição térmica não leva à formação de ferro metálico, mas de óxido de ferro.(98) Conforme descrito anteriormente, a platina atua como uma espécie de "catalisador heterogêneo", auxiliando a completa redução dos íons $\mathrm{Fe}^{3+}$ a $\mathrm{Fe}^{0}$. Ainda, a presença da platina na composição das NPM de FePt confere estabilidade ao ferro metálico de forma que a fase fcc-FePt permanece estável por longos períodos de tempo. Entretanto, o alto custo dos precursores de platina encarece o processo de produção. Por isso, parte desse trabalho de doutorado se focou na síntese de NPM de FeAg, buscando substituir a platina por outro metal nobre de menor custo. Para isso, o método de síntese empregado para as NPM de FePt foi repetido substituindo-se o $\mathrm{Pt}(\mathrm{acac})_{2}$ por precursores de prata. A possibilidade de sucesso na síntese fundamenta-se por ambos os metais nobres possuírem grande estabilidade na estrutura $f c c$, bem como valores relativamente próximos de potenciais-padrão de eletrodo $(+1,2 \vee$ e $+0,80 \vee$, respectivamente 
para Pt e Ag). Tal proximidade possibilitaria a redução de $\mathrm{Ag}^{+}$a $\mathrm{Ag}^{0}$ por redutores dióis como o HDD, haja vista seu sucesso na redução $\mathrm{Pt}^{2+}$ a $\mathrm{Pt}^{0}$ nas sínteses de FePt. Além do menor custo da prata, outro fator motivante para a substituição da platina é sua já conhecida propriedade bactericida, sendo esta uma funcionalidade adicional do material às almejadas aplicações biomédicas. O objetivo do método é a obtenção de pequenos núcleos de prata sobre os quais espécies oxidadas de ferro possam ser reduzidas a sua forma metálica e serem incorporados ao núcleo de prata. Assim, a exemplo do observado para as NPM de FePt, espera-se que a Ag confira estabilidade química ao ferro em sua forma metálica no interior da liga FeAg, possibilitando a obtenção de partículas altamente magnéticas e quimicamente estáveis de FeAg.

Inicialmente duas sínteses foram realizadas usando o mesmo método empregado para as NPM de FePt. Dois precursores de Ag foram testados: acetato de prata e nitrato de prata (amostras FeAg-01 e FeAg-02, respectivamente). Um segundo método, baseado em trabalhos de Liu et al. foi testado na presença de $\mathrm{Fe}(\mathrm{acac})_{3}$ e utilizando acetato de prata como precursor. (99) Para a primeira amostra, o precursor de ferro foi adicionado no início da síntese (FeAg-03). Já para a amostra $\mathrm{FeAg}-04$, o $\mathrm{Fe}(\mathrm{acac})_{3}$ foi adicionado durante o patamar de temperatura de $150^{\circ} \mathrm{C}$. Visando melhorar a magnetização do produto final, os precursores metálicos foram adicionados para obter partículas com composição $\mathrm{Fe}: \mathrm{Ag}=80: 20$. A análise por EDX das 4 amostras (Figura 33) acusou as composições atômicas Fe:Ag de 75:25, 79:21, 73:27 e 65:35 respectivamente para as amostras de FeAg-01 a FeAg-04, indicando que ambos os metais foram incorporados à amostras em uma proporção próxima à composição nominal usada entre seus precursores.

Figura 33 - Espectros EDX obtidos para as amostras FeAg-01, FeAg-02, FeAg-03 e FeAg-04 indicando as respectivas composições relativas entre $\mathrm{Fe}$ e $\mathrm{Ag}$ presentes nas amostras.

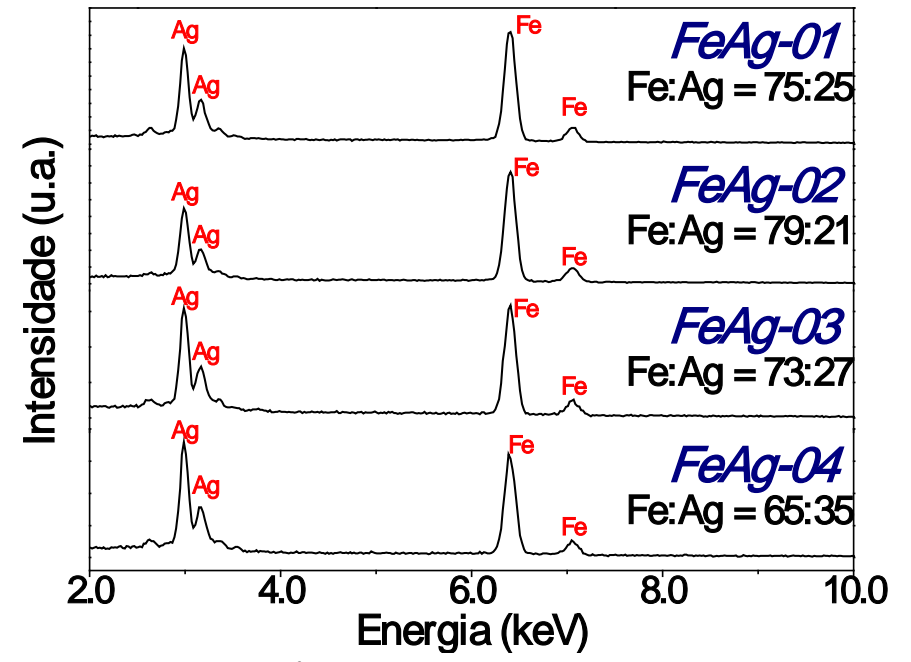

Fonte: Autoria própria. 
Na Figura 34, os difratogramas das quatro amostras são compostos por nove picos em regiões relativamente próximas aos picos característicos da fase $\mathrm{Ag}_{3} \mathrm{Fe}_{2}$ (padrão JCPDS 49-1287). Entretanto, a relação das intensidades relativas entre os picos gerou uma dúvida quanto à obtenção da referida fase: a reflexão do plano (440) centrada em $62,3^{\circ}$ em $2 \theta$, deveria apresentar a maior intensidade enquanto que as cinco reflexões centradas em 35,2, 38,1, 42,9, 64,8 e 77,6 deveriam apresentar intensidades similares. Na verdade, as posições e intensidades relativas entre todos os picos que compõem os difratogramas indicam a obtenção de uma mistura entre as fases $f c c$ da prata metálica e espinélio invertido da magnetita. Ainda, principalmente para as amostras obtidas em benziléter, os picos característicos da fase $f c c-A g$ apresentam claramente um menor alargamento comparado ao alargamento dos picos relativos à fase $\mathrm{Fe}_{3} \mathrm{O}_{4}$, o que indica que ferro e prata presentes na amostra devam estar segregados, e não na forma de liga. Tal afirmação pode ser visivelmente observada analisando as imagens de MET da Figura 35.

Figura 34 - DRX das amostras de FeAg-01 a FeAg-04 comparadas aos padrões JCPDS ds fases fcc$\mathrm{Ag}, \mathrm{Fe}_{3} \mathrm{O}_{4}, \mathrm{Ag}_{2} \mathrm{O}$ e $\mathrm{Ag}_{3} \mathrm{Fe}_{2}$.

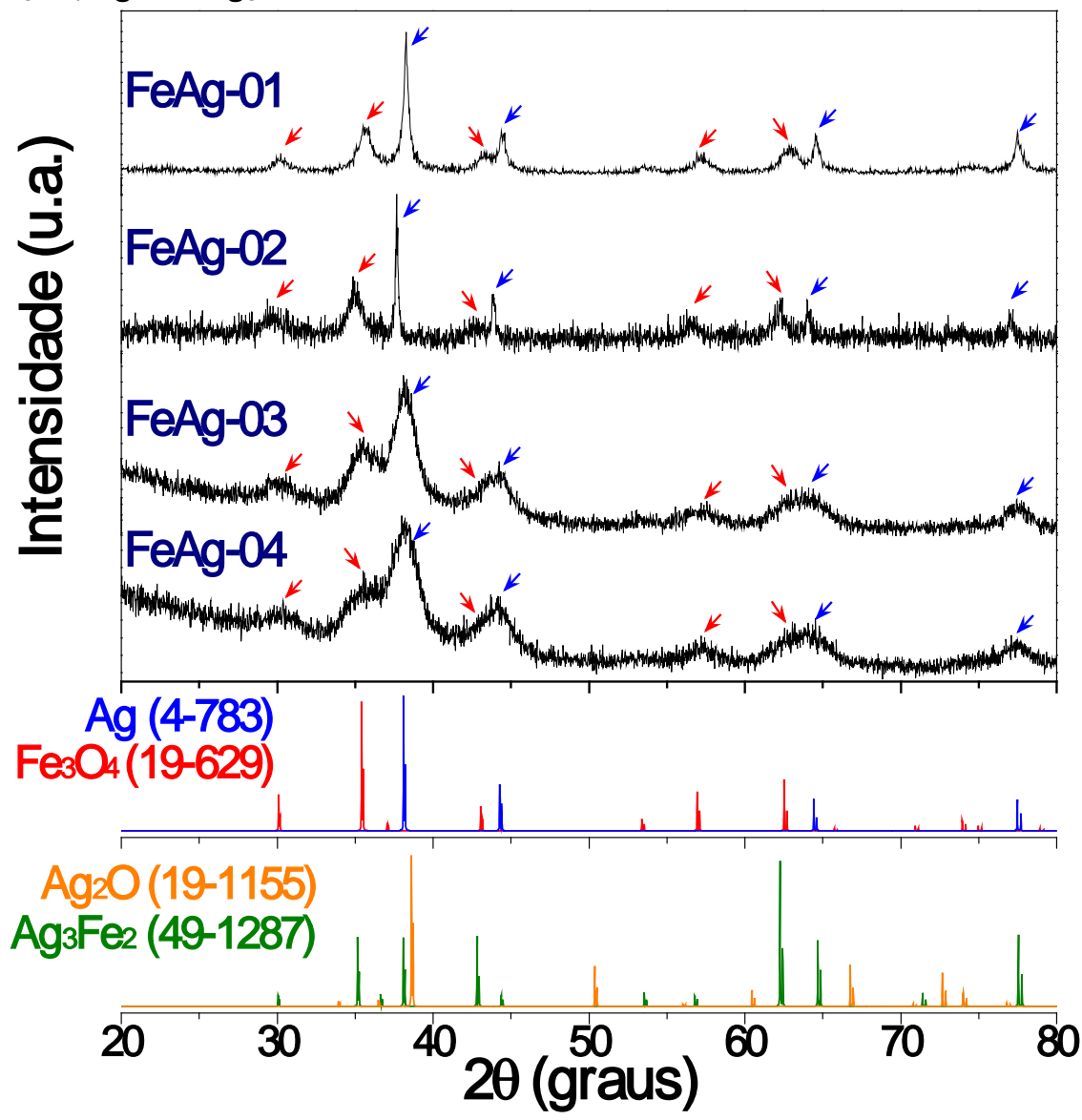

Fonte: Autoria própria. 
Figura 35 - Imagens de MET das amostras FeAg-01 a FeAg-04 juntamente com seus respectivos histogramas de contagem de partículas.

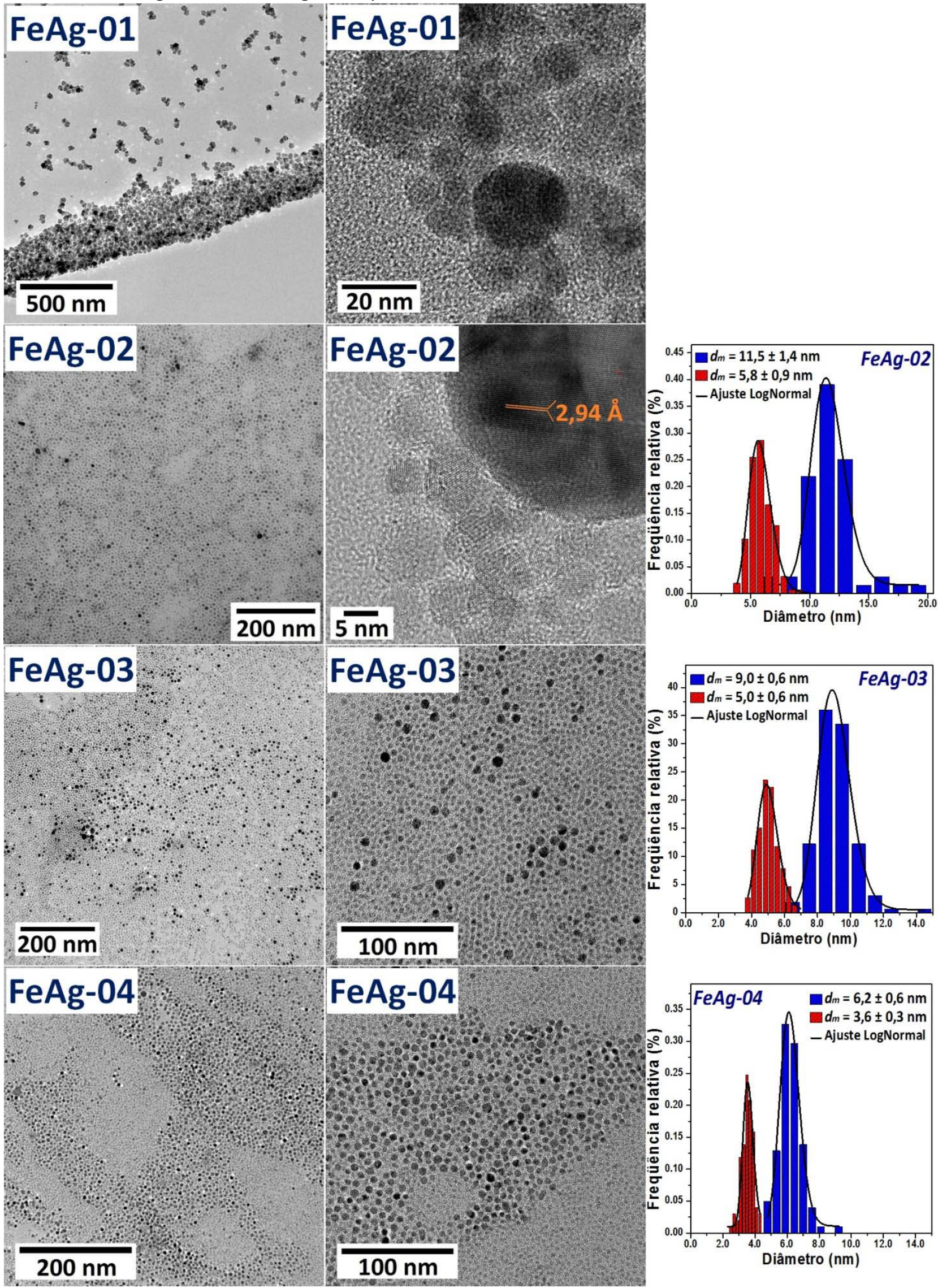

Fonte: Autoria própria. 
Confirmando os dados de DRX, as imagens de MET mostram duas populações de nanopartículas, o que é evidenciado pela observação de partículas com diferentes distribuições de tamanho e contrastes de imagem para uma mesma amostra. Comparando as duas amostras sintetizadas em benziléter, o precursor $\mathrm{AgNO}_{3}$ parece proporcionar um maior controle morfológico, uma vez que a amostras FeAg-02 é composta somente por partículas esféricas divididas em duas distribuições de tamanho: $11,5 \pm 1,4 \mathrm{~nm}$ e $5,8 \pm 0,9$. As partículas com maior diâmetro médio, dado seu maior contraste, são compostas pela fase $f c c-A g$, a qual possui uma maior densidade eletrônica comparada à magnetita, fase esta que compõe as partículas de $6 \mathrm{~nm}$.

Com relação às amostras sintetizadas na mistura octadeceno-oleilamina, observa-se que, apesar da presença de duas distribuições de nanopartículas com diferentes composições, o método empregado proporcionou um maior controle de tamanho e forma para ambos os tipos de partículas, uma vez que nanopartículas monodispersas de $\mathrm{Ag}$ e de $\mathrm{Fe}_{3} \mathrm{O}_{4}$ foram obtidas nos dois casos. É interessante observar que, mesmo na ausência de redutores dióis, partículas de Ag metálica foram formadas, o que mostra o caráter redutor já relatado na literatura para a oleilamina (OAm).(100) Ainda, quando o ferro é adicionado desde o início da síntese (FeAg-03), partículas de $\mathrm{Ag}$ e de $\mathrm{Fe}_{3} \mathrm{O}_{4}$ com maior diâmetro médio (9,0 e 5,0 nm, respectivamente) são obtidas com relação às partículas obtidas quando o ferro é adicionado somente após o patamar de temperatura em $150^{\circ} \mathrm{C}(6,2$ e $3,6 \mathrm{~nm})$. Essa diferença de tamanhos deve estar relacionada a um efeito do surfactante. Para a amostra $\mathrm{FeAg}-03$, a presença de íons $\mathrm{Ag}^{+}$e $\mathrm{Fe}^{3+}$ resulta em uma menor razão surfactante/metais, o que significa que toda a oleilamina disponível deve se dividir para atuar nos processos de formação das nanopartículas de $\mathrm{Ag}$ e de $\mathrm{Fe}_{3} \mathrm{O}_{4}$. Já para a amostra FeAg-04, a OAm atua exclusivamente sobre os íons $\mathrm{Ag}^{+}$no início da síntese. Quando o precursor de ferro é posteriormente adicionado junto ao surfactante ácido oleico (AO), essa mistura de surfactantes $\mathrm{OAm} / \mathrm{AO}$ passa a atuar no processo de formação das partículas de $\mathrm{Fe}_{3} \mathrm{O}_{4}$. Dessa forma, durante a fase de nucleação, uma maior quantidade de surfactante está disponível para atuar na superfície das partículas recém-formadas, atuando como uma barreira no processo de crescimento e resultando em nanopartículas com menores dimensões.

O maior diâmetro das nanopartículas de $\mathrm{Ag}$ comparadas às de magnetita indicam uma considerável diferença entre as temperaturas de nucleação das fases magnetita e fcc-Ag. Indicam ainda que a nucleação da fase magnetita deva se iniciar após a nucleação e crescimento das NP de Ag. Quanto menor as dimensões das nanopartículas que compõem um sistema, maior a energia livre de superfície $\left(\Delta G_{S}\right)$ do sistema. Para diminuir $\Delta G_{S}$, os monômetros (pequenos clusters contendo o metal de interesse) presentes no meio reacional têm uma maior afinidade 
pela superfície da partícula, o que promove seu crescimento. Nas tentativas de obtenção da fase $\mathrm{FeAg}$, as partículas de Ag formadas possuem dimensões relativamente grandes, o que diminui a afinidade dos monômeros (clusters de espécies oxidadas de ferro que darão origem à fase de óxido de ferro) pela superfície da prata, dando origem à partículas segregadas de magnetita. Diante disso, acredita-se que utilizando NP de Ag com dimensões extremamente reduzidas como sementes no processo de crescimento mediado por sementes evitaria a formação de NP de magnetita, pois o crescimento de uma camada desse óxido sobre a superfície das NP de Ag seria preferencial no sentido de diminuir a $\Delta \mathrm{G}_{\mathrm{s}}$ do sistema. Essa discussão está de acordo com a Teoria Clássica de Nucleação, a qual é muito relatada na literatura para compreensão da formação de muitos sistemas particulados.(101)

Embora a presença de duas fases segregadas seja observada em todas as amostras, as técnicas de caracterização empregadas não garantem se todo o ferro está na forma de óxido. Uma parcela deste elemento poderia estar presente na estrutura cristalina da $\mathrm{Ag}$, formando uma liga metálica rica em Ag. De fato, o difratograma da amostra FeAg-02 apresenta um deslocamento de $0,5^{\circ}$ em 3 picos característicos da fase $f c c-\mathrm{Ag}$ para menores valores de $2 \theta$ com relação ao padrão JCPDS 4-783. Tal deslocamento poderia ser explicado pela presença de átomos de ferro em posições intersticiais da rede cristalina da prata metálica, o que causaria uma expansão da rede, resultando em aumento dos parâmetros de rede e, consequentemente, das posições dos picos de DRX. A imagem de alta resolução da amostra FeAg-02 mostra uma NP com alto contraste de imagem rodeada por NP menores. A partícula maior e mais escura mostra planos cristalinos cuja medida da distância interplanar $(d)$ é $d=2,94 \AA$. É interessante ressaltar que o maior valor de $d$ encontrado para a estrutura fcc-Ag ocorre para o plano [111], cujo valor é 2,359 ̊̊ (JCPDS 4-783). No entanto, a distância interplanar medida encontra-se próximo aos valores 2,970 e $2,967 \AA$, os quais correspondem ao plano [220] das respectivas fases cristalográficas $\mathrm{Ag}_{3} \mathrm{Fe}_{2}$ e $\mathrm{Fe}_{3} \mathrm{O}_{4}$. Tal observação indica que uma parcela do ferro da amostra pode estar presente na forma de liga.

O comportamento magnético das amostras obtidas em benziléter foi investigado por VSM. As curvas de magnetização da Figura 36 indicam um comportamento superparamagnético para ambas as amostras, com respectivos valores de magnetização de saturação de 41,5 e 44,6 emu $\mathrm{g}^{-1}$ e coercividade desprezível, 30 e 27 Oe, respectivamente. A ausência de descontinuidades nas curvas indica o comportamento de uma única fase magnética que, embora não seja totalmente conclusiva, é mais um indicativo da obtenção de fases segregadas de $f c c-\mathrm{Ag}$ e $\mathrm{Fe}_{3} \mathrm{O}_{4}$, sendo o magnetismo das amostras creditado à magnetita. 
Figura 36 - Curvas de histerese magnética obtidas à temperatura ambiente para as amostras FeAg-01 e FeAg-02. Em destaque, uma ampliação da região central das curvas.

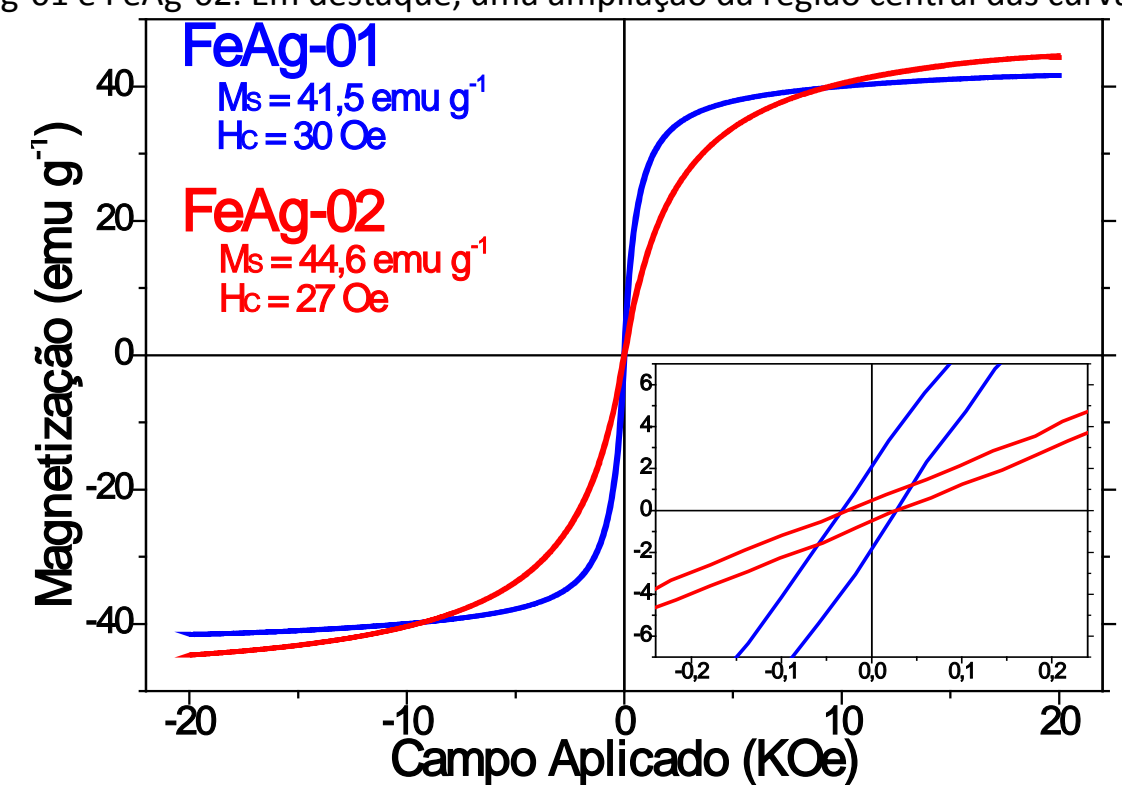

Fonte: Autoria própria.

Embora NP monodispersas de FeAg ainda não foram obtidas, somente a proporção Fe:Ag $=80: 20$ foi testada. De fato, considerando que a estrutura cristalina da prata forma-se antes da nucleação da fase magnetita e diante do maior raio atômico da prata $\left(R_{\text {calculado }}=1,65 \AA\right)$ com relação ao ferro $\left(R_{\text {calculado }}=1,56 \AA\right.$ ), (93) dificilmente a estrutura cristalina da prata seria capaz de abrigar uma carga tão alta de ferro como a empregada nas sínteses. Ainda, temperaturas de $300^{\circ} \mathrm{C}$ são insuficientes para a transição entre as fases cúbica de face centrada da prata $\mathrm{Ag}$ e cúbica de corpo centrado (bcc, do inglês body-centered cubic) do ferro de modo que a estrutura cristalina do ferro pudesse abrigar uma composição de $20 \%$ de prata. Assim, o aumento da composição em prata das partículas (60\%, por exemplo) poderia facilitar a formação da fase $\mathrm{Ag}_{3} \mathrm{Fe}_{2}$ almejada. Uma segunda possibilidade seria recobrir nanopartículas de $\mathrm{Ag}$ com óxido de ferro seguida de tratamento térmico em atmosfera redutora para obtenção da liga FeAg. Para a realização do recobrimento poderia ser utilizado o método de crescimento mediado por semente, que se mostrou eficiente para o recobrimento de NPM de FePt. $(43,98)$ As duas possibilidades são tratadas como perspectivas para futuros trabalhos do grupo.

\subsubsection{Nanopartículas de FeCo}

As sínteses de FeCo foram realizadas utilizando os precursores metálicos em uma proporção que levasse à obtenção de NP com composição Fe:Co $=60: 40$. Esta proporção foi 
escolhida porque trabalhos da literatura relatam que a mesma apresenta maiores valores de $M_{s}$ quando comparados com NP com composição equimolar.(102)

NP de FeCo foram sintetizadas via decomposição térmica de precursores $\mathrm{Fe}(\mathrm{acac})_{3} \mathrm{e}$ Co(acac) 2 , a partir de modificações de trabalhos de Chaubey et al.(102) Esta síntese foi realizada em atmosfera redutora de $\mathrm{H}_{2}$, haja vista que trabalhos da literatura indicam que compostos 1,2alcanodióis não são capazes de reduzir cátions $\mathrm{Fe}^{3+}$ e $\mathrm{Co}^{2+}$ para suas formas metálicas. A principal variável entre as 3 amostras sintetizadas foi o solvente: benziléter, octiléter e benziléter purificado foram respectivamente empregados paras as amostras FeCo-01, FeCo-02 e FeCo-03.

Figura 37 - Difratogramas obtidos para as amostras FeCo-01, FeCo-02, FeCo-03 e FeCo-04. Na parte inferior do gráfico são apresentados os padrões de difração JCPDS das fases cristalográficas $\alpha$-Fe (vermelho), FeCo (azul) e $\mathrm{CoFe}_{2} \mathrm{O}_{4}$ (verde).

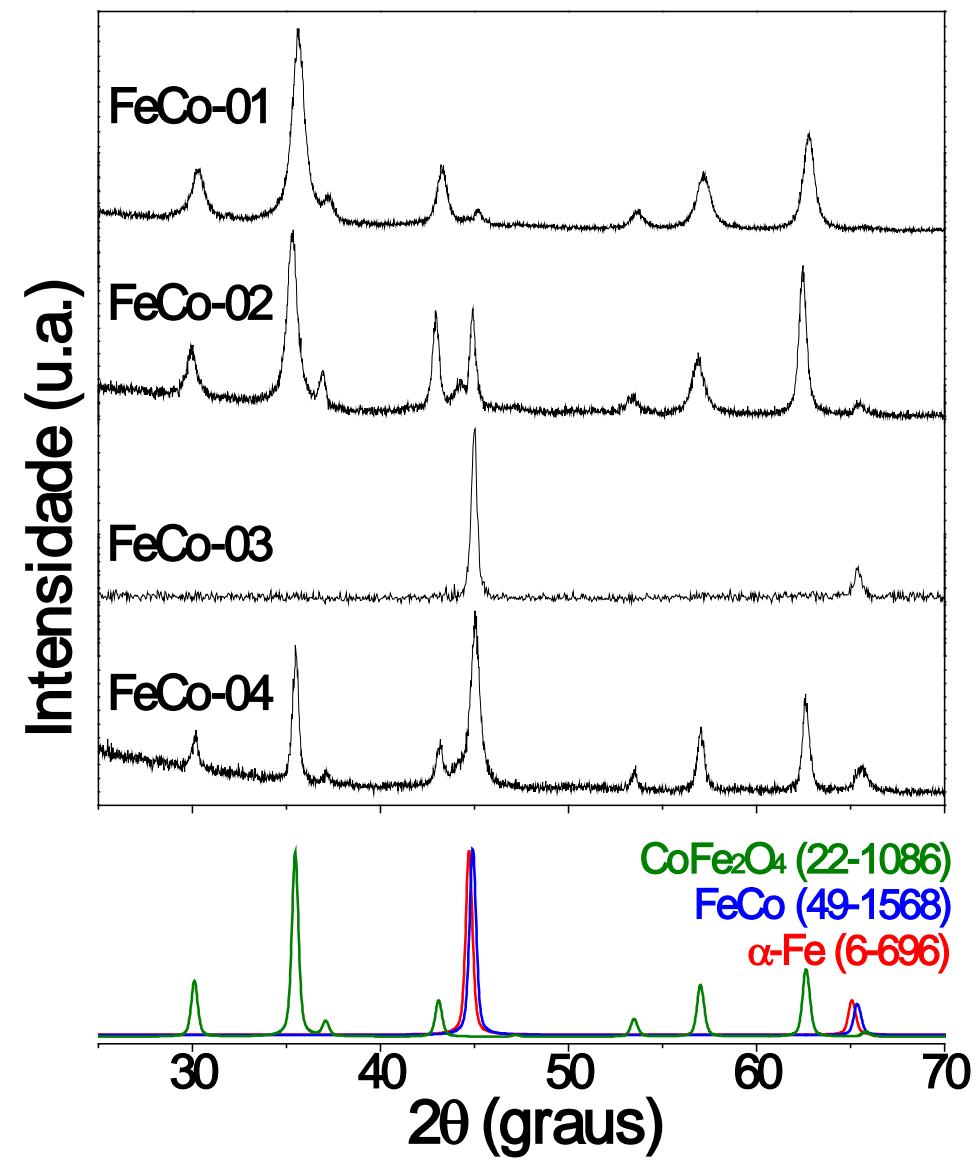

Fonte: Autoria própria.

Diferentemente do observado para as NP de FePt, a análise por DRX indicou a obtenção de uma mistura de fases para a amostra FeCo-01. Conforme pode ser observado no primeiro difratograma da Figura 37 , os picos centrados em $30,3,35,6,43,3,53,7,57,2$ e $62,8^{\circ}$ em $2 \theta$ referem-se respectivamente aos planos (220), (311), (440), (422), (511) e (440) da estrutura espinélio inverso da ferrita de cobalto $\left(\mathrm{CoFe}_{2} \mathrm{O}_{4}\right) \cdot(103,104)$ Já o pequeno pico em $45,2^{\circ}$ em $2 \theta$ 
refere-se ao plano (110) da fase bcc-FeCo. Esta fase cristalográfica apresenta grande similaridade com a fase $\alpha-F e$, com os picos levemente deslocados para maiores valores de $2 \theta$ devido ao menor raio atômico do cobalto $\left(R_{\text {calculado }}=1,52 \AA\right)$ com relação ao raio do ferro $\left(R_{\text {calculado }}=1,56\right.$ Å).(93)

Durante a síntese da amostra FeCo-01 foi observada a condensação de um líquido incolor nas paredes do balão de reação em temperaturas próximas a $90-100^{\circ} \mathrm{C}$, o qual aparentemente era água. Por isso, a amostra FeCo-02 foi sintetizada utilizando como solvente $10 \mathrm{~mL}$ de benziléter previamente tratado a $90^{\circ} \mathrm{C}$ sob vácuo por 24 horas. Este tratamento teve como objetivo eliminar qualquer quantidade de água ou outras impurezas voláteis que pudessem estar presentes na composição do benziléter. Comparando-se as amostras FeCo-01 e FeCo-02 pode-se afirmar que, embora a fase $\mathrm{CoFe}_{2} \mathrm{O}_{4}$ ainda esteja presente, a utilização de benziléter purificado foi positiva para a obtenção da fase FeCo (amostra FeCo-02), uma vez que um claro aumento na intensidade relativa do pico em $45,2^{\circ}$ e o surgimento de um pequeno pico em $65,4^{\circ}$ são observados. Esses dois picos são atribuídos às reflexões dos planos (110) e (200) da fase bccFeCo. A prévia purificação do benziléter também é reportada em outros trabalhos de síntese de NP.(105) O mesmo não ocorre para o octiléter, outro solvente amplamente reportado em sínteses de NP via decomposição térmica. Para analisar a efeito do solvente sobre a fase obtida, substituiu-se o benziléter por octiléter na síntese das amostras FeCo-03 e FeCo-04.

O difratograma da amostra FeCo-03 indica a obtenção somente da fase bcc-FeCo, com as reflexões dos planos (110) e (200) centrados respectivamente em 45,0 e 65,4 em $2 \theta$. A presença dessa única fase na amostra indica que o octiléter é o solvente mais adequado para a síntese de NPM de FeCo. Cabe lembrar que este mesmo solvente também mostrou-se mais eficiente no controle composicional de NPM de FePt.

Considerando que a amostra FeCo-03 foi preparada sob fluxo de gás $\mathrm{H}_{2}$, sendo este um redutor muito mais forte que o HDD, o mesmo procedimento experimental foi repetido na ausência do diol (amostra FeCo-04). Na ausência do redutor diol, novamente uma mistura das fases $\mathrm{CoFe}_{2} \mathrm{O}_{4}$ e FeCo foi obtida, o que indica que o diol possui um papel importante no processo de redução para formação da fase FeCo ou mesmo na estabilização dessa fase após a formação da NP. Entretanto, tal papel ainda não pôde se elucidado.

As amostras FeCo-03 e FeCo-04 tiveram a morfologia e tamanho de suas NPM analisadas por MET (Figura 38). Embora a análise por DRX tenha indicado sucesso na obtenção da fase FeCo, nenhuma das amostras analisadas apresentou homogeneidade de morfologia e tamanho. As imagens da amostra FeCo-03 mostram NP aproximadamente cúbicas com dimensões entre 100 e 
$180 \mathrm{~nm}$ juntamente com NP esféricas de menores dimensões, das quais uma análise estatística resulta em um diâmetro médio de $12,7 \mathrm{~nm}(\sigma=11,7 \%)$. Da mesma forma, a amostra FeCo-04 é composta por duas distribuições de tamanho onde partículas com morfologia irregular e dimensões ao redor de $100 \mathrm{~nm}$ coexistem com NP esferoidais com diâmetro médio de 12,2 nm ( $\sigma$ = 15,5\%). É importante observar para ambas as amostras que as partículas menores tendem a se posicionar preferencialmente nas imediações nas partículas maiores, o que indica a existência de uma força de atração entre as mesmas. Tal força é um indicativo do caráter ferromagnético da amostra, o qual deve-se principalmente às elevadas dimensões de uma parcela das partículas que compõem cada amostra, com tamanho acima do diâmetro crítico do superparamagnetismo $\left(d_{c}=23,6 \mathrm{~nm}\right.$ à temperatura ambiente) para NP de FeCo.(106)

Figura 38 - Imagens obtidas por MET para as amostras FeCo-03 e FeCo-04 juntamente com seus respectivos histogramas de contagem de NP.
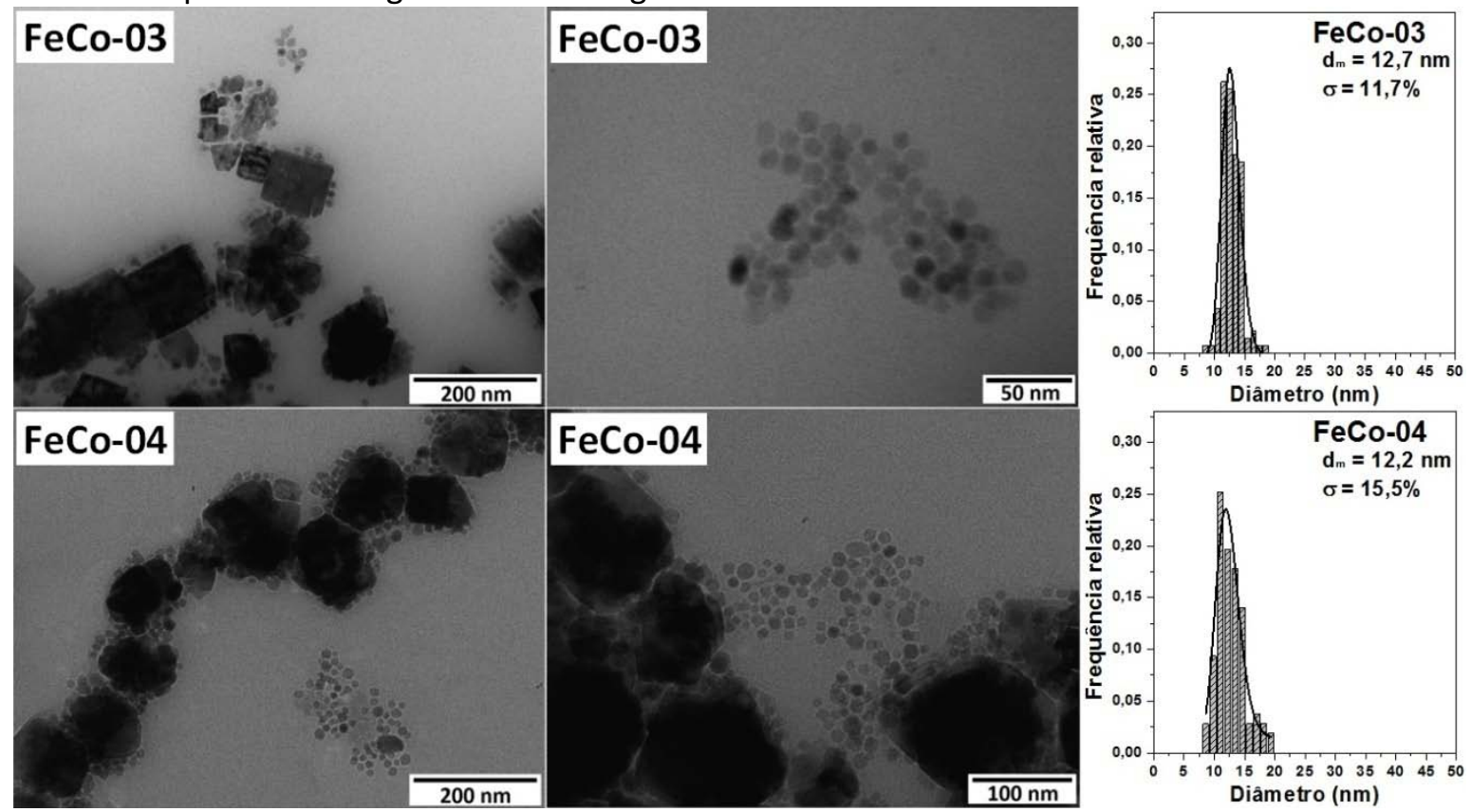

Fonte: Autoria própria.

A composição entre os dois metais presentes nas amostras foi analisada de forma semiquantitativa por EDX (Figura 39). Os espectros EDX obtidos para todas as amostras de FeCo apresentam 3 bandas centradas em 6,4, 6,9 e 7,6 keV, as quais são relativas, respectivamente, às linhas $K \alpha$ do ferro e $K \alpha$ e $K \beta$ do cobalto. Na realizada, a banda centrada em 6,9 keV corresponde à possível sobreposição entre as linhas $\mathrm{K} \alpha$ do cobalto (em 6,9 keV) e $\mathrm{K} \beta$ do ferro (em 7,1 keV). A partir da integração das banda foi possível obter de maneira semi-quantitativa, as composições relativas entre ferro e cobalto de cada amostra. As composições Fe:Co obtidas respectivamente para as amostras de FeCo-01 a FeCo-04 são 80:20, 61:39, 62:38 e 58:42. Considerando a 
composição almejada (Fe:Co $=60: 40$ ), a amostra FeCo-01 apresentou o pior controle composicional entre as amostras analisadas. Tal observação, a exemplo dos resultados obtidos para as NPM de FePt, mostra que o benziléter não é eficiente quanto ao controle de composição dos produtos. Entretanto, a purificação deste solvente levou à composição muito próxima à nominal, o que indica que impurezas voláteis presente no solvente são as responsáveis pelo baixo controle observado.

Figura 39 - Espectros de EDX obtido para as amostras de NP de FeCo.

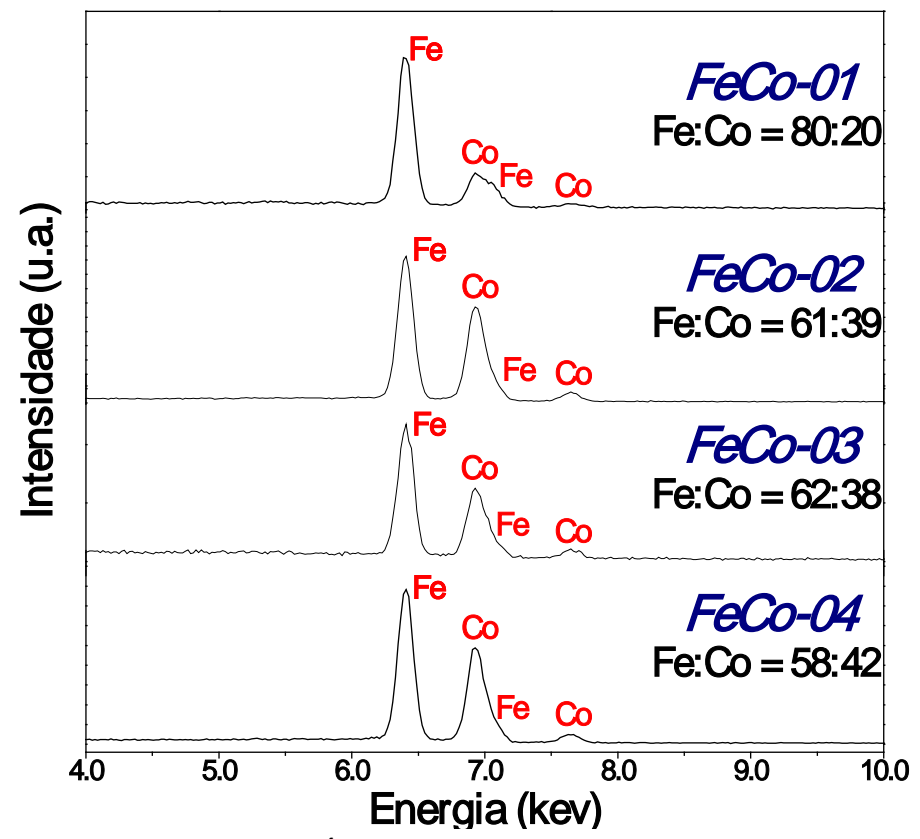

Fonte: Autoria própria.

Na Figura 40, as curvas de magnetização das amostras de FeCo-02, FeCo-03 e FeCo-04 mostram a existência de uma pequena histerese magnética para as três amostras analisadas. Os respectivos valores de coercividade medidos para tais amostras são 0,36, 0,29, e 0,44 kOe, o que indica um pequeno caráter ferromagnético. Dado que a transição entre o comportamento ferromagnético e superparamagnético de um material é dependente do tamanho das partículas que o constitui, o ferromagnetismo observado pode estar relacionado à grande polidispersividade das amostras, as quais possuem partículas com dimensões tanto acima quanto abaixo do diâmetro crítico do superparamagnetismo da fase FeCo $\left(d_{c}=23,6 \mathrm{~nm}\right)$.(106) Embora aplicações biomédicas e catalíticas de NPM tenham preferência por NP superparamagnéticas, alguns trabalhos na literatura reportam o interesse por materiais com um pequeno caráter ferromagnético, os quais tendem a apresentar um maior potencial de aquecimento para aplicações de hipertermia magnética anti-câncer, sendo este potencial diretamente proporcional 
à frequência do AMF aplicado.(107,108) Assim, acredita-se que NP de FeCo com dimensões entre 20 e 30 nm sejam ideais para tal aplicação.

Figura 40 - Curvas de histerese magnética obtidas à temperatura ambiente para as amostras de NP de FeCo. As curvas referem-se às amostras como sintetizadas, sem normalização por sua massa magnética. Em destaque, uma ampliação da região central das curvas.

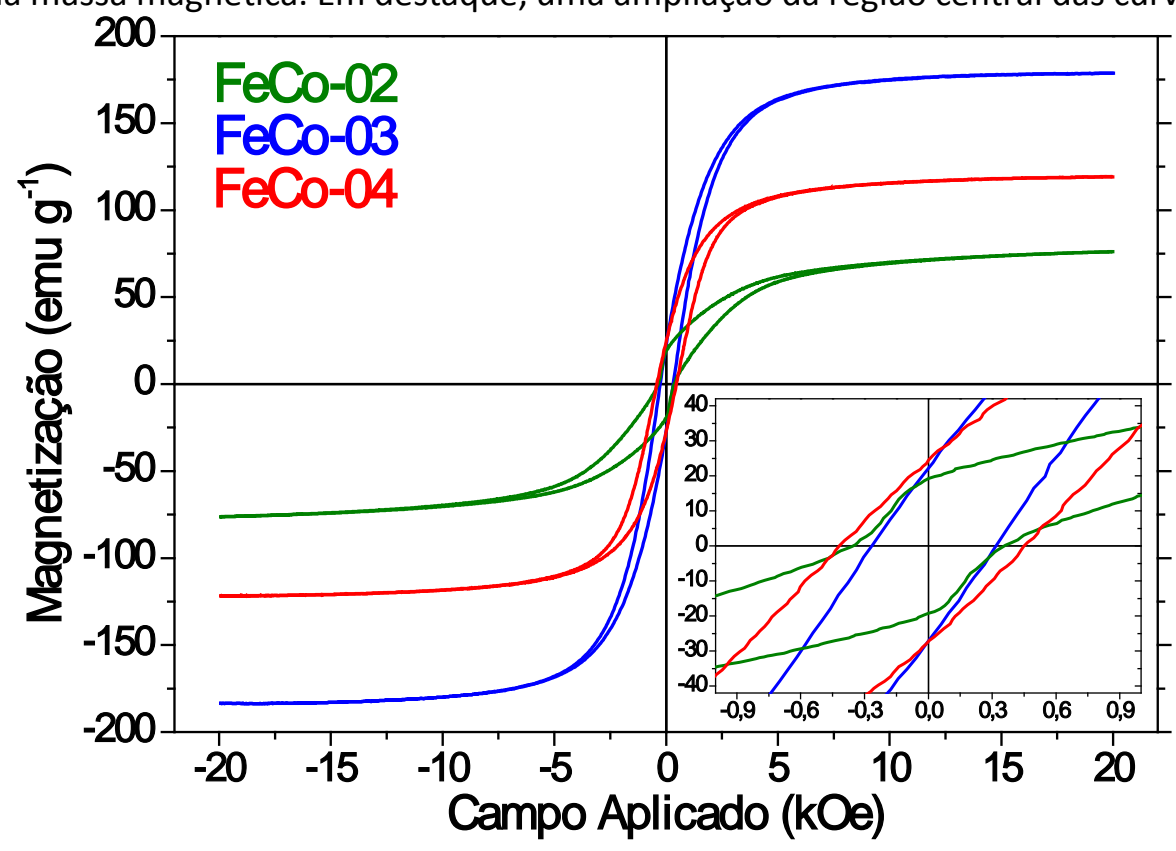

Fonte: Autoria própria.

A amostra FeCo-03 apresentou o maior valor de magnetização de saturação entre todas as amostras analisadas, atingindo o valor de 181,2 $\mathrm{emu} \mathrm{g}^{-1}$ (relativamente próximo ao valor 240 emu $\mathrm{g}^{-1}$ característico da liga FeCo em sua forma bulk).(109) A amostra FeCo-02 apresentou o menor valor de $M_{S}\left(76,2\right.$ emu g $\left.^{-1}\right)$, o que já era esperado, haja vista que esta amostra apresentou como fase cristalográfica principal a $\mathrm{CoFe}_{2} \mathrm{O}_{4}$, que assim como outra ferritas, apresenta valores de $M_{s}$ bem inferiores aos normalmente observados para os metais Fe (218 emu g $\left.{ }^{-1}\right)(110)$ e Co $\left(162\right.$ emu $\left.^{-1}\right)(91)$ e para a liga FeCo $\left(240\right.$ emu g $\left.^{-1}\right)$.(109) É importante observar que mesmo a amostra FeCo-02 apresentando o menor valor de $\mathrm{M}_{\mathrm{s}}$, este encontra-se acima do valor reportado para a fase $\mathrm{CoFe}_{2} \mathrm{O}_{4}$ em sua forma bulk $\left(74\right.$ emu g $\left.{ }^{-1}\right),(111)$ mostrando que a fase FeCo têm grande contribuição para o magnetismo da amostra. Ainda com relação à amostra FeCo-02, é possível observar uma descontinuidade em sua curva de histerese em baixos valores do campo magnético aplicado. Tal descontinuidade, melhor observada na ampliação da região central das curvas, que cria uma espécie de "cintura" nas curvas de histereses, é conhecida como wasp waist, e ocorre devido ao acoplamento magnético entre duas ou mais fases magnéticas presentes na amostra,(112) neste caso, $\mathrm{FeCo}$ e $\mathrm{CoFe}_{2} \mathrm{O}_{4}$, conforme já analisado por DRX (Figura 37). A partir dos dados de DRX era possível prever que a amostra FeCo-04 apresentaria $M_{s}$ 
intermediário (120,5 emu $\mathrm{g}^{-1}$ ) entre as amostras FeCo-02 e FeCo-03, uma vez que a amostra apresenta uma maior composição em FeCo comparada à $\mathrm{FeCo}-02$, ainda que a fase $\mathrm{CoFe}_{2} \mathrm{O}_{4}$ esteja presente.

Embora a análise por MET tenha indicado falta de controle morfológico e de tamanho em todos as rotas sintéticas de NP de FeCo empregadas, é importante ressaltar a boa estabilidade contra oxidação apresentada pelas amostras, haja vista que as mesmas foram lavadas, armazenadas e caracterizadas em atmosfera de ar. Conhecendo-se a forte tendência à oxidação dos elementos $\mathrm{Fe}$ e $\mathrm{Co}$ quando na presença de $\mathrm{O}_{2}$, sendo esta tendência ainda mais forte para $\mathrm{NP}$, os resultados aqui apresentados podem ser avaliados positivamente como um avanço, ao qual soma-se ainda o bom controle composicional observado pelas análises de EDX. Trabalhos futuros devem focar nas condições de síntese para melhorar o controle morfológico.

\subsubsection{Nanopartículas sintetizadas em oleilamina}

A oleilamina é um composto quase sempre presente nas sínteses de nanopartículas via sistemas de decomposição térmica. Trata-se de uma alquilamina primária de cadeia longa com fórmula molecular $\mathrm{C}_{18} \mathrm{H}_{37} \mathrm{~N}$ com uma insaturação entre os carbonos 9 e 10 da cadeia. Seu extenso uso justifica-se por ser líquida à temperatura ambiente, o que facilita os processos de purificação das partículas após a síntese, além de apresentar ótima relação custo-benefício, comparada a outras alquilaminas. O composto pode atuar como um doador de elétrons em temperaturas elevadas, sendo esta uma de suas muitas propriedades interessantes. A literatura relata diferentes funções da oleilamina na síntese de nanopartículas, dentre elas a de surfactante, de solvente ou mesmo de agente redutor. Em alguns casos, ela ainda pode atuar como um ligante na complexação de íons metálicos, formando compostos metaestáveis. Uma vez formados, tais compostos passam a atuar como precursores metálicos secundários, alterando as condições de decomposição térmica e de formação da nanopartícula.(100)

Com base em trabalho de $\mathrm{Xu}$ et al.,(113) um procedimento experimental foi executado somente na presença de oleilamina e $\mathrm{Fe}(\mathrm{acac})_{3}$ para a síntese de NPM de óxido de ferro. Entretanto, a análise por DRX da amostra refutou a formação da fase óxido desejada. Uma análise preliminar do difratograma da amostra FeC-01 indicava a formação de uma mistura entre 4 fases de Fe metálico: $\alpha$-Fe, $\gamma$-Fe, $\varepsilon$-Fe e $\delta$-Fe. Entretanto, após a leitura de alguns artigos que relatam o crescente interesse em nanopartículas de carbetos metálicos e as interessantes propriedades apresentadas por esses compostos, as análises de DRX da amostra foram 
analisadas com base na formação de carbeto. O difratograma da amostra FeC-01 (Figura 41) apresenta grande semelhança com o padrão JCPDS de carbeto de ferro ( $\left.\mathrm{Fe}_{3} \mathrm{C}, 76-1877\right)$. Embora o pico principal centrado em $44,8^{\circ}$ seja característico de ambas as fase $\mathrm{Fe}_{3} \mathrm{C}$ e $\alpha$-Fe, a ausência do pico (200) em $65,0^{\circ}$ indica que a amostra não apresenta $\alpha$-Fe em sua composição. Ainda, nenhuma das fases metálicas de ferro possui reflexões em $35,7^{\circ}, 37,7^{\circ}, 39,7^{\circ}, 40,8^{\circ}$ ou $58,2^{\circ}$ em $2 \theta$, as quais são observadas para a amostra $\mathrm{FeC}-01$, sendo também características da fase $\mathrm{Fe}_{3} \mathrm{C}$.

Figura 41 - DRX da amostra FeC-01 ecomparada aos padrões JCPDS das fases $\mathrm{Fe}_{3} \mathrm{C}, \alpha-\mathrm{Fe}, \delta$-Fe, $\varepsilon$ Fe e $\gamma$-Fe.

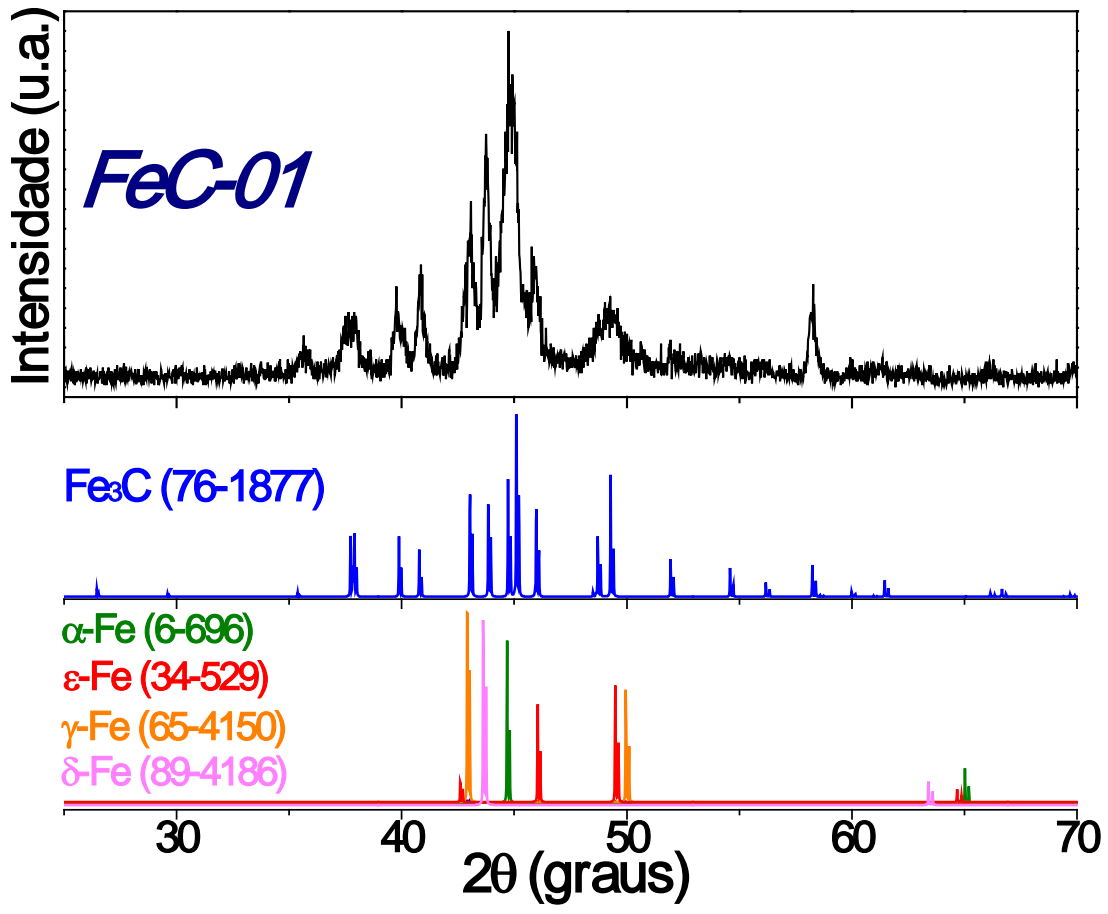

Fonte: Autoria própria.

Figura 42 - Imagens de MET da amostra FeC-01.

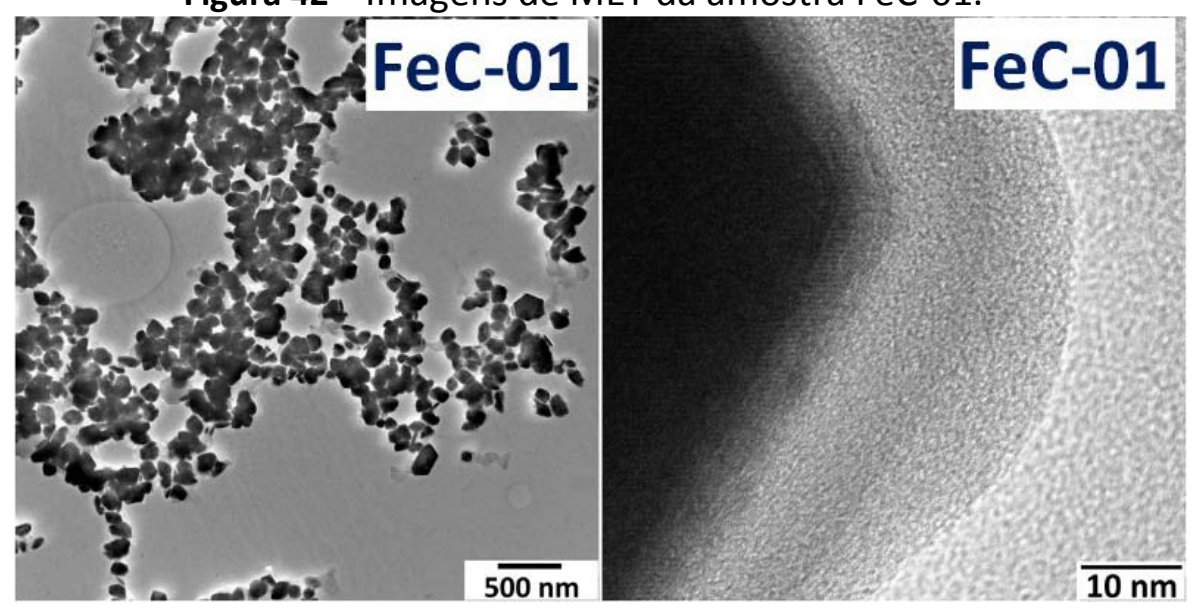

Fonte: Autoria própria. 
A análise de MET (Figura 42) indicou a presença de partículas com morfologia heterogênea, com dimensões no intervalo entre 80 e 250 nm. A imagem de alta resolução mostra uma camada de menor contraste sobre a superfície das partículas, o que acredita-se ser composto por carbono amorfo. A presença dessa camada, além de proporcionar maior estabilidade à fase carbeto, pode ser modificada com grupos funcionais (carboxilato, amina, etc.), o que possibilitaria a posterior funcionalização com biocompostos e/ou compostos catalíticos.

Um grande número de trabalhos da literatura mostram um atual interesse por carbetos metálicos. Tal interesse advém de propriedades diferenciadas desse tipo de material bem como da dificuldade no preparo desse tipo de material em condições brandas de temperatura e pressão.(114) Como exemplo, Pepperhoff e Acet relatam que o processo de obtenção da fase cementita $\left(\mathrm{Fe}_{3} \mathrm{C}\right)$ ocorre a partir do lento resfriamento de ferro fundido, o que requer temperaturas acima de $1260^{\circ} \mathrm{C}$. Isso pode ser observado no diagrama de fases da liga ferrocarbono (Figura 43).(115) Tal observação mostra a importância dos resultados aqui apresentados, uma vez que partículas de carbeto de ferro foram obtidas através de um método de síntese bastante simples e em temperaturas moderadas $\left(340^{\circ} \mathrm{C}\right)$. Isso acabou por motivar o trabalho de mestrado de um integrante de nosso grupo, o qual em sua dissertação encontrou as condições mínimas necessárias para obtenção das partículas de $\mathrm{Fe}_{3} \mathrm{C}$ (refluxo a $340^{\circ} \mathrm{C}$ por 180 minutos).(116) Sínteses realizadas em condições inferiores a essa resultam em NP de óxido de ferro (mistura de $\mathrm{Fe}_{3} \mathrm{O}_{4}$ e $\mathrm{FeO}$ ). Embora este tipo de material não estivesse no projeto, alguns dos dados obtidos são aqui apresentado suscintamente devido ao seu ineditismo, o que vem atualmente motivando o trabalho de outros integrantes do grupo.

Figura 43 - Diagrama de equilíbrio de fases ferro-carbeto de ferro destacando a composição atômica de $25 \%$ em carbono correspondente à fase cementita $\left(\mathrm{Fe}_{3} \mathrm{C}\right) .(115)$

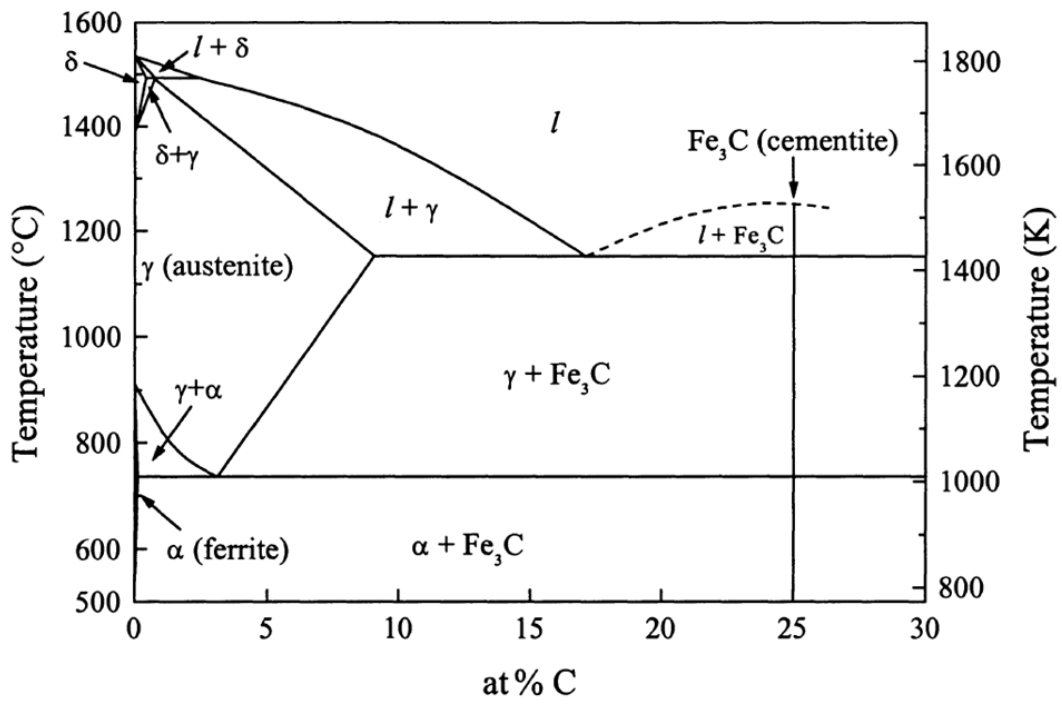

Fonte: PEPPERHOFF, W.; ACET, M. 2001, p. 163. 
Figura 44 - DRX das amostras CoC-01 e CoC-02 comparadas aos padrões JCPDS das fases $\mathrm{Co}_{2} \mathrm{C}$, $\mathrm{Co}_{3} \mathrm{C}$, fcc-Co e $h c p-\mathrm{Co}$. Em destaque, imagens de MET da amostra CoC-02.
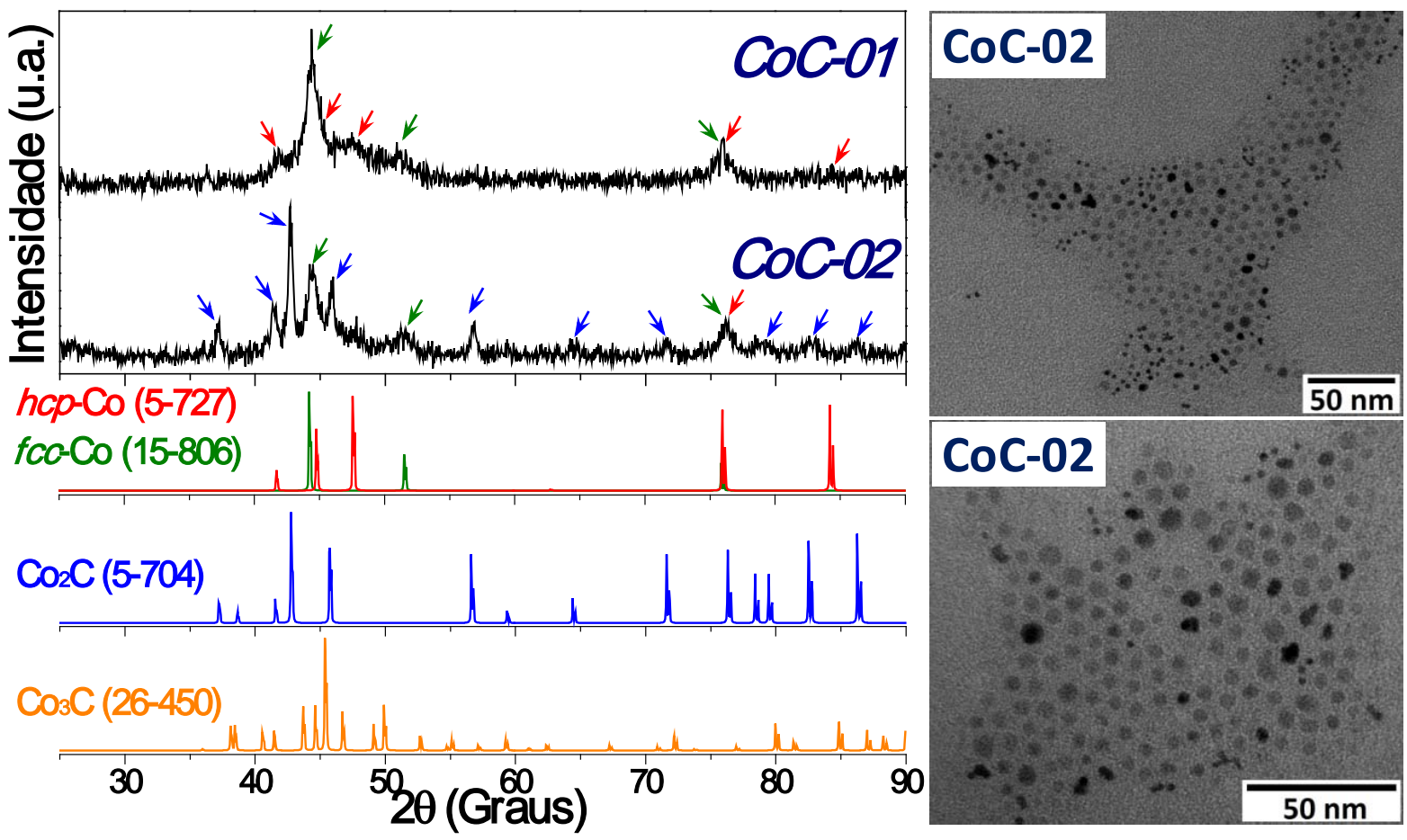

Fonte: Autoria própria.

Diferentemente do observado para o ferro, a simples substituição do precursor $\mathrm{Fe}(\mathrm{acac})_{3}$ por $\mathrm{Co}(\mathrm{acac})_{2}$ não leva à formação da fase carbeto de cobalto. Conforme apresentado na Figura 44, tal procedimento leva a obtenção de uma mistura entre as fases $f c c$-Co e $h c p$-Co (amostra CoC-01). Entretanto, quando a síntese é realizada em atmosfera de $\mathrm{H}_{2}$, uma nova mistura entre as duas fases metálicas do $\mathrm{Co}$ e a fase ortorrômbica de carbeto de cobalto $\left(\mathrm{Co}_{2} \mathrm{C}, \mathrm{JCPDS} 5-704\right)$ é observada (amostra CoC-02). A imagem de MET da amostra CoC-02 apresenta NP com morfologia quase-esférica com dimensões entre 2 e $8 \mathrm{~nm}$. Tais NP se dividem em duas distribuições de tamanho, sendo uma ao redor de $3 \mathrm{~nm}$ e a outra com cerca de $5 \mathrm{~nm}$. Embora o controle morfológico ainda não seja completo, ele foi melhor para a amostra CoC-02 em comparação com a amostra FeC-01. Entretanto, alguns ajustes que levem a NP monodispersas compostas somente pela fase de carbeto metálico ainda são necessários.

Cabe aqui ressaltar que os dados referentes aos sistemas de partículas de carbetos metálicos foram desenvolvido em conjunto com outros dois projetos de doutorado. O mesmo método foi aplicado com sucesso na obtenção de partículas de carbetos de outros metais, dentre eles níquel, molibdênio e tungstênio. Os resultados não são aqui apresentados. Embora o método de síntese tenha mostrado grande eficiência para obtenção das fases de carbeto metálico em temperatura moderadas, alguns ajustes que levem a um maior controle morfológico 
ainda se fazem necessários. Ainda, algumas observações feitas durantes as sínteses têm gerado algumas dúvidas quanto ao mecanismo de formação da fase carbeto, em especial, a origem do carbono que compõe essa fase. Os estudos ainda estão sendo realizados e desenvolvidos em nosso grupo de pesquisa e o esforço tem convergindo neste sentido.

\subsubsection{Nanopartículas de óxidos metálicos}

Devido à dificuldade encontrada na síntese de NPM monodispersas de $\alpha$-Fe e FeCo diretamente no meio reacional, uma nova alternativa foi testada: redução térmica de NPM de óxidos metálicos. Este método foi desenvolvido durante o estágio do tipo doutorado sanduíche que o aluno realizou no Instituto de Ciencia de Materiales de Madrid, Espanha. Para isso, NPM de óxido de ferro e óxido misto de ferro e cobalto foram sintetizadas, tiveram sua superfície recoberta com sílica e foram submetidas a tratamento térmico em atmosfera redutora para obtenção das fases metálicas desejadas. Os experimentos de recobrimento com sílica, cujo intuito é evitar a coalescência entre as partículas durante os tratamentos térmicos, é discutido mais adiante (item 4.3.2), assim como os experimentos de redução térmica (item 4.4).

Nanopartículas de óxidos metálicos foram sintetizadas através de dois métodos de síntese distintos. O primeiro método tem como base trabalho de Salas et al.,(30) o qual realiza a decomposição térmica do precursor oleato de ferro(III) em meio de 1-octadeceno e ácido oleico para produzir NPM de óxido de ferro. Este mesmo método foi também empregado no preparo de óxido misto de ferro e cobalto utilizando uma mistura $\mathrm{Fe}(\mathrm{ol})_{3}$ e $\mathrm{Co}(\mathrm{ol})_{2}$ na proporção 2:1. O segundo método (aqui descrito como método de Moraes) teve como base experimentos previamente realizados por outro integrante de nosso grupo de pesquisa durante seu mestrado.(117) Comparado ao método de Salas, os diferenciais deste segundo método são o uso do precursor $\mathrm{Fe}(\mathrm{acac})_{3}$ e de uma rampa de aquecimento diferenciada.

\subsubsection{Sínteses pelo método de Salas}

Conforme mostrado na Tabela 5 da parte experimental (item 3.2.1.2), para todas as sínteses de NPM óxido de ferro foram empregados as seguintes quantidades de reagentes: $\mathrm{Fe}(\mathrm{ol})_{3}(2,25 \mathrm{mmol})$, ácido oleico $(1,1 \mathrm{mmol})$ e 1-octadeceno $(25 \mathrm{~mL})$. Diferentes rampas de aquecimento foram testadas para avaliar sua influência sobre o tamanho e a forma das NPM, as quais são mostradas na Figura 13 da parte experimental. Os parâmetros experimentais de cada síntese e seus resultados são apresentados na Tabela 11. 
Tabela 11 - Parâmetros experimentais empregados em cada síntese e resultados obtidos.

\begin{tabular}{|c|c|c|c|c|c|}
\hline Amostra* & $\begin{array}{c}\text { Taxa de } \\
\text { aquecimento } \\
\left({ }^{\circ} \mathrm{C} / \mathrm{min}\right)\end{array}$ & $\begin{array}{c}\text { Patamar de } \\
\text { temperatura em } \\
200^{\circ} \mathrm{C}\end{array}$ & Forma das NPM & $\begin{array}{c}\text { Tamanho } \\
\text { médio (nm) }\end{array}$ & $\sigma^{*}$ \\
\hline $\mathrm{FeOx}-02$ & 0,5 & Não & Octaédrica & 17,5 e 33,6 & 9 e $32 \%$ \\
\hline $\mathrm{FeOx}-03$ & 0,5 & Sim & Octaédrica & 11,1 e 16,1 & 13 e $25 \%$ \\
\hline $\mathrm{FeOx}-04$ & 1 & Não & Heterogênea & 9,3 & $30 \%$ \\
\hline $\mathrm{FeOx}-05$ & 4 & Não & Esférica & 9,2 & $8 \%$ \\
\hline $\mathrm{FeOx}-06$ & 5 & Não & Esférica & 10,3 & $5 \%$ \\
\hline $\mathrm{FeOx}-07$ & 10 & Sim & Esférica & 15,2 & $7 \%$ \\
\hline
\end{tabular}

${ }^{*} \sigma=$ grau de polidispersividade. Fonte: Autoria própria.

Figura 45 - Imagens de MET das amostras de NPM de óxido de ferro obtidas pelo método de Salas.

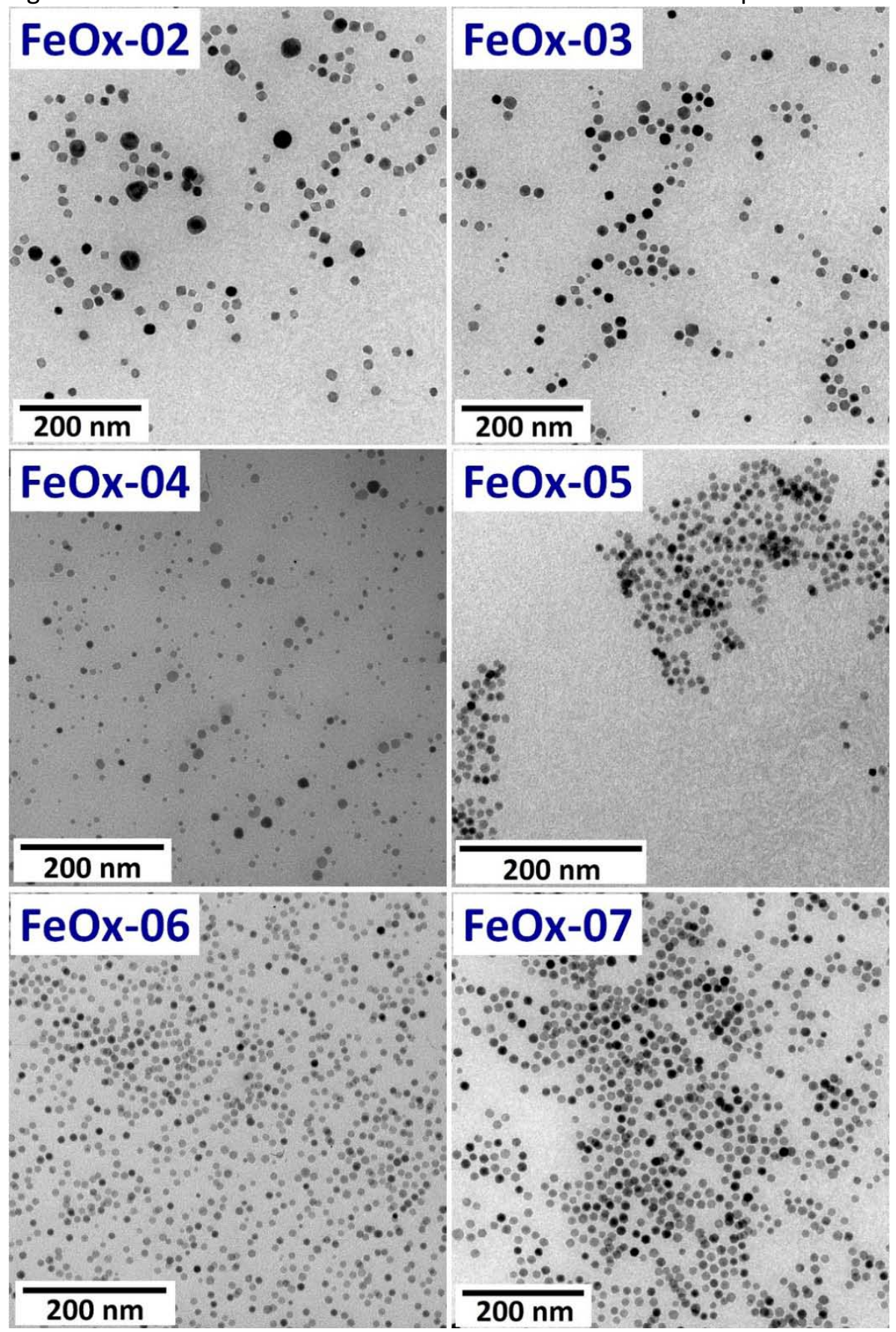

Fonte: Autoria própria. 
A taxa de aquecimento tem papel fundamental no controle das características finais do produto. Como mostrado nas imagens da Figura 45, um aquecimento rápido favorece a formação de partículas esféricas (amostras FeOx-05, FeOx-06 e FeOx-07) enquanto partículas octaédricas são favorecidas com aquecimentos mais lentos. Tal relação deve-se ao tempo de formação das partículas, uma vez que altas taxas de aquecimento aceleram os processos de nucleação e crescimento, impedindo que os núcleos formados cresçam em alguma direção preferencial. Assim, como o crescimento ocorre igualmente em todas as direções, a forma esférica é observada. Com aquecimentos mais lentos, as condições cinéticas de formação das partículas permitem um crescimento preferencial na direção [110] comparada à direção [111], e o nanocristal exibe a face <111> mais estável, levando à forma octaédrica.(30)

Além da forma, a taxa de aquecimento também tem influência sobre o tamanho médio e a distribuição de tamanho das NPM, conforme mostrado dos histogramas de contagem de partículas da Figura 46.

Figura 46 - Histogramas de contagem de partículas das amostras de NPM de óxido de ferro mostrando os valores de tamanho médio $\left(d_{m}\right)$ e de grau de polidispersividade obtidos a partir de ajustes do tipo LogNormal.

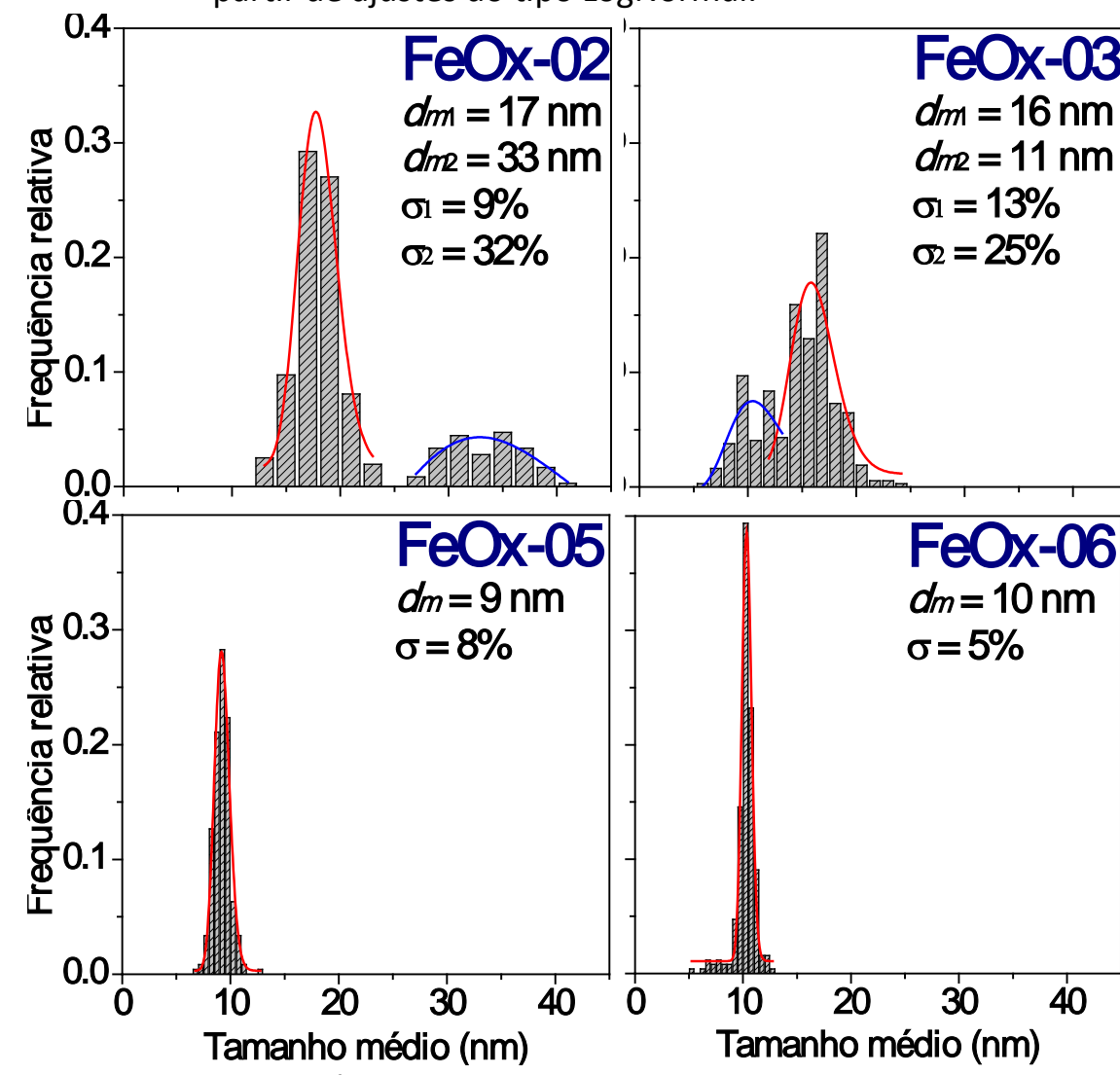

Fonte: Autoria própria.

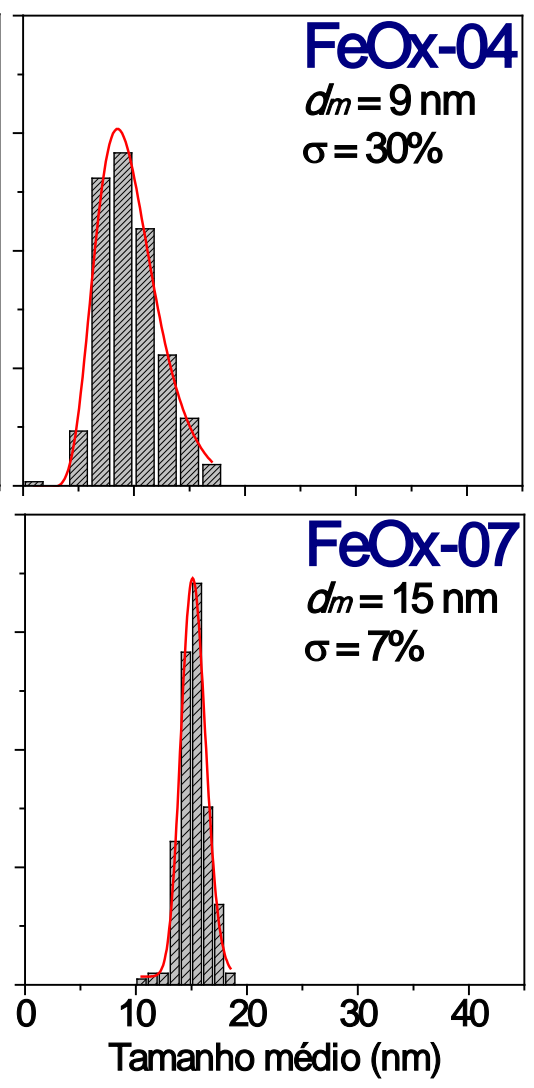


Amostras FeOx-02, FeOx-03 e FeOx-04 apresentam distribuição de tamanho alargada, com grau de polidispersividade superior a 10\%. Esta relação é explicada com base na consagrada Teoria de LaMer e Dinegar:(118) Aquecimento rápido permite que a etapa de nucleação ocorra rápida e homogeneamente e permite também que a etapa de crescimento ocorra na mesma temperatura para todas as partículas. Já um aquecimento lento leva à ocorrência simultânea das etapas de nucleação e crescimento, isto é, enquanto parte dos núcleos estão se formando, núcleos já formados estão em crescimento, o que alarga a distribuição de tamanho da amostra. As imagens de TEM das amostras FeOx-02 e FeOx-03 mostram duas distribuições de tamanho para cada amostra. Entretanto, o uso de um patamar de temperatura em $200^{\circ} \mathrm{C}$ reduz o tamanho médio de ambas as distribuições, embora não seja suficiente para levar a uma amostra monodispersa.

As imagens de MET das amostras FeOx-05, FeOx-06 e FeOx-07 mostram que taxas de aquecimento superiores a $4^{\circ} \mathrm{C} \mathrm{min}{ }^{-1}$ produzem amostras com estreita distribuição de tamanho ( $\sigma$ $<9 \%$ ), as quais podem ser classificadas como monodispersas. Ainda, a combinação de uma alta taxa de aquecimento $\left(10^{\circ} \mathrm{C} \mathrm{min}^{-1}\right) \mathrm{com}$ o patamar de temperatura em $200^{\circ} \mathrm{C}$ para a amostra FeOx-07 levou a uma distribuição de tamanho bastante satisfatória $(\sigma=7 \%)$.

Embora evidenciado que a taxa de aquecimento tem influência sobre o tamanho médio das partículas, a relação entre esses dois parâmetros não é tão clara. Aumentando a taxa de aquecimento de 4 para $5^{\circ} \mathrm{C} \mathrm{min}^{-1}$ e novamente para $10^{\circ} \mathrm{C} \mathrm{min}^{-1}$ respectivamente para as amostras FeOx-05, FeOx-06 e FeOx-07, o tamanho médio também aumenta (9,2, 10,3 e 15,2 nm). Entretanto, é curioso que as amostras FeOx-02 e FeOx-03, ambas aquecidas a $0,5^{\circ} \mathrm{C} \min ^{-1}$, mostraram os maiores tamanho médios de partícula entre todas as amostras. Uma possível explicação é a ocorrência de uma competição entre os processos de nucleação e crescimento durante a formação das partículas. Usando taxas de aquecimento extremas (muito lento ou muito rápido), a taxa de crescimento domina a taxa de nucleação, resultando em partículas maiores. Já o uso de taxas de aquecimentos intermediárias (entre 1 e $4^{\circ} \mathrm{C} \mathrm{min}^{-1}$ ) parece acelerar a taxa de nucleação. A influência da taxa de aquecimento sobre a competição entre as etapas de nucleação e de crescimento já foi relatada por Nandwana et al.(119) na síntese de NPM de FePt.

A síntese da amostra FeOx-07 foi repetida utilizando uma mistura dos precursores $\mathrm{Fe}(\mathrm{ol})_{3}$ $(1,7 \mathrm{mmol})$ e $\mathrm{Co}(\mathrm{ol})_{2}(0,8 \mathrm{mmol})$ para obtenção de NPM de óxido misto de ferro e cobalto. A exemplo da amostra FeOx-07, um satisfatório controle morfológico foi alcançado. NPM monodispersas com tamanho médio de $10,9 \mathrm{~nm}$ e grau de polidispersividade de $8 \%$ foram obtidas, conforme mostra a Figura 47. 
Figura 47 - Imagens de TEM das NPM de óxido misto de ferro e cobalto obtidas pelo método de Salas e o histograma de contagem de partículas referente a amostra.
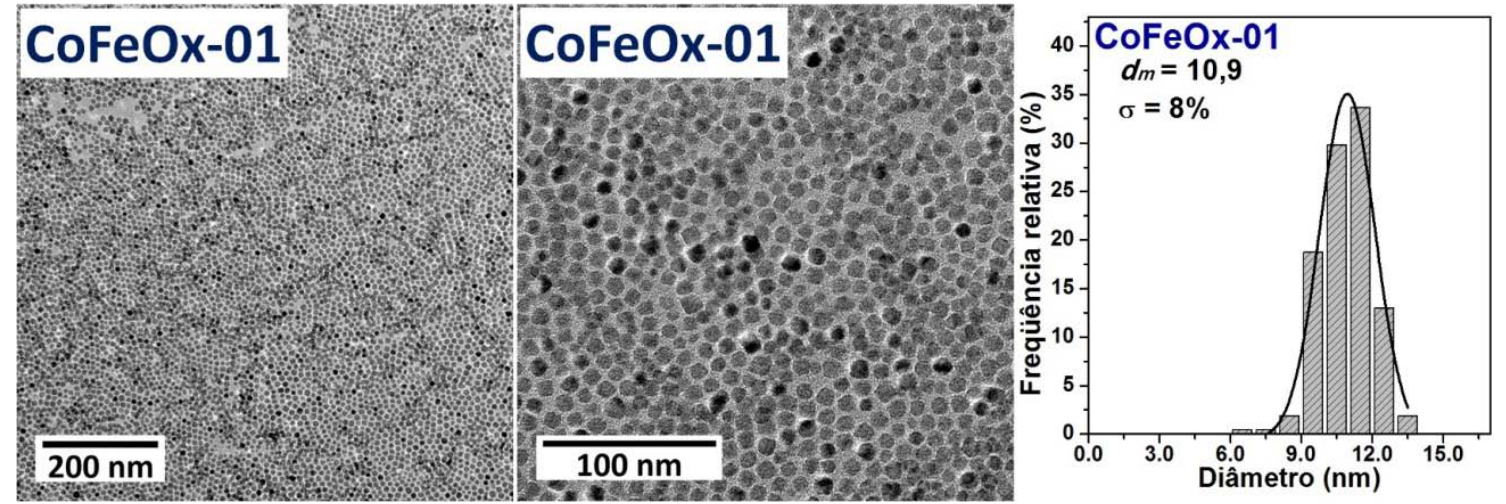

Fonte: Autoria própria.

A análise por DRX das amostras FeOx-07 e CoFeOx-01 (Figura 48) indicou a obtenção das fases magnetita $\left(\mathrm{Fe}_{3} \mathrm{O}_{4}\right)$ e ferrita de cobalto $\left(\mathrm{CoFe}_{2} \mathrm{O}_{4}\right)$, ambas com estrutura espinélio inverso. Observa-se um maior alargamento dos picos do difratograma da amostra contendo cobalto, o que é justificado pela menor dimensão das NPM que compõem a amostra. A análise por EDX da amostra contendo cobalto indicou uma composição relativa entre os metais de Fe:Co = 70:30, a qual está relativamente próxima à composição $\mathrm{Fe}: \mathrm{Co}=67: 33$ esperada para a ferrita de cobalto.

Figura 48 - DRX das amostras de óxido de ferro e ferrita de cobalto comparados aos padrões JCPDS das fases $\mathrm{Fe}_{3} \mathrm{O}_{4}, \mathrm{FeO}, \alpha$-Fe, $\mathrm{CoFe}_{2} \mathrm{O}_{4}, \mathrm{CoO}$ e fcc-Co.

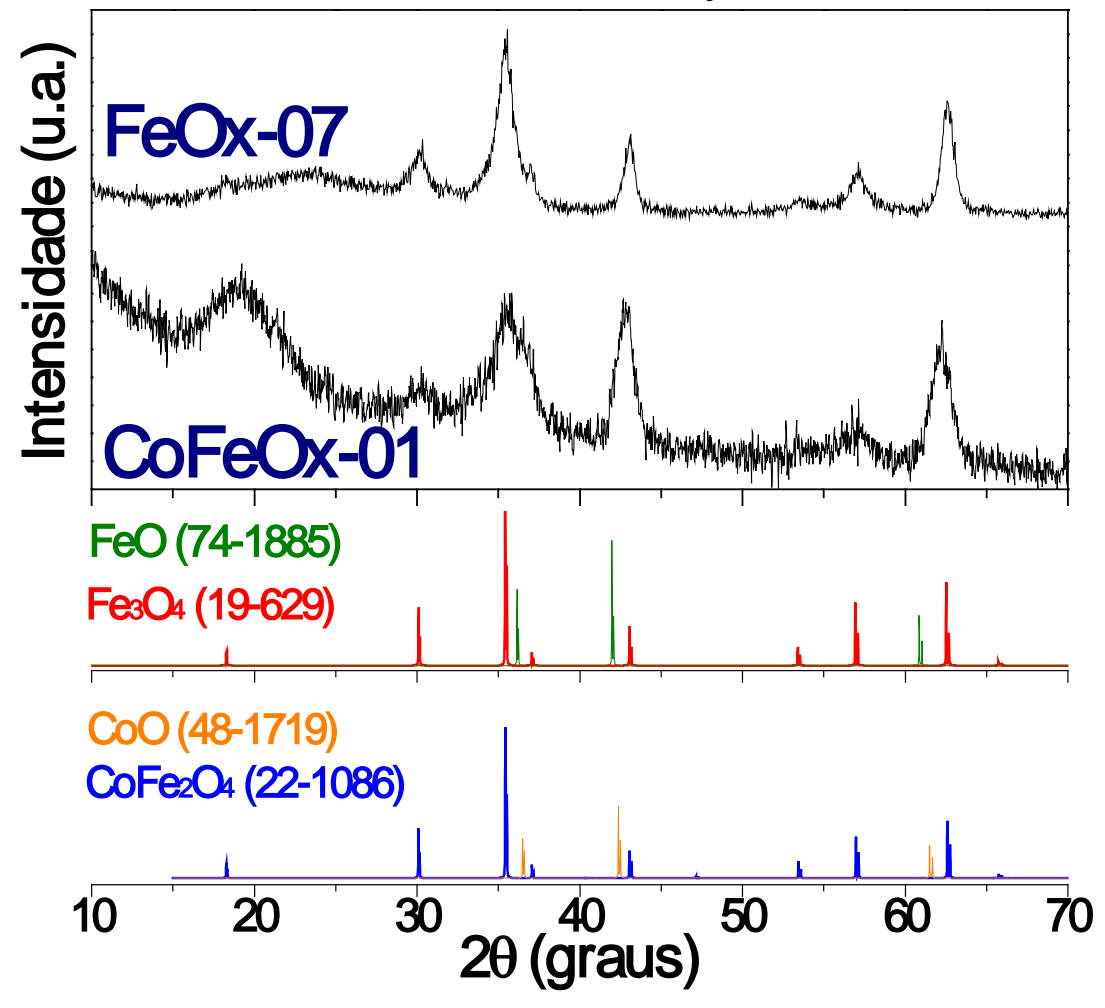

Fonte: Autoria própria. 


\subsubsection{Sínteses pelo método de Moraes}

O método de Moraes baseia-se na decomposição térmica de $\mathrm{Fe}(\mathrm{acac})_{3}$ em meio de 1octadeceno (solvente) e ácido oleico (surfactante). O intuito do uso deste método era síntesar de NPM de magnetita com dimensões superiores a $15 \mathrm{~nm}$, as quais seriam recobertas com sílica e reduzidas através de redução térmica. Entretanto, a caracterização das amostras indicaram a obtenção da fase wustita ( $\mathrm{FeO}$ ), o que instigou a curiosidade a respeito deste sistema e motivou esta parte do trabalho de doutorado. Três parâmetros de síntese foram variados: quantidade de surfactante, presença do patamar intermediário em $150^{\circ} \mathrm{C}$ e temperatura final de síntese. A Tabela 12 resume as variações dos parâmetros de cada síntese bem como os resultados de DRX.

Tabela 12 - Parâmetros respectivos a cada síntese de NPM e resultados da análise de DRX.

\begin{tabular}{|c|c|c|c|c|c|c|c|}
\hline Amostra & $\begin{array}{c}\text { OD* } \\
(\mathrm{mmol})\end{array}$ & $\begin{array}{c}\text { AO* } \\
\text { (mmol) }\end{array}$ & $\begin{array}{c}\mathrm{Fe}(\mathrm{acac})_{3} \\
(\mathrm{mmol})\end{array}$ & $\begin{array}{c}\mathrm{Co}(\mathrm{acac})_{2} \\
\text { (mmol) }\end{array}$ & $\begin{array}{l}\text { Patamar } \\
150^{\circ} \mathrm{C} / 1 \mathrm{~h}\end{array}$ & $\begin{array}{l}\mathrm{T}_{\text {final }} \\
\left({ }^{\circ} \mathrm{C}\right)\end{array}$ & $\begin{array}{c}\text { Fases } \\
\text { cristalográficas }\end{array}$ \\
\hline $\mathrm{FeOx}-08$ & 25 & 5 & 2 & - & não & 320 & $\mathrm{FeO}$ \\
\hline FeOx-09 & 25 & 5 & 2 & - & $\operatorname{sim}$ & 320 & $\mathrm{FeO}+\mathrm{Fe}_{3} \mathrm{O}_{4}$ \\
\hline FeOx-10 & 25 & 5 & 2 & - & $\operatorname{sim}$ & 290 & $\mathrm{Fe}_{3} \mathrm{O}_{4}$ \\
\hline FeOx-11 & $27,5^{* *}$ & 2,5 & 2 & - & $\operatorname{sim}$ & 320 & $\mathrm{Fe}_{3} \mathrm{O}_{4}+\mathrm{FeO}$ \\
\hline FeOx-12 & $22,5^{* *}$ & 7,5 & 2 & - & $\operatorname{sim}$ & 320 & $\mathrm{Fe}_{3} \mathrm{O}_{4}+\mathrm{FeO}+\alpha-\mathrm{Fe}$ \\
\hline $\mathrm{CoFeOx}-02$ & 25 & 5 & 1,3 & 0,7 & não & 320 & *n.a. \\
\hline CoFeOx-03 & 25 & 5 & 1,3 & 0,7 & $\operatorname{sim}$ & 320 & $(\mathrm{Fe}, \mathrm{Co})_{1-\mathrm{x}} \mathrm{O}$ \\
\hline
\end{tabular}

*n.a. = não analisado. Fonte: Autoria própria.

No difratograma da amostra FeOx-08 (Figura 49), a fase wustita foi obtida a partir do precursor $\mathrm{Fe}(\mathrm{acac})_{3}$ mesmo na ausência de agentes redutores. Trabalhos anteriores de nosso grupo mostram que o monóxido de carbono produzido na decomposição térmica incompleta do ânion acetilacetonato em atmosfera inertepode promover a redução de $\mathrm{Fe}^{3+}$ por um processo de spillover de CO quando na presença de núcleos de platina (catalisador heterogêneo).(26) Embora o ânion acetilacetonato esteja presente na síntese, variações na temperatura de refluxo bem como na quantidade de ácido oleico promovem alterações na estrutura cristalina da amostra. Diminuindo a temperatura de refluxo de $320^{\circ} \mathrm{C}$ para $290^{\circ} \mathrm{C}$, NPM compostas somente pela fase magnetita foram obtidas (FeOx-10), o que mostra um menor caráter redutor do sistema de síntese. Ainda, a diminuição de 50\% na quantidade de ácido oleico com resulta em uma mistura das fases magnetita e wustita, com predominância da primeira, o que também aponta um menor caráter redutor do sistema. Deve-se notar que aumentando-se a quantidade de ácido oleico (amostra FeOx-12) é obtida uma mistura entre as fases cristalinas magnetita, wustita e $\alpha$-Fe. 
Figura 49 - DRX das amostras de óxido de ferro comparadas aos padrões JCPDS das fases wustita (vermelho), magnetita (azul) e $\alpha$-ferro (verde). Os losangos coloridos destacam os picos de difração relativos a cada fase cristalina presente na constituição das amostras.

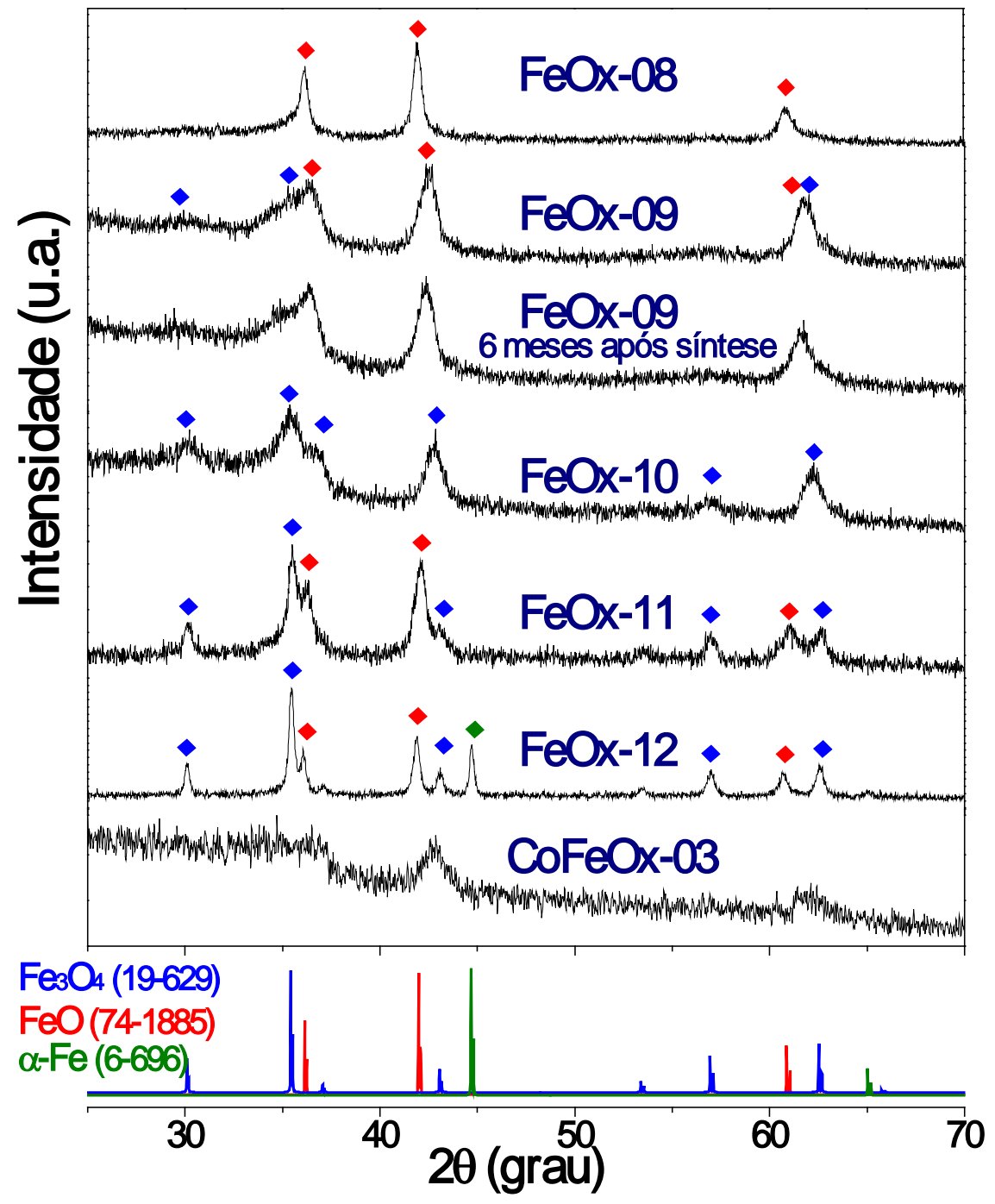

Fonte: Autoria própria.

A presença da fase $\alpha-F e$ na constituição da amostra FeOx-12, sugere que o caráter redutor observado na síntese em questão está relacionado à presença do ácido oleico, uma vez que uma quantidade maior deste reagente foi empregada nesta síntese. Ainda, considerando a presença de magnetita como única fase constituinte da amostra FeOx-10, é possível destacar a influência da temperatura na redução dos íons $\mathrm{Fe}^{3+}$ presentes no sistema. Assim, a análise conjunta de ambos os parâmetros (quantidade de ácido oleico e temperatura final da síntese) aponta a possibilidade de que a redução observada deve-se à decomposição parcial do ácido oleico em temperaturas ao redor de $320^{\circ} \mathrm{C}$, a qual não ocorre a $290^{\circ} \mathrm{C}$. De fato, Salas et al. (30) mostram através de análises de termogravimetria (TGA/DTG) que o oleato de ferro(III) começa a se decompor a partir de $\mathrm{T}=315^{\circ} \mathrm{C}$, o que suportaria a hipótese de que a decomposição do ácido oleico auxiliaria a redução de $\mathrm{Fe}^{3+}$ para $\mathrm{Fe}^{2+}$ na formação da fase wustita. 
Figura 50 - Imagens de TEM das amostras de óxido de ferro (FeOx-08 a FeOx-12) e de óxido misto de ferro e cobalto (CoFeOx-02 e CoFeOx-03). Em destaque, tabela apresentando as dimensões médias e grau de polidispersividade relativos a cada amostra.

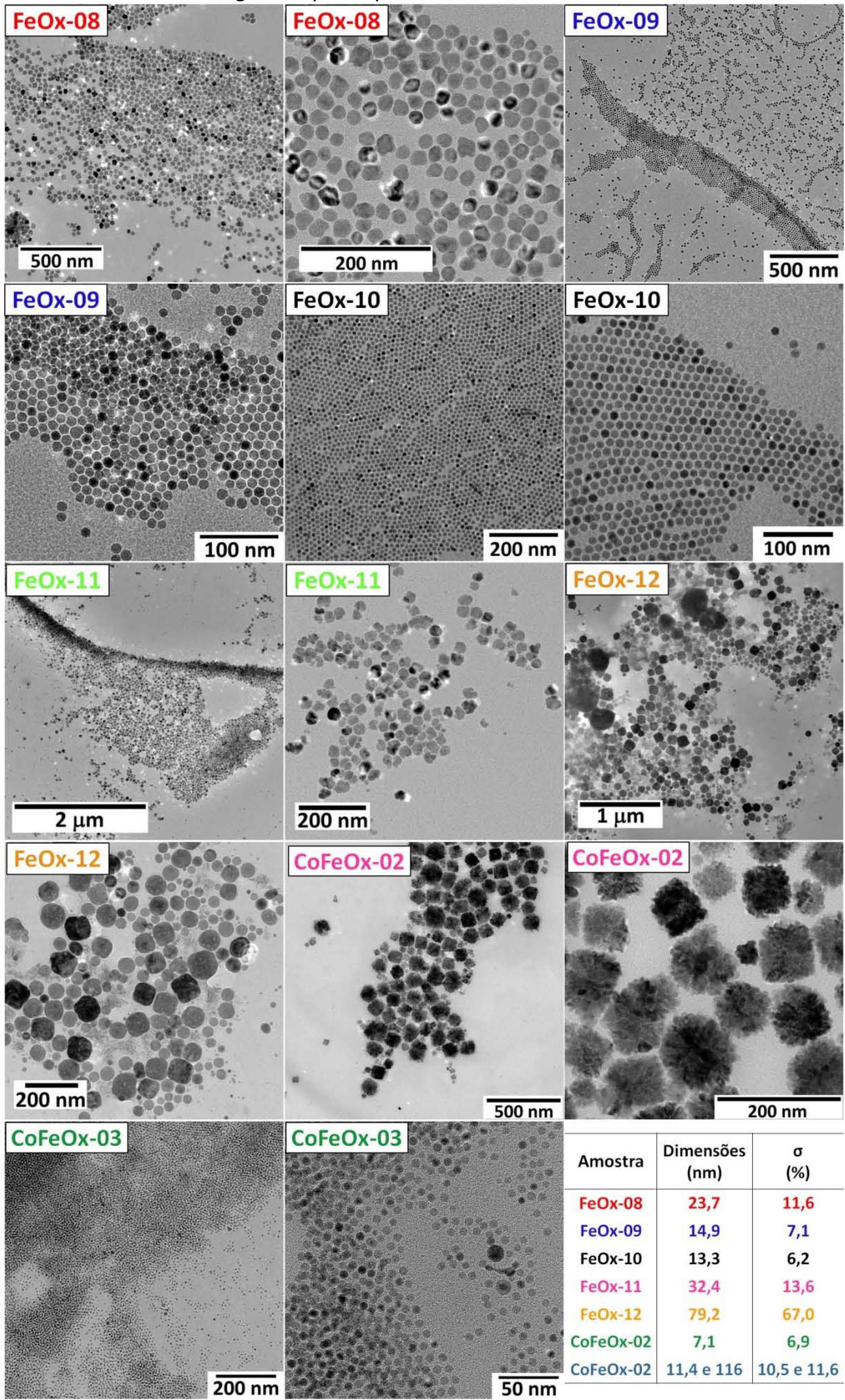

Fonte: Autoria própria. 
A Figura 50 apresenta as imagens de MET das amostras de óxido de ferro e de óxido misto de ferro e cobalto obtidas pelo método de Moraes enquanto que os histogramas de contagem de partículas são apresentados na Figura 51. O aquecimento rápido e direto até o refluxo a $320^{\circ} \mathrm{C}$ empregado para a amostra FeOx-08 resultou em NPM com dimensões ao redor de 23,7 nm, morfologia irregular e grau de polidispersividade de $11,6 \%$. Alguns trabalhos na literatura relatam que, durante a síntese de NP de óxido de ferro na presença de ácido oleico, o complexo Fe(ol) ${ }_{3}$ é formado como intermediário a partir da reação do ácido com íons $\mathrm{Fe}^{3+}$ e passa a atuar como precursor de Fe para a nucleação e crescimento das NPM. ${ }^{34} \mathrm{Na}$ síntese da amostra FeOx-08, o rápido aquecimento até $320^{\circ} \mathrm{C}\left(10^{\circ} \mathrm{C} \mathrm{min}{ }^{-1}\right)$ pode promover a nucleação e crescimento das NPM antes que todo o $\mathrm{Fe}(\mathrm{ol})_{3}$ tenha sido formado. Assim, a presença de dois diferentes precursores metálicos explicaria a alta polidispersividade da amostra FeOx-08. O aquecimento mais lento poderia sobrepor essas duas etapas, o que aumentaria ainda mais sua polidispersividade.

Figura 51 - Ajustes do tipo LogNormal aplicados aos histogramas de contagem de NPM. Para facilitar a visualização, os ajustes são apresentados em escala linear (à esquerda) e escala logarítmica (à direita). As cores de cada curva fazem referência às cores usadas nas legendas de cada imagem de TEM da Figura 51.
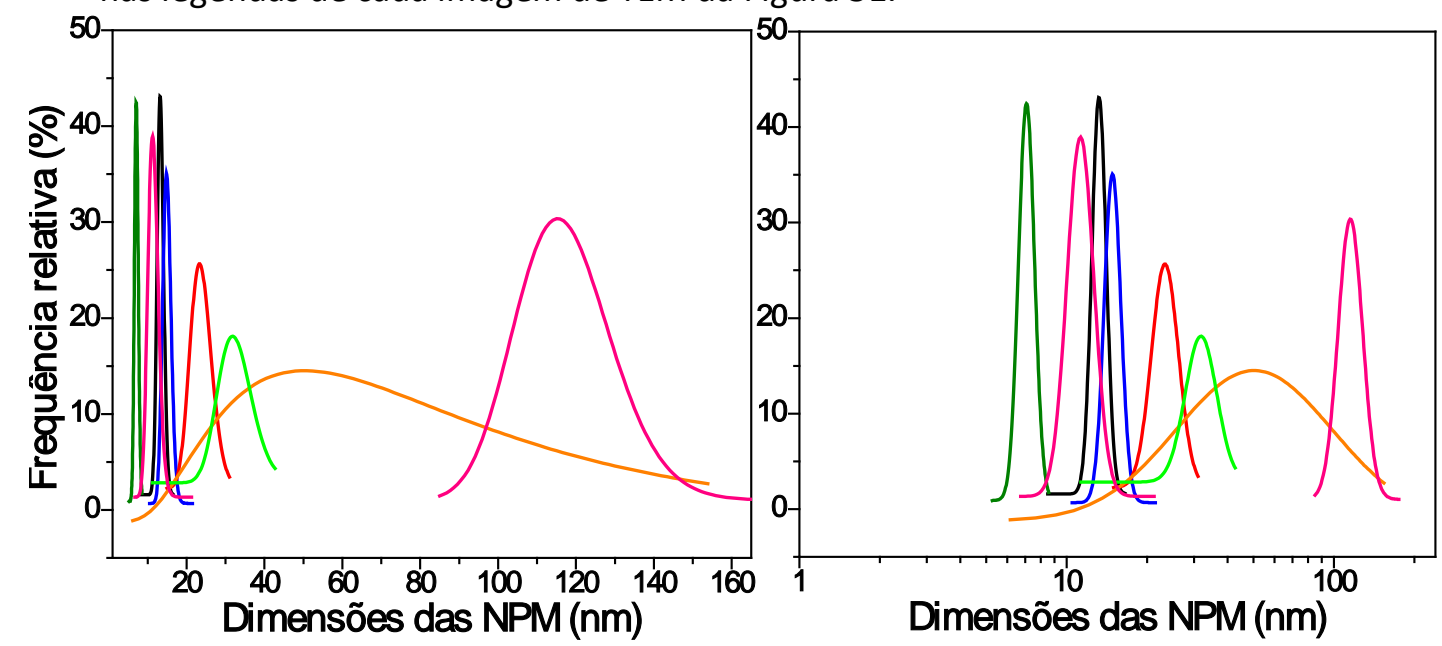

Fonte: Autoria própria.

Para garantir que todo o $\mathrm{Fe}(\mathrm{ol})_{3}$ tenha sido formado antes da nucleação das NP, um patamar de temperatura intermediário em $150^{\circ} \mathrm{C}$ por 1 hora foi inserido na rampa de aquecimento da amostra FeOx-09. Esta temperatura foi escolhida por estar um pouco abaixo da temperatura de decomposição do $\mathrm{Fe}(\mathrm{acac})_{3}$, ao redor de $180^{\circ} \mathrm{C}$.(26) Desta vez, a síntese resultou em um considerável controle morfológico, uma vez que NP esféricas com 14,9 nm foram obtidas sem alterações em sua composição. Essa diminuição de tamanho já era indicada pela análise de DRX, dado o maior alargamento dos picos presentes no difratograma desta amostra. Acredita-se que este patamar intermediário permita que todo o $\mathrm{Fe}^{3+}$ presente no sistema seja complexado 
como oleato férrico antes que os processos de nucleação e crescimento das NPM sejam iniciados, levando a uma maior uniformidade da morfologia das partículas. A mesma uniformidade não foi alcançada para a amostra FeOx-11. Embora para esta amostra o patamar intermediário tenha sido utilizado, a diminuição da quantidade de ácido oleico em $50 \%$ resulta em uma razão molar $\mathrm{Fe}^{3+} / \mathrm{AO}=0,8$, o que possibilita que somente $41,5 \%$ dos íons férricos presentes no sistema possa estar complexado na forma de oleato férrico. Isso causa um efeito similar ao observado para a amostra FeOx-08, uma vez que nucleação e crescimento das NPM ocorrem tendo dois diferentes precursores como fonte de $\mathrm{Fe}^{3+}$.

Já para a amostra FeOx-12, um excesso de 1,5 mmol de ácido oleico está presente, o que possibilita que $100 \%$ dos íons $\mathrm{Fe}^{3+}$ sejam complexados na forma de oleato férrico. Seria então esperado para esta amostra um grande controle morfológico, o que não ocorreu. O excesso de ácido oleico levou à maior heterogeneidade de morfologia observada dentre todas as amostras, o que parece estar relacionado ao processo de redução dos íons $\mathrm{Fe}^{3+}$, haja vista que a análise por DRX acusou a presença de 3 diferentes fases cristalinas nesta amostra.

É importante observar que, para as amostras FeOx-08, FeOx-11 e FeOx-12, a morfologia irregular das NPM, bem como suas maiores dimensões parecem ser resultado do processo de coalescência entre partículas menores. Isso fica mais evidente ao analisar as imagens da amostra CoFeOx-02, que mostram agregados de $117 \mathrm{~nm}$ com morfologia aproximadamente cúbica, formados por partículas de 10,5 nm. Assim como no caso das NPM de óxido de ferro, o uso de um patamar intermediário em $150^{\circ} \mathrm{C}$ leva a formação de NPM com maior controle morfológico, o que resultou na amostra CoFeOx-03 com NPM esféricas com 7,1 nm e grau de polidispersividade de 6,9\%. A análise de DRX dessa amostra (Figura 49) mostrou que, a exemplo das amostras de óxido de ferro, a fase wustita foi também obtida para a amostra CoFeOx-03 sintetizada na presença dos cátions $\mathrm{Fe}^{3+}$ e $\mathrm{Co}^{2+}$. Ainda, análise por EDX indicou a presença de ambos os metais na amostra, em uma composição molar de Fe:Co = 69,31. Combinando os resultados de ambas as técnicas pode-se inferir a obtenção de NPM de wustita mista de ferro e cobalto. Cabe aqui ressaltar que, até o presente, somente há relatos dessa fase cristalina na fase bulk,(120,121) e não em nanoescala.

Apesar da eficiência do patamar intermediário em $150^{\circ} \mathrm{C}$ no controle da forma das NPM, a mesma eficiência não foi observada quanto ao controle da estrutura cristalina das amostras. Os difratogramas das amostras FeOx-08 e FeOx-09 (Figura 49) mostram que a segunda possui magnetita como fase cristalina secundária. A explicação mais provável está na estabilidade da fase wustita, a qual é menor quanto menor as dimensões das partículas. A wustita 
estequiométrica não existe como uma fase estável. Esta falta de estabilidade advém da própria instabilidade dos íons $\mathrm{Fe}^{2+}$, que possuem a tendência de oxidar-se a $\mathrm{Fe}^{3+}$. Para que seja mantido o balanço de cargas eletrostáticas da estrutura sal-gema da wustita, a oxidação de três íons $\mathrm{Fe}^{2+}$ dá origem a dois íons $\mathrm{Fe}^{3+}$ e uma vacância de ferro, o que leva à falta de estequiometria da wustita, normalmente denominada $\mathrm{Fe}_{1-\mathrm{x}} \mathrm{O}$ ou $\mathrm{Fe}_{1-3 \mathrm{x}}^{2+} \mathrm{Fe}_{2 \mathrm{x}}^{3+} \square_{\mathrm{x}} \mathrm{O}^{2-}$ ( $\square=$ vacância de ferro).(122) A Figura 52 ilustra o processo de formação de vacâncias na estrutura da wustita.

Figura 52 - Estrutura sal-gema da wustita seguida de ilustração do processo de formação de vacâncias de ferro na estrutura cristalina da wustita.

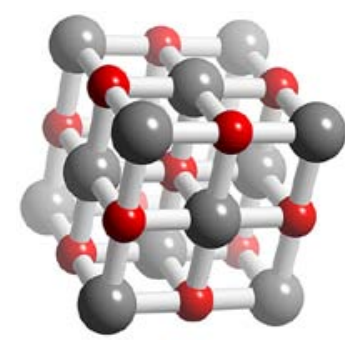

Fonte: Autoria própria.

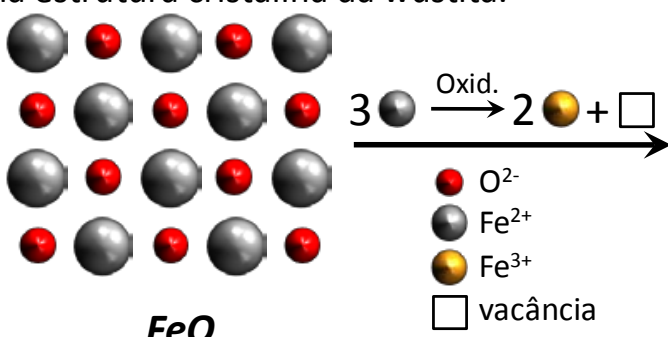

$\mathrm{FeO}$

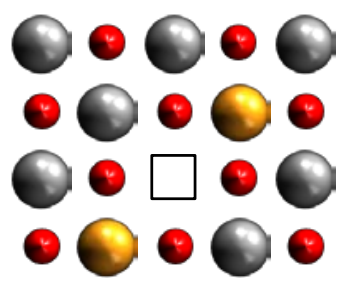

$\mathrm{Fe}^{2+}{ }_{1-3 x} \mathrm{Fe}^{3+}{ }_{2 x} \square_{x} \mathrm{O}^{2-}$

É importante ressaltar que a oxidação ocorre mais pronunciadamente na superfície do material, a qual está mais exposta. Isso aumenta a tendência à oxidação para materiais formados por menores partículas, explicando a presença de magnetita como fase secundária na estrutura cristalina da amostra FeOx-09. Comparando o segundo e terceiro difratogramas da Figura 49 observa-se que, embora o processo de oxidação ocorra em pequena proporção, a fase wustita se mantém mesmo após armazenamento da amostra por 6 meses em atmosfeta não controlada.

Algumas das amostras de NPM de óxido de ferro foram submetidas às medidas de VSM para análise de seu comportamento magnético (Figura 53). A amostra FeOx-08 apresenta o maior valor de coercividade entre as amostras analisadas o que é resultado das maiores dimensões das NPM que compõem a amostra. Entretanto, por ser composta por wustita (wustita estequiométrica é anti-ferromagnética), FeOx-08 não apresenta a maior magnetização de saturação. A maior $\mathrm{M}_{\mathrm{S}}$ é observada para a amostra FeOx-10, a qual apresenta somente magnetita (ferrimagnética) em sua composição. Embora apresente magnetita como fase secundária em sua composição, a amostra FeOx-09 apresentou a menor $\mathrm{M}_{\mathrm{S}}$, o que deve-se às menores dimensões das NPM que compõem tal amostra (efeito spin-canting).(123) É interessante notar um aumento de 3,5 emu $\mathrm{g}^{-1}$ na $\mathrm{M}_{\mathrm{S}}$ da amostra FeOx-09 seis meses após sua síntese. Embora a análise por DRX não tenha mostrado alterações visíveis na estrutura da amostra FeOx-09 após 6 meses, o aumento de $M_{S}$ é explicado pela oxidação parcial da fase wustita para a fase magnetita, aumentando o caráter ferrimagnético da amostra. 
Figura 53 - Curvas de histerese magnética obtidas a 298 K. Em destaque, ampliação da região central das curvas e respectivos valores de $\mathrm{M}_{\mathrm{s}}$ e $\mathrm{H}_{\mathrm{C}}$. Os valores não estão normalizados pela massa magnética das amostras.

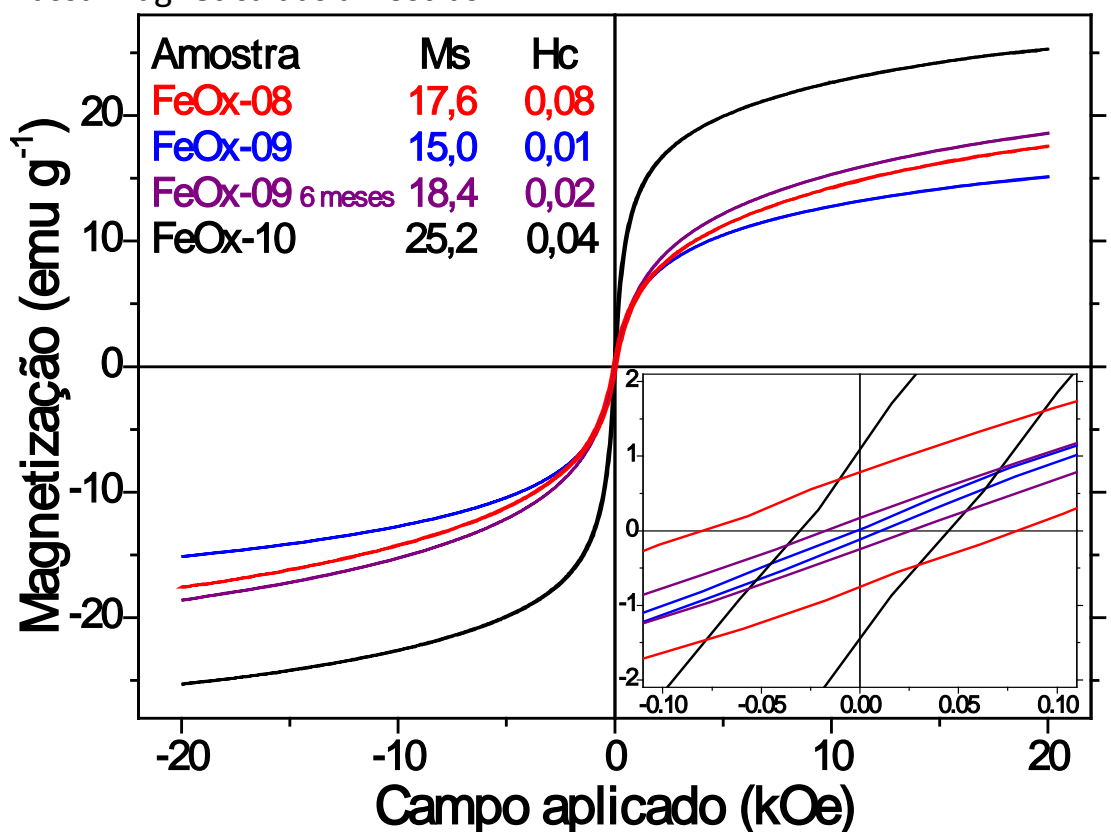

Fonte: Autoria própria.

\subsection{Funcionalização da superfície das NPM}

\subsubsection{Recobrimento com carboximetil-dextrana}

A carboximetil-dextrana é um derivado aniônico do polissacarídeo dextrana (Figura 54). Ela tem sido extensamente aplicada na biocompatibilização de sistemas de nanopartículas para aplicações biomédicas. Dentre os fatores que motivam seu uso estão: aumento do tempo de circulação no sangue e da estabilidade coloidal das partículas, menor toxicidade e maior versatilidade de funcionalização adicional.(124,125)

Figura 54 - Fragmento da estrutura molecular da carboximetil-dextrana.

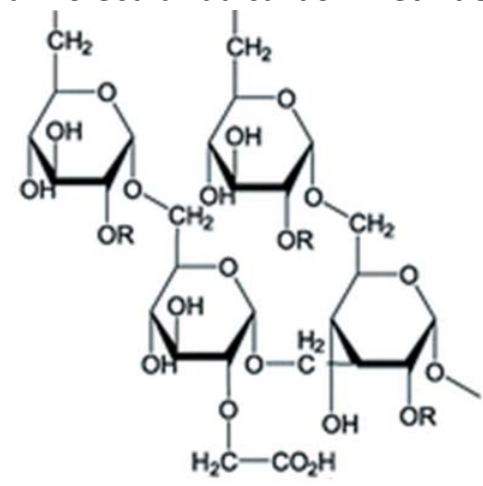

Fonte: HILL, A., et al., 2014.(126) 
Na Figura 55, os espectros FTIR das amostras FeOx-01 e FeOx@CM-Dex são comparados ao espectro da amostra de carboximetil-dextrana pura. Os espectros de ambas as amostras contendo NPM apresentam uma banda de absorção na região de $585 \mathrm{~cm}^{-1}$, a qual se refere ao estiramento vibracional de ligações Fe-O característico de magnetita. No espectro da amostra não recoberta (em vermelho), a banda alargada na região próxima a $3400 \mathrm{~cm}^{-1}$ é atribuída ao estiramento de grupos hidroxila presentes sobre a superfície das NPM de magnetita e de interações do tipo ligações de hidrogênio entre esses grupos.(81,127) Esta banda é observada ainda mais alargada no espectro da CM-Dex pura (em verde) devido à presença de grupos hidroxilas alcoólicos na estrutura do composto. A presença de CM-Dex sobre a superfície das NPM de magnetita é confirmada no espectro da amostra recoberta (em azul) principalmente pela presença das bandas em $1154 \mathrm{~cm}^{-1}$ e $1010 \mathrm{~cm}^{-1}$, referentes respectivamente aos estiramentos assimétrico e simétrico de ligações C-O em éteres saturados.(81) Observa-se também a presença da banda em $912 \mathrm{~cm}^{-1}$ característica de desdobramentos de anéis $\alpha$-glucopiranose, bem como o surgimento das em $2928 \mathrm{~cm}^{-1}$ e $2860 \mathrm{~cm}^{-1}$ atribuídas respectivamente aos estiramentos assimétrico e simétrico de ligações $\mathrm{C}-\mathrm{H}$ em grupos metileno,(81,125) confirmando a eficiência do processo de recobrimento empregado. Cabe ressaltar que o maior alargamento da banda na região de $3400 \mathrm{~cm}^{-1}$ para a amostra recoberta indica a presença de interações do tipo ligação de hidrogênio, as quais ocorrem entre os grupos alcoólicos da CM-Dex e hidroxila da superfície das NPM e mantém o polissacarídeo adsorvido às NPM (Figura 56).(81)

Figura 55 - Espectros FTIR obtidos para CM-Dex pura (verde) e para as amostras de NPM de magnetita antes (FeOx-01, em vermelho) e após o recobrimento com CM-Dex (FeOx@CM-Dex,em azul).

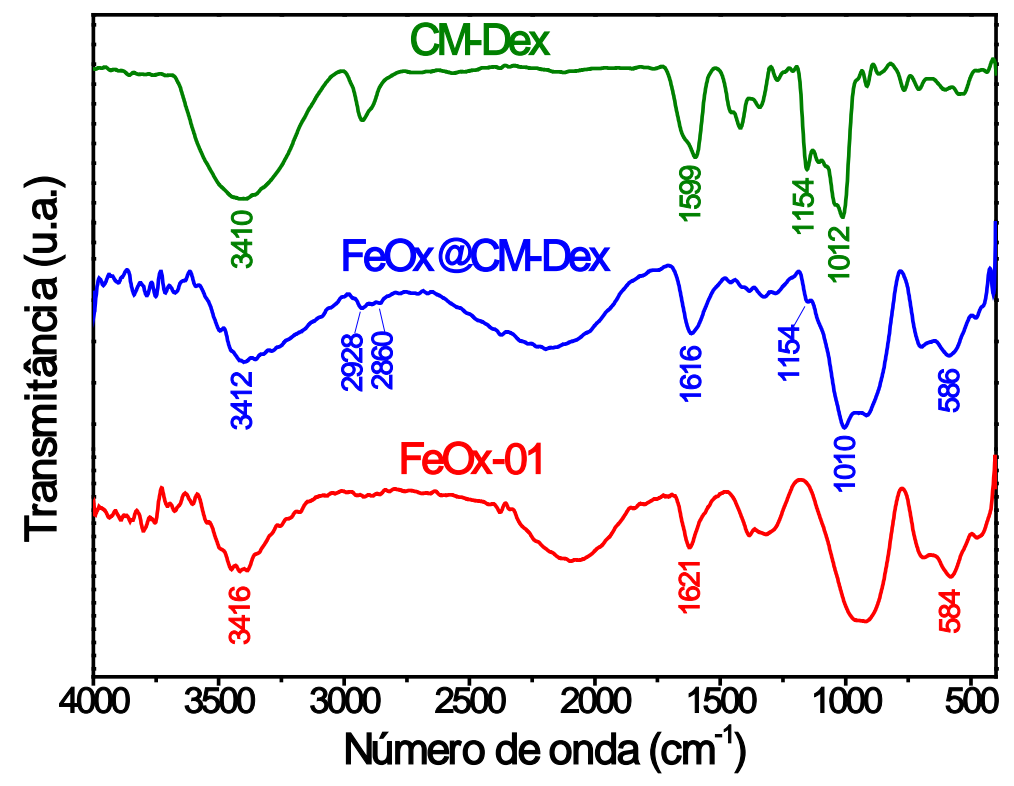

Fonte: Autoria própria. 
Figura 56 - Esquema ilustrativo da adsorção da CM-Dex sobre a superfície das NPM de magnetita.
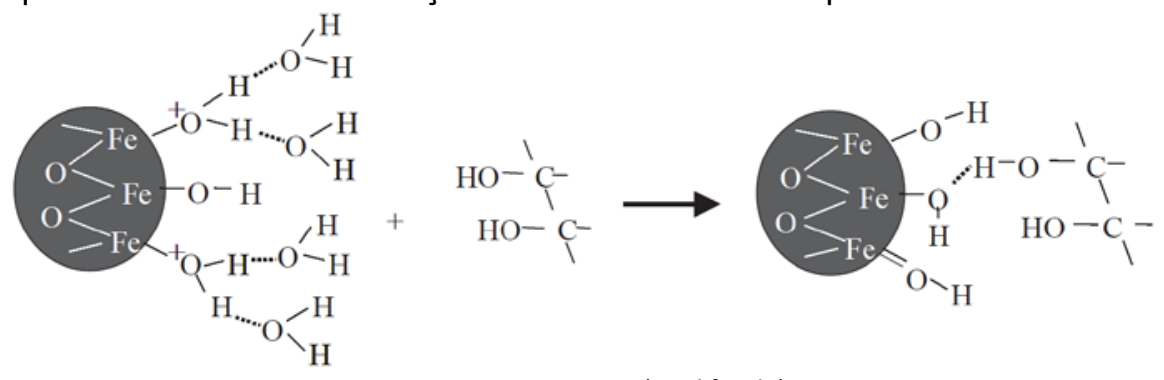

Fonte: BAUTISTA, M.C., et al., 2005.(81) (modificado) $^{\text {(20) }}$

\subsubsection{Recobrimento com sílica}

O recobrimento com sílica foi realizado via hidrólise de tetraetilortosilicato (TEOS) em sistema de microemulsão inversa. $(44,45)$ Três amostras de NPM foram usadas como núcleo magnético: FeOx-07 (amostras FeOx@S1 a FeOx@S7), FeOx-08 (amostras FeOx@S8 e FeOx@S9) e CoFeOx-02 (amostra CoFeOx@S1). A intenção é obter NP com estrutura core-shell (caroçocasca) compostas por um caroço magnético de óxido de ferro ou óxido misto de ferro e cobalto e uma casca de sílica. A escolha da sílica deve-se à sua estabilidade térmica, capaz de evitar a sinterização das NPM durante a redução térmica. Ainda, a sílica é hidrofílica, apresenta biocompatibilidade e baixa toxicidade em muitos sistemas biológicos e pode ser facilmente funcionalizada com biocompostos graças aos grupos silanóis presentes em sua superfície.(128)

Para controlar a espessura da camada de recobrimento, alguns parâmetros experimentais do processo foram variados: tipo de agitação, tempo de reação, e concentrações de TEOS e de NPM (Tabela 13). As amostras após recobrimento foram analisadas por MET (Figura 57).

Tabela 13 - Condições experimentais usados nos recobrimentos com sílica e resultados obtidos.

\begin{tabular}{|c|c|c|c|c|c|c|c|}
\hline \multirow[b]{2}{*}{ Amostra } & \multicolumn{2}{|c|}{ Núcleo magnético } & \multirow{2}{*}{$\begin{array}{l}\text { TEOS } \\
(\mathrm{mL})\end{array}$} & \multirow[b]{2}{*}{ Agitação } & \multirow{2}{*}{$\begin{array}{l}\text { Tempo de } \\
\text { reação (h) }\end{array}$} & \multicolumn{2}{|c|}{ Recobrimento } \\
\hline & $\begin{array}{l}\text { Diâmetro } \\
\text { (nm) }\end{array}$ & $\begin{array}{c}\text { Massa } \\
\text { (mg) }\end{array}$ & & & & $\begin{array}{l}\text { Espessura } \\
\text { (nm) }\end{array}$ & Homogeneidade \\
\hline FeOx@S1 & 15,2 & 5 & 0,15 & magnética & 72 & - & - \\
\hline FeOx@S2 & 15,2 & 5 & 0,15 & mecânica & 16 & - & - \\
\hline FeOx@S3 & 15,2 & 5 & 0,10 & mecânica & 24 & 9 & média \\
\hline FeOx@S4 & 15,2 & 5 & 0,15 & mecânica & 24 & 9 & muito alta \\
\hline FeOx@S5 & 15,2 & 5 & 0,15 & mecânica & 48 & 14 & alta \\
\hline FeOx@S6 & 15,2 & 5 & 0,15 & mecânica & 72 & 14 & alta \\
\hline FeOx@S7 & 15,2 & 5 & 0,10 & mecânica & 72 & 12 & alta \\
\hline FeOx@S8 & 15,2 & 20 & 0,15 & mecânica & 24 & 6 & baixa \\
\hline FeOx@S9 & 15,2 & 30 & 0,15 & mecânica & 24 & 5 & baixa \\
\hline FeOx@S10 & 23,7 & 5 & 0,15 & mecânica & 24 & 12 & baixa \\
\hline FeOx@S11 & 23,7 & 20 & 0,15 & mecânica & 24 & 10 & muito alta \\
\hline CoFeOx@S1 & 10,9 & 2,5 & 0,15 & mecânica & 24 & 4,5 & alta \\
\hline
\end{tabular}

Fonte: Autoria própria. 
Figura 57 - Imagens de MET das amostras de NPM após serem submetidas ao procedimento de recobrimento com sílica.

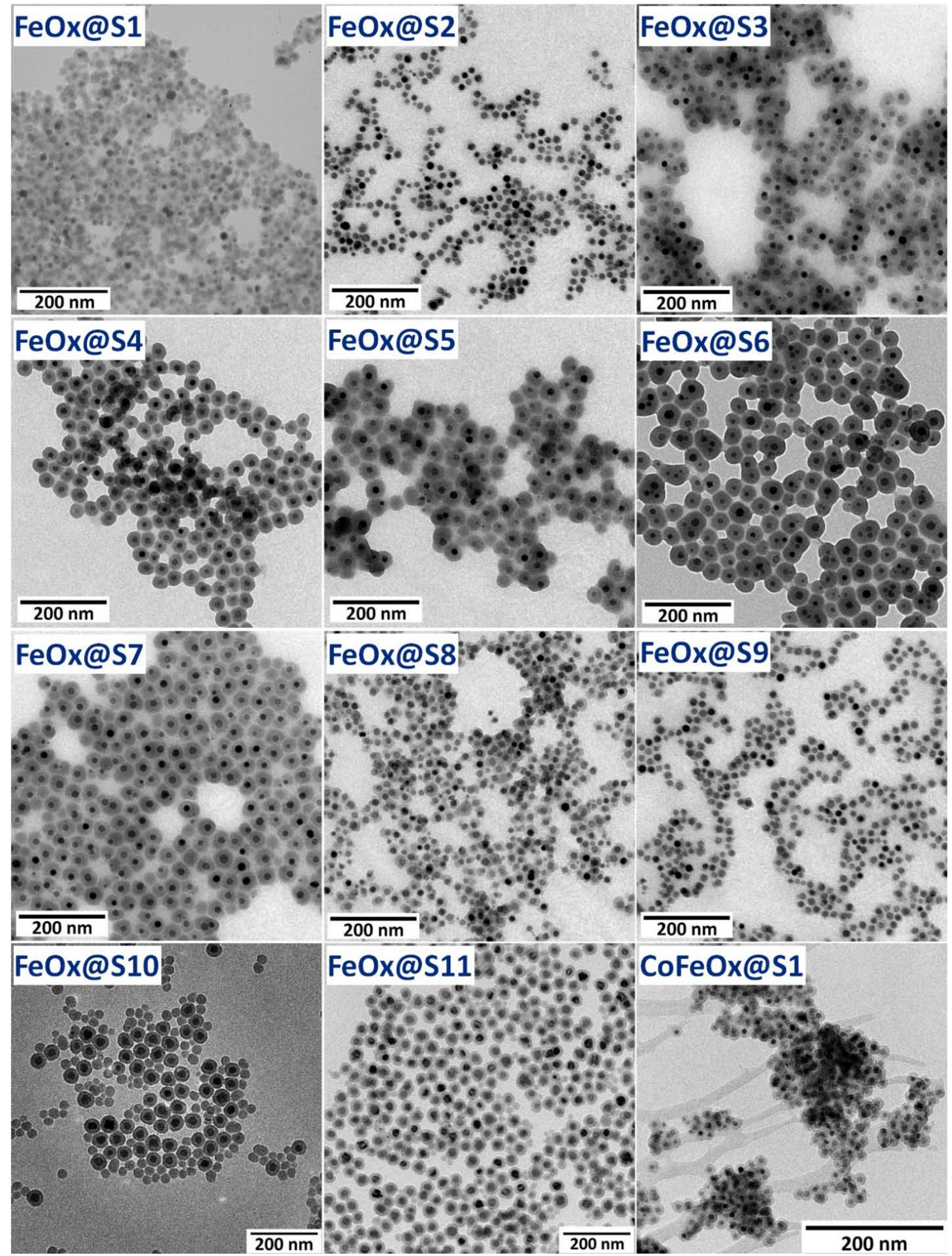

Fonte: Autoria própria.

O tipo de agitação usada no processo de recobrimento mostrou grande influência sobre o estado de agregação dos caroços de magnetita. O uso de agitação magnética causa aglomeração 
entre as NPM, resultando em uma espécie de matriz de sílica com NPM dispersas em seu interior (amostras FeOx@S1). Isso deve-se à atração magnética exercida pela barra magnética de agitação sobre as NPM inseridas no interior das micelas, o que causa coalescência entre essas micelas e resulta na formação de sílica como uma fase contínua.

Com agitação mecânica, uma homogênea camada de $\mathrm{SiO}_{2}$ pode ser obtida sobre cada partícula individual. A espessura da camada de sílica mostrou-se diretamente proporcional ao tempo de reação e à concentração de TEOS e inversamente proporcional à concentração de NPM. Como mostrado na Figura 58, após 16 horas de reação (FeOx@S2), as NPM ainda apresentam caráter hidrofóbico, sendo necessários tempos maiores de reação para um recobrimento satisfatório. Para reações com 24 e 48 horas (amostras FeOx@S4 e FeOx@S5), a espessura da camada foi aumentado para $9 \mathrm{~nm}$ e $14 \mathrm{~nm}$, respectivamente. Essa relação concorda com a reação de primeira ordem proposta por Ohmori et al. para a hidrólise de TEOS.(129) Entretanto, um novo aumento para 72 horas (amostra FeOx@S6) não resulta em uma casca mais espessa, o que sugere um limite máximo no tempo de reação ao redor de 48 horas. Como partículas de sílica sem caroço magnético não foram formadas, este limite mostra a concentração de TEOS como um fator limitante sobre a formação da casca de sílica.

Figura 58 - Sistemas bifásicos contendo as amostras FeOx@S2, FeOx@S4 e FeOx@S4 dispersas entre as fases água e hexano.

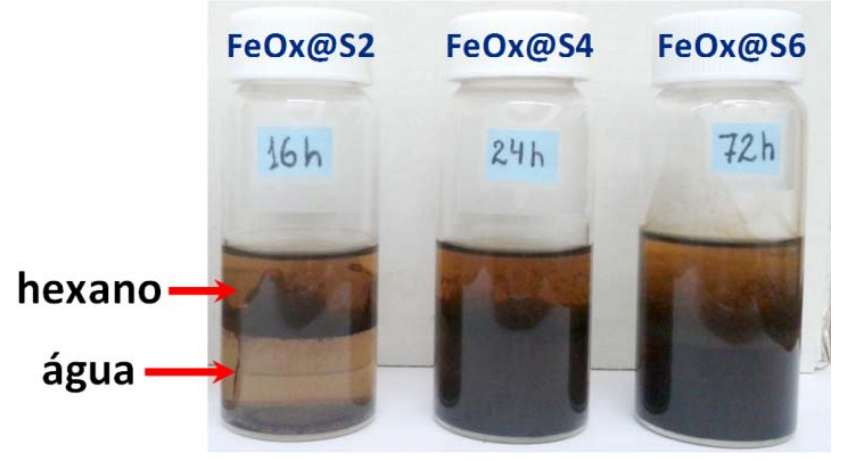

Fonte: Autoria própria.

A diminuição da concentração de TEOS leva à diminuição da espessura da camada de sílica. Diminuindo-se em 33\% a concentração de TEOS, a espessura cai de $14 \mathrm{~nm}$ para $12 \mathrm{~nm}$ após 72 horas de reação (FeOx@S7). A mesma diminuição de 33 \% faz com que a espessura caia de 9 $\mathrm{nm}$ para $8 \mathrm{~nm}$ após 24 horas de reação. Entretanto, embora haja a diminuição da espessura da casca, a homogeneidade do recobrimento é comprometida. Já aumentos de $300 \%$ e $500 \%$ na concentração de NPM resultam em camadas de recobrimento com 6 e $5 \mathrm{~nm}$ de espessura, respectivamente (amostras FeOx@S8 e FeOx@S9). Ainda, assim como para a diminuição da 
concentração de TEOS, o aumento na concentração de NPM resulta na queda na homogeneidade no recobrimento acompanhado por um maior grau de agregação entre os caroços de NPM.

Variando-se o diâmetro das NPM, a concentração de NP adicionada à microemulsão deve ser alterada para obtenção de recobrimentos homogêneos: NP maiores demandam uma maior concentração de NP. Para o recobrimento da amostra FeOx-08 com NPM de 23,7 nm, o uso das mesmas condições usadas para a amostra FeOx@S4 resulta em extensa formação de partículas de sílica sem caroço magnético (amostra FeOx@S10). Com o aumento de 200\% na concentração de NPM, a formação de partículas de sílica é praticamente eliminada e uma homogênea camada de recobrimento de $10 \mathrm{~nm}$ é obtida (FeOx@S11). A necessidade de maiores concentrações de NP deve-se à relação entre o número de NPM individuais adicionadas e a quantidade de micelas disponíveis na microemulsão. Para evitar a formação de partículas segregadas de sílica, essas quantidades devem ser iguais. Segundo a literatura, a quantidade de micelas em uma microemulsão é controlada pela razão $(R)$ entre as quantidades da fase aquosa e do surfactante (neste caso, $\mathrm{R}=\mathrm{NH}_{4} \mathrm{OH} /$ Igepal).(51) Assim, para o recobrimento de partículas maiores, esta devem ser adicionadas em maior quantidade (em massa) ao sistema de forma que o número de NP seja mantido constante e igual à quantidade de micelas presentes no sistema de microemulsão. NPM de $\mathrm{CoFe}_{2} \mathrm{O}_{4}$ (amostra CoFeOx-01) também foram recobertas utilizando o método de hidrólise de TEOS em sistemas de microemulsão. Considerando o menor diâmetro dessas NPM (10,9 nm), uma massa de $2,5 \mathrm{mg}$ foi utilizado para a obtenção de uma homogênea camada de sílica com 4,5 nm de espessura (Figura 57).

A literatura apresenta alguns possíveis mecanismos para o processo de recobrimento aqui empregado. A maior divergência entre os diferentes mecanismos propostos está no momento em que a NPM é internalizada pela micela. Ding et al.(51) propõem que a internalização ocorre antes da adição de TEOS graças à substituição do ácido oleico presente na superfície das NPM por moléculas do surfactante Igepal. Essa substituição conferiria hidrofilicidade às partículas, que então teriam maior afinidade pelo ambiente aquosos do interior das micelas. Uma vez internalizadas, espécies parcialmente hidrolisadas de TEOS passariam a substituir as moléculas de Igepal, dando origem à camada de sílica. Entretanto, nossas observações discordam do mecanismo proposto por Ding, uma vez que mesmo após 16 horas de reação de recobrimento, o produto ainda mantém seu caráter hidrofóbico (Figura 58). Este caráter indica a presença de ácido oleico (e não Igepal) sobre a superfície dessas NPM mesmo após 16 horas de reação. Trabalhos de Guardia et al.(130) relatam a ocorrência de uma forte ligação covalente entre o 
grupo carboxílico do ácido oleico e a superfície das NPM de óxido de ferro, o que torna improvável a substituição do ácido oleico por moléculas de Igepal na superfície das partículas.

A Figura 59 compara os espectros FTIR das amostras de NP antes e após o recobrimento com sílica (espectros azul e vermelho, respectivamente) com o espectro obtido para uma amostra cujo processo de recobrimento foi interrompido imediatamente antes da adição de TEOS (espectro verde). No espectro da amostra não recoberta, a presença de ácido oleico é confirmada pela presença de bandas em 2920 e $2850 \mathrm{~cm}^{-1}$ atribuídas respectivamente aos estiramentos assimétrico e simétrico de grupos metileno. A banda característica de grupos carboxilato aparece deslocada de $1710 \mathrm{~cm}^{-1}$ para $1408 \mathrm{~cm}^{-1}$, indicando que o ácido oleico encontra-se quimicamente ligado à superfície das NPM através desse grupo. O espectro verde apresenta somente bandas características do óxido de ferro e do ácido oleico, as quais são similares às bandas observadas para a amostra não recoberta. Para a amostra recoberta, a presença da camada de sílica é confirmada pela presença de 5 bandas centradas em 1188, 1098, 952, 801 e $469 \mathrm{~cm}^{-1}$ no espectro da amostra FeOx@S4. Tais bandas são respectivamente atribuídas aos modos óptico-longitudinal e transversal de estiramentos assimétricos $\mathrm{Si}-\mathrm{O}-\mathrm{Si}$, estiramentos de grupos $\mathrm{Si}-\mathrm{OH}$, estiramentos simétricos de grupos $\mathrm{Si}-\mathrm{O}-\mathrm{Si}$ e desdobramentos de grupos $\mathrm{Si}-\mathrm{O}-\mathrm{Si}$. A ausência de bandas características de grupos éter alifáticos e aromáticos na região entre 1250 e $1050 \mathrm{~cm}^{-1}$ do espectro verde indica que as NP não apresentam moléculas de Igepal em sua superfície, contrariando o mecanismo de Ding.(51)

Figura 59 - Espetros FTIR obtidos para as amostras de NPM antes e após recobrimento com sílica. Em verde, espectro de uma amostra de NP coletadas imediatamente antes da adição de TEOS.

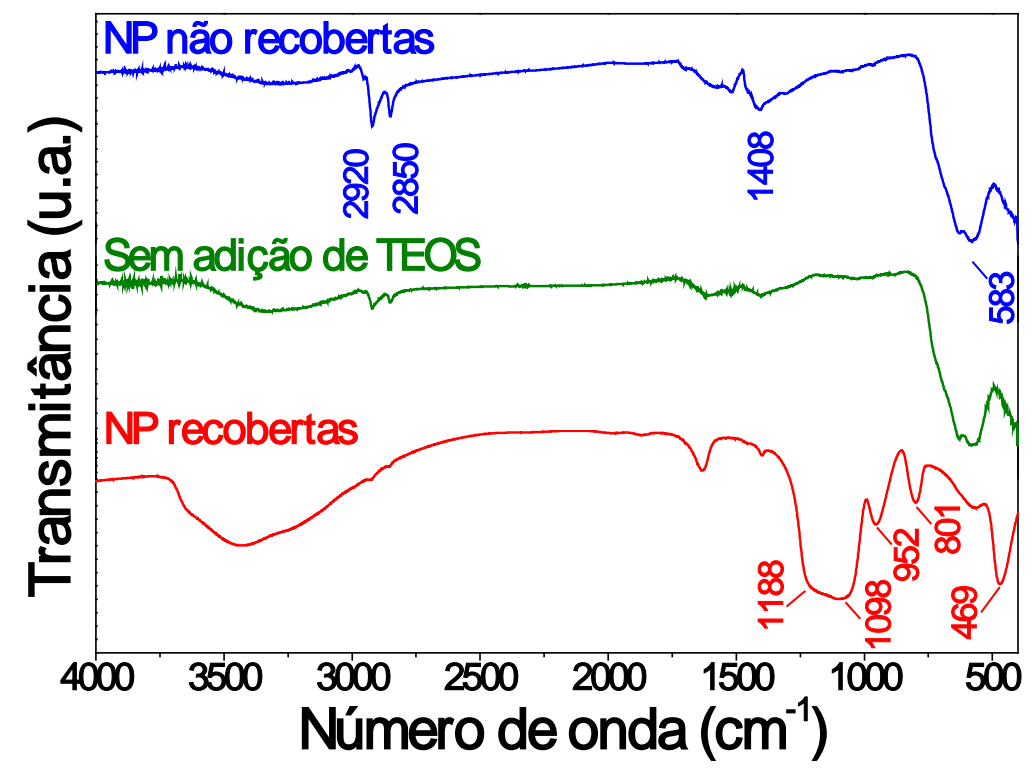

Fonte: Autoria própria. 
Figura 60 - llustração esquemática do mecanismo proposto para o processo de recobrimento de NP com sílica via hidrólise básica de TEOS em sistema de microemulsão inversa.
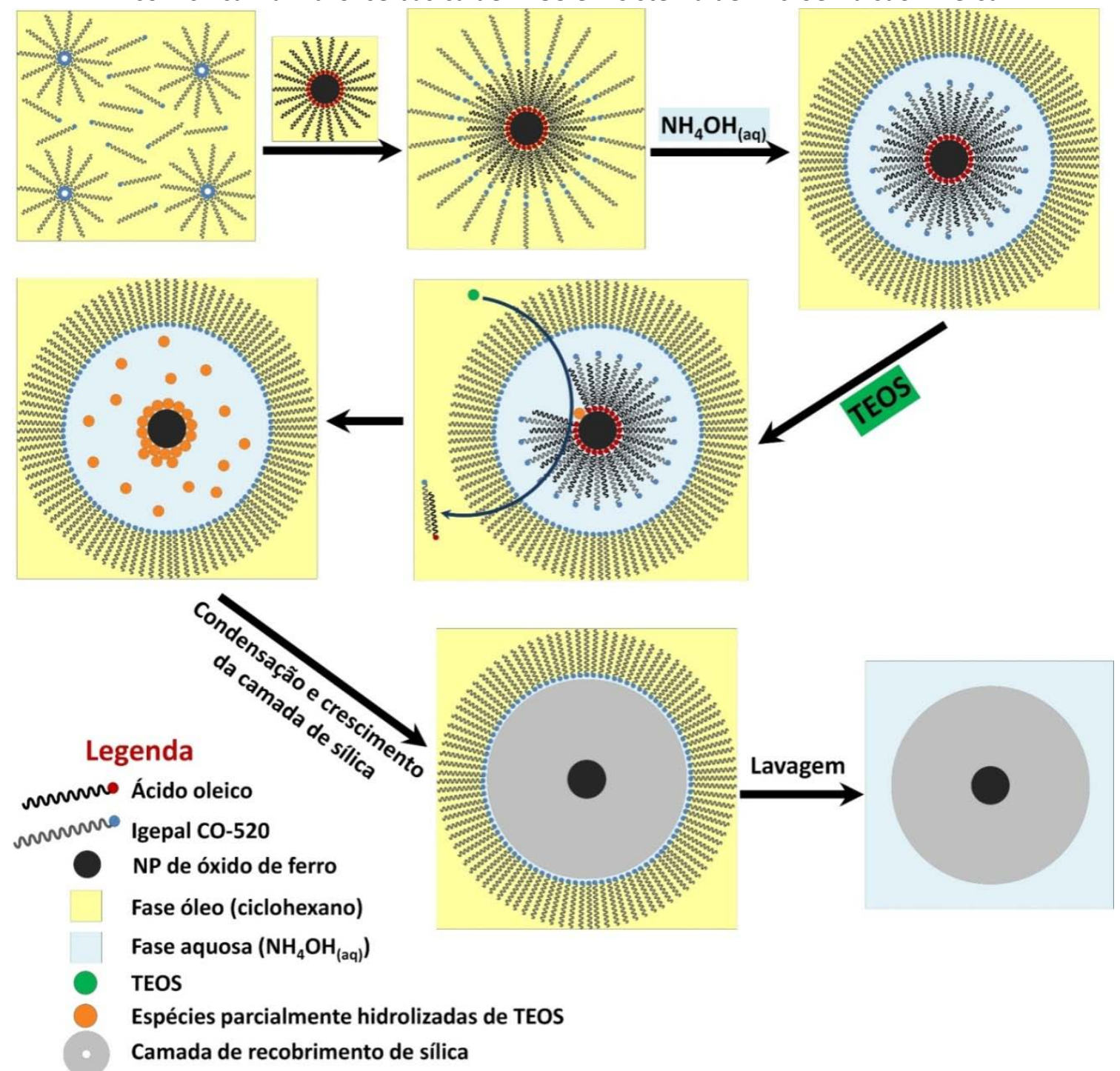

Fonte: Autoria própria.

Com base nas análises de MET e FTIR e no caráter hidrofóbico da amostra FeOx@S2, é proposto o provável mecanismo para o processo de recobrimento de NPM via hidrólise de TEOS em sistemas de microemulsão, o qual é ilustrado na Figura 60. Após a adição das NPM ao meio, a cadeia orgânica das moléculas de Igepal interage positivamente com a cadeia de moléculas de ácido oleico, formando uma dupla camada de surfactantes na superfície das NP, a qual permite que as mesmas sejam internalizadas pelas micelas. As moléculas de TEOS, presentes na fase óleo devido a seu caráter apolar, são hidrolisadas na interface água/ciclohexano, dando origem a espécies parcialmente hidrolisadas que rapidamente são transferidas para o interior das micelas. Tais espécies são muito instáveis e passam a se condensar na superfície das NPM, deslocando a dupla camada de surfactantes alí presentes. Com a contínua hidrólise do TEOS, mais espécies parcialmente hidrolisadas estão disponíveis no interior das micelas e reações de condensação 
entre tais espécies resultam no crescimento da camada de sílica sobre a superfície das NPM em uma estrutura core-shell. Uma vez que não são observadas bandas características do Igepal no espectro da amostra colhida antes da adição de TEOS, a interação positiva entre as cadeias orgânicas desse surfactante e do ácido oleico não é forte o suficiente para persistir após a etapa de lavagem, sendo as moléculas de Igepal eliminadas durante esta etapa.

\subsubsection{Recobrimento das NPM com anatase}

Com vistas a aplicações em catálise heterogênea, o processo de recobrimento foi posteriormente testado para a obtenção de NPM recobertas com óxido de titânio. Para isso, um teste inicial (amostra FeOx@T1) foi realizado usando o mesmo procedimento adotado para a amostra FeOx@S4 no qual o TEOS foi substituído por tetraisopropóxido de titânio (TIPT, 205 $\mu \mathrm{L}=$ 0,66 mmol). Conforme mostra a Figura 61, o método adotado não se mostrou eficiente: uma fase contínua de óxido de titânio contendo NPM em seu interior pode ser observada. De fato, já era esperada uma maior dificuldade quanto ao recobrimento com $\mathrm{TiO}_{2}$, visto que alcóxidos de titânio possuem menor estabilidade e uma cinética de hidrólise muito superior à de alcóxidos de silício.

Figura 61 - Imagens de MET das amostras obtidas nas tentativas de recobrimento com anatase através do método de microemulsão.
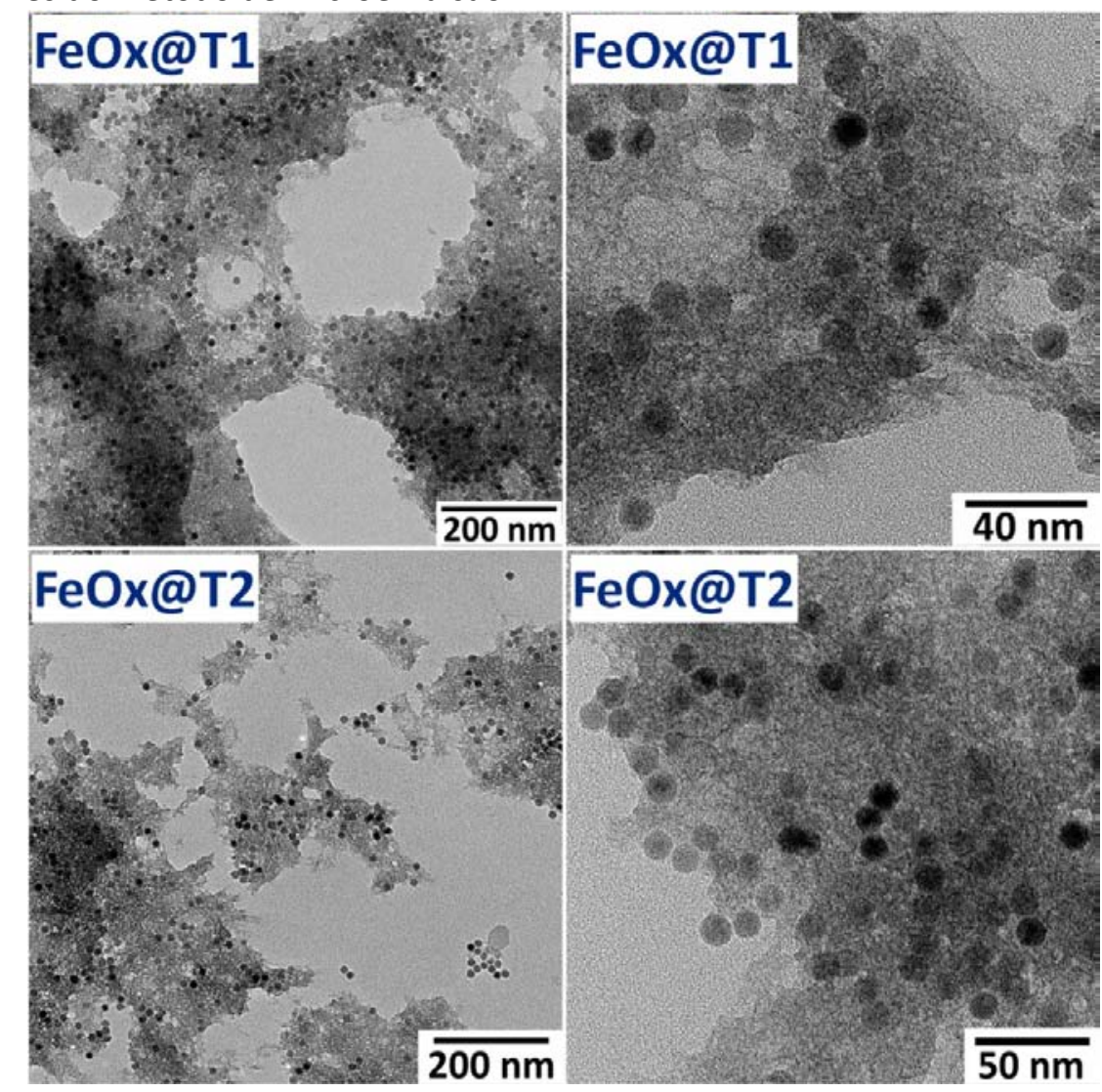

Fonte: Autoria própria. 
Buscando reduzir a cinética da reação de hidrólise, o hidróxido de amônio (catalisador da reação) foi substituído por água (amostra FeOx@T2). Entretanto, novamente não foi alcançado o recobrimento homogêneo das NPM individuais. Uma alternativa seria o uso de alcóxidos nos quais o titânio encontra-se mais impedido estericamente (tert-butóxido de titânio, por exemplo), o que diminuiria a cinética da reação de hidrólise. A desvantagem do uso deste reagente é o custo elevado do mesmo, o que encareceria o processo de produção. A análise por DRX (Figura 62) não apresenta picos característicos de fases de óxido de titânio, o que mostra a baixa cristalinidade da matriz visualmente observada na imagem de MET. Essa baixa cristalinidade é mais um indicativo da cinética acelerada da reação de hidrólise.

Figura 62 - Difratograma das amostras obtidas antes e após recobrimento com $\mathrm{TiO}_{2}$.

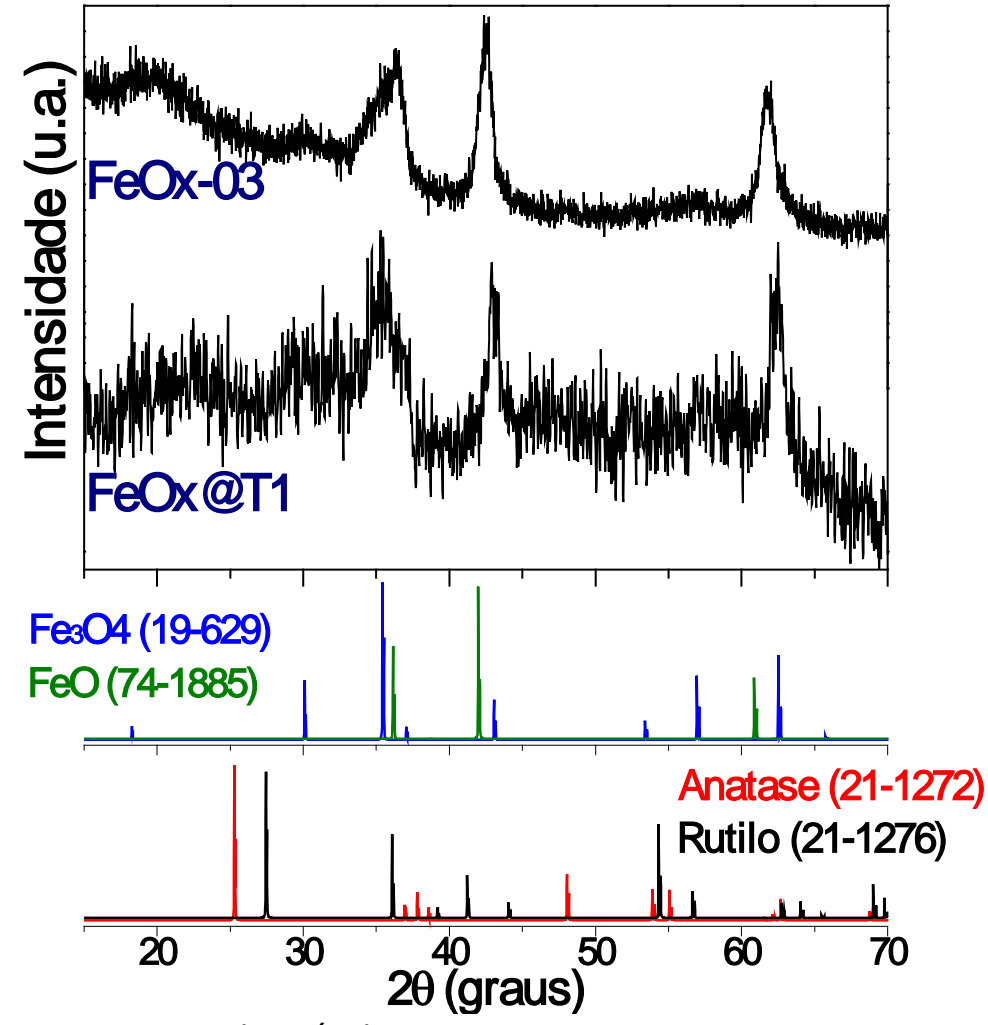

Fonte: Autoria própria.

Dada a ineficiência do método de hidrólise de TIPT em meio de microemulsão, uma nova metodologia passou a ser considerada. O método relatado inicialmente por Cheng et al.(83) e posteriormente usado por Damato et al..(82) utiliza a reação de tetrabutóxido de titânio com etileno glicol, dando origem a partículas de glicolato de titânio. As partículas são posteriormente hidrolisadas em água quente $\left(70^{\circ} \mathrm{C}\right)$ para formar partículas de $\mathrm{TiO}_{2}$ na fase anatase. As dimensões das partículas obtidas pelos autores estão no intervalo entre 240 e 420 nm. 
Neste trabalho de doutorado, este método foi modificado substituindo-se o tetrabutóxido de titânio por tetraisopropóxido de titânio, o que apresenta uma vantagem financeira frente ao precursor tetrabutóxido. Inicialmente o procedimento foi testado na ausência de NPM para obtenção de partículas de $\mathrm{TiO}_{2}$. As imagens da Figura 63 (amostra $\mathrm{TiO}_{2}$ ) mostram que a troca do precursor foi eficaz para diminuição do tamanho das partículas de $\mathrm{TiO}_{2}$, uma vez que partículas esféricas com diâmetro médio de $170 \mathrm{~nm}$ foram obtidas. A análise por DRX (Figura 64) aponta a anatase como fase majoritária, com bruquita como fase secundária e ausência da fase rutilo. A obtenção da anatase ao invés de rutilo é explicada termodinamicamente. Embora ambas as fases tenham entropia próximas $\left(49,9 \mathrm{~J} \mathrm{~K}^{-1} \mathrm{~mol}^{-1}\right.$ para anatase e $50,6 \mathrm{~J} \mathrm{~K}^{-1} \mathrm{~mol}^{-1}$ para rutilo), a entalpia de superfície da anatase é consideravelmente menor $\left(0,4 \mathrm{~J} \mathrm{~m}^{-2}\right.$ contra $2,2 \mathrm{~J} \mathrm{M}^{-2}$ do rutilo), o que contribui para que esta fase apresente menor energia de Gibbs $(\Delta G=\Delta H-T \Delta S) .{ }^{26,27}$ A Tabela 14 traz as atribuições referentes a cada pico observado no difratograma dessa amostra. Nota-se que alguns dos picos observados correspondem à reflexão de mais de um plano, o que deve-se ao considerável alargamento dos picos constituintes do difratograma. Esse alargamento não seria esperado para partículas de $170 \mathrm{~nm}$, mas pode ser explicado por policristalinidade da amostra. De fato, o diâmetro médio de cristalito (calculado pela equação de Scherrer(92) usando a reflexão do plano (101) da fase anatase) é de 4,5 nm, comprovando o caráter policristalino da amostra.

Figura 63 - Imagens de MET da amostra de partículas de TiO2.

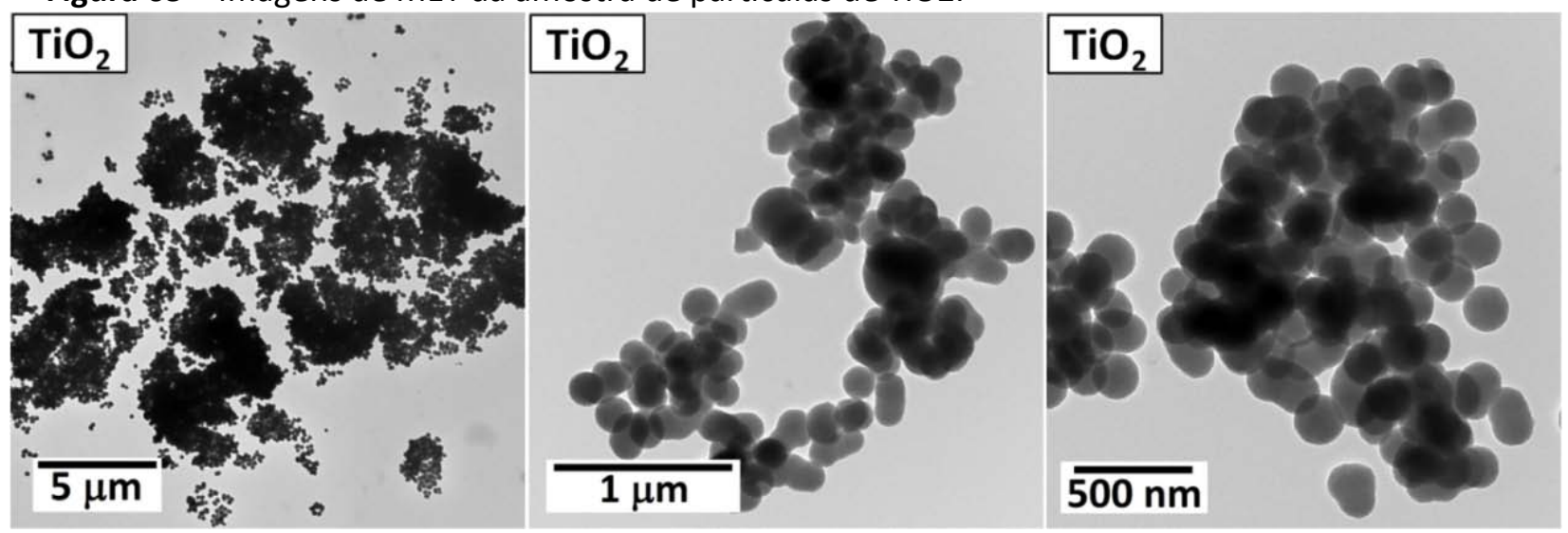

Fonte: Autoria própria. 
Figura 64 - Difratogramas das amostras de partículas de $\mathrm{TiO}_{2}$ e de NPM após recobrimento com $\mathrm{TiO}_{2}$ comparadas aos padrões JCPDS das fases anatase, bruquita, rutilo, magnetita, cohenita, wustita e $\alpha$-ferro.

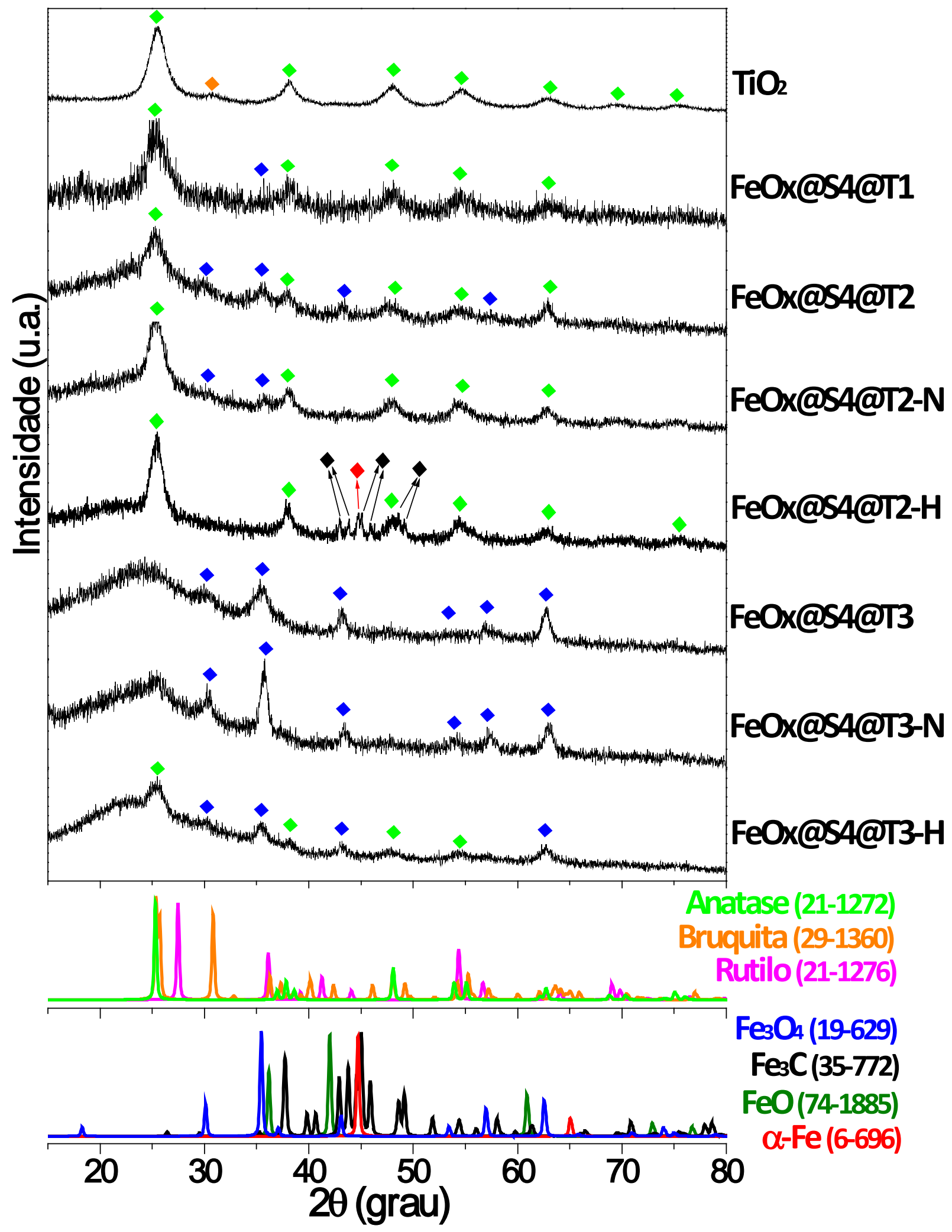

Fonte: Autoria própria. 
Tabela 14 - Atribuições dos picos observados no difratograma da amostra de partículas de $\mathrm{TiO}_{2}$.

\begin{tabular}{c|c|c|c}
\hline $\begin{array}{c}\mathbf{2 \theta} \\
\text { (experimental) }\end{array}$ & plano & $\begin{array}{c}\mathbf{d} \\
\text { (teórico) }\end{array}$ & fase \\
\hline 25,5 & $(101)$ & 3,5200 & anatase \\
\hline 30,9 & $(121)$ & 2,9000 & bruquita \\
\hline \multirow{2}{*}{38,1} & $(103)$ & 2,4310 & \\
& $(004)$ & 2,3780 & anatase \\
& $(112)$ & 2,3320 & \\
\hline 48 & $(200)$ & 1,8920 & anatase \\
\hline \multirow{2}{*}{54,7} & $(105)$ & 1,6999 & anatase \\
& $(211)$ & 1,6665 & anatase \\
\hline \multirow{2}{*}{62,9} & $(213)$ & 1,4930 & Anatase \\
\hline \multirow{2}{*}{69,6} & $(204)$ & 1,4808 & 1,3641 \\
\hline
\end{tabular}

Fonte: Oxford Cryosystems, 2004. (131)

Com relação ao recobrimento de NPM com $\mathrm{TiO}_{2}$, trabalhos da literatura relatam que o contato físico entre as fases magnetita e anatase influencia negativamente a eficiência fotocatalítica da fase de $\mathrm{TiO}_{2}$. Segundo alguns autores, isso deve-se à foto-dissolução da magnetita e à recombinação elétron-buraco que ocorre devido à transferência eletrônica entre as fases.(132,133) Para evitar tal problema, optou-se por realizar o recobrimento com anatase sobre NPM previamente recobertas com sílica. Para isso, a amostra FeOx@S4 foi empregada. As imagens de MET das amostras recobertas com anatase são apresentadas na Figura 65.

O ajuste das quantidades relativas entre o precursor de titânio e as NPM tem grande influência no recobrimento. Usando uma razão mássica $\left(R=m_{\text {TIPT }} / m_{N P M}\right)$ de 110 (amostra FeOx@S4@T1), embora o recobrimento tenha ocorrido, ele não foi eficiente dado o excesso da fase $\mathrm{TiO}_{2}$ comparada à fase de óxido de ferro. Já para valores de $\mathrm{R}=11$ e $\mathrm{R}=6$, recobrimentos com espessuras de 12 e 2 nm foram respectivamente obtidos para as amostras FeOx@S4@T2 e FeOx@S4@T3.

A análise por EDX indicou a incorporação de titânio em ambas as amostras, sendo a incorporação diretamente proporcional ao valor de R. As composições metálicas molares medidas para as amostras FeOx@S4@T2 e FeOx@S4@T3 foram respectivamente $\mathrm{Fe}_{13} \mathrm{Si}_{52} \mathrm{Ti}_{35}$ e $\mathrm{Fe}_{15} \mathrm{Si}_{61} \mathrm{Ti}_{23}$. Isso significa que a amostra FeOx@S4@T2 possui estrutura cristalina composta por 14,1\% em $\mathrm{Fe}_{3} \mathrm{O}_{4}, 45,3 \%$ em $\mathrm{SiO}_{2}$ e 40,6\% em $\mathrm{TiO}_{2}$. Já a composição da amostra FeOx@S4@T3 é de $17,4 \%$ em $\mathrm{Fe}_{3} \mathrm{O}_{4}, 55,0 \%$ em $\mathrm{SiO}_{2}$ e $27,6 \%$ em $\mathrm{TiO}_{2}$. Tais porcentagens são dadas em massa da respectiva fase cristalográfica. A análise por DRX das amostras de NPM recobertas com $\mathrm{TiO}_{2}$ (Figura 64) mostra que, para $R=110$, a estrutura cristalina é composta quase que em sua 
totalidade por anatase. Com a diminuição de R, picos referentes à fase magnetita adquirem maior intensidade em detrimento da diminuição dos picos característicos da anatase, corroborando os dados de EDX.

Figura 65 - Imagens de MET das amostras de NPM após recobrimento com $\mathrm{TiO}_{2}$. Nas imagens, é possível distinguir o núcleo magnético e as duas camadas de recobrimento $\left(\mathrm{SiO}_{2}\right.$ e $\left.\mathrm{TiO}_{2}\right)$ pela diferença de contraste.

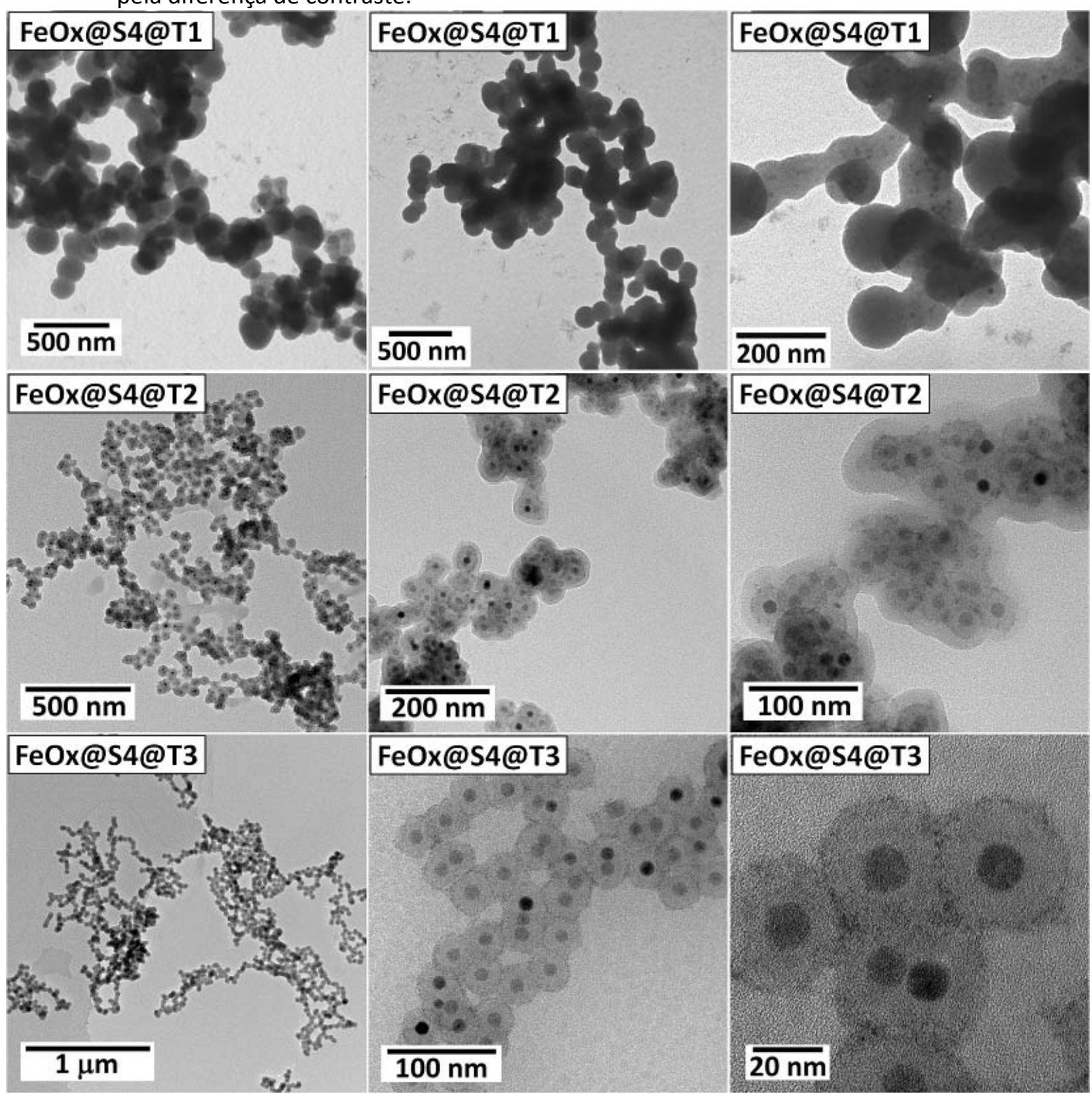

Fonte: Autoria própria.

Visando alcançar a melhor atividade catalítica possível, tratamentos térmicos a $250^{\circ} \mathrm{C}$ foram realizados em atmosfera de $\mathrm{N}_{2}$ e de $\mathrm{H}_{2}$ para as amostras recobertas com dióxido de titânio para aumentar a cristalinidade da fase anatase. As amostras tratadas termicamente em atmosfera de $\mathrm{N}_{2}$ (FeOx@S4@T2-N e FeOx@S4@T3-N) mostram um aumento de sua cristalinidade, comprovado pelo menor alargamento dos picos observado em seus respectivos 
difratogramas, mas sem modificações quanto às fases presentes nas amostras. Já o tratamento térmico em $\mathrm{H}_{2}$ levou a alterações na estrutura cristalina das amostras. Picos característicos da anatase, ausentes no difratograma da amostra FeOx@S4@T3 são visíveis para a amostra FeOx@S4@T3-H, o que pode estar relacionado ao aumento de cristalinidade do $\mathrm{TiO}_{2}$. $\mathrm{Na}$ amostra FeOx@S4@T4-H, a presença de picos em 44,7 (plano (100) da fase $\alpha$-Fe) e em 42,8 $, 43,8^{\circ} 45,1^{\circ}$, $45,9^{\circ}, 48,6^{\circ}$ e $49,2^{\circ}$ (planos (211), (102), (031), (112), (131) e (221) da fase cohenita de carbeto de ferro) indicam redução do núcleo magnético. Como a redução da amostra FeOx@S4@T3, para a qual foi usada menor quantidade do precursor de titânio, não levou à formação da fase carbeto, acredita-se que o carbono da fase carbeto deve provir de material orgânico remanescente do recobrimento com $\mathrm{TiO}_{2}$.

\subsection{Redução térmica de NPM de óxidos metálicos}

Embora alguns trabalhos reportem a síntese de partículas metálicas de Fe via redução térmica de óxidos de ferro, a temperatura de redução parece não ser um consenso entre os autores. Karaagac et al. reportam a completa redução de partículas de hematita a $\alpha$-Fe a $400^{\circ} \mathrm{C} .(134)$ Pozas et al. mostram através de experimentos de redução por temperatura programada (TRP) que tal redução ocorre ao redor de $470^{\circ} \mathrm{C}$, embora as análises de DRX apresentadas pelos autores mostrem a necessidade de um tratamento isotérmico a $600^{\circ} \mathrm{C}$ para a completa redução.(135) O mesmo Karaagac et al. reporta em trabalho mais recente que temperaturas de $800^{\circ} \mathrm{C}$ são necessárias, embora a $600^{\circ} \mathrm{C}$ é possível obter amostras com uma composição majoritária em $\alpha$-Fe.(136) Neste trabalho se buscou encontrar as condições menos drásticas capazes de promover a completa redução de NPM de óxido de ferro a ferro metálico. Conforme já mencionado, os tratamento térmicos foram realizados com NPM previamente recobertas com sílica. O prévio recobrimento visa evitar processos de sinterização entre as NPM, o que alteraria sua forma e dimensões, alterando consequentemente suas propriedades. Nos estudos aqui apresentados foram variados parâmetros experimentais, como fluxo de gás $\mathrm{H}_{2}$ (30 $\left.90 \mathrm{~L} \mathrm{~h}^{-1}\right)$, temperatura $\left(400-600^{\circ} \mathrm{C}\right)$ e tempo de redução $(4-15 \mathrm{~h})$, os quais são resumidos na Tabela 15 e também apresentados ao lado dos difratogramas respectivos a cada amostra (Figuras 66 e 67). 
Tabela 15 - Condições experimentais utilizadas para cada amostra durante a etapa de redução térmica e seus respectivos resultados obtidos por DRX.

\begin{tabular}{|c|c|c|c|c|c|}
\hline \multicolumn{4}{|c|}{ Condições de redução } & \multicolumn{2}{|c|}{ Resultados de DRX } \\
\hline Amostra & $\begin{array}{c}\text { Temperatura } \\
\text { de redução }\left({ }^{\circ} \mathrm{C}\right)\end{array}$ & $\begin{array}{l}\text { Tempo de } \\
\text { redução (h) }\end{array}$ & $\begin{array}{l}\text { Fluxo de } \mathrm{H}_{2} \\
\qquad\left(\mathrm{~L} \mathrm{~h}^{-1}\right)\end{array}$ & Fases cristalinas* & $\begin{array}{l}\text { Tamanho de } \\
\text { Cristalito (nm) }\end{array}$ \\
\hline FeOx@S4 & - & - & - & $\mathrm{Fe}_{3} \mathrm{O}_{4}$ & 14,9 \\
\hline FeOx@S11 & - & - & - & $\mathrm{FeO}$ & 9,8 \\
\hline CoFeOx@S1 & - & - & - & $\mathrm{CoFe}_{2} \mathrm{O}_{4}$ & n.c. \\
\hline FeOx@S4R1 & 400 & 4 & 60 & $\mathrm{Fe}_{3} \mathrm{O}_{4}$ & n.c. \\
\hline FeOx@S4R2 & 500 & 4 & 30 & $\mathrm{Fe}_{3} \mathrm{O}_{4}+\mathrm{FeO}+\alpha-\mathrm{Fe}$ & n.c. \\
\hline FeOx@S4R3 & 600 & 4 & 30 & $\mathrm{Fe}_{3} \mathrm{O}_{4}+\mathrm{FeO}+\alpha-\mathrm{Fe}$ & n.c. \\
\hline FeOx@S4R4 & 500 & 15 & 30 & $\mathrm{Fe}_{3} \mathrm{O}_{4}+\mathrm{FeO}+\alpha-\mathrm{Fe}$ & n.c. \\
\hline FeOx@S4R5 & 500 & 4 & 90 & $\mathrm{FeO}+\alpha-\mathrm{Fe}+\mathrm{Fe}_{3} \mathrm{O}_{4}$ & n.c. \\
\hline FeOx@S4R6 & 600 & 4 & 90 & $\alpha-\mathrm{Fe}+\mathrm{FeO}$ & 12,7 \\
\hline FeOx@S11R1 & 600 & 4 & 90 & $\alpha-\mathrm{Fe}$ & 21,7 \\
\hline CoFeOx@S1R1 & 600 & 4 & 90 & $b c c-\mathrm{FeCo}+\mathrm{CoFe}_{2} \mathrm{O}_{4}$ & n.c. \\
\hline
\end{tabular}

* As fases são apresentadas em ordem decrescente com relação à quantidade presente na amostra; n.c. = não calculado. Fonte: Autoria própria.

A análise de DRX mostra que temperaturas de 400 e $500^{\circ} \mathrm{C}$ proporcionam uma redução parcial, com formação da fase wustita (picos em $42,1^{\circ}, 61,1^{\circ}$ referentes aos planos (200) e (220)) e $\alpha$-Fe (pico em $44,6^{\circ}$ do plano (110)). Para as amostras reduzidas a $500^{\circ} \mathrm{C}$, nenhum progresso na redução foi observado com o aumento do tempo de reação para 15 horas (FeOx@S4R3). Já com o aumento do fluxo de $\mathrm{H}_{2}$ para $90 \mathrm{~L} \mathrm{~h}^{-1}$ (FeOx@S4R4), a intensidade relativa dos picos característicos às fases wustita e $\alpha$-Fe cresce com relação aos picos da magnetita, mostrando um avanço no processo de redução. A redução completa somente foi alcançada com o aumento simultâneo da temperatura para $600^{\circ} \mathrm{C}$ e do fluxo de $\mathrm{H}_{2}$ para $90 \mathrm{~L} \mathrm{~h}^{-1}$, o que mostra que o processo de redução é diretamente dependente desses dois parâmetros. Isso é confirmado pelo difratograma da amostra FeOx@S4R6, o qual é composto por dois picos centrados em $44,7^{\circ}$ e $65.1^{\circ}$ em $2 \theta$, respectivamente atribuídos às reflexões dos planos (110) and (200) da estrutura cúbica de corpo centrado ( $b c c$, do inglês body-centered cubic). A presença da fase wustita nas amostras parcialmente reduzidas aponta tal fase como intermediária no processo de redução, conforme já havia sido observado por Varanda et al. em trabalhos sobre a redução de partículas de hematita e de goetita à $\alpha$-Fe. $(137,138)$ Cabe ressaltar que a amostra reduzida apresenta considerável estabilidade química, haja vista que a fase $\alpha$-Fe se mantém mesmo após exposição ao ar por 4 meses (FeOx@S4R6b). Isso mostra a eficiência do processo de passivação com vapor 
de etanol. Entretanto, um pequeno grau de oxidação é mostrado pela presença de 3 picos de baixa intensidade característicos da wustita.

Figura 66 - Difratogramas das amostras reduzidas comparados ao da amostra não-reduzida e aos padrões JCPDS das fases $\mathrm{Fe}_{3} \mathrm{O}_{4}$, $\mathrm{FeO}$ e $\alpha$-Fe.

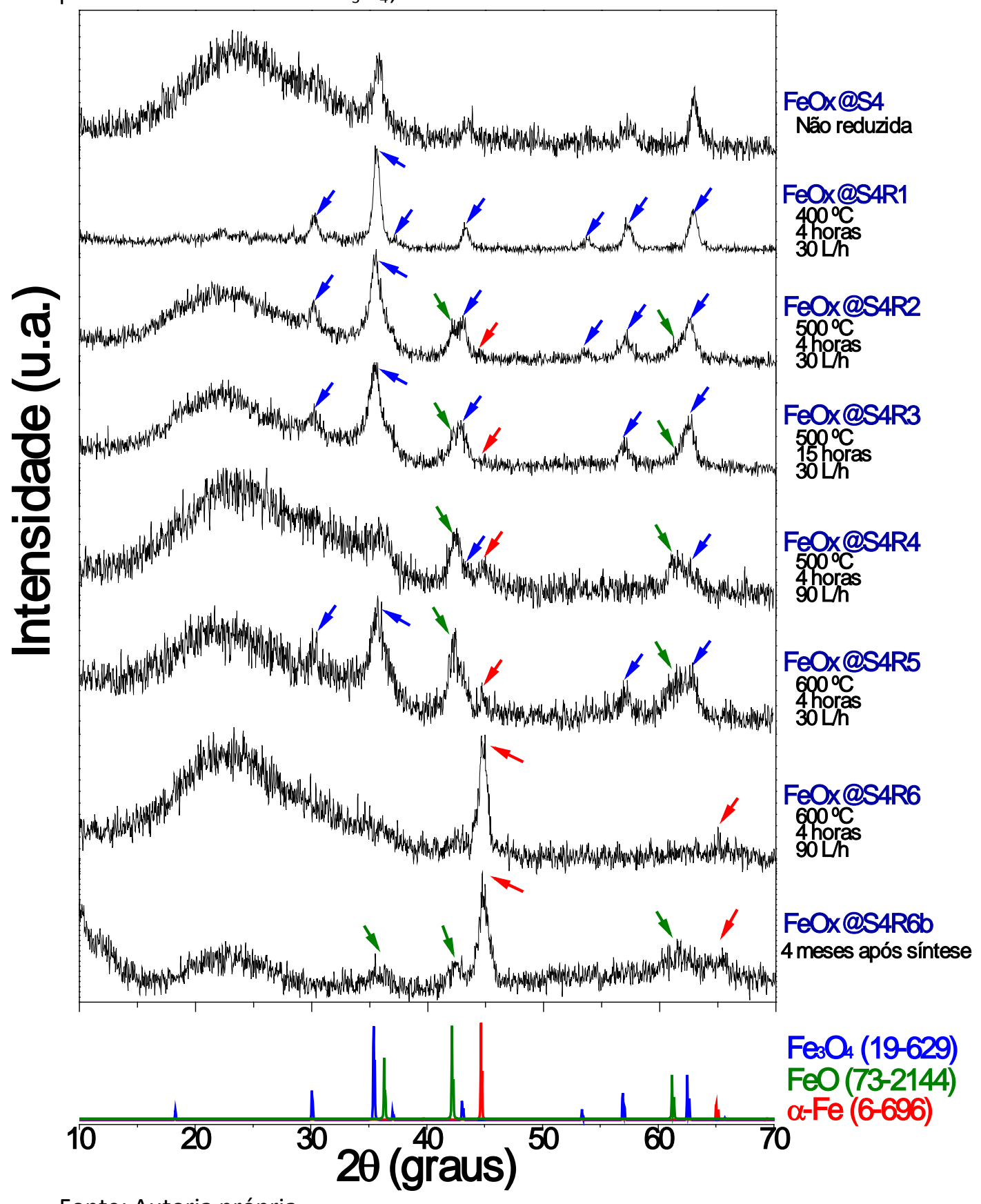

Fonte: Autoria própria.

As condições empregadas na redução da amostra FeOx@S4R6 são mais drásticas que as condições normalmente reportadas na literatura.(134,135,138) Tal diferença pode estar relacionada às pequenas dimensões das NPM ou mesmo à presença da camada de recobrimento de sílica. Com relação às dimensões das NP, temperaturas entre 400 e $500^{\circ} \mathrm{C}$ são normalmente reportadas para partículas maiores que 100 nm. $(135,138,139)$ A diminuição do núcleo de 
magnetita resulta em um aumento de sua razão área de superfície por volume e, consequentemente, de sua reatividade, a qual pode estar dificultando o processo de redução. Ainda, este processo pode estar sendo dificultado devido à presença da camada de recobrimento com sílica. Sabe-se que a taxa de redução de óxido de ferro para ferro metálico em $\mathrm{H}_{2}$ é principalmente controlada pela remoção de moléculas de água produzidas na redução.(140,141) Dessa forma, a casca de sílica pode bloquear o processo de desidratação, atuando como uma barreira para a redução.

Figura 67 - DRX das amostras de óxido de ferro e ferrita de cobalto após redução comparados às amostras não-reduzidas. Em cores, os padrões JCPDS das fases $\mathrm{Fe}_{3} \mathrm{O}_{4}, \mathrm{FeO}, \alpha$-Fe, $\mathrm{CoFe}_{2} \mathrm{O}_{4}$ e bcc-FeCo.

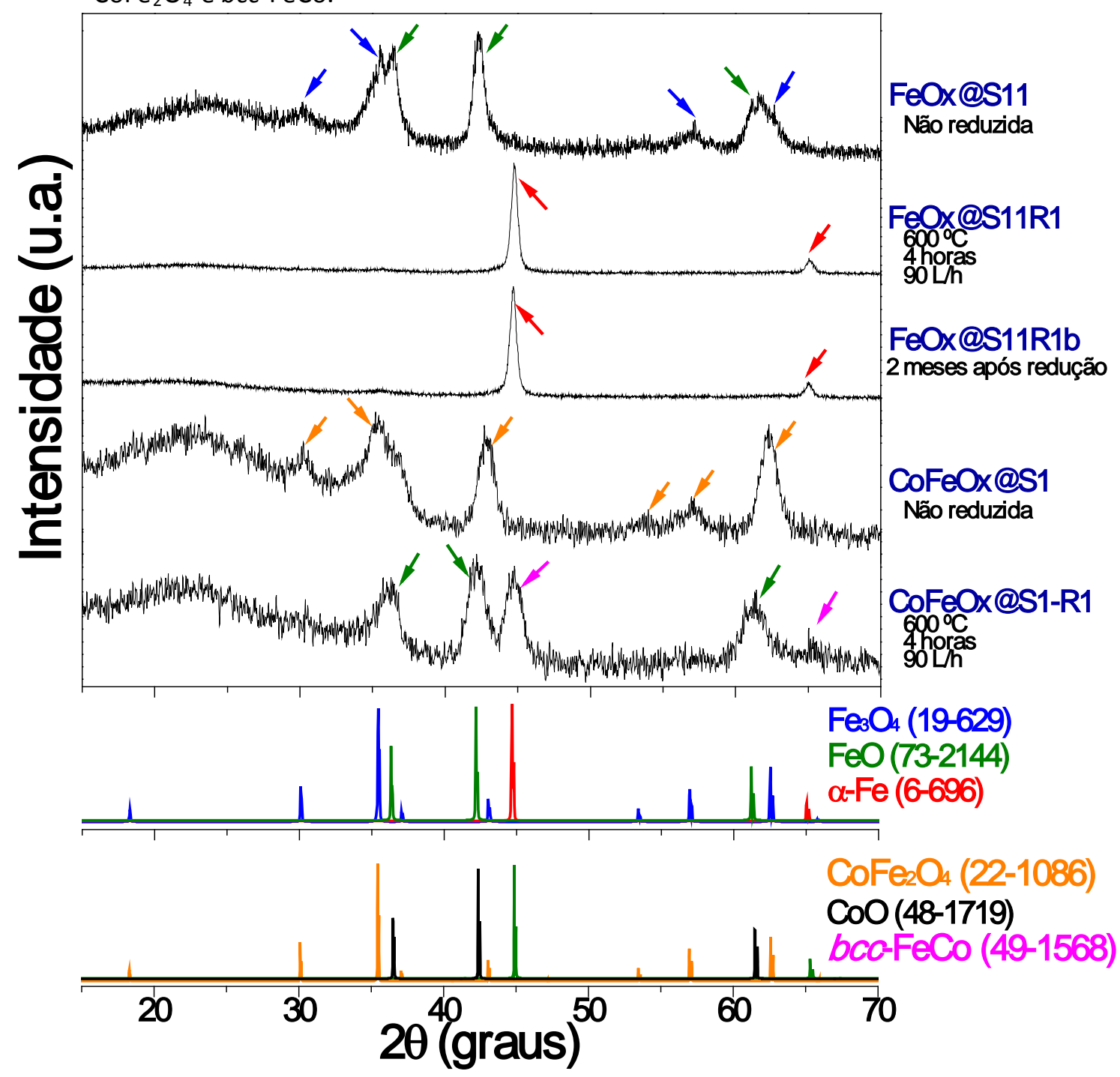

Fonte: Autoria própria.

As mesmas condições aplicadas à amostra FeOx@S4R6 foram empregadas na redução de NPM de óxido de ferro com 23,7 nm recobertas com sílica (amostra FeOx@S11R1) e de NPM de ferrita de cobalto também recobertas com sílica (CoFeOx@S1R1). Os difratogramas da Figura 67 
indicam sucesso na redução da amostra de óxido de ferro, novamente com estabilidade química da fase $\alpha$-Fe, que se mantém mesmo após 2 meses de exposição ao ar. Com relação à amostra CoFeOx@S1R1, embora uma fase óxido ainda esteja presente após a redução, a presença da fase bcc-FeCo é comprovada pelos picos centrados em $44,8^{\circ}$ e $65,3^{\circ}$. A presença da fase óxido pode estar relacionado à redução incompleta da amostra ou mesmo à camada de passivação. Ambos os casos seriam resultado das menores dimensões das NP de $\mathrm{CoFe}_{2} \mathrm{O}_{4}(10,9 \mathrm{~nm})$ comparadas às NP de óxido de ferro $(15,2$ e $23,7 \mathrm{~nm})$. Isso porque partículas menores possuem uma maior relação área de superfície por volume, o que aumenta a reatividade das NP (por exemplo, oxidação). Ainda, considerando que uma camada de óxido seja formada sobre a superfície das NP metálicas durante o processo de passivação, a razão entre as quantidades da fase metálica no interior da NP e da fase óxido em sua superfície é menor quanto menor as dimensões da NP, o que aumenta a contribuição do óxido na análise de DRX.

As imagens de MET das amostras FeOX@S4R6, FeOx@S11R1 e CoFeOx@S1R1 (Figura 68) mostram que a estrutura casca-caroço foi mantida após o recobrimento, o que demonstra a eficiência da sílica em evitar processos de sinterização inter-partículas durante os tratamentos térmicos. Na imagem da amostra com caroço magnético de 15,2 nm (FeOx@S4R6) observa-se espaços (ocos) entre o caroço magnético e a casca de sílica, o que indica uma diminuição do tamanho do caroço magnético. Esses espaços são melhores observados na Figura 69. Tal diminuição, explicada pela perda de oxigênio durante a redução e ao menor volume da estrutura $b c c$ da fase $\alpha$-Fe em comparação ao volume da estrutura espinélio inverso da magnetita, é corroborada pela análise de DRX (Tabela 15), a qual aponta tamanhos médios de cristalito de 14,9 e 12,7 nm respectivamente para as amostras FeOx@S4 e FeOx@S4R6. Embora menos pronunciada, a diminuição do caroço magnético também é observada na imagem da amostra com caroço de 23,7 nm (FeOx@S11R1). Entretanto, esta diminuição não é corroborada pelo cálculo do tamanho médio de cristalito, o qual cresce de 9,8 nm para 21,7 nm após a redução. Como as imagens de TEM não mostram qualquer aumento do caroço magnético, este crescimento refere-se à transformação de um sistema policristalino (caroço de wustita) para monocristalino (caroço de ferro metálico). A imagem de maior aumento da amostra FeOx@S11R1 mostra que a camada de sílica possui grande rugosidade, o que é um indicativo de mesoporosidade. A estrutura porosa da sílica, embora confira uma menor estabilidade química ao núcleo magnético, possibilitaria que fármacos com dimensões moleculares apropriadas fossem aprisionados nos poros da sílica, o que resultaria em um produto com potencial para aplicação em entrega controlada de fármacos (drug delivery).(142) 
Figura 68 - Imagens de MET das amostras reduzidas a $600^{\circ} \mathrm{C}$ sob fluxo de $\mathrm{H}_{2}$ de $90 \mathrm{~L} \mathrm{~h}^{-1}$.
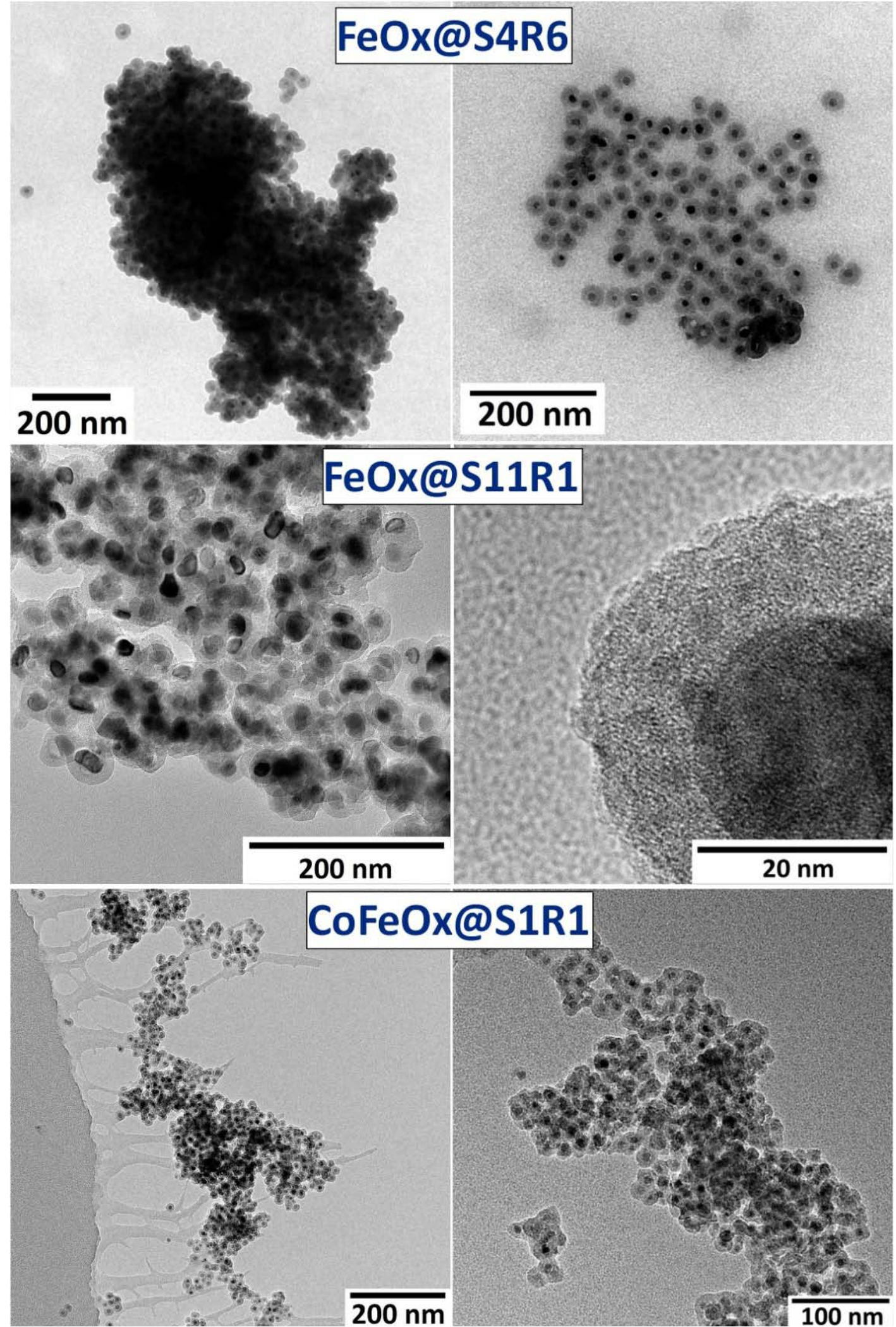

Fonte: Autoria própria.

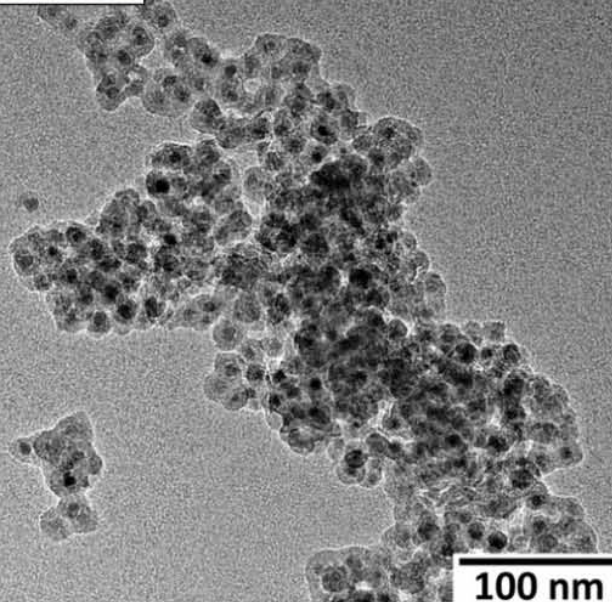


Figura 69 - Ampliações das imagens de MET da amostra com caroço magnético de 15,2 nm (FeOx@S4R6) destacando os espaço existentes entre a fase magnética e a camada de sílica.

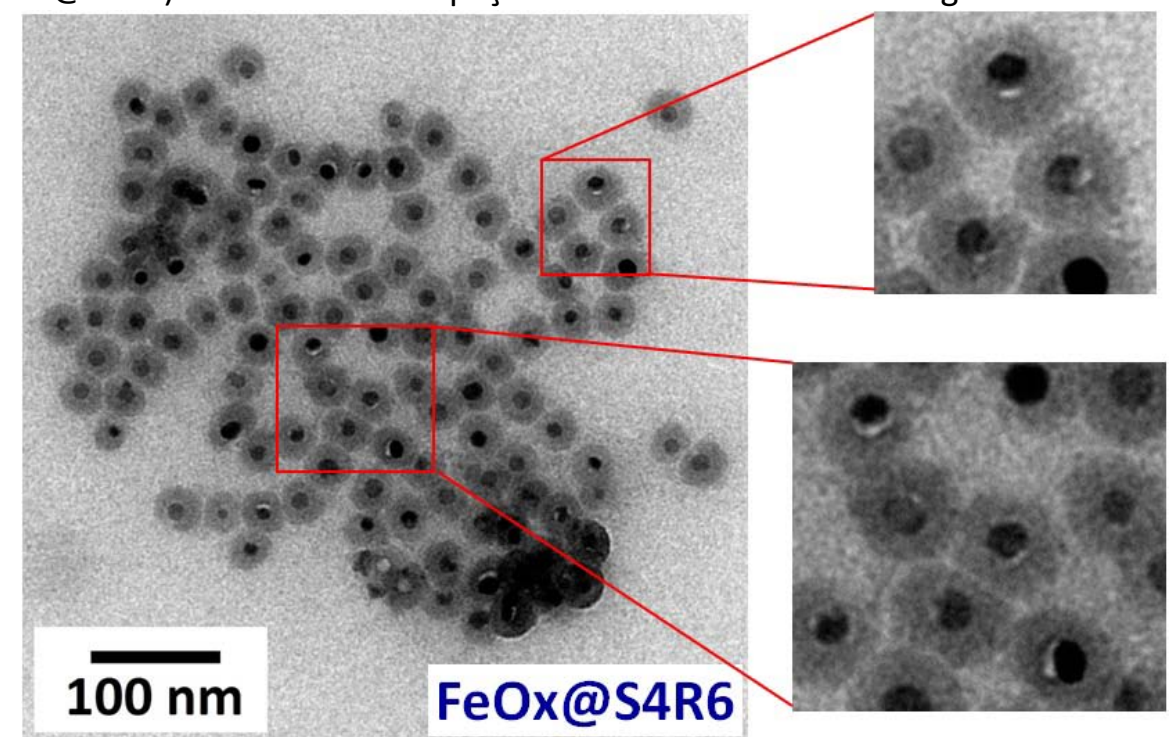

Fonte: Autoria própria.

As curvas de magnetização da Figura 70 mostram o comportamento magnético das amostras com caroços magnéticos de 15,2 e 23,7 antes e após a redução. Vale salientar que os dados foram normalizados pela massa de ferro presente em cada amostra, a qual foi determinada previamente por ICP. A amostra FeOx@S11 apresenta a menor $\mathrm{M}_{\mathrm{S}}$ entre todas as amostras, o que deve-se ao comportamento anti-ferromagnético da fase $\mathrm{FeO}$ que compõe a amostra. Quanto às amostras reduzidas, mesmo apresentando $M_{s}$ inferior a 218 emu $\mathrm{g}^{-1}$ (valor reportado para a fase $\alpha$-Fe em sua forma bulk), um considerável aumento de $M_{S}$ é observado após a redução: 21,3\% e 163,9\% respectivamente para as amostras com menor (FeOx@S4R6) e maior caroço magnético (FeOx@S11R1). O maior $\mathrm{M}_{\mathrm{s}}$ da amostra FeOx@S11R1 deve-se a dois fatores: (i) maior proporção da fase $\alpha$-Fe no interior da NP em comparação à fase óxido presente na camada de passivação; (ii) à menor razão área de superfície/volume, o que reduz o efeito de spin canting, no qual os momentos magnéticos localizados na superfície da partícula formam um ângulo de inclinação médio com a direção do campo, não contribuindo inteiramente à magnetização da amostra.(123) A curva de magnetização da amostra FeOx@S4R6 apresenta uma descontinuidade em sua curva de histerese no intervalo de campo magnético entre -0,2 e 0,2 kOe. Tal descontinuidade, que cria uma espécie de "cintura" nas curvas de histereses, é conhecida como wasp waist, e ocorre devido aos acoplamentos magnéticos entre duas ou mais fases magnéticas presentes na amostra.(112) A observação deste efeito é um indicativo da presença de uma fase magnética de óxido de ferro como camada de passivação. 
Figura 70 - Curvas de magnetização a $290 \mathrm{~K}$ para as amostras de NP de óxido de ferro antes e após redução térmica destacando os respectivos valores de $\mathrm{M}_{\mathrm{S}}$ e $\mathrm{H}_{\mathrm{c}}$. A região central das curvas é ampliada como destaque no canto inferior direito do gráfico.

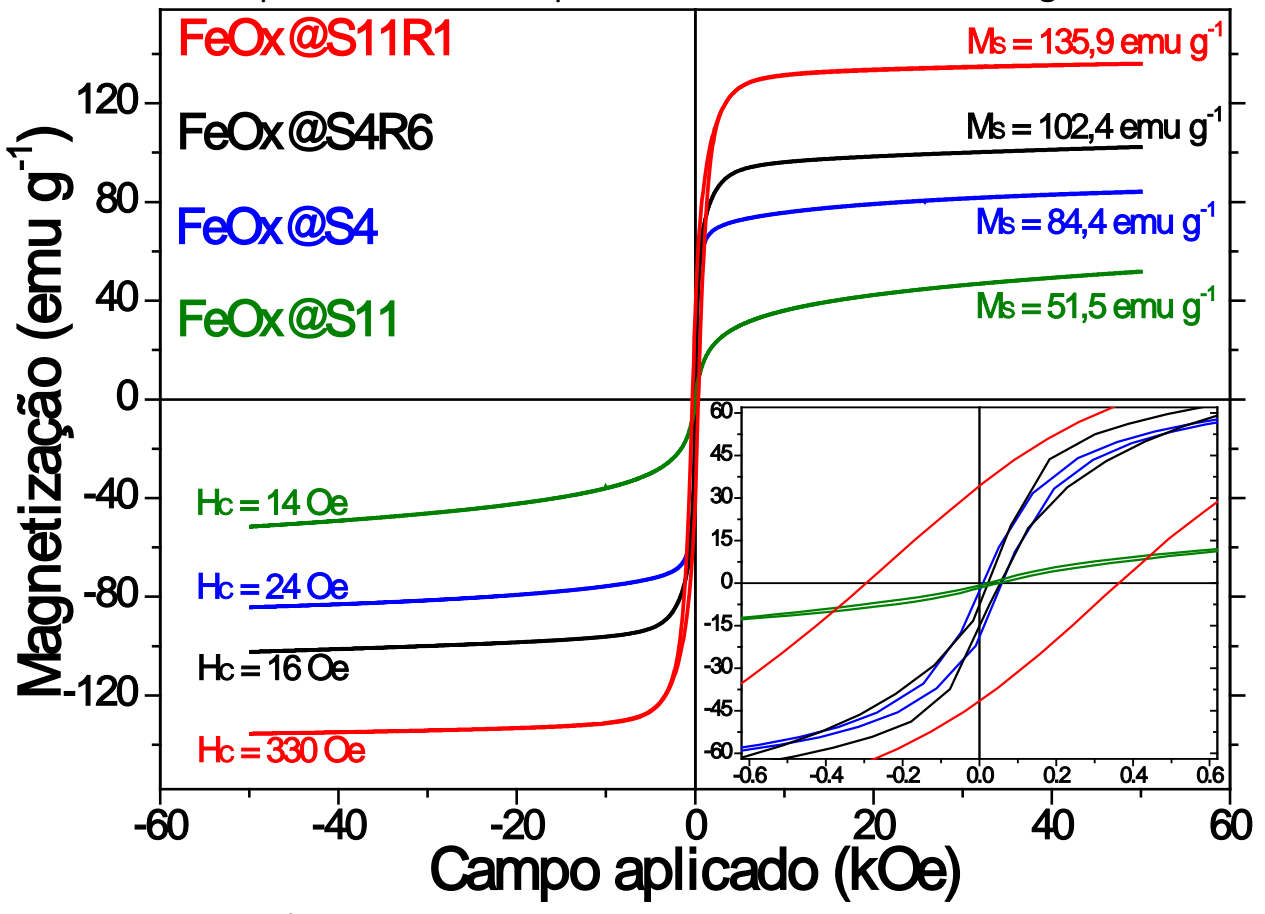

Fonte: Autoria própria.

O processo de redução não resultou em um grande aumento da coercividade, uma vez que as amostras FeOx@S4 e FeOx@S4R6 apresentam respectivamente $\mathrm{H}_{\mathrm{C}}$ de 24 e 16 Oe, indicando um comportamento bastante próximo ao superparamagnetismo para ambas as amostras. Já para a amostra FeOx@S11R1, a presença de um maior núcleo de $\alpha$-Fe confere certo grau de ferromagnetismo à amostra, indicado pelo aumento de $\mathrm{H}_{\mathrm{C}}$ de 14 para 330 Oe. Embora aplicações biomédicas e catalíticas de NPM tenham preferência pelo comportamento superparamagnético, alguns trabalhos na literatura reportam o interesse por materiais com um pequeno caráter ferromagnético, os quais tendem a apresentar um maior potencial de aquecimento para aplicações de hipertermia magnética anti-câncer, sendo este potencial diretamente proporcional à frequência do campo magnético alternado aplicado.

É importante observar que as curvas de magnetização aparecem um pouco deslocadas para valores positivos de campo, o que poderia ser resultado do efeito exchange bias entre o núcleo de ferro metálico e a camada de passivação de óxido de ferro.(130) Entretanto, o ocorrência de tal efeito somente poderia ser afirmada conhecendo-se a fase cristalina presente na camada de passivação, haja vista que o mesmo normalmente ocorre em interfaces de contato entre materiais ferromagnético e anti-ferromagnético. Alguns autores têm analisado o efeito exchange bias em nanomateriais observando a existência de deslocamentos entre curvas de magnetização field-cooled (FC) e zero field-cooled (ZFC).(143) Essas curvas foram obtidas para a 
amostra FeOx@S4R6. Analisando a Figura 71, nenhum deslocamento é observado entre as duas curvas, o que torna improvável que os deslocamentos nas curvas de magnetização das amostras sejam causados pelo efeito exchange bias. Uma possível explicação para tal deslocamento é a existência de uma pequena magnetização remanente no eletroímã do equipamento de VSM.

Figura 71 - Curvas de magnetização ZFC e FC obtidas para a amostra Feox@S4R6. A região central das curvas é ampliada como destaque no canto inferior direito do gráfico.

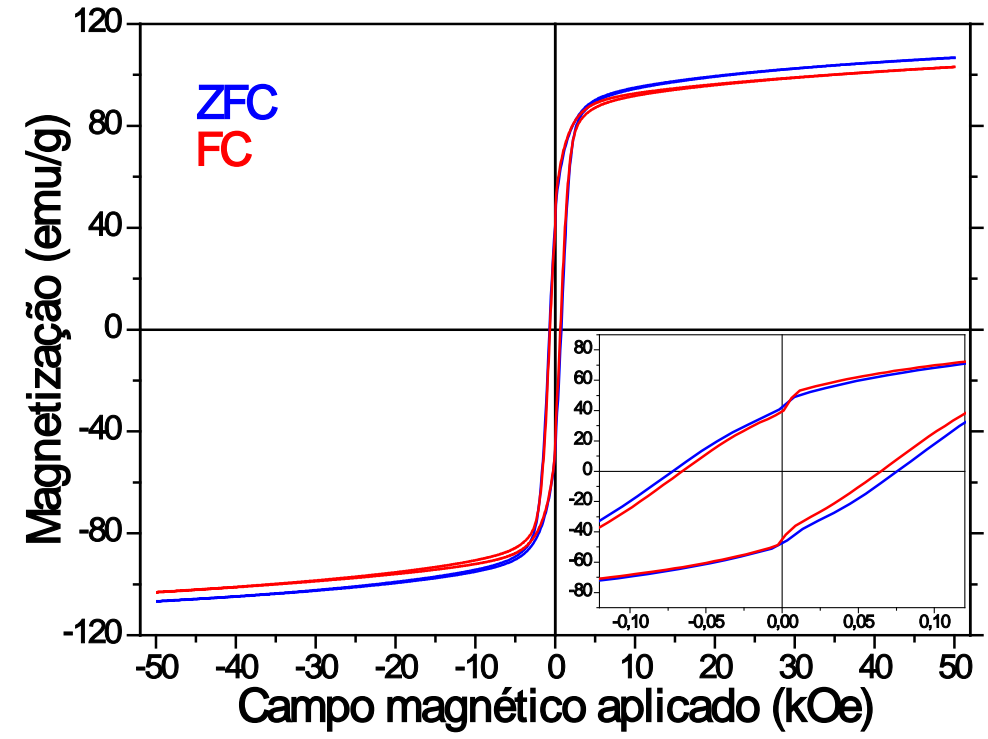

Fonte: Autoria própria.

\subsection{Ensaios da aplicabilidade das NPM em biomedicina e catálise}

Visando aplicações biomédicas, ensaios de estabilidade coloidal, estabilidade química e de hipertermia magnética foram realizados. Os ensaios de estabilidade coloidal foram realizados somente para as amostras FeOx@CM-Dex, FeOx@S4 e FeOx@S4R6. Esta última também teve sua estabilidade química analisada. Já para aplicações catalíticas, ensaios de degradação foto catalítica do corante cristal violeta foram realizados para a amostra FeOx@S4@T2.

\subsubsection{Ensaios da estabilidade coloidal}

Quando dispersas em meio líquido, as partículas podem adquirem carga elétrica em sua superfície, o que afeta a distribuição dos íons do meio ao seu redor. Os contra-íons são atraídos pela superfície enquanto os co-íons são repelidos, formando uma dupla camada elétrica ao redor da partícula. Como o próprio nome diz, esta camada possui duas regiões: uma região interna ocupada por contra-íons fortemente ligados à superfície da partícula e uma região externa na qual os contra-íons e co-íons se distribuem de acordo com o equilíbrio entre forças eletrostáticas 
e movimento térmico. Medindo o potencial elétrico ao redor da partícula observa-se que o mesmo decai com o aumento da distância da superfície até atingir o potencial do próprio meio líquido, denominado potencial zero. Com a aplicação de um campo elétrico, cada partícula juntamente com os contra-íons fortemente ligados a ela se move juntamente como uma unidade, criando um plano de cisalhamento entre esta unidade e o meio. O potencial neste plano de cisalhamento é denominado potencial zeta. Em linhas gerais, o potencial zeta pode ser visto como a medida da magnitude da repulsão ou da atração eletrostática entre partículas dispersas em um meio líquido. A adsorção ou ligação de compostos à superfície das partículas alteram não somente a distribuição dos contra-íons e co-íons em sua vizinhança, mas também a distância entre o plano de cisalhamento e a superfície da partícula, alterando o valor do potencial zeta. Dessa forma, o potencial zeta é função da carga superficial da partícula, de camadas de compostos adsorvidos na interface com o meio e da natureza/composição do meio que a circunda. Esse potencial pode ser determinado experimentalmente e, como ele reflete a carga efetiva nas partículas, ele se correlaciona com a repulsão eletrostática entre elas e com a estabilidade coloidal para partículas em suspensão.(144)

Neste trabalho foram realizadas medidas de potencial zeta em função do pH da dispersão de partículas para analisar as condições de pH em que as mesmas apresentam estabilidade coloidal. Tais medidas foram realizadas para os sistemas de NPM recobertas com CM-Dex e NPM recobertas com sílica. A Figura 72 apresenta as curvas da potencial zeta em função do pH para a amostra de NPM de magnetita obtida via sistema micela antes (FeOx-01) e após (FeOx@CM-Dex) o recobrimento com carboximetil-dextrana.

Figura 72 - Medidas de potencial zeta em função do pH para as amostras FeOx-01 e FeOx@CMDex.

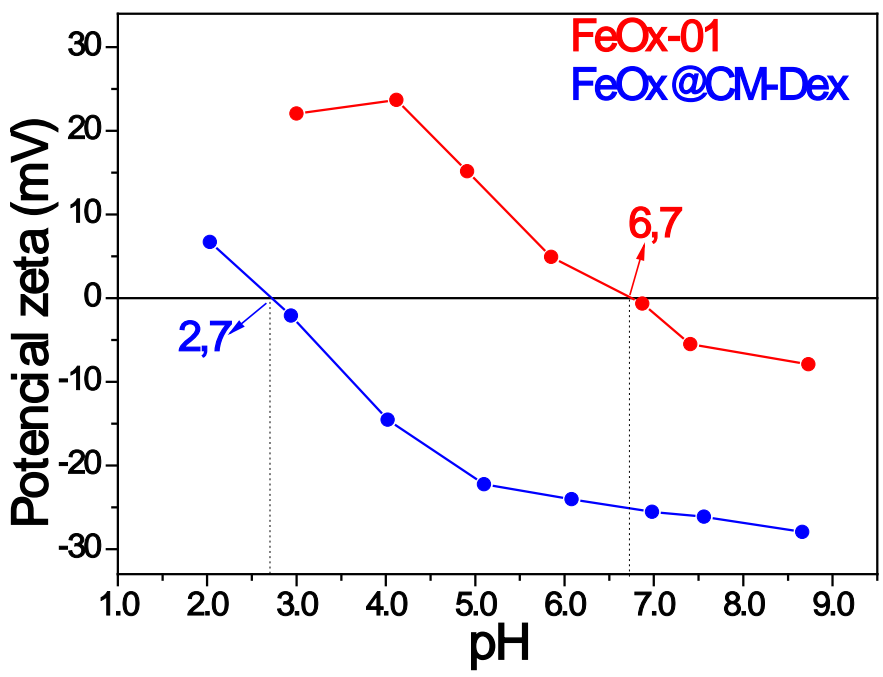

Fonte: Autoria própria. 
O ponto isoelétrico (PI) determina o $\mathrm{pH}$ no qual a superfície da partícula não apresenta carga elétrica líquida, isto é, o pH no qual a aplicação de um campo elétrico não afeta a velocidade e o deslocamento das partículas. Pode-se notar na Figura 72 que o valor de 6,7 obtido para o ponto isoelétrico da curva referente às nanopartículas não recobertas encontra-se em conformidade com o valor obtido na literatura para nanopartículas de magnetita.(145) 0 recobrimento das NPM com CM-Dex levou a uma drástica queda do valor de PI para 2,7, o que é explicado pela menor acidez dos grupos alcoólicos orgânicos presentes na estrutura do biocomposto comparada à acidez das hidroxilas inorgânicas presentes na superfície das NPM de magnetita.(81)

A repulsão eletrostática entre as partículas é maior quanto maior o módulo do potencial zeta, se sobrepondo à tendência à agregação das partículas causada pela ação das forças de Van der Waals.(146) Assim, as curvas da Figura 72 mostram que o intervalo de pH de maior estabilidade coloidal também é alterado após o recobrimento. A amostra FeOx-01 é mais estável no intervalo $3<\mathrm{pH}<4$. Já a amostra recoberta com CM-Dex apresenta maior estabilidade em valores de $\mathrm{pH}$ maiores que 5. Isso mostra a vantagem do recobrimento, uma vez que o intervalo de estabilidade foi expandido. Entretanto, trabalhos da literatura normalmente relatam que suspensões de partículas que apresentem valores de potencial zeta superiores a +30 eV ou inferiores $-30 \mathrm{eV}$ em um dado $\mathrm{pH}$ apresentam estabilidade coloidal nestas condições.(146) Embora toda a curva medida para a amostra FeOx@CM-Dex esteja contida no intervalo de -30 a $+30 \mathrm{eV}$, os valores de potencial zeta medidos em pH superior a 5 estão muito próximas ao valor de $-30 \mathrm{eV}$. Ainda, tal expansão inclui o pH fisiológico $(7,4)$, o que deve ser encarado com um avanço quanto à aplicabilidade dessas NPM em biomedicina.

A estabilidade coloidal das amostras recobertas com sílica foi investigada antes e após a redução térmica. As medidas de potencial zeta em função do pH (Figura 73) mostram que ambas as amostras apresentam ponto isoelétrico inferior a 2,2, o qual está muito próximo aos valores reportados para partículas de sílica. $(147,148)$ Sabendo-se que partículas de óxido de ferro possuem ponto isoelétrico entre 6,0 e $6,8,(145)$ os baixos valores observados para as amostras corroboram o recobrimento dos núcleos magnéticos com sílica, conforme já observado nas imagens de MET. Comparando as duas curvas é possível que a amostra não reduzida apresenta estabilidade coloidal em uma faixa de $\mathrm{pH}$ mais extensa $(\mathrm{pH}>3)$ comparada à amostra reduzida $(\mathrm{pH}>4,5)$. Entretanto, ambas as amostras apresentam alta repulsão eletrostática e, consequentemente estabilidade, em pH fisiológico. Vale ressaltar que, comparadas à CM-Dex, o 
recobrimento com sílica resultou em partículas com maior menor tendência à agregação, o que faz delas candidatos mais fortes às aplicações biomédicas.

Figura 73 - Medidas de potencial zeta em função do pH para as amostras FeOx@S3 e FeOx@S4R6.

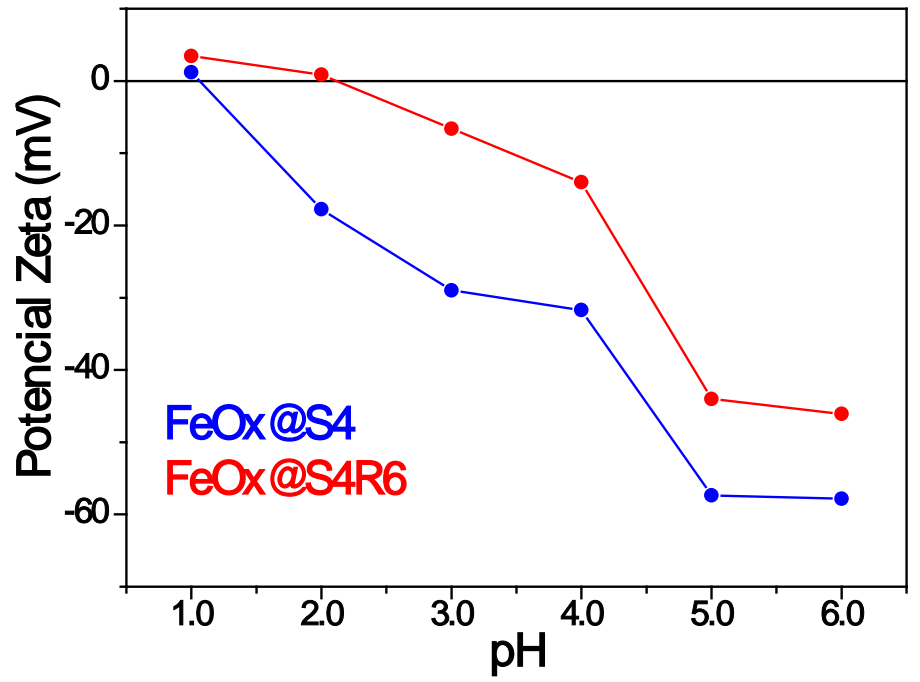

Fonte: Autoria própria.

\subsubsection{Ensaios da estabilidade química em diferentes meios tamponados}

Conforme já relatado no item 4.4, a fase $\alpha$-Fe presente nas amostras reduzidas apresentou estabilidade química sob exposição ao ar, o que deve-se à formação de uma fina camada de passivação entre o caroço magnético e a casca de sílica. A estabilidade química desta fase bem como da fase de óxido de silício foi também analisada em meios líquidos tamponados com diferentes valores de $\mathrm{pH}$. Os ensaios foram realizados utilizando a amostra FeOx@S4R6 dispersa em tampões acetato $(\mathrm{pH}=4,5)$ e fosfato $(7,4)$. A dispersão foi dialisada sob fraca agitação por 144 horas, sendo colhidas alíquotas do meio de diálise em diferentes tempos. Para cada alíquota, a concentração de ferro e de silício foi medida por ICP. Após 144 horas de agitação, as partículas foram lavadas e analisadas por MET (Figura 74) e DRX (Figura 75).

O núcleo magnético é atacado quando em meio de tampão acetato, uma vez que a presença de partículas ocas de sílica podem ser observadas. Já em tampão fosfato, o efeito ocorre sobre a camada de recobrimento: a camada de sílica, até então esférica e homogênea, perde sua forma definida e diminui de espessura, enquanto que o caroço magnético permanece inalterado. Esse efeito das condições do meio é corroborado pela análise de DRX da Figura 75: o difratograma da amostra em acetato mostra diminuição na intensidade dos picos característicos da fase $\alpha-F e, ~ o$ que indica a baixa estabilidade dessa fase neste meio em questão. O difratograma 
da amostra em fosfato permanece praticamente inalterado comparado ao difratograma da amostra de partida, ainda indicando a presença da fase $\alpha$-Fe.

Figura 74 - Imagens de MET das amostras mantidas por 144 horas em meios de tampão acetato e fosfato.
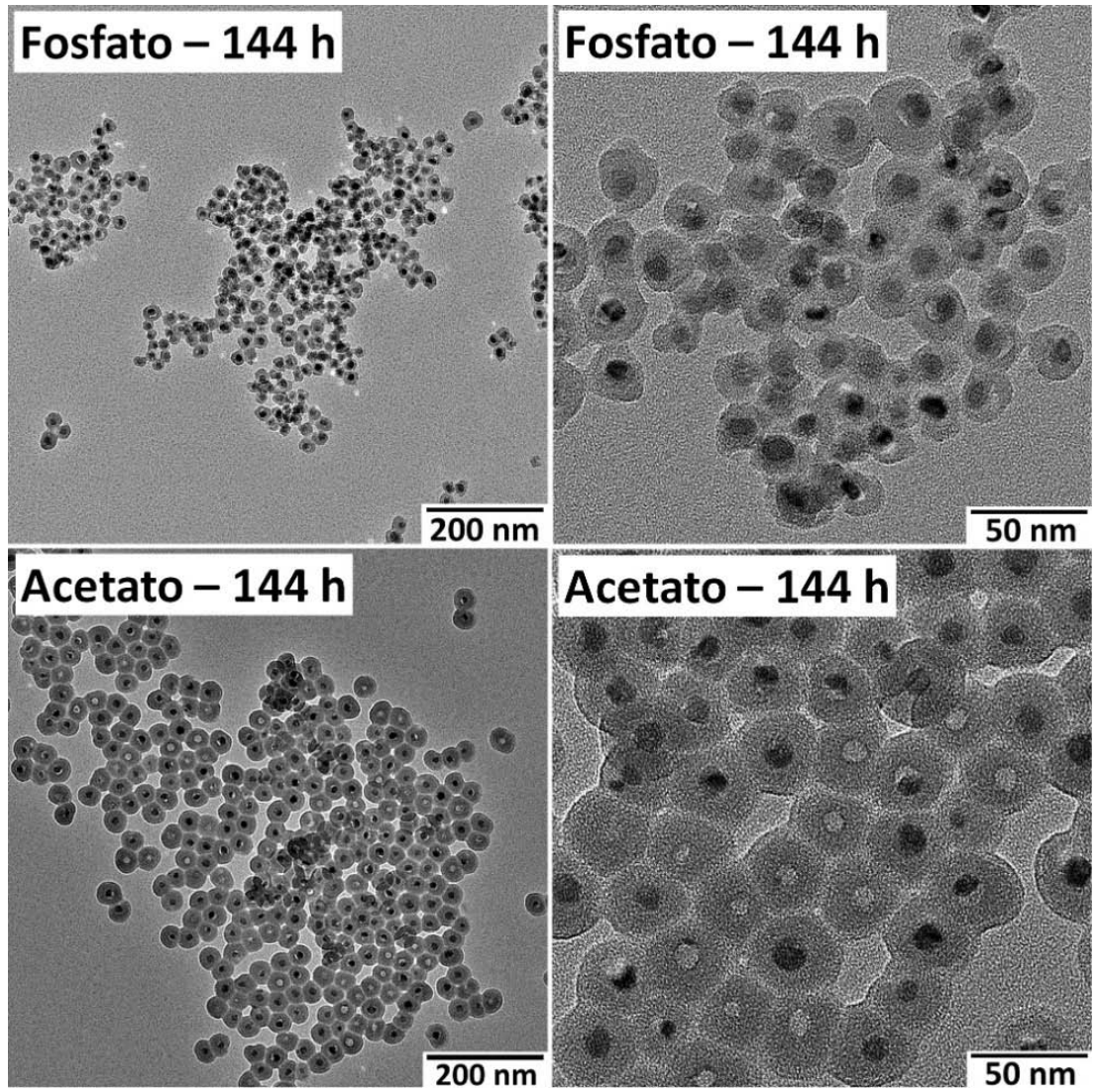

Fonte: Autoria própria.

Figura 75 - DRX das amostras mantidas por 144 horas tampões acetato e fosfato comparados ao da amostra FeOx@S3-R6 original. Em cores, os padrões JCPDS das fases $\mathrm{Fe}_{3} \mathrm{O}_{4}$ e $\mathrm{FeO}$.

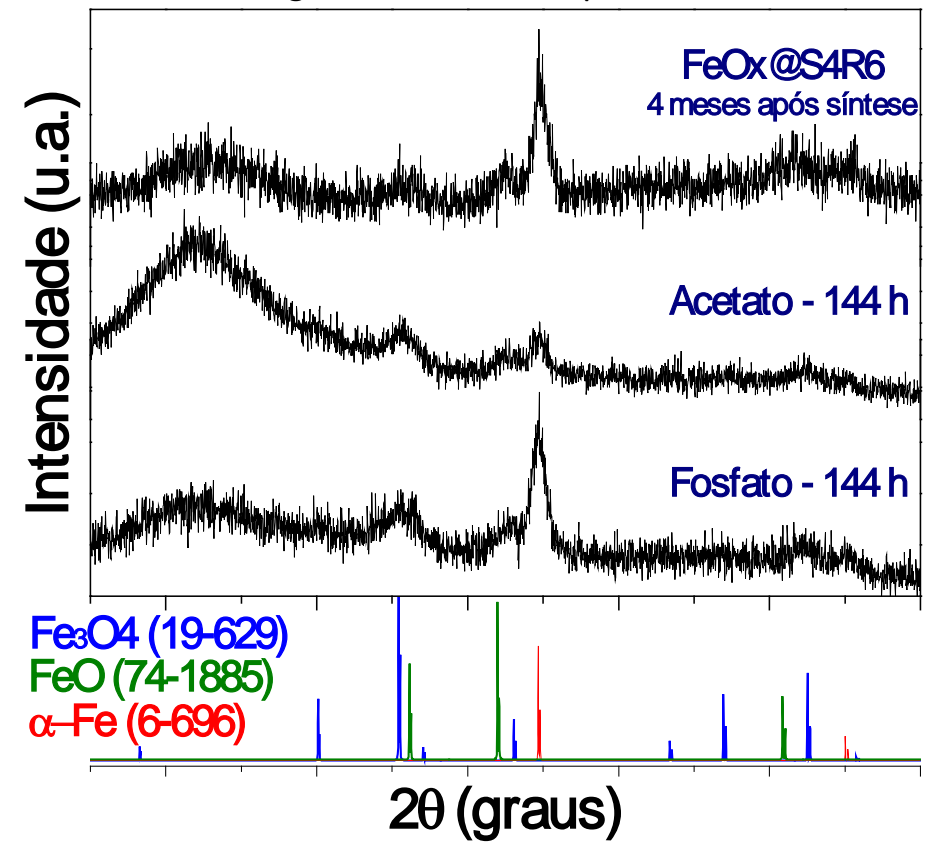

Fonte: Autoria própria. 
A Figura 76 apresenta a variação das concentrações de ferro e silício nas soluções tampão em função do tempo. Tais concentrações são diretamente proporcionais à taxa de dissolução das fases $\alpha-\mathrm{Fe}$ e $\mathrm{SiO}_{2}$, respectivamente. Conforme já observado nas análises de DRX e MET, cada solução afeta as partículas de uma maneira diferente. Em meio de tampão acetato (curvas em azul), embora a camada de sílica pareça não ser afetada, o caroço magnético é atacado e sofre dissolução, o que explica o aumento da concentração de ferro no meio tamponado. Essa dissolução do caroço é mais um indicativo da porosidade da sílica, uma vez que a casca de $\mathrm{SiO}_{2}$ não é capaz de proteger a fase magnética. A maior taxa de dissolução é observada entre 20 e 40 horas. É interessante notar que após 70 horas a concentração de ferro atinge um máximo, mas as imagens da Figura 74 mostram que, mesmo após 144 horas, parte dos caroços magnéticos está presente. Tal comportamento indica a existência de um equilíbrio químico no processo de dissolução e que este processo é cessado quando este equilíbrio é atingido.

Figura 76 - Variação das concentrações de ferro (০) and silício ( $\square$ ) em função do tempo de contato entre as NPM da amostra FeOx@S4R6 com soluções tampão fosfato (curvas em vermelho) e acetato (curvas em azul). As concentrações foram medidas por ICP.

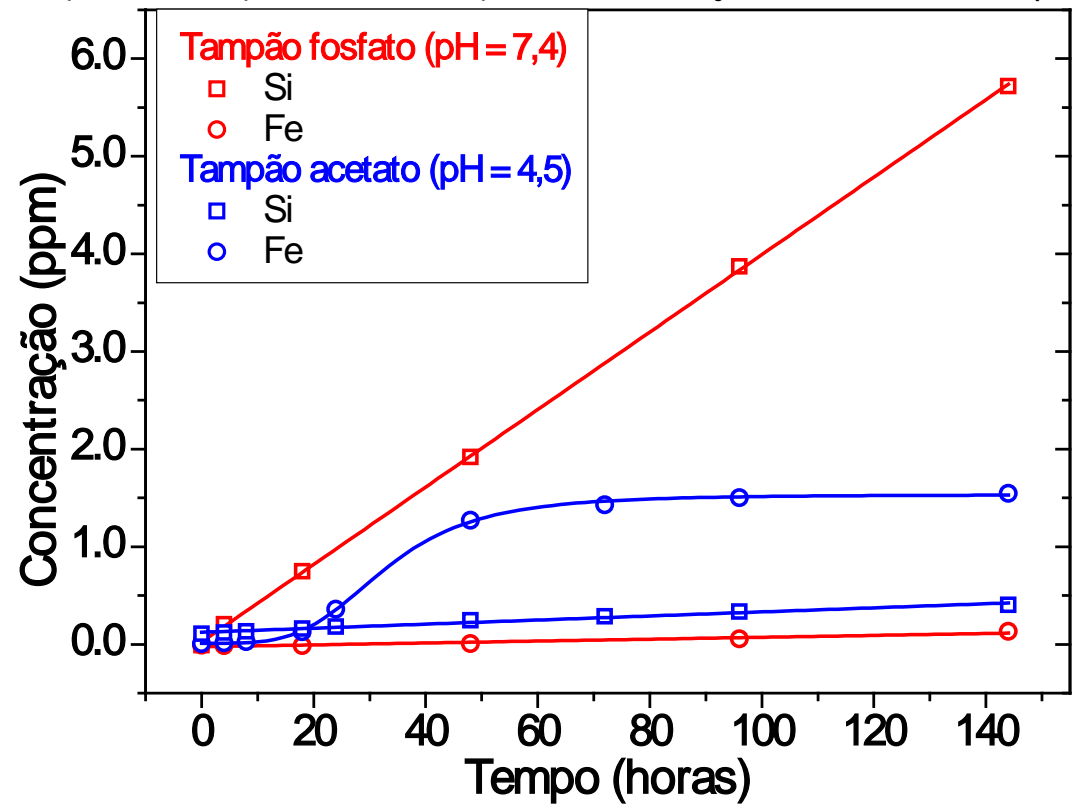

Fonte: Autoria própria.

Para o tampão fosfato, a concentração de silício aumenta linearmente com o tempo enquanto que a concentração de ferro permanece praticamente constante. Alguns autores relatam que, embora seja um processo lento, a sílica pode ser dissolvida em meio aquoso, sendo este processo acelerado com o aumento do $\mathrm{pH}$, da temperatura e de concentrações salinas. (149-151) A dissolução é ainda mais acelerada quanto trata-se de sílica porosa como resultado de sua estrutura menos reticulada. Assim como já mostrado nas imagens de alta resolução da 
amostra FeOx@S11-R1 (Figura 68), a elevada taxa de dissolução observada em nossos ensaios indicam a presença de uma estrutura porosa para a camada de sílica mesmo após a redução térmica. Pode-se observar as partículas recobertas com sílica têm suas dimensões reduzidas durante a dissolução, mas o comportamento linear da curva de concentração de silício em tampão fosfato é mantido. Isso indica que as dimensões das partículas não afetam significantemente a taxa de dissolução, o que concorda com observações relatadas por Rimer et al.(152) Nota-se na Figura 74 uma perda de forma da camada de sílica e um maior grau de agregação entre as partículas. Comportamento similar foi relatado por Chen et al. em trabalho sobre o efeito da recobrimentos poliméricos sobre a degradação de NPM recobertas por sílica. Segundo os autores, tal fenômeno deve-se ao equilíbrio dinâmico entre os processos dissolução e rede-posição de silicato.(153)

Embora a amostra não seja qumicamente estável nos meios em questão, a dissolução da sílica em tampão fosfato poderia ser aproveitada em aplicações de entrega controlada de fármacos. Sendo a sílica porosa, fármacos com moléculas de tamanho apropriado poderiam ser aprisionados nesses poros e, com a dissolução da sílica, os mesmo seriam lentamente liberados em um local. Ainda, como é relatado que a temperatura tem influência sobre a taxa de dissolução da sílica,(154) a presença do núcleo magnético permitiria o aquecimento local das partículas por hipertermia magnética, o que permitiria acelerar a liberação do fármaco. Entretanto, esta possibilidade é somente uma idéia inicial, a qual necessita ser melhor investigada e pode ser encarada como perspectiva para trabalhos futuros.

\subsubsection{Ensaios de hipertermia magnética}

Os ensaios de hipertermia magnética foram realizados somente para NPM recobertas com sílica. Duas amostras reduzidas foram testadas: FeOx@S4R6 e FeOx@S11R1, cujos resultados são comparados aos resultados da amostra FeOx@S11 não reduzida. Para cada amostra, diferentes concentrações de NP foram testadas: 0, 2,5, 5 e $10 \mathrm{mg} \mathrm{mL}^{-1}$ e os resultados foram comparados com os da água pura. Uma concentração adicional de1,25 mg mL ${ }^{-1}$ foi testada para a amostra FeOx@S11R1.

Análise por EDX das amostras indicou composição molar relativa entre os elementos ferro e silício de $\mathrm{Fe}_{47} \mathrm{Si}_{53}$ para as amostras FeOx@S11 e FeOx@S11R1 e de Fe:Si = 20:80 para a amostra FeOx@S4R6. Essas porcentagens foram usadas para normalizar as curvas de aquecimento pela massa de ferro das amostras. Os resultados de EDX nos permite calcular a massa relativa entre o 
núcleo magnético e a casca de $\mathrm{SiO}_{2}$, bem como normalizar as concentrações das amostras pela massa de material magnético (Tabela 16).

Tabela 16 - Composições mássicas relativas entre as fases cristalinas presentes em cada amostra (calculada por EDX) e concentrações das suspensões de NP (normalizadas pela massa de material magnético).

\begin{tabular}{|c|c|c|c|c|c|c|}
\hline \multirow[b]{2}{*}{ Amostra } & \multirow[b]{2}{*}{ Fase } & \multirow[b]{2}{*}{$\begin{array}{l}\text { Composição } \\
\text { Relativa (\%) }\end{array}$} & \multicolumn{4}{|c|}{ Concentração de material magnético $\left(\mathrm{mg}_{(\mathrm{Fe})} \mathrm{mL}^{-1}\right)$} \\
\hline & & & $\begin{array}{c}\text { Teste } 1 \\
\left(10 \mathrm{mg} \mathrm{mL}^{-1}\right)\end{array}$ & $\begin{array}{c}\text { Teste } 2 \\
\left(5 \mathrm{mg} \mathrm{mL}^{-1}\right)\end{array}$ & $\begin{array}{c}\text { Teste } 3 \\
\left(2,5 \mathrm{mg} \mathrm{mL}^{-1}\right)\end{array}$ & $\begin{array}{c}\text { Teste } 4 \\
\left(1,25 \mathrm{mg} \mathrm{mL}^{-1}\right)\end{array}$ \\
\hline FeOx@S11 & $\begin{array}{c}\mathrm{Fe}_{3} \mathrm{O}_{4} \\
\mathrm{SiO}_{2}\end{array}$ & $\begin{array}{l}53 \\
47\end{array}$ & 5,3 & 2,65 & 1,32 & - \\
\hline FeOx@S11R1 & $\begin{array}{c}\alpha-\mathrm{F} \varepsilon \\
\mathrm{SiO}_{2}\end{array}$ & $\begin{array}{l}44,9 \\
55,1\end{array}$ & 4,5 & 2,25 & 1,13 & 0,56 \\
\hline FeOx@S4R6 & $\begin{array}{l}\alpha-\mathrm{F} \varepsilon \\
\mathrm{SiO}_{2}\end{array}$ & $\begin{array}{l}19,1 \\
80,9\end{array}$ & 1,9 & 0,95 & 0,48 & - \\
\hline
\end{tabular}

Fonte: Autoria Própria.

Figura 77 - Curvas de aquecimento das amostras de $\mathrm{NPM}$ de $\mathrm{Fe}_{3} \mathrm{O}_{4}$ e $\alpha$-Fe recobertas com sílica.

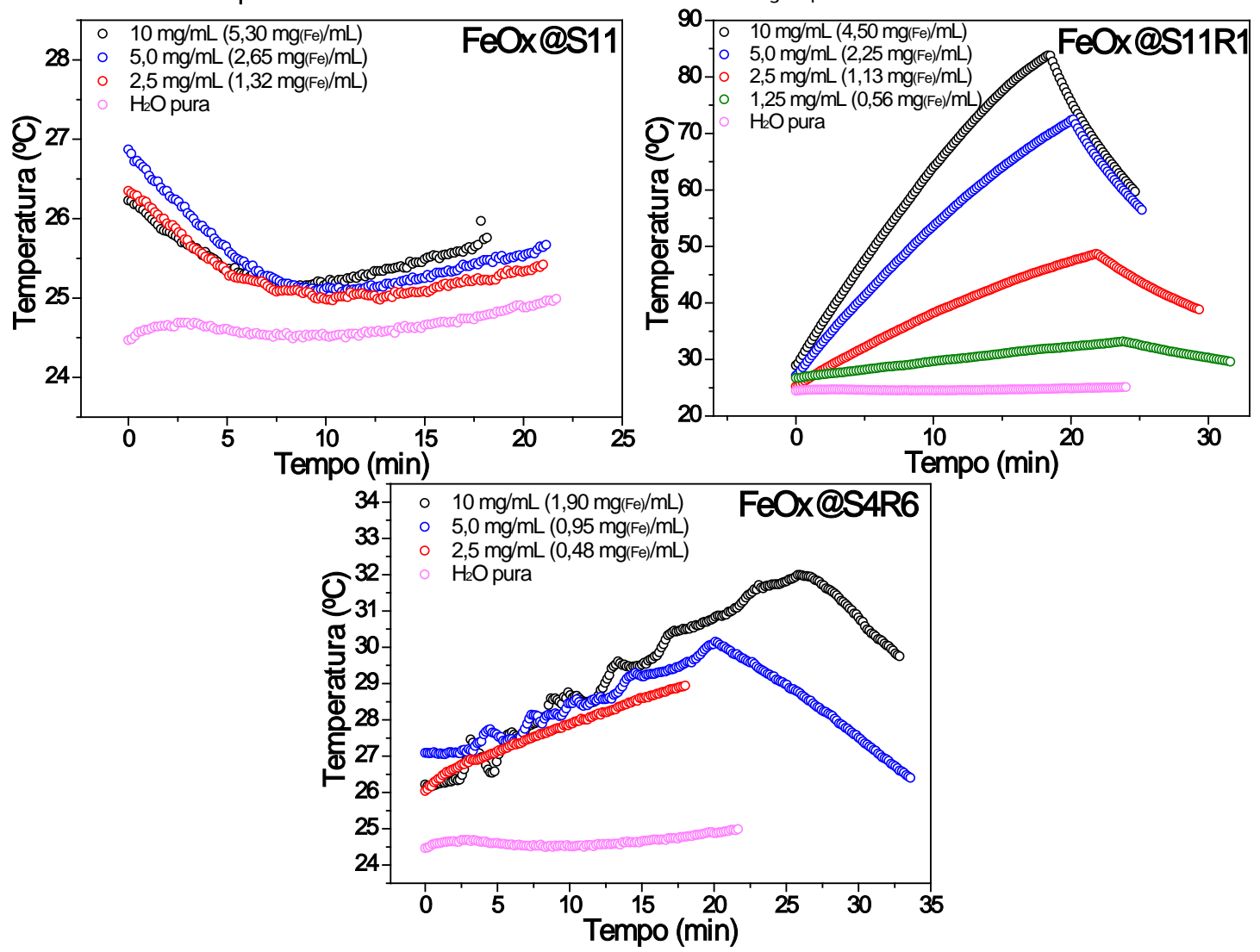

Fonte: Autoria própria.

Comparando as curvas de aquecimento das amostras FeOx@S11 e FeOx@S11R1 mostradas na Figura 77, observa-se que a redução térmica foi positiva para o aumento da capacidade de aquecimento por hipertermia magnética. Para a amostra não reduzida, todas as concentrações de NP testadas apresentaram comportamento similar ao da água pura, indicando 
ausência de aquecimento quando exposto ao campo. Já a amostra reduzida contendo caroço magnético de $23,7 \mathrm{~nm}$ apresentou taxas médias de aquecimento $(\Delta \mathrm{T} / \Delta \mathrm{t})$ de $3,0^{\circ} \mathrm{C} \mathrm{min}^{-1}, 2,2^{\circ} \mathrm{C}$ $\mathrm{min}^{-1}, 1,1^{\circ} \mathrm{C} \mathrm{min}^{-1}$ e $0,3^{\circ} \mathrm{C} \mathrm{min}^{-1}$ respectivamente para concentrações em ferro de $4,5 \mathrm{mg} \mathrm{mL}^{-1}$, $2,25 \mathrm{mg} \mathrm{mL}^{-1}, 1,13 \mathrm{mg} \mathrm{mL}^{-1}$ e $0,56 \mathrm{mg} \mathrm{mL}^{-1}$. A Figura 78 mostra imagens obtidas a partir da câmera de infravermelho OpTris em diferentes tempos durante o ensaio com a amostra de FeOx@S11R1 (concentração de 4,5 mg $(\mathrm{Fe}) \mathrm{mL}^{-1}$ ). Já para amostra com núcleo magnético de ferro metálico de $15,2 \mathrm{~nm}$, a taxa de aquecimento foi de aproximadamente $\Delta \mathrm{T} / \Delta \mathrm{t}=0,2^{\circ} \mathrm{C} \mathrm{min}^{-1}$ para todas as concentrações testadas. De fato, trabalhos recentes da literatura apontam melhores resultados de hipertermia magnética para partículas com dimensões ao redor do limite entre monodomínio e multidomínio magnético.(68,155,156) Para partículas de ferro e de óxido de ferro, este limite encontra-se no intervalo entre 20 e $40 \mathrm{~nm},(68)$ o que explica os melhores resultados apresentados pela amostra com núcleo de $24 \mathrm{~nm}$. As descontinuidades nas curvas da amostra FeOx@S4R6 são explicadas pela baixa estabilidade coloidal da dispersão analisada.

Figura 78 - Imagens obtidas com a câmera infravermelho OpTris durante ensaio com dispersão da FeOx@S11R1 (concentração de 4,5 mg $(\mathrm{Fe}) \mathrm{mL}^{-1}$ ). A amostra se encontra no ponto central das imagens.

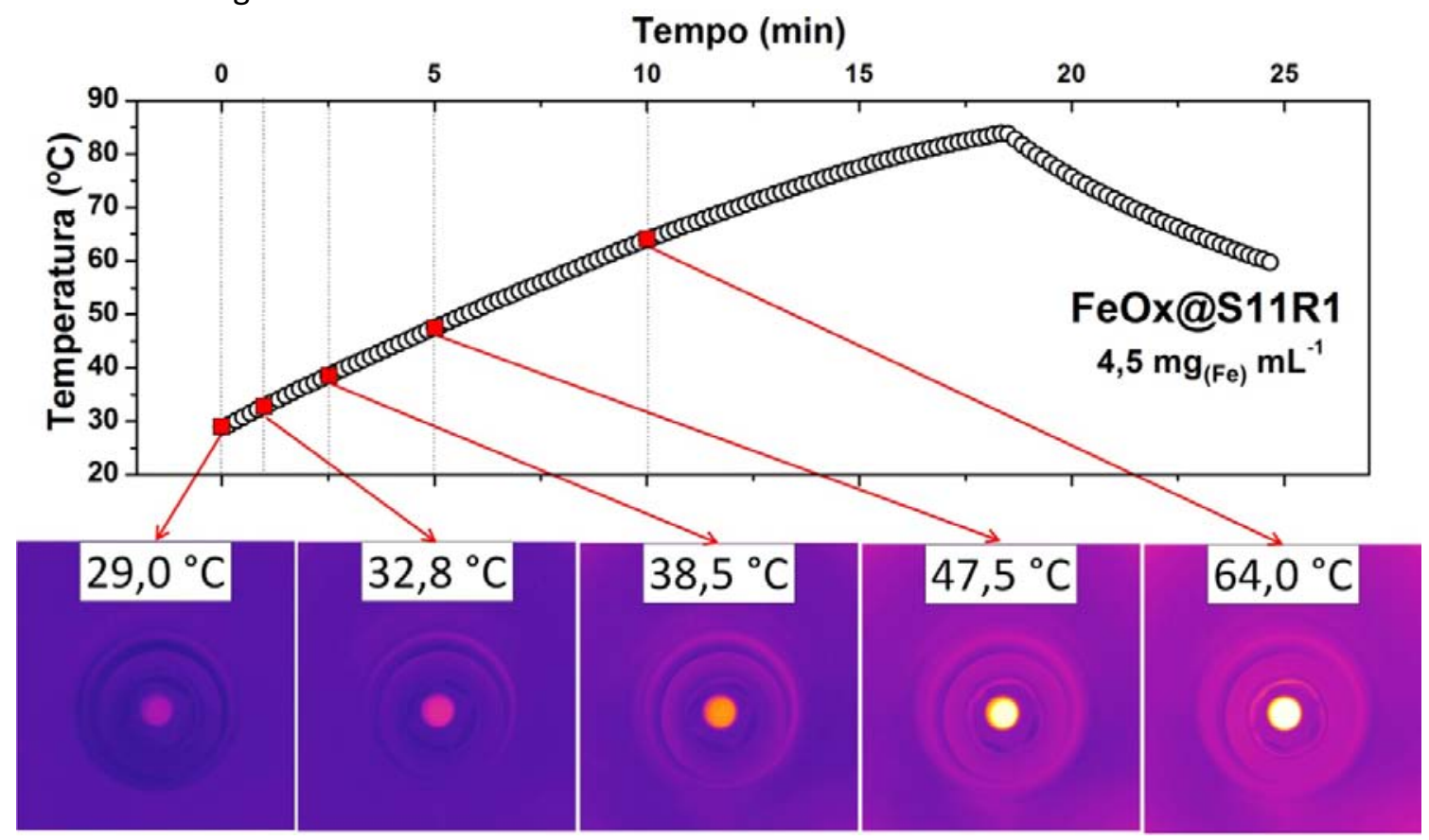

Fonte: Autoria própria.

A partir das curvas de aquecimento da amostra FeOx-S11R1, foram calculados os valores de taxa de absorção específica (SAR, do inglês specific absorption rate) que, de forma simplificada, mede a energia absorvida por unidade de massa do material magnético presente na amostra. O cálculo de SAR se dá pela Equação III: 


$$
S A R=C_{m} \phi(\mathrm{dT} / \mathrm{dt})_{\max }
$$

Equação III

onde $C_{m}$ é a capacidade calorífica da amostra ou da água, cujo valor usado foi $4185 \mathrm{~J} \mathrm{Kg}^{-1} \mathrm{~K}^{-1}, \phi$ é razão entre as massas da dispersão e do material magnético presente nesta dispersão ( $\phi=$ $\left.\mathrm{m}_{\text {dispersão }} / \mathrm{m}_{\mathrm{Fe}}\right)$, sendo assim uma espécie de concentração da amostra e $(\mathrm{dT} / \mathrm{dt})_{\max }$ corresponde à inclinação inicial da curva de aquecimento.(68) Os valores de (dT/dt) $\max$ foram calculados para cada curva de aquecimento pelo ajuste da equação de BoxLucas1 (Equação IV), da qual o produto dos parâmetros $a$ e $b$ é numericamente igual à inclinação inicial da curva analisada. A Figura 79a apresenta o método de cálculo da $(\mathrm{dT} / \mathrm{dt})_{\max }$ da amostra FeOx-S11R1 com concentração de 10 $\mathrm{mg} \mathrm{mL}^{-1}$ de partículas (4,5 mg mL${ }^{-1}$ de ferro metálico). 0 mesmo método foi aplicado para as amostras mais diluídas. Os valores de $(d T / d t)_{\max }$ e de SAR calculados para as diferentes concentrações de NPM são mostrados na Figura 79b.

$$
y=a\left(1-e^{-b x}\right)
$$

Equação IV

Figura 79 - À esquerda, ajuste da equação de BoxLucas1 à curva de aquecimento da amostra FeOx@S11R1, destacando a curva correspondente ao produto dos parâmetros a e b. O gráfico à direita relaciona valores de SAR (curva em azul) e taxas de aquecimento máximas (curva em vermelho) às concentrações normalizadas da amostra.
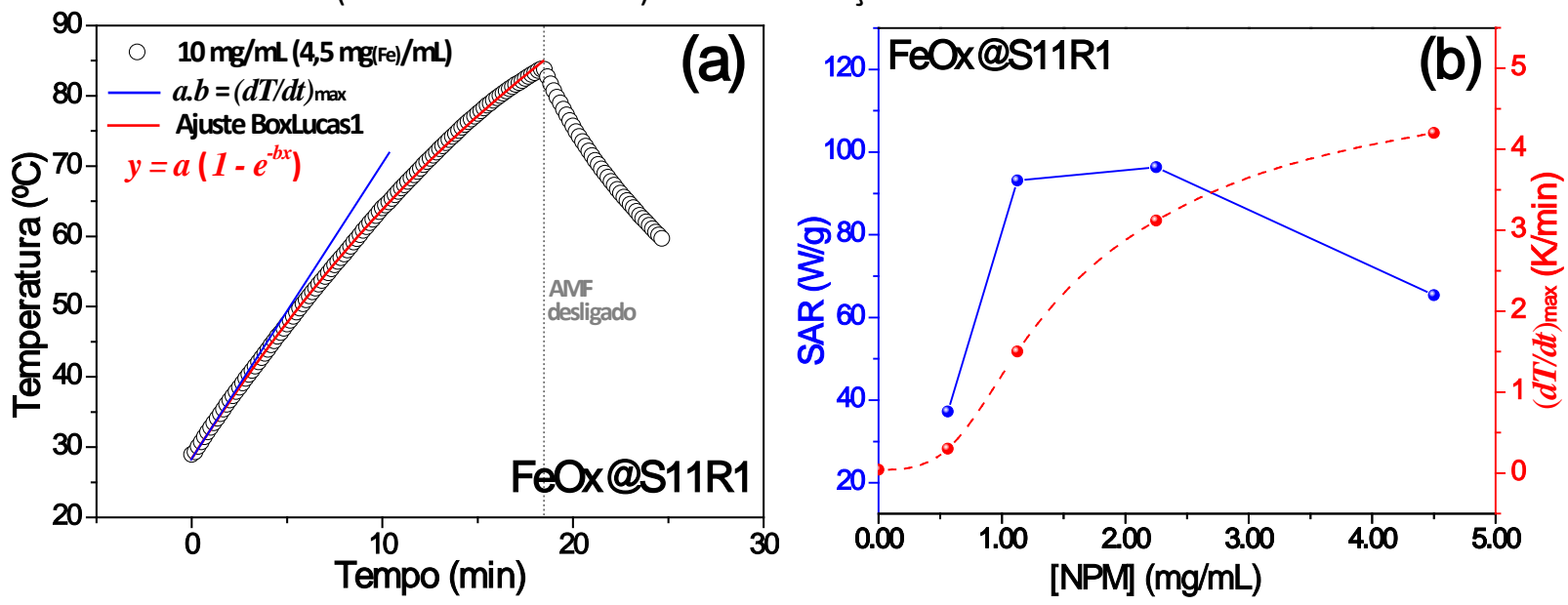

Fonte: Autoria própria.

A literatura relata ensaios de hipertermia de partículas de óxido de ferro com valores de SAR entre 20-300 W g $\mathrm{g}^{-1}$. Os maiores valores são normalmente alcançados para amostras concentradas de partículas, condições estas que muitas vezes não são consideradas como aplicáveis em sistemas vivos. Neste trabalho, as partículas com núcleo magnético de $24 \mathrm{~nm}$ apresentaram valores altos de SAR, mesmo para amostras muito diluídas. Valores de SAR de 37,2 $\mathrm{W} \mathrm{g}^{-1}, 93,1 \mathrm{~W} \mathrm{~g}^{-1}, 96,3 \mathrm{~W} \mathrm{~g}^{-1}$ e $65,4 \mathrm{~W} \mathrm{~g}^{-1}$ foram respectivamente observados para amostras com concentrações de $0,56 \mathrm{mg}_{(\mathrm{Fe})} \mathrm{mL}^{-1}, 1,13 \mathrm{mg}_{(\mathrm{Fe})} \mathrm{mL}^{-1}, 2,25 \mathrm{mg}_{(\mathrm{Fe})} \mathrm{mL}^{-1}$ e $4,50 \mathrm{mg}_{(\mathrm{Fe})} \mathrm{mL}^{-1}$. É 
interessante observar que, embora $(\mathrm{dT} / \mathrm{dt})_{\max }$ aumente com o aumento da concentração da amostra, a amostra com concentração de $2,25 \mathrm{mg}_{(\mathrm{Fe})} \mathrm{mL}^{-1}$ apresenta o maior valor de SAR. Tal observação indica a presença de interações magnéticas dipolares inter-partículas, as quais são maiores para amostras mais concentradas devido à menor distância inter-partículas. Embora o papel de interações dipolares em cálculos de SAR ainda não seja totalmente compreendido, resultados da literatura sugerem uma influência negativa dessas interações sobre a capacidade de aquecimento de nanopartículas magnéticas.(156)

\subsubsection{Ensaios de atividade catalítica}

Dentre as amostras recobertas com $\mathrm{TiO}_{2}$, somente para a FeOx@S4@T2 (antes e após tratamentos térmicos em $\mathrm{N}_{2}$ e $\mathrm{H}_{2}$ ) foram feitos ensaios de atividade catalítica devido à maior cristalinidade da fase anatase. Para comparação, os ensaios também foram realizados para as partículas de $\mathrm{TiO}_{2}$ puro. A Figura 80 apresenta os espectros UV-Vis obtidos a partir de alíquotas colhidas após diferentes intervalos de exposição à radiação UV. Em todos os casos, a absorbância da banda cai em função do tempo de irradiação, indicando a fotodegradação do corante.

Figura 80 - Espectros UV-Vis coletados com diferentes tempos de irradiação com luz UV para as amostras $\mathrm{TiO}_{2}$ e FeOx@S4@T2 antes e após os tratamentos térmicos em $\mathrm{N}_{2}$ (FeOx@S4@T2-N)e H (FeOx@S4@T2-H).
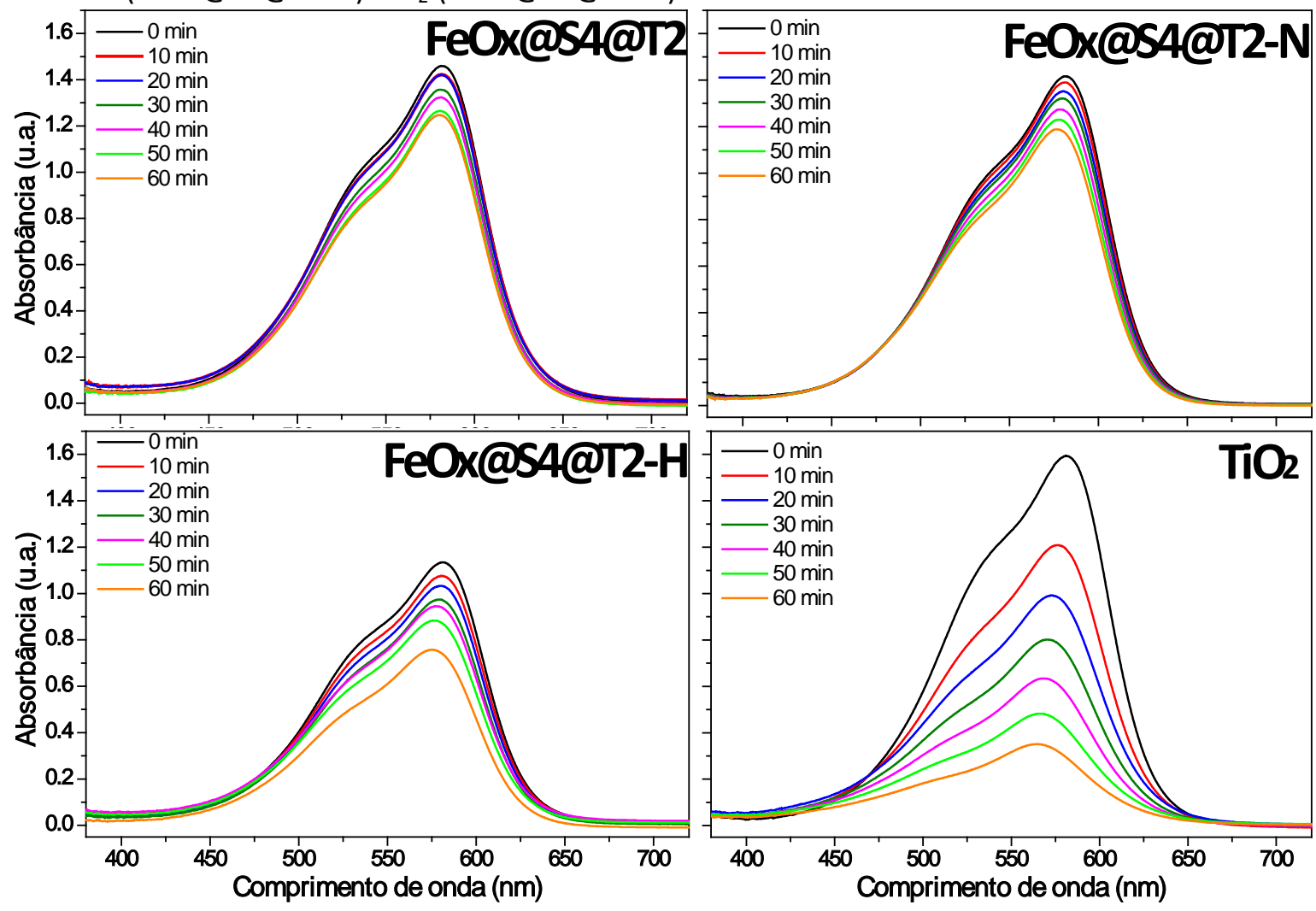

Fonte: Autoria própria. 
A área da banda respectiva a cada amostra foi integrada de modo a permitir uma comparação quantitativa da fotoatividade de cada catalisador (Figura 81a). A fotólise direta na ausência de fotocatalisador mostrou-se desprezível nas condições experimentais empregadas, o que deve-se às paredes do reator de borosilicato atuarem como filtro de radiação UV de maior energia (UVB e UVC). A fotoatividade das amostras contendo o núcleo magnético foi menor que a observada para as partículas de $\mathrm{TiO}_{2}$ puro, o que contraria pesquisas recentes que relatam a capacidade da sílica de facilitar a adsorção do corante cristal violeta (CV), aumentando assim a fotoatividade da anatase.(157) Entretanto, cabe ressaltar que a camada de recobrimento de $\mathrm{TiO}_{2}$ corresponde somente a $40,6 \%$ da massa total das amostras analisadas enquanto que a amostra de $\mathrm{TiO}_{2}$ pura tem $100 \%$.

A normalização das áreas das bandas de $\mathrm{CV}$ pela massa de $\mathrm{TiO}_{2}$ presente em cada amostra (Figura 81b) mostra que, embora a anatase pura ainda apresente maior fotoatividade, a diferença com relação à fotoatividade das amostras contendo núcleo magnético não é grande. $O$ aumento da cristalinidade da amostra recozida em atmosfera de $N_{2}$, (observada nos difratogramas da Figura 64) não mostrou influência sobre a fotoatividade da amostra FeOx@S4@T2-N, o que é observado pela similaridade das curvas preta e vermelha nos dois gráficos da Figura 81. Já o tratamento realizado em atmosfera redutora de $\mathrm{H}_{2}$ aumentou em $78,3 \%$ a fotoatividade do material após $60 \mathrm{~min}$ de irradiação. Este aumento é mais evidente comparando os espectros colhidos em t=0 min para as amostras FeOx@S4@T2 e FeOx@S4@T2-H. A área absoluta da banda do espectro da amostra reduzida é $23,4 \%$ menor que da amostra FeOx@S4@T2. Isso sugere que tal diferença se deva principalmente ao processo de adsorção do corante, o que pode ser resultado de uma maior exposição da superfície de sílica durante o processo de redução térmica. Além da maior adsorção inicial do corante, a amostra reduzida apresenta também uma queda mais pronunciada da área integrada, o que indica uma maior absorção da luz UV pelas partículas que compõem a amostra. Como a análise de DRX (Figura 64) indicou a formação das fases magnéticas de $\alpha$-Fe e de $\mathrm{Fe}_{3} \mathrm{C}$, é possível que essas fases estejam auxiliando no processo de absorção da radiação UV. A verificação de tal possibilidade necessita de mais estudos. Destaca-se aqui que a amostra recozida em $\mathrm{H}_{2}$ apresentou fotoatividade próxima à da anatase pura, com a vantagem de possuir núcleos magnéticos que permitem a recuperação eficiente do catalisador ao final do processo de catálise. 
Figura 81 - (a) Área correspondente às bandas de absorção do cristal violeta (CV) em função do tempo de exposição à radiação UV. Os valores de área foram obtidos a partir da integração dos espectros da Figura 80 no intervalo $430 \mathrm{~nm}<\lambda<700 \mathrm{~nm}$. (b) Valores normalizados pela massa de $\mathrm{TiO}_{2}$ presente nas amostras contendo núcleos magnéticos.
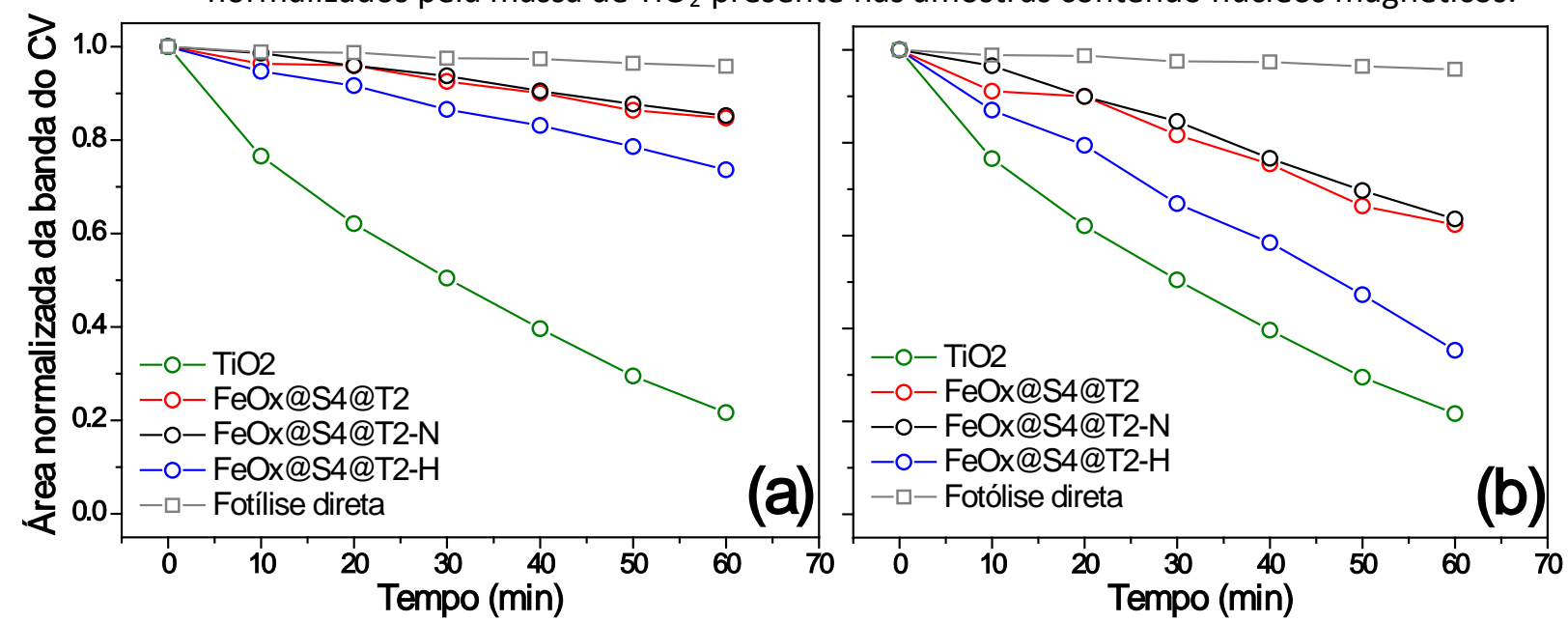

Fonte: Autoria própria.

\section{CONCLUSÕES}

Considerando os objetivos almejados no início deste trabalho bem como as situações que ocorreram durante seu desenvolvimento, algumas conclusões foram tiradas e são apresentadas.

Os surfactantes cátion-substituídos dodecil sulfato de ferro(III) e de cobalto(II) (FeDS e CoDS) foram sintetizados diretamente em meio aquoso usando um método eficiente, simples e de baixo custo. O FeDS possui estrutura molecular $\left[\mathrm{Fe}\left(\mathrm{C}_{12} \mathrm{H}_{25} \mathrm{SO}_{4}\right)_{2}\left(\mathrm{H}_{2} \mathrm{O}\right)_{4}\right] \mathrm{NO}_{3}$. A caracterização do surfactante de cobalto encontra-se em andamento. Usando o FeDS, NPM de magnetita com diâmetro de 3,4 nm foram obtidas em sistemas micelares usando solução de FeDS em 1-octanol com concentração ao redor da cmc. As NPM de magnetita apresentaram comportamento "quase-paramagnético", demonstrando uma possível potencialidade em aplicações de contraste $\mathrm{T}_{1}$ em imagens de ressonância magnética.

O surfactante CoDS foi usado na síntese de NPM de Co metálico utilizando sistema de microemulsão inversa compostos por $n$-heptano/n-butanol/CoDS/água. O diagrama de fases pseudo-ternário desse sistema apresentou uma extensa região de microemulsão inversa, o que pode possibilitar a síntese de NP com maior versatilidade de forma e tamanho.

O processo de síntese de NPM via decomposição térmica mostra-se eficiente quanto à obtenção de NPM bimetálicas de fcc-FePt e bcc-FeCo, de carbetos metálicos de ferro, cobalto, níquel, molibdênio e tungstênio, e de óxidos de ferro e ferro-cobalto. O método proporciona considerável controle de tamanho e morfologia. A mesma eficiência não foi alcançada nas síntese de NPM de FeAg. 
Para as NPM de FePt e FeCo, a escolha do solvente e do redutor alcanodiol é de grande importância, uma vez que tem influência direta sobre a composição relativa entre os metais e as dimensões das partículas. O aumento da cadeia carbônica do diol resulta na diminuição das dimensões das NPM. Os melhores resultados quanto à composição das fases foram alcançados com o solvente octiléter.

A oleilamina mostra-se um poderoso composto na síntese de NPM, uma vez que pode atuar simultaneamente como solvente, agente de superfície e agente redutor. Sínteses realizadas somente na presença de oleilamina e dos precursores metálicos $\mathrm{Fe}(\mathrm{acac})_{3}$ e $\mathrm{Co}(\mathrm{acac})_{3}$ resultaram respectivamente na obtenção de NPM compostas por carbetos metálicos $\left(\mathrm{Fe}_{3} \mathrm{C} \mathrm{e} \mathrm{Co}_{2} \mathrm{C}\right) . \mathrm{O}$ mesmo método foi aplicado com eficiência na síntese de NP de carbetos de Ni, Mo e W.

Variações na rampa de aquecimento têm influência sobre a morfologia e distribuição de tamanho das NPM de óxido de ferro obtidas via decomposição térmica. O uso de altas taxas de aquecimento favorecem a forma esférica e distribuições de tamanho mais estreitas. A substituição do precursor oleato por acetilacetonato resulta na formação da fase wustita, mesmo na ausência de agentes redutores, o que parece estar relacionado à decomposição incompleta do oleato de ferro formado como intermediário durante a síntese. Este método foi também usado no preparo de NPM de óxido misto de ferro e cobalto, formando a fase cobalto-wustita, da qual não há relatos em escala nanométrica até o momento na literatura.

As NPM de óxido de ferro foram recobertas com sílica via hidrólise básica de TEOS em sistemas de microemulsão inversa. A espessura da camada de sílica é diretamente proporcional ao tempo da reação de hidrólise e pode ser controlada variando-se este parâmetro. O provável mecanismo de reação foi estudado e proposto.

A redução térmica das NPM de óxido de ferro resultou em partículas de $\alpha$-Fe, levando a aumentos de $21,3 \%$ e $163,9 \%$ nos valores de $M_{s}$ das amostras contendo respectivamente caroços magnéticos de 15,2 e $23,7 \mathrm{~nm}$, o que era o principal objetivo deste trabalho. A camada de recobrimento de sílica não somente evita processos de sinterização, mas também confere hidrofilicidade e estabilidade coloidal em valores de $\mathrm{pH}>3$. As condições de redução menos drásticas capazes de reduzir completamente as fases óxidos a metal foram: tratamento térmico a $600^{\circ} \mathrm{C}$ por 4 horas com fluxo de $\mathrm{H}_{2}$ de $90 \mathrm{~L} \mathrm{~h}^{-1}$ seguido de passivação com vapor de etanol à temperatura ambiente por 1 hora. As amostras apresentaram estabilidade química em atmosfera de ar por longos períodos. Já em meio líquido, ensaios realizados em tampões acetato e fosfato mostram processos de dissolução das fases $\alpha-\mathrm{Fe}$ e $\mathrm{SiO}_{2}$ respectivamente nos referidos meios. 
NPM recobrimentas com anatase foram obtidas usando método baseado no uso de etilenoglicol como complexante. A espessura da camada de anatase foi variada entre 2 e $12 \mathrm{~nm}$ pelo controle da razão mássica entre TIPT e NPM.

Os ensaios de hipertermia magnética mostram altos valores de SAR mesmo com dispersões diluídas de NPM de $\alpha-\mathrm{Fe}$, o que indica a potencialidade deste material em hipertermia magnética. As partículas com núcleo magnético de 23,7 nm apresentaram valores de SAR de 37,2 $W \mathrm{~g}^{-1}, 93,1 \mathrm{~W} \mathrm{~g}^{-1}, 96,3 \mathrm{~W} \mathrm{~g}^{-1}$ e $65,4 \mathrm{~W} \mathrm{~g}^{-1}$ respectivamente para dispersões de NPM com concentrações de $0,56 \mathrm{mg}_{(\mathrm{Fe})} \mathrm{mL}^{-1}, 1,13 \mathrm{mg}_{(\mathrm{Fe})} \mathrm{mL}^{-1}, 2,25 \mathrm{mg}_{(\mathrm{Fe})} \mathrm{mL}^{-1}$ e $4,50 \mathrm{mg}_{(\mathrm{Fe})} \mathrm{mL}^{-1}$.

Os ensaios de atividade fotocatalítica mostram que as amostras magnéticas possuem fotoatividade próxima à da amostra de anatase pura. Todavia, a proximidade entre os valores de fotoatividade unida à presença do caroço magnético para recuperação do catalisador ao final da reação mostram são um avanço neste campo.

\section{PERSPECTIVAS}

No decorrer do desenvolvimento do trabalho aqui apresentado muitas observações foram feitas e situações vivenciadas. Dentre elas, algumas foram investigadas mais a fundo e os frutos dessas investigações foram aqui apresentados e discutidos. Outras, devido ao tempo limitado, foram colocadas em espera para investigações futuras, sendo as mesmas encaradas como perspectivas para o desenvolvimento de trabalhos posteriores em nosso grupo de pesquisa. Assim, as principais perspectivas desse trabalho são:

$\checkmark$ Finalizar a caracterização da estrutura molecular do surfactante CoDS;

$\checkmark$ Caracterizar os surfactantes substituídos com os cátions níquel e crômio e usá-los na síntese de NPM via sistemas de microemulsão inversa;

$\checkmark$ Estudar a possibilidade de aplicação da amostra de NPM de magnetita obtidas via sistema micelar (FeOx@CM-Dex) como agente de contraste $\mathrm{T}_{1}$ em imagens de ressonância magnética;

$\checkmark$ Testar outras composições relativas entre os metais ferro e prata na síntese de NPM de FeAg;

$\checkmark$ Testar o método de crescimento mediado por semente para recobrimento de NP de Ag com óxido de ferro e posterior redução térmica para preparar NPM de FeAg;

$\checkmark$ Estudar a estrutura porosa das NPM recobertas com sílica de forma a possibilitar sua aplicação em sistemas de entrega controlada de fármacos; 
$\checkmark$ Realizar os testes de citotoxicidade in vitro e in vivo para as amostras recobertas com sílica e com CM-Dex.

\section{REFERÊNCIAS}

1 KIM, D.K.; ZHANG, Y.; VOIT, W.; RAO, K.V.; MUHAMMED, M. Synthesis and characterization of surfactant-coated superparamagnetic monodispersed iron oxide nanoparticles. Journal of Magnetism and Magnetic Materials, v. 225, n. 1-2, p. 30-36, 2001.

2 ANDRADE, V.M.; VIVAS, R.J. C.; PEDRO, S.S.; TEDESCO, J.C.G.; ROSSI, A.L.; COELHO, A.A.; ROCCO, D.L.; REIS, M.S. Magnetic and magnetocaloric properties of $\mathrm{La}_{0.6} \mathrm{Ca}_{0.4} \mathrm{MnO}_{3}$ tunable by particle size and dimensionality. Acta Materialia, v. 102, p. 49-55, 2016.

3 EHSANI, M. H.; KAMELI, P.; GHAZI, M. E.; RAZAVI, F. S.; TAHERI, M. Tunable magnetic and magnetocaloric properties of $\mathrm{La}_{0.6} \mathrm{Sr}_{0.4} \mathrm{MnO}_{3}$ nanoparticles. Journal of Applied Physics, v. 114, n. 22, p. 223907, 2013.

4 TANG, S.C.N.; LO, I.M.C. Magnetic nanoparticles: Essential factors for sustainable environmental applications. Water Research, v. 47, n. 8, p. 2613-2632, 2013.

5 De TORO, J. A.; MARQUES, D. P.; MUÑIZ, P.; SKUMRYEV, V.; SORT, J.; GIVORD, D. High temperature magnetic stabilization of cobalt nanoparticles by an antiferromagnetic proximity effect. Physical Review Letters, v. 115, n. 5, p. 057201, 2015.

6 CHO, S. G.; JEON, K. W.; KIM, J.; KIM, K. H.; KIM, J. Synthesis and ferromagnetic properties of magnetic ink for direct printing. IEEE Transactions on Magnetics, v. 47, n. 10, p. 3157-3159, 2011.

7 FREY, N. A.; PENG, S.; CHENG, K.; SUN, S. Magnetic nanoparticles: synthesis, functionalization, and applications in bioimaging and magnetic energy storage. Chemical Society Reviews, v. 38, n. 9, p. 2532, 2009.

8 GOVAN, J.; GUN'KO, Y. Recent advances in the application of magnetic nanoparticles as a support for homogeneous catalysts. Nanomaterials, v. 4, n. 2, p. 222-241, 2014.

9 POLSHETTIWAR, V.; VARMA, R.S. Green chemistry by nano-catalysis. Green Chemistry, v. 12, n. 5, p. 743, 2010.

10 VARANDA, L.C.; JAFELICCI JUNIOR, M.; BECK JUNIOR, W. Magnetic and multifunctional magnetic nanoparticles in nanomedicine: Challenges and trends in synthesis and surface engineering for diagnostic and therapy applications. In: Biomedical Engineering, Trends in Materials Science. Rijeka: InTech, 2011, p. 397-424.. 
11 ORTEGA, D. Biomedical applications of magnetic nanoparticles. In: ENCYCLOPEDIA of inorganic and bioinorganic chemistry. Chichester: John Wiley, 2015. p. 1-19.

12 PARTON, E.; DE PALMA, R.; BORGHS, G. Biomedical applications using magnetic nanoparticles. Solid State Technology, v. 50, n. 8, p. 47, 2007.

13 CALLISTER, W.D. Materials science and engineering: An introduction. Hoboken: John Wiley, 2007. $832 \mathrm{p}$.

14 FARIA, R.N.; LIMA, L.F.C. Introdução ao magnetismo dos materiais. São Paulo: Editora Livraria da Física, 2005. 198 p.

15 GUIMARÃES, A.P. Principles of nanomagnetism. Heidelberg: Springer, 2009. 224 p.

16 ALVES, Tatiana Midori Martins Telles. Síntese e caracterização de nanopartículas de óxidos de ferro para aplicações biomédicas. 2007. 83f. Dissertação (Mestrado em Física) - Instituto de Física "Gleb Wataghin", Universidade Estadual de Campinas, Campinas, 2007.

17 SUN, S. Recent advances in chemical synthesis, self-assembly, and applications of fept nanoparticles. Advanced Materials, v. 18, n. 4, p. 393-403, 2006.

18 FREITAS, J. C.; BRANCO, R. M.; LISBOA, I. G. O.; COSTA, T. P.; CAMPOS, M. G. N.; JAFELICCI JR, M.; MARQUES, R. F. C. Magnetic nanoparticles obtained by homogeneous coprecipitation sonochemically assisted. Materials Research, v. 18, p. 220-224, 2015.

19 KUMAR, A.; YADAV, N.; RANA, D. S.; KUMAR, P.; ARORA, M.; PANT, R.P. Structural and magnetic studies of the nickel doped $\mathrm{CoFe}_{2} \mathrm{O}_{4}$ ferrite nanoparticles synthesized by the chemical co-precipitation method. Journal of Magnetism and Magnetic Materials, v. 394, p. 379-384, 2015.

20 LÓPEZ PÉREZ, J. A.; LÓPEZ QUINTELA, M. A.; MIRA, J.; RIVAS, J.; CHARLES, S. W. Advances in the preparation of magnetic nanoparticles by the microemulsion method. The Journal of Physical Chemistry B, v. 101, n. 41, p. 8045-8047, 1997.

21 LIVERI, V.T. Controlled synthesis of nanoparticles in microheterogeneous systems. New York: Springer, 2006. $167 \mathrm{p}$.

22 PHURUANGRAT, A.; KUNTALUE, B.; THONGTEM, S.; THONGTEM, T. Synthesis of cubic CuFe $\mathrm{O}_{2}$ nanoparticles by microwave-hydrothermal method and their magnetic properties. Materials Letters, $\mathrm{v}$. 167, p. 65-68, 2016. 
23 YOU, C.; ZHANG, J.; SHEN, Y.; SONG, Z. Facile hydrothermal synthesis and growth kinetics of fe-based magnetic nanoparticles. Acta Metallurgica Sinica (English Letters), v. 20, n. 6, p. 434-440, 2007.

24 DUMITRACHE, F.; MORJAN, I.; FLEACA, C.; BADOI, A.; MANDA, G.; POP, S.; MARTA, D.S.; HUMINIC, G.; HUMINIC, A.; VEKAS, L.; DAIA, C.; MARINICA, O.; LUCULESCU, C.; NICULESCU, A.-M. Highly magnetic $\mathrm{Fe}_{2} \mathrm{O}_{3}$ nanoparticles synthesized by laser pyrolysis used for biological and heat transfer applications. Applied Surface Science, v. 336, p. 297-303, 2015.

25 MIGUEL, O.B.; MORALES, M.P.; SERNA, C.J.; VEINTEMILLAS-VERDAGUER, S. Magnetic nanoparticles prepared by laser pyrolysis. IEEE Transactions on Magnetics, v. 38, n. 5, p. 2616-2618, 2002.

26 BECK JUNIOR, W.; SOUZA, C. G. S.; SILVA, T. L.; JAFELICCI JR., M.; VARANDA, L. C.Formation mechanism via a heterocoagulation approach of fept nanoparticles using the modified polyol process. The Journal of Physical Chemistry C, v. 115, n. 21, p. 10475-10482, 2011.

27 SUN, S.; MURRAY, C.B; WELLER, D.; FOLKS, L.; MOSER, A. Monodisperse FePt Nanoparticles and Ferromagnetic FePt Nanocrystal Superlattices. Science, v. 287, n. 5460, p. 1989-1992, 2000.

28 VARANDA, L.C.; JAFELICCI, M. Self-Assembled FePt nanocrystals with large coercivity: reduction of the fcc-to-L $1_{0}$ ordering temperature. Journal of the American Chemical Society, v. 128, n. 34, p. 1106211066, 2006.

29 PARK, J.; AN, K.; HWANG, Y.; PARK, J. G.; NOH, H. J.; KIM, J. Y.; PARK, J. H.; HWANG, N. M.; HYEON, T. Ultra-large-scale syntheses of monodisperse nanocrystals. Nature Materials, v. 3, n. 12, p. 891-895, 2004.

30 SALAS, G.; CASADO, C.; TERAN, F. J.; MIRANDA, R.; SERNA, C. J.; MORALES, M. P. Controlled synthesis of uniform magnetite nanocrystals with high-quality properties for biomedical applications. Journal of Materials Chemistry, v. 22, n. 39, p. 21065, 2012.

31 LU, A. H.; SALABAS, E. L.; SCHÜTH, F. Magnetic nanoparticles: synthesis, protection, functionalization, and application. Angewandte Chemie International Edition, v. 46, n. 8, p. 1222-1244, 2007.

32 LÓPEZ-QUINTELA, M.A. Synthesis of nanomaterials in microemulsions: formation mechanisms and growth control. Current Opinion in Colloid \& Interface Science, v. 8, n. 2, p. 137-144, 2003.

33 LÓPEZ-QUINTELA, M.A.; RIVAS, J. Chemical reactions in microemulsions: a powerful method to obtain ultrafine particles. Journal of Colloid and Interface Science, v. 158, n. 2, p. 446-451, 1993.

34 HUNTER, R. J. Foundations of colloid science. Oxford: Oxford University, 2001. 816 p. 
35 MO, C.; ZHONG, M.; ZHONG, Q. Investigation of structure and structural transition in microemulsion systems of sodium dodecyl sulfonate+n-heptane+n-butanol+water by cyclic voltammetric and electrical conductivity measurements. Journal of Electroanalytical Chemistry, v. 493, n. 1-2, p. 100-107, 2000.

36 ROSEN, M.J. Surfactants and interfacial phenomena. 3rd ed. Hoboken: John Wiley, 2004. p. 105-177.

37 SHINODA, K.; LINDMAN, B. Organized surfactant systems: Microemulsions. Langmuir, v. 3, n. 2, p. 135-149, 1987.

38 MANIASSO, N. Ambientes micelares em química analítica. Química Nova, v. 24, n. 1, p. 87-93, 2001.

39 CHIN, A.B.; YAACOB, I.I. Synthesis and characterization of magnetic iron oxide nanoparticles via w/o microemulsion and Massart's procedure. Journal of Materials Processing Technology, v. 191, n. 1-3, p. 235-237, 2007.

40 CUSHING, B.L.; KOLESNICHENKO, V.L.; O'CONNOR, C. J. Recent advances in the liquid-phase syntheses of inorganic nanoparticles. Chemical Reviews, v. 104, n. 9, p. 3893-3946, 2004.

41 DUXIN, N.; BRUN, N.; COLLIEX, C.; PILENI, M. P. Synthesis and magnetic properties of elongated Fe-Cu alloys. Langmuir, v. 14, n. 8, p. 1984-1989, 1998.

42 FIEVET, F.; LAGIER, J.; BLIN, B.; BEAUDOIN, B.; FIGLARZ, M. Homogeneous and heterogeneous nucleations in the polyol process for the preparation of micron and submicron size metal particles. Solid State lonics, v. 32-33, p. 198-205, 1989.

43 VARANDA, L.C.; IMAIZUMI, M.; SANTOS, F. J.; JAFELICCI JR, M. Iron oxide versus $\mathrm{Fe}_{55} \mathrm{Pt}_{45} / \mathrm{Fe}_{3} \mathrm{O}_{4}$ : Improved magnetic properties of core/shell nanoparticles for biomedical applications. IEEE Transactions on Magnetics, v. 44, n. 11, p. 4448-4451, 2008.

44 LEE, D. C.; MIKULEC, F. V.; PELAEZ, J. M.; KOO, B.; KORGEL, B. A. Synthesis and magnetic properties of silica-coated FePt nanocrystals. The Journal of Physical Chemistry B, v. 110, n. 23, p. 11160-11166, 2006.

45 SOUZA, C.G.S.; BECK JR, W.; VARANDA, L. C. Multifunctional luminomagnetic

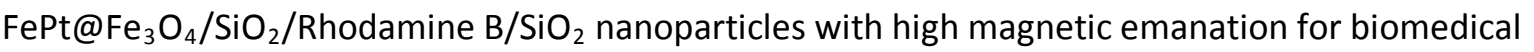
applications. Journal of Nanoparticle Research, v. 15, n. 4, p. 1545, 2013.

46 RAHMAN, I.A.; PADAVETTAN, V. Synthesis of silica nanoparticles by sol-gel: Size-dependent properties, surface modification, and applications in silica-polymer nanocomposites - A review. Journal of Nanomaterials, v. 2012, p. 1-15, 2012. 
47 SINGH, L. P.; BHATTACHARYYA, S. K.; KUMAR, R.; MISHRA, G.; SHARMA, U.; SINGH, G.; AHALAWAT, S. Sol-Gel processing of silica nanoparticles and their applications. Advances in Colloid and Interface Science, v. 214, p. 17-37, 2014.

48 STÖBER, W.; FINK, A.; BOHN, E. Controlled growth of monodisperse silica spheres in the micron size range. Journal of Colloid and Interface Science, v. 26, n. 1, p. 62-69, 1968.

49 FINNIE, K. S.; BARTLETT, J. R.; BARBÉ, C. J. A.; KONG, L. Formation of silica nanoparticles in microemulsions. Langmuir, v. 23, n. 6, p. 3017-3024, 2007.

50 LIN, C. H.; CHANG, J. H.; YEH, Y. Q.; WU, S. H.; LIU, Y. H.; MOU, C. Y. Formation of hollow silica nanospheres by reverse microemulsion. Nanoscale, v. 7, n. 21, p. 9614-9626, 2015.

51 DING, H. L.; ZHANG, Y. X.; WANG, S.; XU, J. M.; XU, S. C.; LI, G. H. $\mathrm{Fe}_{3} \mathrm{O}_{4} @ \mathrm{SiO}_{2}$ core/shell nanoparticles: The silica coating regulations with a single core for different core sizes and shell thicknesses. Chemistry of Materials, v. 24, n. 23, p. 4572-4580, 2012.

52 ZHANG, M.; CUSHING, B.L.; O'CONNOR, C. J. Synthesis and characterization of monodisperse ultrathin silica-coated magnetic nanoparticles. Nanotechnology, v. 19, n. 8, p. 085601, 2008.

53 VOGT, C.; TOPRAK, M. S.; MUHAMMED, M.; LAURENT, S.; BRIDOT, J. L.; MÜLLER, R. N. High quality and tuneable silica shell-magnetic core nanoparticles. Journal of Nanoparticle Research, v. 12, n. 4, p. 1137-1147, 2010.

54 SANTRA, S.; TAPEC, R.; THEODOROPOULOU, N.; DOBSON, J.; HEBARD, A.; TAN, W. Synthesis and characterization of silica-coated iron oxide nanoparticles in microemulsion: The effect of nonionic surfactants. Langmuir, v. 17, n. 10, p. 2900-2906, 2001.

55 GAO, J.; GU, H.; XU, B. Multifunctional magnetic nanoparticles: Design, synthesis, and biomedical applications. Accounts of Chemical Research, v. 42, n. 8, p. 1097-1107, 2009.

56 PANKHURST, Q. A.; THANH, N. T. K.; JONES, S. K.; DOBSON, J. Progress in applications of magnetic nanoparticles in biomedicine. Journal of Physics D: Applied Physics, v. 42, n. 22, p. 224001, 2009.

57 HAO, R.; XING, R.; XU, Z.; HOU, Y.; GAO, S.; SUN, S. Synthesis, functionalization, and biomedical applications of multifunctional magnetic nanoparticles. Advanced Materials, v. 22, n. 25, p. 2729-2742, 2010.

58 CALERO, M.; GUTIÉRREZ, L.; SALAS, G.; LUENGO, Y.; LÁZARO, A.; ACEDO, P.; MORALES, M. P.; MIRANDA, R.; VILLANUEVA, A. Efficient and safe internalization of magnetic iron oxide nanoparticles: Two fundamental requirements for biomedical applications. Nanomedicine: Nanotechnology, Biology and Medicine, v. 10, n. 4, p. 733-743, 2014. 
59 MEDEIROS, S.F.; SANTOS, A.M.; FESSI, H.; ELAISSARI, A. Stimuli-responsive magnetic particles for biomedical applications. International Journal of Pharmaceutics, v. 403, n. 1-2, p. 139-161, 2011.

60 JIANG, Q.L.; ZHENG, S.W.; HONG, R.Y.; DENG, S.M.; GUO, L.; HU, R.L.; GAO, B.; HUANG, M.; CHENG, L.F.; LIU, G.H.; WANG, Y.Q. Folic acid-conjugated $\mathrm{Fe}_{3} \mathrm{O}_{4}$ magnetic nanoparticles for hyperthermia and MRI in vitro and in vivo. Applied Surface Science, v. 307, p. 224-233, 2014.

61 ARTEAGA-CARDONA, F.; ROJAS-ROJAS, K.; COSTO, R.; MENDEZ-ROJAS, M.A.; HERNANDO, A.; DE LA PRESA, $P$. Improving the magnetic heating by disaggregating nanoparticles. Journal of Alloys and Compounds, v. 663, p. 636-644, 2016.

62 GONZALEZ-FERNANDEZ, M.A.; TORRES, T.E.; ANDRÉS-VERGÉS, M.; COSTO, R.; DE LA PRESA, P.; SERNA, C.J.; MORALES, M.P.; MARQUINA, C.; IBARRA, M.R.; GOYA, G.F. Magnetic nanoparticles for power absorption: Optimizing size, shape and magnetic properties. Journal of Solid State Chemistry, v. 182, n. 10, p. 2779-2784, 2009.

63 SADAT, M.E.; PATEL, R.; SOOKOOR, J.; BUD'KO, S. L.; EWING, R. C.; ZHANG, J.; XU, H.; WANG, Y.; PAULETTI, G. M.; MAST, D. B.; SHI, D. Effect of spatial confinement on magnetic hyperthermia via dipolar interactions in Fe3O4 nanoparticles for biomedical applications. Materials Science and Engineering: $\mathrm{C}, \mathrm{v}$. 42, p. 52-63, 2014.

64 YAZDANI, F.; FATTAHI, B.; AZIZI, N. Synthesis of functionalized magnetite nanoparticles to use as liver targeting MRI contrast agent. Journal of Magnetism and Magnetic Materials, v. 406, p. 207-211, 2016.

65 GROMAN, E. V.; BOUCHARD, J. C.; REINHARDT, C. P.; VACCARO, D. E. Ultrasmall mixed ferrite colloids as multidimensional magnetic resonance imaging, cell labeling, and cell sorting agents. Bioconjugate Chemistry, v. 18, n. 6, p. 1763-1771, 2007.

66 MARCU, A.; POP, S.; DUMITRACHE, F.; MOCANU, M.; NICULITE, C.M.; GHERGHICEANU, M.; LUNGU, C.P.; FLEACA, C.; IANCHIS, R.; BARBUT, A.; GRIGORIU, C.; MORJAN, I. Magnetic iron oxide nanoparticles as drug delivery system in breast cancer. Applied Surface Science, v. 281, p. 60-65, 2013.

67 AGIOTIS, L.; THEODORAKOS, I.; SAMOTHRAKITIS, S.; PAPAZOGLOU, S.; ZERGIOTI, I.; RAPTIS, Y. S. Magnetic manipulation of superparamagnetic nanoparticles in a microfluidic system for drug delivery applications. Journal of Magnetism and Magnetic Materials, v. 401, p. 956-964, 2016.

68 ANDRÉS VERGÉS, M.; COSTO, R.; ROCA, A. G.; MARCO, J. F.; GOYA, G. F.; SERNA, C. J.; MORALES, M. P. Uniform and water stable magnetite nanoparticles with diameters around the monodomain-multidomain limit. Journal of Physics D: Applied Physics, v. 41, n. 13, p. 134003, 2008. 
70 JOHNSON, B.F.G. Nanoparticles in Catalysis. Topics in Catalysis, v. 24, n. 1, p. 147-159, 2003.

71 SHYLESH, S.; SCHÜNEMANN, V.; THIEL, W. R. Magnetically separable nanocatalysts: Bridges between homogeneous and heterogeneous catalysis. Angewandte Chemie International Edition, v. 49, n. 20, p. 3428-3459, 2010.

72 MYAKONKAYA, O.; HU, Z.; NAZAR, M. F.; EASTOE, J. Recycling functional colloids and nanoparticles. Chemistry - A European Journal, v. 16, n. 39, p. 11784-11790, 2010.

73 DALPOZZO, R. Magnetic nanoparticle supports for asymmetric catalysts. Green Chemistry, v. 17, n. 7, p. 3671-3686, 2015.

74 HUDSON, R.; FENG, Y.; VARMA, R. S.; MOORES, A. Bare magnetic nanoparticles: sustainable synthesis and applications in catalytic organic transformations. Green Chemistry, v. 16, n. 10, p. 4493-4505, 2014.

75 RANADE, M. R.; NAVROTSKY, A.; ZHANG, H. Z.; BANFIELD, J. F.; ELDER, S. H.; ZABAN, A.; BORSE, P. H.; KULKARNI, S. K.; DORAN, G. S.; WHITFIELD, H. J. Energetics of nanocrystalline $\mathrm{TiO}_{2}$. Proceedings of the National Academy of Sciences, v. 99, n. Supplement 2, p. 6476-6481, 2002.

76 ZHANG, H.; BANFIELD, J.F. Thermodynamic analysis of phase stability of nanocrystalline titania. Journal of Materials Chemistry, v. 8, n. 9, p. 2073-2076, 1998.

77 ULLAH, Sajjad. Materiais nanoestruturados e filmes finos baseados em $\mathrm{TiO}_{2}$ para aplicação em fotocatálise. 2014. 139 f. Tese (Doutorado em Química) - Instituto de Química de São Carlos, Universidade de São Paulo, São Carlos, 2014.

78 MALHEIRO, A. R.; VARANDA, L. C.; PEREZ, J.; VILLULLAS, H. M. The Aerosol OT + n-butanol + nheptane + water system: Phase behavior, structure characterization, and application to $\mathrm{Pt}_{70} \mathrm{Fe}_{30}$ nanoparticle synthesis. Langmuir, v. 23, n. 22, p. 11015-11020, 2007.

79 LI, Q.; WANG, J.; HE, Y.; LIU, W.; QIU, X. Growth of nearly monodisperse mno nanocrystals in a twosize distribution system. Crystal Growth \& Design, v. 9, n. 7, p. 3100-3103, 2009.

80 DUTZ, S.; ANDRÄ, W.; HERGT, R.; MÜLLER, R.; OESTREICH, C.; SCHMIDT, C.; TÖPFER, J.; ZEISBERGER, M.; BELLEMANN, M. E. Influence of dextran coating on the magnetic behaviour of iron oxide nanoparticles. Journal of Magnetism and Magnetic Materials, v. 311, n. 1, p. 51-54, 2007.

81 BAUTISTA, M. C.; BOMATI-MIGUEL, O.; MORALES, M. P.; SERNA, C. J.; VEINTEMILLAS-VERDAGUER, S. Surface characterisation of dextran-coated iron oxide nanoparticles prepared by laser pyrolysis and coprecipitation. Journal of Magnetism and Magnetic Materials, v. 293, n. 1, p. 20-27, 2005. 
82 DAMATO, T. C.; DE OLIVEIRA, C. C. S.; ANDO, R. A.; CAMARGO, P. H. C. A facile approach to tio 2 colloidal spheres decorated with au nanoparticles displaying well-defined sizes and uniform dispersion. Langmuir, v. 29, n. 5, p. 1642-1649, 2013.

83 CHENG, Y.; GUO, J.; LIU, X.; SUN, A.; XU, G.; CUI, P.. Preparation of uniform titania microspheres with good electrorheological performance and their size effect. Journal of Materials Chemistry, v. 21, n. 13, p. 5051, 2011.

84 NAKAMOTO, K. Infrared and raman spectra of inorganic and coordination compounds. 6th Ed. New York: John Wiley, 1986. 484 p.

85 PEREIRA, R. F. P.; VALENTE, A. J. M.; BURROWS, H. D.; DE ZEA BERMUDEZ, V.; CARVALHO, R. A.; CASTRO, R. A. E. Structural characterization of solid trivalent metal dodecyl sulfates: From aqueous solution to lamellar superstructures. RSC Advances, v. 3, n. 5, p. 1420-1433, 2013.

86 MACHIDA, M.; KAWAMURA, K.; KAWANO, T.; ZHANG, D.; IKEUE, K. Layered Pr-dodecyl sulfate mesophases as precursors of $\mathrm{Pr}_{2} \mathrm{O}_{2} \mathrm{SO}_{4}$ having a large oxygen-storage capacity. Journal of Materials Chemistry, v. 16, n. 30, p. 3084, 2006.

87 GOYA, G. F.; BERQUÓ, T. S.; FONSECA, F. C.; MORALES, M. P. Static and dynamic magnetic properties of spherical magnetite nanoparticles. Journal of Applied Physics, v. 94, n. 5, 2003.

88 KIM, B. H.; HACKETT, M. J.; PARK, J.; HYEON, T. Synthesis, characterization, and application of ultrasmall nanoparticles. Chemistry of Materials, v. 26, n. 1, p. 59-71, 2014.

89 KIM, B. H.; LEE, N.; KIM, H.; AN, K.; PARK, Y. I.; CHOI, Y.; SHIN, K.; LEE, Y.; KWON, S. G.; NA, H. B.; PARK, J. G.; AHN, T. Y.; KIM, Y. W.; MOON, W. K.; CHOI, S. H.; HYEON, T. Large-scale synthesis of uniform and extremely small-sized iron oxide nanoparticles for high-resolution $\mathrm{T}_{1}$ magnetic resonance imaging contrast agents. Journal of the American Chemical Society, v. 133, n. 32, p. 12624-12631, 2011.

90 NA, H. B.; LEE, J. H.; AN, K.; PARK, Y. I.; PARK, M.; LEE, I. S.; NAM, D. H.; KIM, S. T.; KIM, S. H.; KIM, S. W.; LIM, K. H.; KIM, K. S.; KIM, S. O.; HYEON, T. Development of aT 1 contrast agent for magnetic resonance imaging using mno nanoparticles. Angewandte Chemie, v. 119, n. 28, p. 5493-5497, 2007.

91 TRACY, J. B.; WEISS, D. N.; DINEGA, D. P.; BAWENDI, M. G. Exchange biasing and magnetic properties of partially and fully oxidized colloidal cobalt nanoparticles. Physical Review B, v. 72, n. 6, p. 064404, 2005.

92 CULLITY, B.D. Elements of x-ray diffraction. Reading: Addison-Wesley, 1956. 514 p.

93 CLEMENTI, E.; RAIMONDI, D.L. Atomic screening constants from SCF functions. The Journal of Chemical Physics, v. 38, n. 11, p. 2686, 1963. 
94 SUN, S.; ZENG, H. Size-controlled synthesis of magnetite nanoparticles. Journal of the American Chemical Society, v. 124, n. 28, p. 8204-8205, 2002.

95 SONG, H. M.; KIM, W. S.; LEE, Y. B.; HONG, J. H.; LEE, H. G.; HUR, N. H. Chemically ordered FePt 3 nanoparticles synthesized by a bimetallic precursor and their magnetic transitions. Journal of Materials Chemistry, v. 19, n. 22, p. 3677, 2009.

96 WANG, C.; VAN DER VLIET, D.; MORE, K. L.; ZALUZEC, N. J.; PENG, S.; SUN, S.; DAIMON, H.; WANG, G.; GREELEY, J.; PEARSON, J.; PAULIKAS, A. P.; KARAPETROV, G.; STRMCNIK, D.; MARKOVIC, N. M.; STAMENKOVIC, V. R. Multimetallic Au/FePt ${ }_{3}$ nanoparticles as highly durable electrocatalyst. Nano Letters, v. 11, n. 3, p. 919-926, 2011.

97 COLAK, L.; HADJIPANAYIS, G.C. Chemically synthesized FePt nanoparticles with controlled particle size, shape and composition. Nanotechnology, v. 20, n. 48, p. 485602, 2009.

98 BECK JUNIOR, Watson. Nanopartículas magnéticas metálicas recobertas com óxido de ferro: intensificação das propriedades magnéticas da nanopartícula e funcionalização para aplicação em biomedicina. 2011. 94 f. Dissertação (Mestrado em Ciências) - Instituto de Química de São Carlos, Universidade de São Paulo, São Carlos, 2011.

99 LIU, S.; CHEN, G.; PRASAD, P. N.; SWIHART, M. T. Synthesis of monodisperse Au, Ag, and Au-Ag alloy nanoparticles with tunable size and surface plasmon resonance frequency. Chemistry of Materials, v. 23, n. 18, p. 4098-4101, 2011.

100 MOURDIKOUDIS, S.; LIZ-MARZÁN, L.M. Oleylamine in nanoparticle synthesis. Chemistry of Materials, v. 25, n. 9, p. 1465-1476, 2013.

101 SUN, Y. Controlled synthesis of colloidal silver nanoparticles in organic solutions: Empirical rules for nucleation engineering. Chemical Society Reviews, v. 42, n. 7, p. 2497-2511, 2013.

102 CHAUBEY, G. S.; BARCENA, C.; POUDYAL, N.; RONG, C.; GAO, J.; SUN, S.; LIU, J. P. Synthesis and stabilization of FeCo nanoparticles. Journal of the American Chemical Society, v. 129, n. 23, p. 72147215, 2007.

103 GAMARRA, L. F.; AMARO, E.; ALVES, S.; SOGA, D.; PONTUSCHKA, W. M.; MAMANI, J. B.; CARNEIRO, S. M.; BRITO, G. E. S.; FIGUEIREDO NETO, A. M. Characterization of the biocompatible magnetic colloid on the basis of $\mathrm{Fe}_{3} \mathrm{O}_{4}$ nanoparticles coated with dextran, used as contrast agent in magnetic resonance imaging. Journal of Nanoscience and Nanotechnology, v. 10, n. 7, p. 4145-4153, 2010.

104 TAMHANKAR, P.M.; KULKARNI, A.M.; WATAWE, S. C. Functionalization of cobalt ferrite nanoparticles with alginate coating for biocompatible applications. Materials Sciences and Applications, v. 02, n. 09, p. 1317-1321, 2011. 
105 GUARDIA, P.; DI CORATO, R.; LARTIGUE, L.; WILHELM, C.; ESPINOSA, A.; GARCIA-HERNANDEZ, M.; GAZEAU, F.; MANNA, L.; PELLEGRINO, T. Water-soluble iron oxide nanocubes with high values of specific absorption rate for cancer cell hyperthermia treatment. ACS Nano, v. 6, n. 4, p. 3080-3091, 2012.

106 SATTLER, K.D. Handbook of nanophysics: nanoparticles and quantum dots. Boca Raton: Taylor and Francis, 2011. v. 3, p. 2-6.

107 HERGT, R.; DUTZ, S.; MÜLLER, R.; ZEISBERGER, M. Magnetic particle hyperthermia: nanoparticle magnetism and materials development for cancer therapy. Journal of Physics: Condensed Matter, v. 18, n. 38, p. S2919, 2006.

108 KITA, E.; ODA, T.; KAYANO, T.; SATO, S.; MINAGAWA, M.; YANAGIHARA, H.; KISHIMOTO, M.; MITSUMATA, C.; HASHIMOTO, S.; YAMADA, K.; OHKOHCHI, N. Ferromagnetic nanoparticles for magnetic hyperthermia and thermoablation therapy. Journal of Physics D: Applied Physics, v. 43, n. 47, p. 474011, 2010.

109 WANG, C.; PENG, S.; LACROIX, L. M.; SUN, S. Synthesis of high magnetic moment CoFe nanoparticles via interfacial diffusion in core/shell structured Co/Fe nanoparticles. Nano Research, v. 2, n. 5, p. 380-385, 2010.

110 FARRELL, D.; MAJETICH, S.A.; WILCOXON, J. P. Preparation and characterization of monodisperse fe nanoparticles. The Journal of Physical Chemistry B, v. 107, n. 40, p. 11022-11030, 2003.

111 LI, X.-H.; XU, C.-L.; HAN, X.-.; QIAO, L.; WANG, T.; LI, F.-S. Synthesis and magnetic properties of nearly monodisperse $\mathrm{CoFe}_{2} \mathrm{O}_{4}$ nanoparticles through a simple hydrothermal condition. Nanoscale Research Letters, v. 5, n. 6, p. 1039-1044, 2010.

112 TAUXE, L.; MULLENDER, T.A.T.; PICK, T. Potbellies, wasp-waists, and superparamagnetism in magnetic hysteresis. Journal of Geophysical Research, v. 101, n. B1, p. 571, 1996.

$113 \mathrm{XU}, \mathrm{Z}$;; SHEN, C.; HOU, Y.; GAO, H.; SUN, S. Oleylamine as both reducing agent and stabilizer in a facile synthesis of magnetite nanoparticles. Chemistry of Materials, v. 21, n. 9, p. 1778-1780, 2009.

114 SAJITHA, E.P.; PRASAD, V.; SUBRAMANYAM, S. V.; MISHRA, A. K.; SARKAR, S.; BANSAL, C. Sizedependent magnetic properties of iron carbide nanoparticles embedded in a carbon matrix. Journal of Physics: Condensed Matter, v. 19, n. 4, p. 46214, 2007.

115 PEPPERHOFF, W.; ACET, M. Constitution and magnetism of iron and its alloys. Heidelberg: Springer, 2001. 226 p. 
116 MARTINÊS, Gustavo Adolfo Lopez. Síntese de nanopartículas magnéticas com elevada magnetização de saturação e estabilidade química. 2013. 62 f. Dissertação (Mestrado em Química) Instituto de Química de São Carlos, Universidade de São Paulo, São Carlos, 2013.

117 MORAES, Daniel Angeli de. Nanopartículas magnéticas decoradas com nanopartículas metálicas visando aplicações em biomedicina. 2012. 69 f. Dissertação (Mestrado em Ciências) - Instituto de Química de São Carlos, Universidade de São Paulo, São Carlos, 2012.

118 LAMER, V.K.; DINEGAR, R.H. Theory, production and mechanism of formation of monodispersed hydrosols. Journal of the American Chemical Society, v. 72, n. 11, p. 4847-4854, 1950.

119 NANDWANA, V.; ELKINS, K.E.; POUDYAL, N.; CHAUBEY, G. S.; YANO, K.; LIU, J. P. Size and shape control of monodisperse FePt nanoparticles. The Journal of Physical Chemistry C, v. 111, n. 11, p. 41854189, 2007.

120 JUNG, I.-H.; DECTEROV, S.A.; PELTON, A. D.; KIM, H.-M.; KANG, Y.-B. Thermodynamic evaluation and modeling of the Fe-Co-O system. Acta Materialia, v. 52, n. 2, p. 507-519, 2004.

121 RAEDER, J.; HOLM, J.; SORENSEN, O. Defects in metal-deficient cobalt-wüstites, (Co, Fe) ${ }_{1-y} \mathrm{O}$. Solid State lonics, v. 12, p. 155-159, 1984.

122 HAZEN, R.M.; JEANLOZ, R. Wüstite $\left(\mathrm{Fe}_{1-\mathrm{X}} \mathrm{O}\right)$ : A review of its defect structure and physical properties. Reviews of Geophysics, v. 22, n. 1, p. 37, 1984.

123 HAN, D.H.; WANG, J.P.; FENG, Y. B.; LUO, H. L. Influence of size and magnetocrystalline anisotropy on spin canting anomaly in fine ferrimagnetic particles. Journal of Applied Physics, v. 76, n. 10, 1994.

124 CREIXELL, M.; HERRERA, A.P.; LATORRE-ESTEVES, M.; AYALA, V.; TORRES-LUGO, M.; RINALDI, C. The effect of grafting method on the colloidal stability and in vitro cytotoxicity of carboxymethyl dextran coated magnetic nanoparticles. Journal of Materials Chemistry, v. 20, n. 39, p. 8539, 2010.

125 AYALA, V.; HERRERA, A.P.; LATORRE-ESTEVES, M.; TORRES-LUGO, M.; RINALDI, C. Effect of surface charge on the colloidal stability and in vitro uptake of carboxymethyl dextran-coated iron oxide nanoparticles. Journal of Nanoparticle Research, v. 15, n. 8, p. 1874, 2013.

126 HILL, A.; PAYNE, C.K. Impact of serum proteins on MRI contrast agents: cellular binding and $\mathrm{T}_{2}$ relaxation. RSC Advances, v. 4, n. 60, p. 31735-31744, 2014.

127 BELESSI, V.; ZBORIL, R.; TUCEK, J.; MASHLAN, M.; TZITZIOS, V.; PETRIDIS, D. Ferrofluids from magnetic-chitosan hybrids. Chemistry of Materials, v. 20, n. 10, p. 3298-3305, 2008. 
128 ZHENG, T.; PANG, J.; TAN, G.; HE, J.; MCPHERSON, G. L.; LU, Y.; JOHN, V. T.; ZHAN, J. Surfactant templating effects on the encapsulation of iron oxide nanoparticles within silica microspheres. Langmuir, v. 23, n. 9, p. 5143-5147, 2007.

129 OHMORI, M.; MATIJEVIĆ, E. Preparation and properties of uniform coated inorganic colloidal particles. Journal of Colloid and Interface Science, v. 160, n. 2, p. 288-292, 1993.

130 GUARDIA, P.; BATLLE-BRUGAL, B.; ROCA, A.G.; IGLESIAS, O.; MORALES, M.P.; SERNA, C.J.; LABARTA, A.; BATLLE, X. Surfactant effects in magnetite nanoparticles of controlled size. Journal of Magnetism and Magnetic Materials, v. 316, n. 2, p. e756-e759, 2007.

131 CRYSTALLOGRAPHICA Search-Match. Version 2.1.1.1. [S.I.]:Oxford Cryosystems, 2004. 1 CD-ROM

132 CHENG, J.P.; MA, R.; LI, M.; WU, J.S.; LIU, F.; ZHANG, X.B. Anatase nanocrystals coating on silicacoated magnetite: Role of polyacrylic acid treatment and its photocatalytic properties. Chemical Engineering Journal, v. 210, p. 80-86, 2012.

133 GAO, Y.; CHEN, B.; LI, H.; MA, Y.Preparation and characterization of a magnetically separated photocatalyst and its catalytic properties. Materials Chemistry and Physics, v. 80, n. 1, p. 348-355, 2003.

134 KARAAGAC, O.; KOCKAR, H.; EBIN, B.; GURMEN, S. Reduction and characterizations of iron particles: Influence of reduction parameters. Journal of Materials Science: Materials in Electronics, v. 24, n. 7, p. 2602-2609, 2013.

135 POZAS, R.; OCAÑA, M.; MORALES, M P.; SERNA, C. J. The influence of protective coatings on the magnetic properties of acicular iron nanoparticles. Nanotechnology, v. 17, n. 5, p. 1421, 2006.

136 KARAAGAC, 0 . Characterizations of iron particles reduced from iron oxide nanoparticles under hydrogen atmosphere. Journal of Superconductivity and Novel Magnetism, v. 26, n. 5, p. 1707-1711, 2013.

137 VARANDA, L.C.; JAFELICCI, M.; TARTAJ, P.; O’ GRADY, K.; GONZÁLEZ-CARREÑO, T.; MORALES, M. P.; MUÑOZ, T.; SERNA, C. J. Structural and magnetic transformation of monodispersed iron oxide particles in a reducing atmosphere. Journal of Applied Physics, v. 92, n. 4, 2002.

138 VARANDA, L.C.; GOYA, G.F.; MORALES, M.P.; MARQUES, R.F.C.; GODOI, R.H.M.; JAFELICCI, M.; SERNA, C.J. Magnetic properties of acicular ultrafine iron particles. IEEE Transactions on Magnetics, v. 38, n. 5, p. 1907-1909, 2002.

139 VARANDA, L.C.; MORALES, M.P.; GOYA, G.F.; IMAIZUMI, M.; SERNA, C.J.; JAFELICCI, M. Magnetic properties of acicular $\mathrm{Fe}_{1-\mathrm{x}} \mathrm{RE}_{\mathrm{x}}(\mathrm{RE}=\mathrm{Nd}, \mathrm{Sm}, \mathrm{Eu}, \mathrm{Tb} ; \mathrm{x}=0,0.05,0.10)$ metallic nanoparticles. Materials Science and Engineering: B, v. 112, n. 2-3, p. 188-193, 2004. 
140 GIESSEN, A. VAN DER; KLOMP, C. The preparation of iron powders consisting of submicroscopic elongated particles by pseudomorphic reduction of iron oxides. IEEE Transactions on Magnetics, v. 5, n. 3, p. 317-320, 1969.

141 POZAS, R.; MORALES, M.P.; SERNA, C. J.; OCANA, M. Acicular iron nanoparticles protected against sintering with aluminium oxide. Boletin de la Sociedad Espanola de Ceramica y Vidrio, v. 43, n. 4, p. 796800, 2004.

142 ARGYO, C.; WEISS, V.; BRÄUCHLE, C.; BEIN, T. Multifunctional mesoporous silica nanoparticles as a universal platform for drug delivery. Chemistry of Materials, v. 26, n. 1, p. 435-451, 2014.

143 MARIÑO-FERNÁNDEZ, R.; MASUNAGA, S.H.; FONTAÍNAA-TROITIÑO, N.; MORALES, M. P.; RIVAS, J.; SALGUEIRINO, V. Goethite ( $\alpha$-FeOOH) nanorods as suitable antiferromagnetic substrates. The Journal of Physical Chemistry C, v. 115, n. 29, p. 13991-13999, 2011.

144 MALVERN INSTUMENTS. Zeta potential: An introduction in 30 minutes. Zetasizer Nanoseries Technical Note, p. 1-6, [20--].Disponível em:

<https://www.caliscc.org/images/presentations/Morante_Zeta_Potential.pdf>. Acesso em: 24/05/2016.

145 CORNELL, R.M. The iron oxides: Structure, properties, reactions, occurrences and uses. 2nd ed. Weinheim: Wiley-VCH, 2003. 664 p.

146 ALVES JÚNIOR, J. A.; BALDO, J. B. the behavior of zeta potential of silica suspensions. New Journal of Glass and Ceramics, v. 4, n. 2, p. 29-37, 2014.

147 AGRAWAL, D.C.; RAJ, R.; COHEN, C. In-situ measurement of silica-gel coating on particles of alumina. Journal of the American Ceramic Society, v. 73, n. 7, p. 2163-2164, 1990.

148 WILHELM, P.; STEPHAN, D. On-line tracking of the coating of nanoscaled silica with titania nanoparticles via zeta-potential measurements. Journal of Colloid and Interface Science, v. 293, n. 1, p. 88-92, 2006.

149 YILDIRIM, A.; BAYINDIR, M. A porosity difference based selective dissolution strategy to prepare shape-tailored hollow mesoporous silica nanoparticles. Journal of Materials Chemistry A, v. 3, n. 7, p. 3839-3846, 2015.

150 PARK, S.-J.; KIM, Y.-J.; PARK, S.-J. Size-dependent shape evolution of silica nanoparticles into hollow structures. Langmuir, v. 24, n. 21, p. 12134-12137, 2008.

151 PARK, J.-H.; GU, L.; von MALTZAHN, G.; RUOSLAHTI, E.; BHATIA, S. N.; SAILOR, M. J. Biodegradable luminescent porous silicon nanoparticles for in vivo applications. Nature Materials, v. 8, n. 4, p. 331-336, 2009. 
152 RIMER, J.D.; TROFYMLUK, O.; NAVROTSKY, A.; LOBO, R. F.; VLACHOS, D. G. Kinetic and thermodynamic studies of silica nanoparticle dissolution. Chemistry of Materials, v. 19, n. 17, p. 41894197, 2007.

153 CHEN, K.; ZHANG, J.; GU, H. Dissolution from inside: a unique degradation behaviour of core-shell magnetic mesoporous silica nanoparticles and the effect of polyethyleneimine coating. Journal of Materials Chemistry, v. 22, n. 41, p. 22005, 2012.

154 MAHON, E.; HRISTOV, D.R.; DAWSON, K. A. Stabilising fluorescent silica nanoparticles against dissolution effects for biological studies. Chemical Communications, v. 48, n. 64, p. 7970-4972, 2012.

155 GOYA, G.F.; LIMA, E.; ARELARO, A.D.; TORRES, T.; RECHENBERG, H.R.; ROSSI, L. Magnetic hyperthermia with $\mathrm{Fe}_{3} \mathrm{O}_{4}$ nanoparticles: the influence of particle size on energy absorption. IEEE Transactions on Magnetics, v. 44, n. 11, p. 4444-4447, 2008.

156 MARTINEZ-BOUBETA, C.; SIMEONIDIS, K.; MAKRIDIS, A.; ANGELAKERIS, M.; IGLESIAS, O.; GUARDIA, P.; CABOT, A.; YEDRA, L.; ESTRADÉ, S.; PEIRÓ, F.; SAGHI, Z.; MIDGLEY, P. A.; CONDE-LEBORÁN, I.; SERANTES, D.; BALDOMIR, D. Learning from nature to improve the heat generation of iron-oxide nanoparticles for magnetic hyperthermia applications. Scientific Reports, v. 3, 2013.

157 ULLAH, S.; FERREIRA-NETO, E.P.; PASA, A. A.; ALCÂNTARA, C. C.J.; ACUÑA, J. J.S.; BILMES, S. A.; MARTÍNEZ RICCI, M. L.; LANDERS, R.; FERMINO, T. Z.; RODRIGUES-FILHO, U. P. Enhanced photocatalytic properties of core@shell $\mathrm{SiO}_{2} @ \mathrm{TiO}_{2}$ nanoparticles. Applied Catalysis B: Environmental, v. 179, p. 333343, 2015. 